


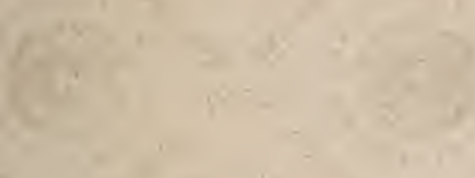

$$
\begin{aligned}
& -4
\end{aligned}
$$

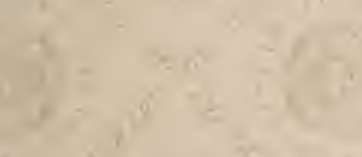$$
+1+x^{2}
$$<smiles>CCC</smiles><smiles>C=C1CCC1C(C)(C)C</smiles>

4

${ }_{10}$

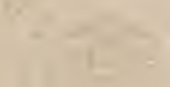
8 $\cos ^{2}=x^{2}=x^{2}+4$

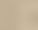
$3=\frac{1}{3}$

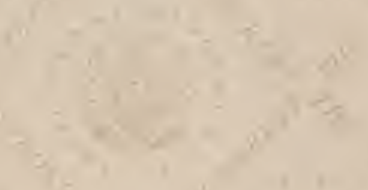

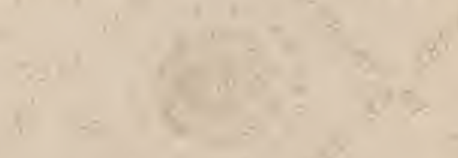
$7^{-3}+2$

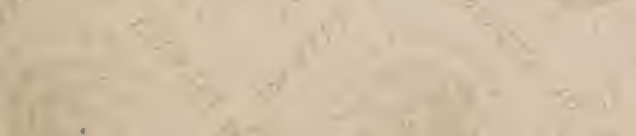





\title{
OUTLINES OF PLANT LIFE
}

WITH SPECIAL REFERENCE TO FORM

AND FUNCTION

\author{
BY \\ CHARLES REID BARNES \\ Professor of Plant Physiology in the University of Chicago
}

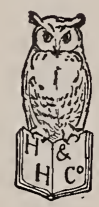

NEW YORK

HENRY HOLT AND COMPANY

I 900 
TWO COPIES RECEIVED.

L. Jorary of Congroses

Offlice of the

MAR 101900

hegister of Copyrights

\section{9}

Copyright, Igoo,

BY

HENRY HOLT \& CO.

\section{SELUNU LOPY, \\ 5903 \\ mar.5.1900}

ROBERT DRUMMOND, PRINTER, NEW YORK. 


\section{OUTLINES OF PLANT LIFE.}

\section{PART I: THE PLANT BODY.}

\section{CHAPTER I.}

\section{INTRODUCTION.}

1. Living matter.-By the combination of powers called life, each living thing controls, for a longer or shorter time, a certain amount of material, which constitutes its body. This material is arranged into definite form ; some remains only for a short time as part of the body and is then discarded; other material remains part of the body as long as life exists.

That which is changing most rapidly is the living substance, called protoplasm. If there are parts of the body not living, they have been formed by the protoplasm and are generally controlled by it.

2. Members. - When the body is large, it is easy to see that it is made up of more or less distinct parts. These are its members. As a rule, the smaller it is, the fewer and less distinct are the members. There are many thousands of plants in which the body does not have any members, but can be distinguished only into the units of which it is built, called cells. Still others consist of a single cell.

In the largest plants the more important members may be divisible into smaller subordinate ones. When these are in- 
spected they too are seen to be made up of a great many minute parts, each consisting of a bit of living protoplasm and some other things which it has made. These parts are called cells. (See $\uparrow 4$.)

Thus, a corn plant has two principal members, a root, below ground, and a shoot above ground. The root consists of many subordinate members, the roots and the rootlets; the shoot consists of stem and leaves: the leaves of sheath and blade, etc. But a duckweed shoot has no distinction of stem and leaf, and only a single root. The pond scums have no members, but consist of a row of cells; while in many diatoms the body is a single cell.

3. Reproduction.-Every plant must provide for its own existence. To do this, it must possess means for securing, or for making, and using food. During this feeding period its most striking characteristic is growth. It must also provide before it dies for the production of new plants of the same kind. When the plant is very simple, both duties must be done by the same cell, but in more complex plants special cells, and in many cases special members, are provided for reproduction. The two processes are sometimes carried on at the same time, but more commonly reproduction occurs at some particular or limited period.

It is convenient to consider first the form of the plant body and those members which are not concerned in reproduction. Parts I and II therefore, treat of the work and parts of the plant which promote its own life and growth, i.e. the vegetative body. Part III discusses the form and action of the reproductive parts, so far as these can be studied without a microscope.

4. The cell.-A plant-cell is a minute portion of living matter, called protoplasm, generally surrounded by a memb rane, called the cell-wall (fig. I).

The protoplasin is the essential part of the cell. It constructs the cell-wall. Rarely, if ever, is it uniform through- 
out, but shows distinct parts, each having special work to do. In the most complete and active cells the greater part of the protoplasm consists of a finely granular or nearly transparent, colorless portion, in which the other parts seem embedded.

Protoplasm is not a single substance, but a mixture of several different substances, so intimately mixed and so easily destroyed that it is not possible to analyze it. Moreover, the nature and amount of the components are probably variable. In all but the youngest cells there are one or more bubbles of water in the protoplasm.

5. Nucleus. - The nucleus is one of the most important parts of the

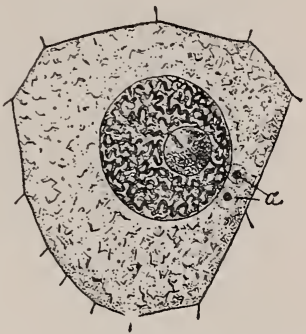

FIG. I.-A cell (the megaspore) from a lily ovule, filled with granular protoplasm, in which is embedded a large spherical nucleus, containing a nucleolus, and accompanied by two centrospheres, $a$. The line around the protoplasm represents the cell-wall, with those of the adjacent cells connected. Magnified 500 diam. - After Guignard. cell. It is generally spherical or ovoid, but in long cells it may become elongated (fig. $2, z$ ). The nucleus may divide into two, and this is commonly followed by the formation of a partition-wall separating the cell into two parts, each containing one of the daughter-nuclei.

6. Plastids. - In most cells there are also other parts, called plastids. In young cells these are small, rounded, colorless bodies. As the cell grows older they increase in size and number. When mature and in cells which lie near the surface of green plants, they are commonly roundish or biscuit-shaped, of spongy texture, and colored yelllowishgreen by a substance known as chlorophyll . These are consequently known as chloroplasts or chlorophyll-bodies (fig. 2). In other cells, particularly those for the storage of food, they may develop into smaller, denser, flattened or roundish, uncolored bodies, whose work is usually to gather starch into 
grains (fig. 3). In other cells, particularly in highly colored parts, the plastids may become of most diverse form and

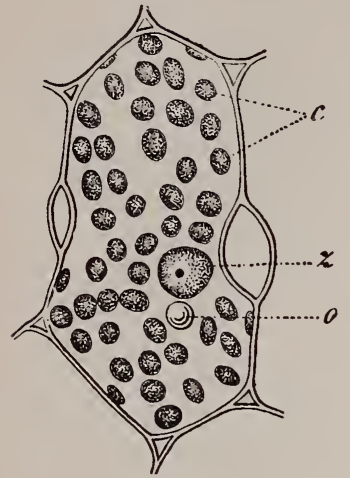

FIG. 2. size, and take on a red or yellow color (fig. 4).

7. Wall. - The cell-wall is

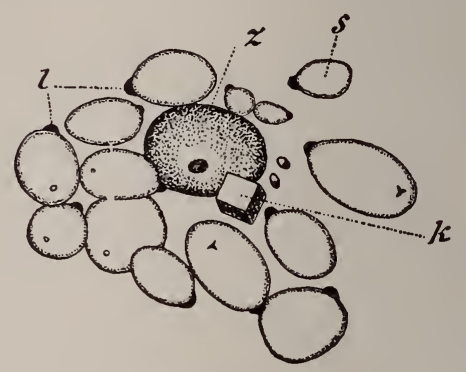

F1s. 3 .

Fig. 2.-A cell from the interior of the leaf of the oat, showing its wall, and some inclusions of the protoplasm. $z$, the nucleus; $c$, chloroplasts; $o$, an oil-drop. Magnified about tooo diam.-After Zimmermann.

Fig. 3. - Part of the cell contents of an inner cell of white potato. $z$, nucleus; $s$, starch grains, each having been formed by a leucoplast, $l$, which is still attached to one side of the grain; $k$, crystalloid. Magnified about 1000 diam.-After Zimmermann.

formed by the protoplasm. In green plants when first formed it consists chiefly of cellulose, with which, as it grows older, various other substances may be mixed. Some of these

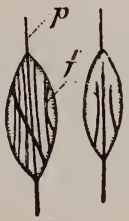

A

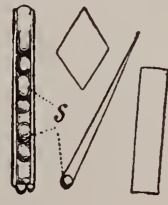

$B$

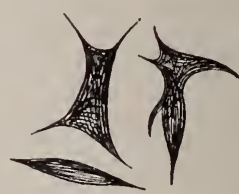

C

FIG. 4. $-A$, chromoplasts from flower leaves of an orchid; $B$, from the root of carrot ; $C$, from the fruit of mountain-ash. Embedded in the protoplasmic body of the chromoplast are sometimes proteid crystalloids, $p$, pigment-crystals, $f$, or starchgrains, s. Magnified about rooo diam - After Schimper.

are present even in the young wall, and may increase with age; others are characteristic of special changes which the wall may undergo. 
8. Growth of the cell-wall.-As the cells become older the wall may increase in thickness. It must also increase in area as the cells grow in size. The growth in area is usually accomplished by putting new particles between the older ones. Growth in thickness is rarely uniform. Pits or pores are formed in the wall when it thickens except at these spots. When the thin parts are large and only certain spots or lines grow thicker, the wall shows projecting spikes, bands, or threads. 


\section{CHAP'TER II.}

\section{SINGLE-CELLED PLANTS AND COLONIES.}

IN the lakes and pools, in ditches and slow streams, on the surface of damp rocks and wood, may be found many sorts of microscopic plants, whose entire body is merely a single cell.

9. Fission-algæ.-The simplest forms of the single-celled green water plants are the fission-algæ. In the central part of the cell is the nucleus, and the whole of the protoplasm is colored by the yellowish-green dye, chlorophyll. Along with it, there is a blue coloring matter, so that in mass these

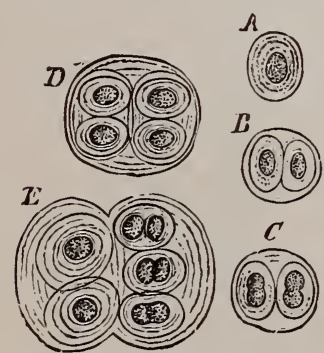

FIr. 5. - A blue-green alga (Gloeocapsa). Single individuals, $A$, and colonies $(B-E)$ of various ages. Magnified 300 diam.-After Sachs. algæ look bluish-green or even blackish. For this reason they are called blue-green algæ to distinguish them from those in which only the yellowgreen color is present.

10. Gelatinous colonies. - The cellwall may be thin, but commonly it is composed of several layers, of which the outer are changed into mucilage. This swells into a transparent jelly when wet, either becoming alike throughout or showing distinct layers. When a number of such forms grow in company (fig. 5), this jelly-like material blends into a single mass in which the associated plants seem to be embedded. 
11. Gelatinous filament-colonies.-In other cases, instead of being held together only by the weak jelly-like portion of the cell-wall, the plants, still practically independent the one of the other, remain connected by the firmer portions of the wall into rows, forming irregularly coiled or serpentine filaments, which are embedded in a profuse jelly (fig. 6). The
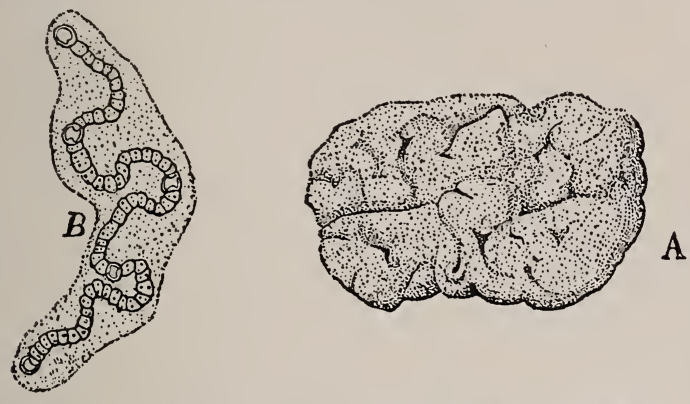

Fig. 6.-Nostoc. $A$, a gelatinous colony, irregularly lobed. Natural size. $B$, a portion of a serpentine filament with five heterocysts (one at each end by which it was separated from the rest of the cells composing the filament, and three intermediate ones) and the jelly belonging to it. Magnified about 400 diam.-After Thuret and Janczewski.

real independence of the cells, even though they remain connected, is shown by the fact that such a chain may be broken up into any number of pieces and each piece will retain all its powers. Here and there in the chain there occur cells unlike the rest, whose purpose seems to be to break the chain into pieces, which work their way out of the jelly and grow into independent colonies. The association of considerable numbers of these plants in colonies gives rise to masses of jelly which vary from the size of a pin-head to $2-5$ centimeters in diameter. They may be found adhering to water-weeds as clear- or dirty-green masses, or sometimes floating free (A, fig. 6).

EXERCISE I.

Nostoc or Rivularia.-I. Observe the size and form of the colonies and the consistence of the jelly enclosing them. (III.) 
2. Crush a bit of a Nostoc colony or a whole one of Rivularia between two glass slips, remove the upper slip, cover with water and observe the coiled (Nostoc) or radiating straight filaments (Rivularia) embedded in the jelly. (Fig. 6.)

12. Filaments of loose organization. - Of very near kin to these plants are the oscillarias, which have received this

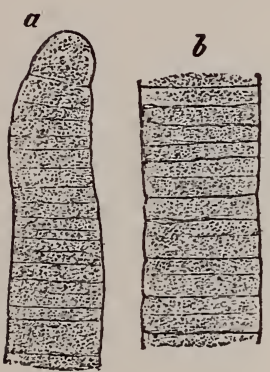

FIG. 7.-Oscillaria. $a$, the tip; $b$, a portion of the nified $54^{\circ}$ diam. - After Strasburger. name from the pendulum-like swinging of their tips (fig. 7). In them the cellwalls remain connected more extensively and more firmly, so that each cell is disk-shaped, and the filament is much less easily separated into its parts. Moreover less of the wall has become jelly-like, so that often this part is not apparent and is difficult to see even when the plants are looked at with the microscope. Even though invisible, it may be detected by the slippery feel of the plants when rubbed gently between the fingers.

\section{EXERCISE II.}

Oscillaria. I. Observe the color of a bit of Oscillaria. (T 9.)

2. With needles tease out the specimen in a drop of water on a glass slip; observe the delicate thread-like form. (Fig. 7.)

3. Transfer a bit of living Oscillaria to a small glass dish or white individual butter plate with a little water; protect it from drying up with a cover; 24 hours later observe the position of the filaments. ( $\boldsymbol{\top}$ I2.)

4. Demonstration. Dip a considerable mass of Oscillaria in hot water for a moment and put in a white butter plate with as small a quantity of water as will cover it. As the water evaporates observe the color deposited on the dish at the edge of the water. ( 9.)

13. Feeding habits. - The feeding habits of the oscillarias are worth notice. These plants are found in permanent puddles and ditches where organic matter is decaying. The sig- 
nificance of this is that some of the ancestors of the green oscillarias probably had offspring which, instead of living upon food prepared by means of the green coloring matter ( 9 I $85 \mathrm{ff}$.), learned to use the organic matter in the water, at first perhaps no more than the present oscillarias do; but gradually they came to live exclusively upon it. As a consequence, they lost their green color and became incapable of existing where organic food cannot be had.

\section{Bacteria.}

14. Fission-fungi.-Along with the loss of color and change of habit went a diminution in size. They have now become so different that they are known as fission-fungi, and popularly as bacteria, bacilli, microbes, germs, etc. These plants, probably the descendants of common ancestors with the fission-algæ, are the smallest known living things (figs. 8, 9). The diameter of many sorts does not exceed .0005 of a millimeter. That would allow 75 to lie side by side upon the edge of the paper on which this book is printed. Thoughiso minute these plants have the same sort of protoplasm and cell-wall as larger ones. They increase in number rapidly by each cell dividing into two, which separate readily into independent plants.

15. Gelatin.-In the fission-fungi, as in the fission-algæ, considerable masses of jelly-like material are produced, in which the plants may lie embedded. The films, sometimes smooth, sometimes wrinkled, which appear on an infusion of organic matter, such as tea or broth, are formed by masses of bacteria which rise to the surface and become embedded in the gelatinous material they produce ( $b$, fig. 8).

Demonstration.-Steep a cupful of chopped hay in hot water for fifteen minutes, and set the infusion, loosely covered, in a warm place. After a day or two, show the film of bacteria which covers the surface of the liquid. 
16. Cilia.-Most species are furnished with organs of movement consisting of fine threads of protoplasm protruded
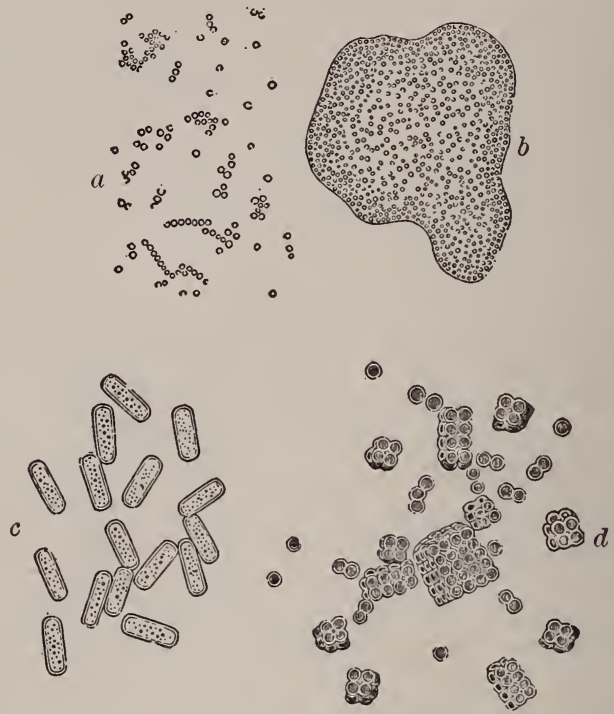

FIg. 8.-Various bacteria. a, Micrococcus, the "blood-portent"; $b$, zooglœa form of the same; $c$, Bacterium aceti, the ferment of vinegar; $d$, Sarcina, a harmless parasite of the human intestine. $a, b$, magnified 300 diam.; $c, 2000$ diam.; $d, 800$ diam.-After Kerner.
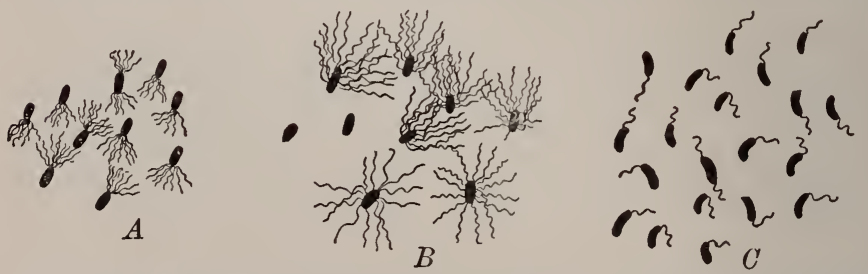

FIG. 9. - Bacteria stained to show cilia. $A$, cilia tufted at one end; $B$, cilia irregularly distributed over body ; $C$, cilium single at one or both ends. $B$, the bacillus of typhoid fever; $C$, the bacillus of Asiatic cholera. Magnified 775 diam.-After Migula.

through the wall. These, by their sudden contraction on one side, lash about like whips, and propel the cell by jerky, darting motions through the fluid in which it swims. These 
lashes, called cilia, may be single at the ends of the cell ( $C$, fig. 9), or many at ends or sides ( $A$, fig. 9), or the whole cell may be covered with them like hairs $(B$, fig. 9). They may be withdrawn or drop off when the plant comes to rest, as when they form the scums previously mentioned.

These plants are most interesting on account of their relation to health and disease, decay, fermentation, etc., which cannot be discussed here.*

17. Yellow-green algæ.-Among the single-celled green plants, one of the most common groups is that represented by fig. Io, which shows one of a large series, in which the body consists of a single cell with its wall, protoplasm, nucleus, and a few relatively large chloroplasts. In this greater specialization of the protoplasm, these plants show the only advance upon the blue-green algæ. The wall in such as this Pleurococcus is almost uniform and quite thin. The cells of some kinds are frequently associated in colonies, embedded in jelly or not.

\section{EXERCISE III.}

Pleurococcus.-I. Examine with a lens pieces of bark bearing Pleurococcus and similar algæ. Note the irregular distribution of the green granular heaps of plants. Is there any similarity to the distribution of higher plants over uncultivated areas?

2. After soaking a piece of bark for a few minutes, scrape off with the nail or a dull knife blade some of the green material, spread it as well as possible in a drop of water on a slip of glass, cover it with a piece of thin glass, avoiding air-bubbles, and examine with a lens. Observe the minuteness of some of the specks, which are mostly single plants The larger ones are clusters of plants.

3. Demonstration. Show a slide under microscope and have pupils

* For further information on these plants, see Frankland: Our Secret Friends and Foes ; Prudden: Story of the Bacteria, Dust and its Dan. gers, Drinking-water and Ice Supplies : Russell: Dairy Bacteriology; Frankel (tr. by Linsley): Bacteriology (medical). 
observe the form and color of single plants, many consisting of two or more cells still joined together, resulting from cell division. ( $\Upsilon_{\mathbf{I}} \mathbf{7}$, fig. IO.)
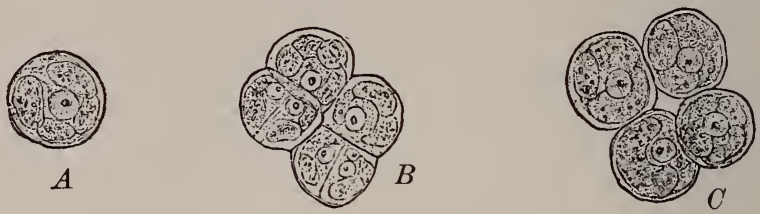

F1G. 10.-Pleurococcus viridis. $A$, a single individual; $B$, a colony shortly after division; $C$, the same after separation. Mlagnified $54^{\circ}$ diam.-After Strasburger.
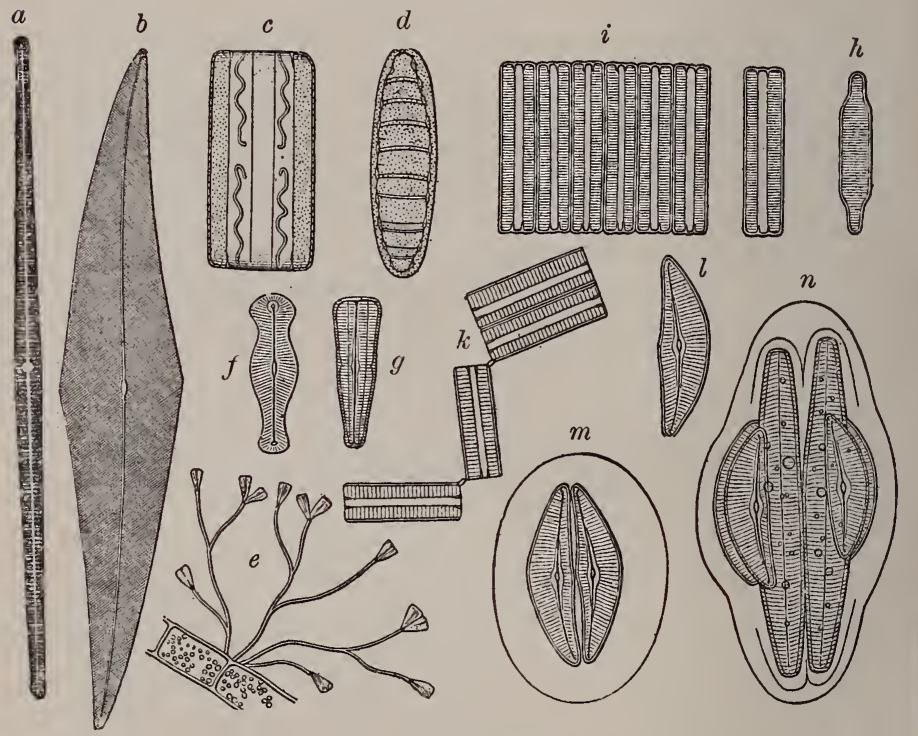

FIG. Ir.-Various diatoms. a, Synedra; b, Pleurosigma; $c$, d, Grommatrphora, side and top views; $e$, colony of Gomfhonema, with branched stalks attached to an alga; $f, g$, single cells of same, more magnified, top and side views; $h$, colony of Diatoma, the cells connected into a zigzag band ; $i, k$, colony and individuals (top and side views) of Fragillaria: $l, m, n$, Corconema. In $m$ the pair is surrounded by jelly preliminary to the escape of the protoplasm and the formation of two new cells (auxospores) which has been completed in $n .-$ After Kerner.

18. Shelled plants.-Other one-celled plants constitute a group known as diatoms, found in both fresh and salt waters, either attached or free-swimming (figs. Ir, I2). The dia- 
toms are very various in form, and present two different aspects. When seen from the side they are generally elongated-rectangular. When looked at from above they are short-cylindric, disk-shaped, boat-shaped, or variously curved or angular. 'They are peculiar in having the cell-wall so filled with silica that scarcely any other material is left. Indeed the plants may be heated to a red heat and boiled in acid without destroying the form and markings of the cellwall, so completely has it become silicified. To permit growth this rigid cell-wall is constructed in two pieces which fit together like the two parts of a pill-box (fig. I2). Each

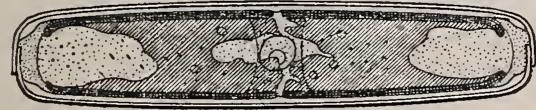

$B$

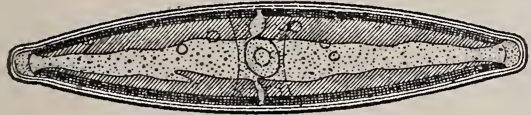

$A$

FIG. 12.-A single diatom (Navicula amphirhynchus). $A$, top view ; $B$, side view, showing overlapping of the valves. The parts shaded by lines are the chloroplasts; the dotted part the protoplasm, with nucleus about the center of cell. Magnified 750 diam.-After Pfitzer.

of these pieces, or valves, is sculptured into regular patterns in lines and dots, which are often so excessively minute or close together as to be barely visible with the highest powers of the microscope ( $b$, fig. I I). Seen in mass, as they may often be on the sides of a glass aquarium, living diatoms appear yellowish-brown. The chloroplasts, which are sometimes single and always few, have a brownish color in addition to the green chlorophyll.

It is not uncommon for the diatoms to form colonies by the adhesion of several or many individuals by means of gelatinous cell-walls. These colonies are ribbon-like, or zig- 
zag chains, or even branched filaments ( $h$, $i$, fig. II). Other sorts may be attached singly or in clusters by a gelatinous stalk ( $e$, fig. I I). In all cases the jelly, like the rest of the cell-wall, is a product of the protoplasm. The slow gliding movements of some free diatoms are due to the protrusion of strands of protoplasm through slits in the valves.
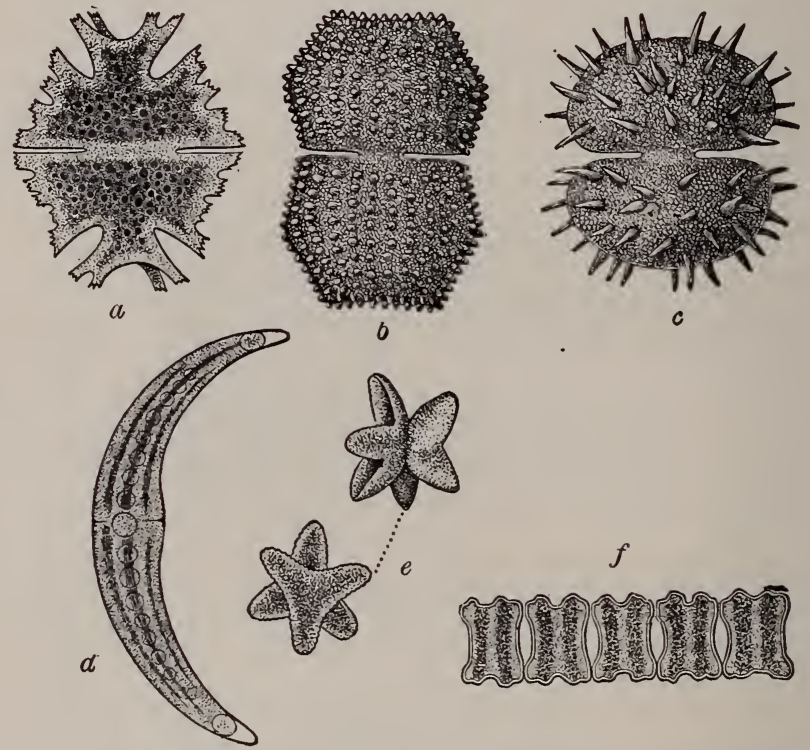

FIG. 13.-Various desmids. a, Micrasterias: $b$, Cosmarium; $c$, Xanthidium; d, Closterium: e, Staurastrum; $f$, Aptogonum. Magnified about 200 diam. -After Kerner.

19. The desmids.-These form another group of onecelled green algæ. They have neither the brownish color nor siliceous wall characteristic of diatoms, but are bright green cells of remarkably diverse and often beautiful forms. As a rule the cell is flattened and is divided almost into two by a deep constriction near the middle ( $a, b, c, e$, fig. I 3 ). Often the body of the cell is covered with warts or spine-like 
projections ( $b, c$, fig. $\left.\mathrm{I}_{3}\right)$, or is prolonged into horn-like or hair-like lobes. These plants also frequently cohere into colonies ( $f$, fig. $\mathrm{I}_{3}$ ). In that case tooth-like projections of the cell-wall may interlock.

20. Summary.-The simplest plants consist of a single cell, which is often protected by a copious mucilage. By this means also the plants are often associated in colonies of various forms. Among the green plants some possess in addition a blue coloring matter; others a brown. Many can move about from place to place. The bacteria are degenerate relatives of the blue-green algæ which have lost their green color, and thus their power to make their own food. 


\section{CHAPTER III.}

\section{FILAMENTOUS ALGÆ.}

Oвviously some of the plants mentioned in the last chapter, such as the oscillarias, are colonies of cells well on the
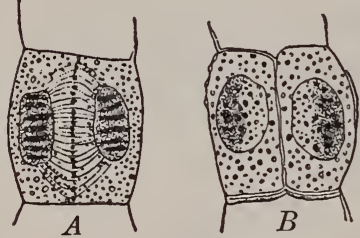

Fig. r4. $-A$, one of the final stages in cell-division. The daughternuclei are still connected by filaments, and across the equatorial plane particles of new cell-wall material are formed $B$, the completion of cell - division; the daughter-nuclei have rounded off and the new wall is like the lateral walls. Magnified 88o diam. - After Strasburger.

In a plane between these daughter-nuclei particles are deposited to form a cell-wall ( $A$, fig. I4). In this way a single one-celled plant of Pleuro-
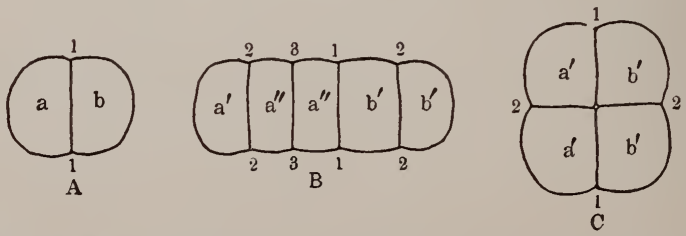

Fig. 15-Diagrams of cell-division. $A$, division of a spherical cell into two hemispherical cells, $a, b$, by the wall $\mathrm{r} \quad b$, the sane after further division in planes 2 , 2. 3, parallel to $x$. $a$ has divided by wall 2 into $a^{\prime}$ and another cell which has again divided by wall 3 into $a^{\prime \prime}$. $a^{\prime \prime}$. $b$ has divided into $b^{\prime}, b^{\prime}$, the inner of which has elongated preparatory to a division into $b^{\prime \prime}, b^{\prime \prime}$, as by wall 3 . $C$, fig. $A$, after a second division, by wall 2 , at right angles to $\mathrm{r}$. 
coccus ( $A$, fig. Io) may divide into two, so that it consists of two hemispherical cells, each capable of independent growth (fig. 23, $A$ ).

In the filamentous algæ the cells formed by such divisions remain connected throughout their whole extent, and as the successive divisions are parallel a cell row results ( $B$, fig. $\mathbf{I}_{5}$ ). When the divisions are in two planes the cells form a flat sheet (c, fig. 15); and when in three planes, a mass.

22. Filamentous algæ. -There is a large number of plants in which the vegetative body throughout life has the form of a filament. The green plants of this sort live almost entirely in water or in wet places, and may be conveniently designated as filamentous alge.

23. Pond scums. Among these none are

Fig. 16.

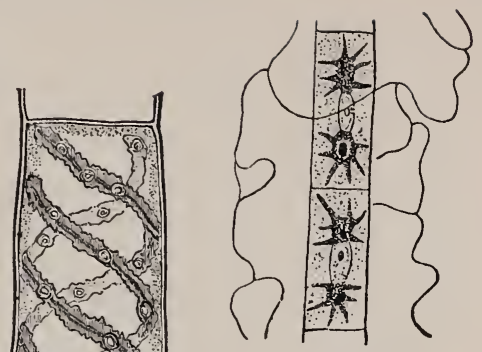

FIG. I7.

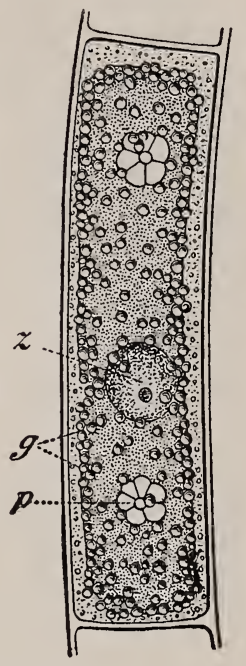

FIG. 18.

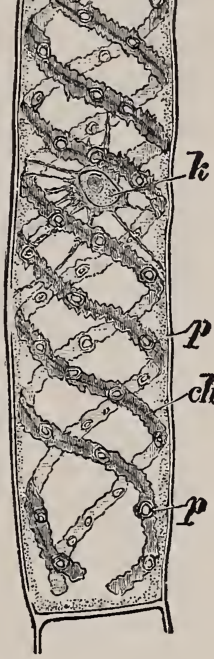

Fig. 16.-A cell from filament of Spirogyra. $c h$, chloroplast (there are three in this cell); $p$, pyrenoids; $k$, nucleus. Magnified 200 diam. -After Strasburger.

FIG 17.- Two cells from filament of Zygnema, showing the gelatinous sheath greatly swollen, and stellate chloroplasts, in which is a pyrenoid, with the nucleus in a strand of protoplasm between them. Magnified 245 diam.-After Klebs.

Fig. 18.-A cell from filament of Mougeotia. The darker body nearly filling cell is the chloroplast (face view) in which are pyrenoids, $p$, and tannin vesicles, $g$. If seen from a direction at right angles it would appear as a narrow stripe in the center of the cell. $z$, the nucleus. Magnified about 200 diam.-After Zimmermann. ing than the pond scums, represented in our waters by several genera (Spiro. gyra, Zygnema, Mougeotia and some others $*)$. They

* To the same group also belong the single-celled desmids already described. 
may be readily recognized, during their vegetative period, by their unbranched filaments, bright green color, and slippery "feel" between the fingers.*

Under the microscope, they are at once distinguished from other filamentous algæ by the shape of their chloroplasts. In Spirogyra these form one or more flattish, spirally wound ribbons, notched on the edges, and embedded in the protoplasm near the cell-wall (ch, fig. I6). In Zygnema there are generally two irregularly star-shaped chloroplasts (fig. I7); while in Mougeotia a single flat, plate-like chloroplast, nearly as wide as the cell, traverses its center (fig. I8). See also fig. I9.

Embedded in the chloroplasts of these and other algæ are usually seen one or more angular, colorless bodies, often surrounded by a jacket of starch. These are stores of reserve food, known as pyrenoids ( $p$, figs. 16, 18).

In these plants there is little or no difference between the parts of the filaments. If broken into two, each part may continue growing with no damage to any part except the cells which were ruptured in severing the plant.

\section{EXERCISE IV.}

Spirogyra._-If fresh material is available examine a few filaments in a white dish for color. If preserved material is used, stain red by immersing for a few minutes in eosin (cheap red ink will answer).

Examine with a lens. Observe

I. Length; whether broken or whole; whether with or without branches.

2. The delicate partitions, like white lines, crossing the green (or red) filaments, dividing the protoplasm of one cell from another. Can the form of the chloroplasts be seen? (Cf. fig. I6.) This can be readily seen only in the larger species. ( $\$$ 23.)

3. Demonstration. Mount a few fresh filaments in water. Show under moderate power the form of the chloroplasts; the reserve food nodules ; the nucleus. (Fig. I6.)

* This slipperiness is due to the gelatinous outer part of the cell-wall (fig. 26), which is only visible after special treatment or on examining the filaments in a thin mechanical solution of Chinese ink. 
24. Base and apex.-But other filamentous algæ show a distinction between base and apex. In Ulothrix (fig. 19) the basal cell is elongated and pointed, and is colorless, because it is not furnished with chloroplasts like the others. By this pointed cell the plant is loosely attached, at least when young, to the substratum, while the green portion waves freely in the water. Thus arises a distinction into two parts, viz., the rhizoid and the thallus.

In Cladophora, Vaucheria, and their allies, the plants are generally attached by a welldeveloped rhizoid region, which is often branched ( $w$, fig. 20 ), as is also the thallus. In contrast with the preceding, therefore, localization of growth, producing branching, may be observed.

25. Branching,-A branch begins by the growth in area of a limited portion of the cellwall. Since growing cells are usually stretched by the water they absorb, the pressure upon the enlarged region causes the wall to bulge outward there. The convexity gradually increases as the region grows, until the swelling becomes an outgrowth whose further lengthening constitutes a branch similar to the main filament. Growth in length may be limited to the tip of

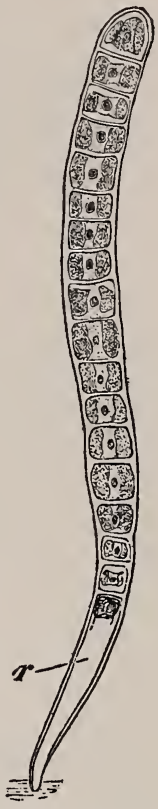

FIG. 19. $-U l 0-$ thrix zonata. A young filament with rhizoid cell, $r$, at base. Magnified 482 diam. - After Dodel-Port.

a filament, or to a narrow zone including one or more cells, or it may occur indifferently in any cell, or in all cells.

\section{EXERCISE V.}

Cladophora.-If fresh material is at hand observe in a white dish ; if preserved specimens are used stain for a few minutes in eosin.

I. How is the plant attached? 
2. Observe form and particularly the abundant branching. Can a single main axis be traced? How many branches arise at one point?

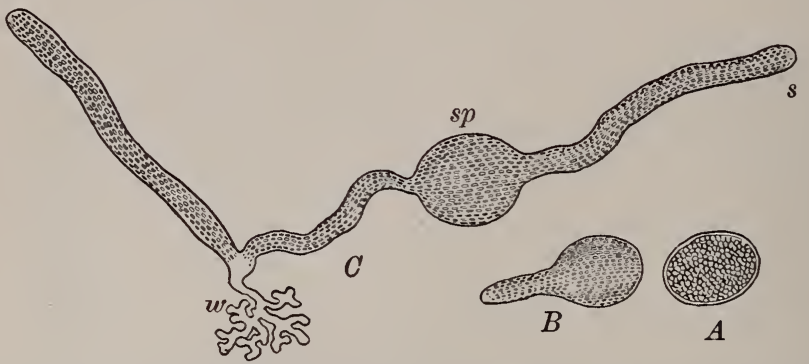

FIG. 20.-A young plant of Vaucheria, developing from the spore. $A$, mature spore; $B$, the same after germination has begun ; $C$, plant further developed from spore, $s p$, with growing apex, $s$, and rhizoid, $w$, by which it attaches itself to the mud. The chloroplasts are numerous and close together next the wall on all sides. Magnified 28 diam.-After Sachs.

26. Partition walls unnecessary.-Many algæ, while externally like others, which are divided into true cells, have not the units of structure separated by cell-walls. In Vaucheria, for example, the whole of the vegetative body forms a single chamber, in which lies the undivided protoplasm, corresponding to many cells, as shown by the numerous nuclei which are distributed through it. The external walls of the cells are formed, but the partition walls are not formed.

27. External segmentation.-A plant body of this construction may attain considerable size and complexity, as in Caulerpa (fig. 2 I), * even to mimicking, upon a small scale, the form of leafy plants. In such cases the external walls become considerably thickened, and across the chamber, from one side to the other, run irregular bars of similar material which act as braces to prevent the collapse of the outer walls (fig. 22 ).

In Caulerpa, particularly, a high degree of development as to external form is reached (fig. $2 \mathrm{I}$ ). There is a stem-like

* Note carefully the scale of the figures. 
axis, $v-s$, creeping in the mud, which bears green leaf-like branches, $b$, on one side and clusters of colorless root-like

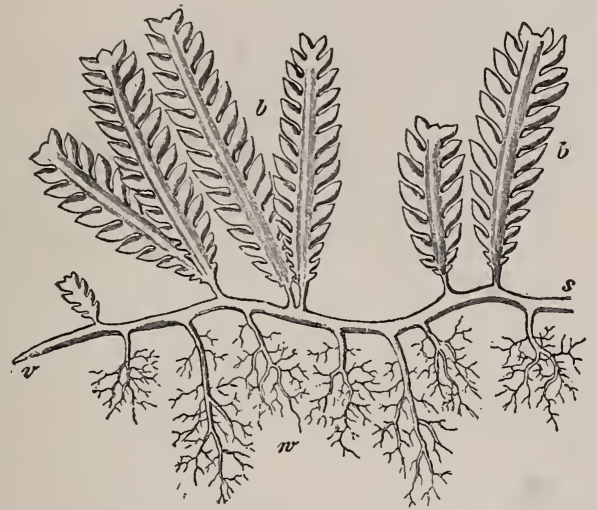

Fig. 2r.-Part of a plant of Caulerpa. See text, I 27. Two-thirds natural size.After Sachs.

branches, $w$, on the other. Not only are a base (posterior end) and an apex (anterior end) distinguishable, but the plant shows a difference between an upper (dorsal) and under (ventral) side, the leaf-like thallus lobes arising from the dorsal side, while rhizoids spring from the ventral side.

28. The thallus.-To the loose aggregation of single cells into colonies of definite form, as well as to the body formed by their more intimate union in the cell rows and masses just described,

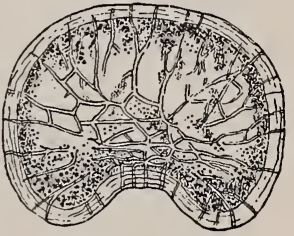

FIG, 22- Transverse section of axis of Caulerpa, showing cross-bars to stiffen wall. Magnified about 25 diam.After Murray. the name thallus is applied. The term is most frequently applied to those more complicated forms which constitute the vegetative bodies of the higher algæ, which are now to be described.

29. Summary.-Instead of being loosely associated in col- 
onies, plant cells may remain firmly united in rows or sheets. Such an aggregation of cells is then called $a$ plant. The form of the plant depends upon the mode of division of the cells. The body may be thread-like, and alike at both ends. Or it may be distinguishable into a base and apex, or even into a root-like part, the rhizoid, and a shoot-like part, the thallus. Either may branch. Branching is due to more rapid local growth of certain regions. In some plants the protoplasm is not, or only incompletely, divided by cellwalls. 
CHAPTER IV.

THE THALLUS OF THE HIGHER ALGÆ.

30. The larger algæ.—From the thread-form algæ, whose body is a single row of cells, it is but a step to those forms whose body consists of a single sheet of cells. One common form has a leaf-like body, which grows attached to stones or other algæ. The broader forms are sometimes $20-25 \mathrm{~cm}$. wide.

The body of the sea-lettuce is somewhat similar in structure, but consists of two layers of cells, and, as fig. 23 shows, is very clearly distinguishable into an organ of attachment, the rhizoid, and the leaflike part for which the name thallus may be kept.

So, from the thread-like bodies we pass through sheet-like to massive bodies of a broadly extended form. Likewise there may be found all intermediate forms between the threadlike algæ and those whose bodies are slender, but are more than one row of cells thick.

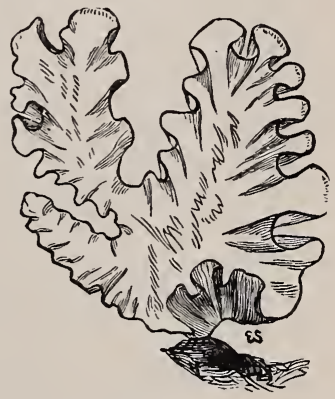

FIG. 23.-A small plant of Ulva lactuca, the sea-lettuce, showing thallus, and rhizoid for attaching it to rocks. Natural size.-From Bessey.

In other marine algæ a still higher specialization of members is reached. One of the red seaweeds may be used to show the gradual advance in complexity. 


\section{Polysiphonia.}

31. External form. - The body of Polysiphonia, a slender alga (fig. 24) which grows in abundance upon rocky sea-

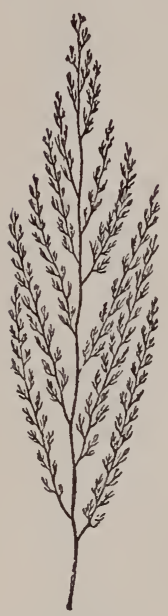

FIG. 24. coasts, is much branched. The main axis is made up in its larger parts of five or more rows of cells, the central row being surrounded by a jacket of at least four others (fig. 25); but at the tips even of the main axis there is only a single row of cells, as in the simplest algæ (fig. 26). The body of Polysiphonia, there-

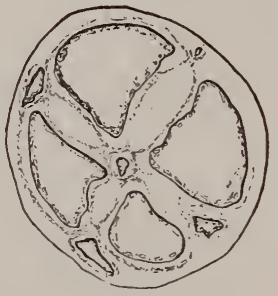

Fig. 25.

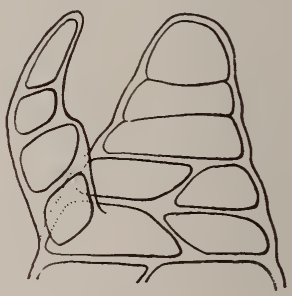

FIG. 26.

FIG. 24.-An entire plant of Polysiphonia, showing mode of branching. Natural size. -After Kützing.

FIG. 25.-Transverse section of one of the branches of Folysithonia, showing a minute central cell with four large and four small cells surrounding it. Magnified about 50 diam.-From a drawing by Mr. Grant Smith.

Fig. 26. - Apex of a branch of Polysiphonia which has nearly ceased growing. Magnified about 100 diam.-From a drawing by Miss Rowan.

fore, is one of the simplest forms composed of cells massed together.

32. Growth.-Growth in length can take place only at the ends of the main axis and its branches, because there each apical cell (fig. 26) produces, by division near its base, the new cells whose later division and enlargement make the mature axes.

33. Color.-In this plant, as in very many of the marine algæ, there is present, in addition to the green of the chloroplasts, a special red coloring nıatter. To the naked eye, this 
color overpowers the green and gives the plant a pink tinge. In other red algæe it is often present in greater quantity and variety of hue, so that brilliant reds and purples, with shadings of brown and green, mark the more striking species.

\section{EXERCISE VI.}

Polysiphonia. - Place a plant in a glass dish over a black or white background. Observe

I. The form of the body and the mode of branching. (Fig. 24.)

2. The mode of attachment at the base, if specimens are entire.

3. Demonstration. Mount the tip of one of the branches and show the high, dome-shaped, apical cell, with segments cut off successively from its base, to be later themselves divided longitudinally. ( 32 , fig. 26.)

4. Cut a transverse section of a medium-sized axis and observe the four large peripheral cells, surrounding a central cell ; the latter to be seen only under compound microscope. (I 3I, fig. 25.)

Between the very simple body of Polysiphonia and the much larger and more complex body of the common bladder-wrack, or Fucus vesiculosus, there are all gradations, which cannot be described here.

\section{Fucus.}

34. External form.-The body of Fucus (fig. 27) is large as compared with the plants previously described. It is often 75-100 $\mathrm{cm}$. long by $\mathrm{I}-2 \mathrm{~cm}$. broad, of greenish-brown color and somewhat leathery texture. Near the base the thallus is contracted into a stalk whose extremity is broadened into a sucker-like disk (often irregularly branched) which attaches the plant firmly to the wave-washed rocks, on which it grows. Above, the thallus is flattened, with a thicker rib in the middle (fig. 28), and branches abundantly by forking. These branches, though often twisted, really lie in the same plane as the flattening (fig. 27). Here and there the thallus has 
pairs of oval bladdery swellings, which, by the gases they contain, give greater buoyancy to the plants in the water.

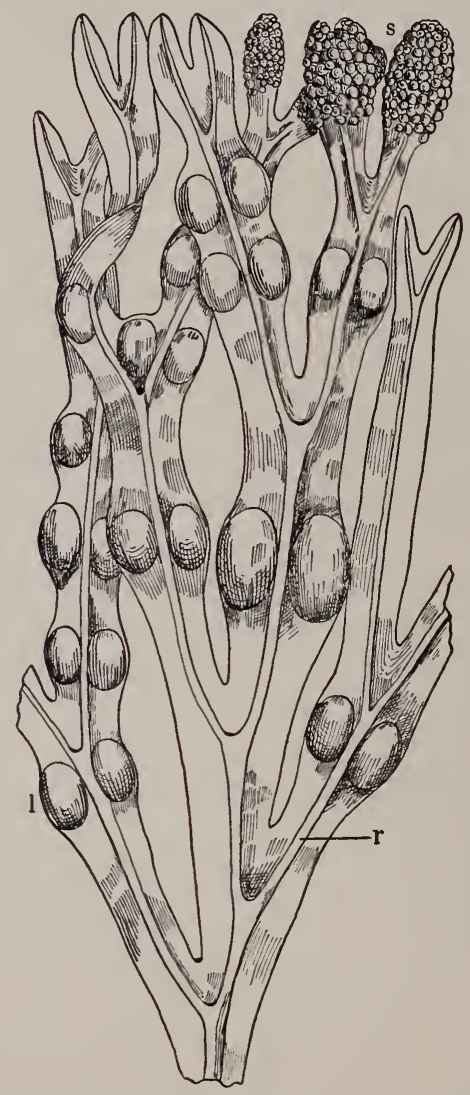

Fig. 27.-Upper part of a plant of Fucus veszcu.osus. $\quad r$, midrib of thallus ; $l$, bladders; $s$, swollen tips covered by numerous elevations, in each of which is a pit which contains many sex-organs. Two thirds natural size--After Luerssen.

35. Growing point.-The very tip of each growing branch is notched and at the bottom of the notch is a group of cells which by division produce all the parts of the thallus. This 
youngest region, found also at the tips of the growing axes of the higher plants, is the growing point. It has no limit below, but as the parts further and further from the apex are examined, they are seen to become more and more unlike with age until the mature form is reached.

36. Mature thallus.-If the mature part of the thallus be cut at right angles and a thin slice be cut off one end, placed on a glass slip and examined with a lens, it shows two distinct regions; a central one, quite translucent, the pith, bounded by an outer brownish opaque region, the cortex. 'The central part is very full of mucilage, produced by a change in the substance of the cell-walls of the pith region. In the bladders this mucilaginous pith does not increase to fill the central space, but this is occupied by a great chamber filled with air and other gases. In the midrib the structure is plainly denser than elsewhere, except in the stalk below, which is like an enlarged midrib without the side wings.

37. Division of labor.-Complete examination of other parts, the attachment disk, the hair pits (fig. 28) with which

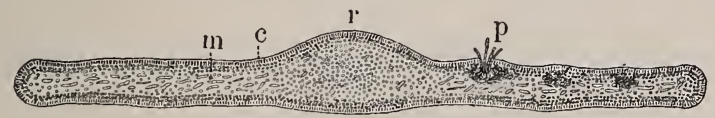

FIG. 28.-A transverse section of the thallus of Fucus, showing midrib, $r$; cortex, $c$; pith, $m$; and a hair pit, $p$. Magnified ro diam. - From a drawing by Mr. C. E. Alien.

many species are covered, etc., would reveal still other ways in which unlikeness arises with age from the uniformity of the growing point. With the change of form there is always division of labor, which we can interpret only in a very imperfect fashion from our own standpoint. The compact cortex is nutritive and probably in part protective ; the bladders serve to increase the buoyancy of the plants when the tide is in ; while the abundant mucilage, found in the interior, probably serves to retain the moisture when the plants are exposed by 
the ebbing tide ; the hair pits are useless, so far as known ; and the strong, elastic disk and stalk above hold the plants in place as they sway constantly back and forth in every wave of the rising or falling tide.

38. Color.-The coloring matter in Fucus and other brown seaweeds is of two kinds, a green (chlorophyll), and a brown. These colors are found chiefly in the cortex, which is, therefore, the food-making tissue (see I 90 ), while the internal tissues may be used for storage of reserve food.

\section{EXERCISE VII.}

Bladder Wrack. (Fucus vesiculosus). - Place a plant in a glass dish or a pan of water. Observe

I. The general form of the body or thallus; its mode of branching. (I 34.)

2. The thicker central region forming a midrib, with thinner wings. (Figs. 27, 28.)

3. Downwards, the thickening of rib and death of wings to form stalk near base.

4. The lobed attachment disk at base of stalk.

5. The swollen regions of the wings here and there. Cut into one of these and observe that it is a bladdcr.

6. The notched tips of some branches; the enlarged and more or less distorted tips of most, forming the receplacles.

7. Scattered on the thallus minute elevations, from which protrude through an opening at the top a tuft of fine hairs. These are the mouths of the hair pits. (Fig. 28.)

8. Crowded on the receptacles, larger warts with a hole at top and similar protruding hairs. These are the mouths of larger pits, conceptacles, which contain the sex-organs.

Cut two thin transverse sections of the thallus, one through the bladder and the other through the general thallus. The latter should include a hair pit. Examine them with a lens and observe

9. In the latter, the denser outer tissues; the cortical region; the looser inner ones, of elongated threads and much mucilage, the medullary region; the thicker denser midrib; the form of the hair pit.

Io. Note the difference between the structure of the bladder and the unswollen wing. Which region is altered to form the bladder? 
39. Summary.-Comparing the thread-form with the thin broad algæ, we find the body of the latter often nearly as simple; but, when the body is thicker, it is often seen to consist of unlike regions. The outer parts are arranged so as to enable the plant to make food for itself by getting the proper material from the water and absorbing the light that falls upon the surface. The inner parts, being too much shaded by the outer to serve for food making, are used for other purposes. Special organs for floating the plant are formed in some of the brown seaweeds.

Other algæ, of slender form, are more complex by having the older cells of an at first single row divided by partitions parallel to the length into five or more cells.

With greater complexity of the body, growth in length usually becomes localized at the tips where all the cells are rapidly dividing. 


\section{CHAPTER V. \\ THE FUNGUS BODY.}

FUnGI are plants without the green coloring matter chlorophyll (see 6), whose body is generally made up of long filaments, either loosely or densely interwoven and united.

40. Origin. - As the bacteria (see I4), the smallest and simplest plants, were probably derived from the lowest algæ by slowly adapting themselves to get ready-made food, so, at various times in the past and therefore at various points in the ascending scale of algal life, certain algæ have adapted themselves to the use of food which they could secure from other beings. Then, having no use for the chlorophyll and chloroplasts, they have gradually lost them. The adoption of the habit has proved highly successful, both among the simple bacteria and the more highly organized true fungi. The ancestors of the present species were-how long ago no one can say-probably at first chiefly, if not exclusively, aquatic. Some, at the present time, have the same habit, growing in infusions of organic matter. Others attach themselves to dead or even living animals or plants in the water. The bodies of dead or living organisms furnish places of growth for a great number of species which have adapted themselves to other than aquatic life. Many live in the soil because it contains in its upper layers more or less organic matter from the offal of plants and animals, or from their dead bodies.

41. Hyphæ. - The filaments of which the fungus body is composed are called hyphæ. Each is the result of growth 
from a single cell, and is comparable to the thread-like body of the filamentous algæ.

There is, naturally, a great variety in the hyphæ of different species of fungi. Some are relatively large; others very small; some of even diameter and caliber, others irregular and with unequally thickened walls; some very thin-walled, others very thick-walled. Between these extremes is to be found a complete gradation.

They grow in length at the apex only. In many kinds partitions are formed at more or less regular intervals, as the growth in length proceeds, while in others no partition-walls are formed. Even when transverse partitions form, they do not separate the filaments into cells, but each chamber, or sometimes the whole filament, represents several or many cells. (Compare 26.)

42. Branching.-As the hyphæ elongate, branching may occur. If a branch is to be formed, a limited area of the cell-wall begins to grow more rapidly than the rest. This allows a slight bulging of the growing region; the swelling increases and soon takes the form of a branch, like the main axis. It may remain short or continue to grow indefinitely in length. Commonly a cross-wall is formed at the base of the branch. If such a branch arises first as a minute pimple, so that it remains connected with the parent axis by a small neck, and has only limited growth in length, it is called a bud and the process is known as budding (fig. 29). Such branches are usually easily broken off, thus readily producing independent plants. (See further

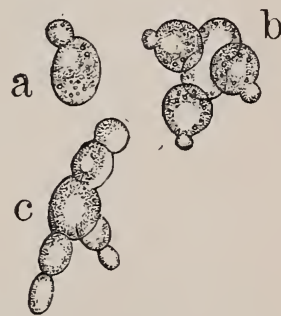

FIG.29.-Beer-yeast(Saccharomyces cerevisia). $a$, a fullgrown plant with a branch (bud) partially developed. $b$, c.colonies formed by budding, the individuals still attached. Magnified 750 diam.-After Reess. under Reproduction,

- 26r.) In some species of fungi, 
profuse branching is the rule; in others, the branches are few.

43. Mycelium.-When branching is profuse, or when a considerable number of individuals grow near together, the filaments often become interwoven and entangled in so complex a web that it is impossible to follow a single hypha for

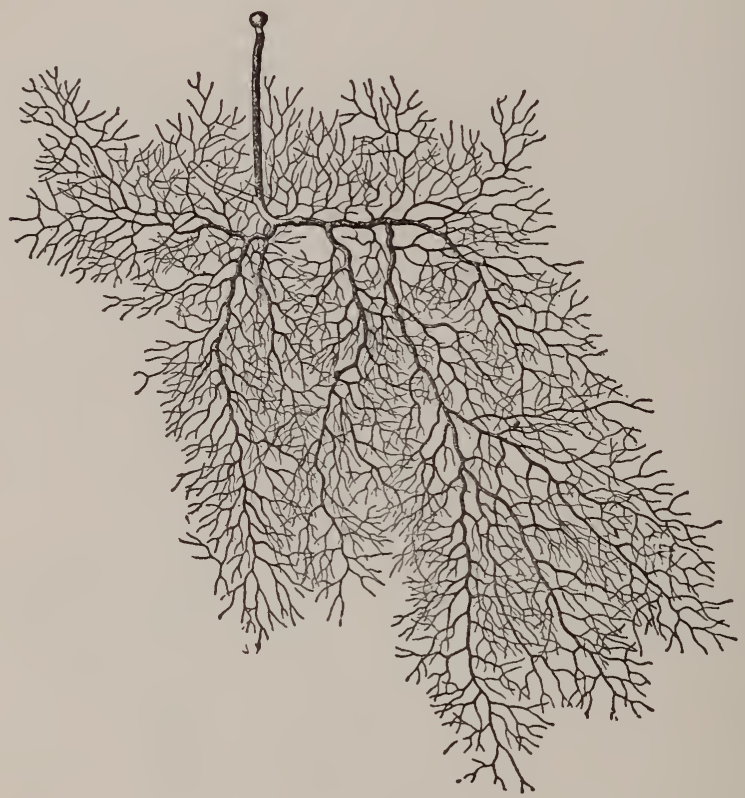

FIG. 3o.-A single plant of Mucor Mucedo, showing the mycelium as it developed from a single spore. It bears a single erect reproductive branch rising above the fluid. Magnified 25 diam.-After Brefeld.

any distance. Such a mat of hyphæ is called a mycelium, a term which is also used to designate the vegetative hyphæ collectively, whether forming a felted mass or not (figs. 30 , 3I). The mycelium may be formed wholly upon the surface of the object upon which the fungus lives ; or part of it may 
lie on the surface, and part may penetrate that object; or all of it may be hidden within the substratum.* In some of the common molds (Mucorini), the cobwebby threads lying upon the surface of the substratum constitute the exposed part of the mycelium, while other hyphæ penetrate deeper; in others (Penicillium, etc.), the superficial hyphæ become so

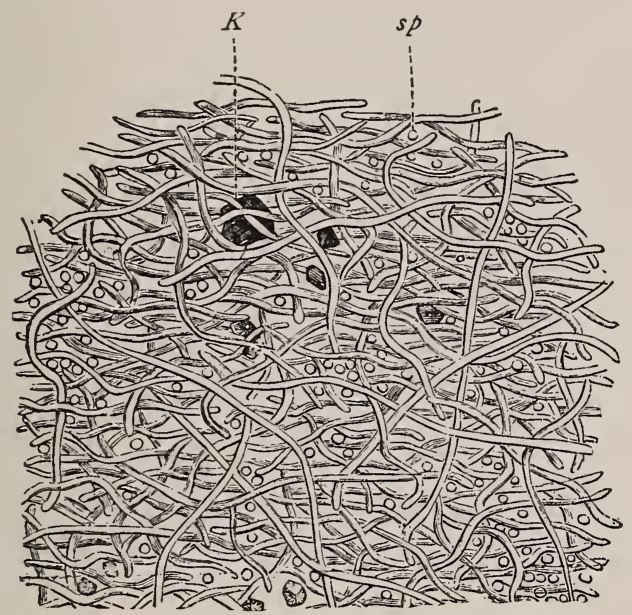

FIg. 3i.-A section of part of the aerial body of Polyporus. sp, hyphæ running at an angle to the section, cut across; $K$, crystals of oxalate of lime. Magnified about 500 diam.-After Vogl.

interwoven that they may be lifted off the substratum (as from jellies, jams, syrups, etc.) as a coherent layer. But in most cases, especially when the fungus grows on a solid medium, the hyphæ become adherent to it and permeate it so that they cannot be separated from it, even by the most careful dissection.

* This non-committal term may be used to designate the material upon which the vegetative part of the fungus grows, whether it be a living body, a dead organism, or organic matter in solid or liquid form. 


\section{EXERCISE VIII.}

Black mold (Rhizopus nigricans).--Before any white or black dots appear on the mold examine the vegetative hypha. ( 4r.) These are of two kinds, $(a)$ those running over the surface of the bread; $(b)$ those penetrating it.

r. Examine $a$. Lift up a few threads with a needle and mount them in water. Study with a lens. Are they white or colorless? Why then is the body composed of them (the mycelizm, 43) white?

2. Examine $b$. With needles tease out hyphæ from a bit of bread in water; free them as far as possible from the débris and mount. Compare with $a$.

After mold has begun to show black dots (spore cases, $\uparrow 27 \mathrm{I}$ ) examine

3. Determine how the branches are placed which bear the spore cases. (Fig. 30.)

4. Compare the white (young) and black (mature) spore cases. Can you find the very smallest ones?

5. Snip off a few ripe spore cases with scissors, handling them cautiously to avoid breaking or tangling them ; mount in alcohol* and examine. Crush (if not already broken) and observe numerous dust-like particles, the spores, which escape. (Fig. I46.)

44. Parasites.-Especially is this true of those fungi which grow in the interior of living organisms. The higher plants are liable to be fastened upon by parasitic fungi, and compelled to act as hosts to their unbidden and unwelcome guests. Such a host plant may be entered when a mere seedling, in which case the fungus grows with its growth, or it may not be attacked until older or even mature. The host may be permeated in all its parts by the fungus filaments ; or certain members only, such as the leaves, flower parts or twigs, may be affected. The effect of the fungus upon the host is often scarcely visible to the unaided eye ; sometimes a local disturbance is manifested by swelling, unnatural color or growth ; sometimes the affected members become distorted

* Because water will not wet them. Replace alcohol as it evaporates ; it does so rapidly. 
and useless or are even killed; sometimes the disease is general and is followed, slowly or quickly, by general death of the host. (See further $\uparrow 84,369$. )

45. Infection.-These internal parasites obtain entrance to their hosts in various ways. Sometimes the young hypha, growing from a special reproductive body (spore), * so minute that it may easily float in the air and fall upon a leaf, creeps along the surface till it finds one of the microscopic openings in the skin of the leaf, into which it grows ( $s p$, fig. 32). These external openings are connected with irregular

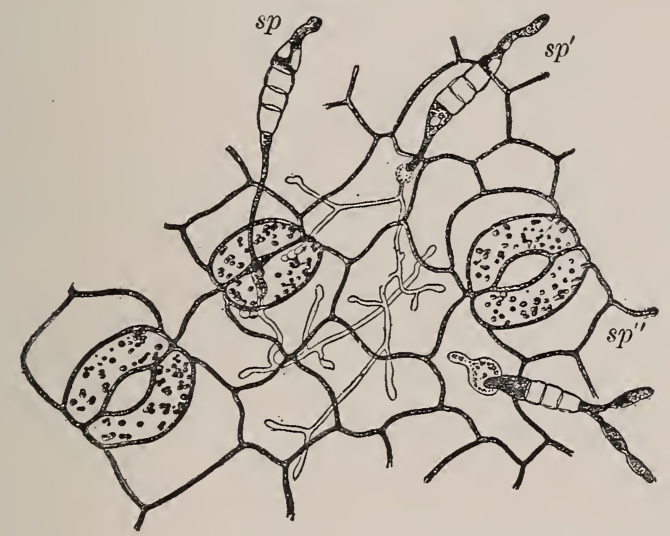

FIG 32.-Young hyphæ of Exobasidium developing from spores, sp, entering the air-pores of the leaf of the cranberry. Others, from $s p^{\prime}, s p^{\prime \prime}$, penetrate the skin directly. Magnified about 600 diam.-After Woronin.

spaces between most of the cells of the softer parts (fig. ro6), which are also the parts in which the food-supply is most abundant. In these, therefore, the fungus develops, breaking out to the surface again to form or set free its reproductive bodies.

Or, the young hyphæ may excrete at their tips a substance 
which so softens or dissolves the cell-walls of the host that they penetrate these cells readily, not only at the surface ( $s p^{\prime}, s p^{\prime \prime}$, fig. $\left.3^{2}\right)$, but in the interior.* They then branch

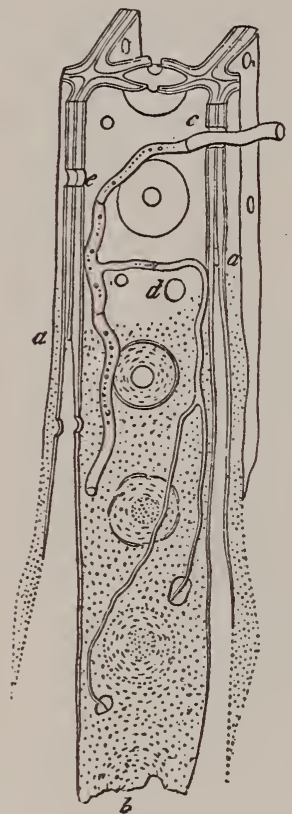

FIG. 33. - Hyphæ of Trametes lini perforating at $c$ the walls of a wood-cell of Scotch pine and destroying the primary wall of the cell. $a, e$, holes made by hyphx. Magnified about 800 diam. - After R. Hartig. freely, often growing in the spaces between the cells, often passing through the cells themselves (fig. 33).

Plants are often attacked when mere seedlings. From either a bit of mycelium or a spore that has survived the winter or the dry season, a hypha grows, which, almost as soon as the seedling emerges from the seed, penetrates it. The fungus, in these cases, may develop quickly and kill the young plant (as in the "damping off " disease in greenhouses), or it may derelop slowly and not reach its maturity until the host is also mature.

46. Haustoria.-Those fungi which grow upon the surface of living plants (and those which grow in the internal air-spaces) often have special branches for fastening themselves to the host or absorbing food from it. In the surface fungi these are usually very short, disklike or lobed branches which do not penetrate the cells of the host. In other cases they are branches of minute diameter, which enter the cells, and either enlarge into a knob (fig. 34) or branch profusely (fig. 35).

* The penetration of cell-walls is probably assisted by such pressure as the growing hypha can exert. 


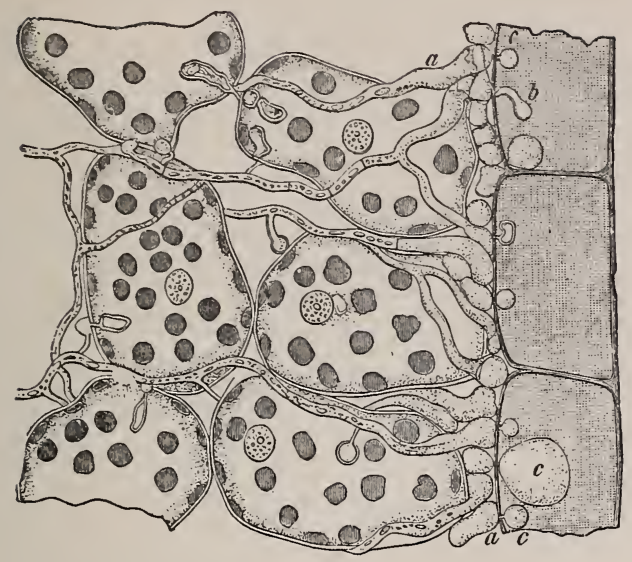

Fig. 34.-Epidermis and a few cortical cells of cowberry with mycelium of Calyptospora occupying the intercellular spaces and pressing knob-like ends against the cells from which a slender branch penetrates the wall and enlarges in the interior into sac-like haustoria, $b, b$. $a, c$, reproductive branches. Magnified 420 diain.-After R. Hartig

\section{EXERCISE IX.}

Mildew (Microsphara), a surface parasite.-Examine dried leaf bearing mildew. Observe

I. The whitish interlacing hyphæ on surface of leaf, forming the mycelium. (ף 43.)

2. The distribution of the fungus : does it cover the whole leaf or only occur in patches? Compare the earlier and later gathered leaves as to this.

3. Demonstration. Scrape a bit of the mycelium from the surface of the leaf after moistening it for a few minutes with a 5\% solution of potassic hydrate. Mount and show $(a)$ the colorless branching hyphæ; $(b)$ the erect branches bearing the spores; $(c)$ the spores.

4. Examine, as before, one of the older leaves. Observe the yellowish dots scattered over the mycelium, the immature fruits. Associated with these the black mature fruits, which contain sporangia with spores. ( $(27$ I.)

White rust (Cystopus portulace), an internal parasite.

1. Demonstration. Boil a leaf of purslane for a minute or two in $5 \%$ potassic hydrate. Tease apart the tissues of leaf with needles on a slide, 
mount and show the mycelium of the fungus consisting of tangled hyphæ ramifying among the cells of leaf.

( $\Upsilon$ १ $44,45$.

Examine a dried leaf. Observe

2. The white blisters (spore beds) here and there on the surface; the thin membrane (the epidermis of the leaf) by which they are covered; in older blisters the cracking and final disappearance of this skin. ( 269 , fig. 141.)

3. The white powdery spores which jar out or can be dislodged with needle.

47. Fusion.-When the hyphr of a fungus grow very close together, they frequently cohere and become so changed in appearance as to lose all trace of resemblance to filaments. Not only fusion but thickening and division occur, and a section of the resulting structure has much the appearance of

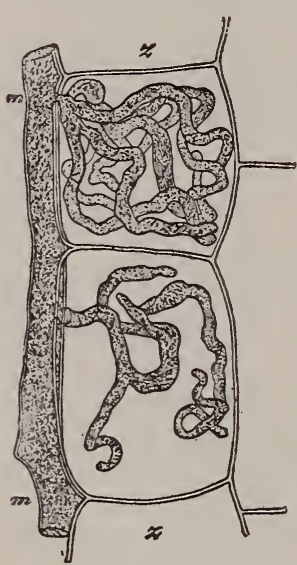

FIG. 35 .

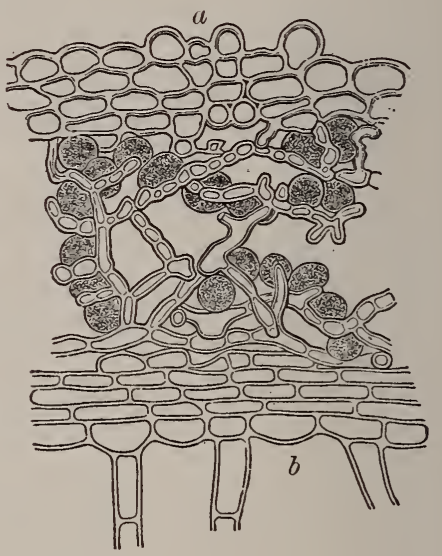

FIG. 36.

FIG. 35.- Branching haustoria of Peronospora. $m, m$, the hypha traversing an intercellular space of the host: $z, z$, two haustoria penetrating two cells of the host and branching therein. The other contents of host-cells not shown. Magnified about 400 diam.- After De Bary.

Fig. 36.-A section through the mycelium of a lichen showing hyphæe near upper surface, $a$, and lower surface, $b$, fused into a false tissue; only in central region are the filaments recognizable. The dark spheres are imprisoned algx. Magnified 650 diam. -After Bornet.

a section of the tissues of a higher plant (fig. $3^{6}$ ). These changes are particularly apt to occur at and near the surface 
of the more massive parts, where they are necessary to impart firmness, rigidity, or durability.

The interweaving and fusion of the hyphæ sometimes produce cord-like or strap-like structures of considerable size. The mycelia of the higher fungi frequently form them, and they may be found in the leaf-mold of forests or in rotten stumps or between boards in wet places.

48. Lichens. - The body of lichens is a mycelium woven about the simpler algæ, rarely about other small green plants, which are thus imprisoned. The fungus hyphæ usually predominate and in great measure determine the form of the body and its texture. Sometimes the algæ are present in such numbers that the hyphæ seem merely distributed among them. In form the body may be broad and thin (fig. 2 I 5 ), or slender and shrub-like; in some cases it is so thin and adherent, or so interwoven with the substratum, that it seems to form a mere crust over it. In texture it may be tough and leathery, with the hyphæ near the surface fused into a false tissue $(a, b$, fig. 36). When gelatinous algæ, such as Nostoc (see II ) are imprisoned, the body may be gelatinous while wet. In all cases the algæ supply the fungus with food, and are in turn supplied with water absorbed by the spongy mycelium. (See further $\uparrow 164,185,367$.)

\section{EXERCISE $\mathrm{X}$.}

Lichen (Physcia stellaris).---Soften a plant by soaking it in water for a few minutes. Observe

I. The mycelium, forming a connected leaf-like lobed thallus. Com. pare as many other forms as are available. ( 48 , fig. 215.)

2. Compare the color when dry and wet. In the latter condition, the mycelium is more translucent and the imprisoned green algæ show through more plainly. (Figs. 36, 216.)

3. The tufts of hyphæ extending from lower surface to bark, the holdfasts or rhizines.

4. Occupying the central region on the upper surface, the round colored disks, the clusters of spore cases. 
Cut a vertical section through a part of the thallus. Observe

5. The layers of the thallus; above and below, dense layers, the upper and lower cortical layers; between them, the medullary layer, with green alga distributed unequally through it. (Fig. 36.)

49. Summary.-The fungi, though descended from the algæ, have adapted their body to new conditions of life so completely that it shows little resemblance to that of the algæ. All have colorless (non-green) bodies, composed of slender hyphæ, frequently much branched and interwoven, and either applied to the surface or penetrating the substratum. Some kinds live on dead organic matter (saprophytes); some are external and some internal parasites. The latter enter the host through pores, or by perforating the skin, often causing deformity or disease or death. When strength or protection or durability is necessary, the hyphæ may become inseparably fused into a false tissue. Lichens are special kinds of fungi, associated for life with simple algæ from which they derive their food. 


\section{CHAPTER VI.}

\section{LIVERWORTS AND MOSSES.}

50. Alternation of generations.-In the liverworts and mosses, as in all the plants higher in the scale, there occur two well-marked phases in the course of their lives. One of these phases is marked by the formation of sexual reproductive cells, or gametes, the egg and sperm (see 9304 ), whence it is called the sexual phase, or the gametophyte. The other is characterized by the formation of non-sexual reproductive cells, the spores (see 263 ), whence it is called the non-sexual phase, or sporophyte. These two phases alternate with each other; i.e., the eggs produced by the gametophyte do not form a new gametophyte but a sporophyte; and the spores of the sporophyte do not form a new sporophyte but a gametophyte. Representing the gametophyte by $G$ and the sporophyte by $S$ the sequence is $G \ggg \rightarrow S_{\gg \rightarrow} G \ggg S \rightarrow G \rightarrow S$, and so on, generation after generation. Often the gametophyte forms other gametophytes repeatedly, but usually the succession is interrupted, sooner or later, by the formation of fertile eggs and from these a sporophyte. In such cases the

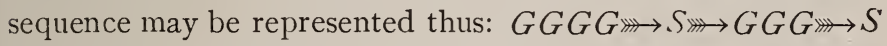
$\ggg G G$, etc. The sporophyte of these plants never propagates its own form. To this regular sequence of the two phases the phrase alternation of generations has been applied.*

* Rather obscure suggestions of the alternation of generations are to be found among the algæ and fungi, but they are not definite enough to warrant discussion in this book. Let the student notice, however, that this feature does not appear suddenly in plant life, though introduced abruptly into the account of it. 
In each phase, a body of form and structure suited to its special work is produced. In the higher liverworts and mosses both phases have nutritive work to do, but in many this is confined to the gametophyte, and in all the gametophyte carries on the greater part of it. To this phase, therefore, attention is first given.

\section{Liverworts.}

51. The thallus.-The form and structure of the vegetative body of the simplest liverworts is scarcely different from that of some of the green algæ. The body is a thallus with rhizoids (fig. 37). The rhizoids are usually filaments arising
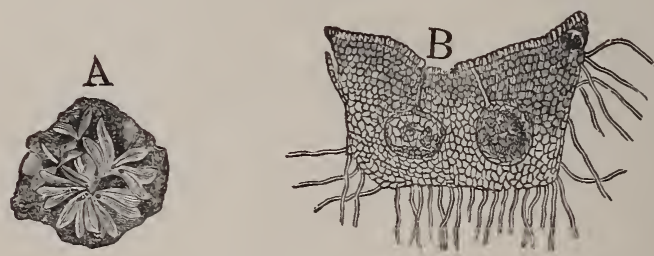

FIG. 37.-A, plants of Riccia sorocarpa, on the ground. Gametophyte phase. Natural size. $B$, a vertical section of one of the thick lobes of the thallus, showing nearly uniform structure. The thallus has nearly covered over two young sporophytes which appear as though in the interior. Rhizoids arise from the ventral side and flanks. Magnified about 25 diam.--After Bischoff.

from the under side and flanks of the thallus. They serve to fasten the thallus to the substratum, and perhaps assist it in absorbing water. The thallus is usually thin and flat, though sometimes much crisped. Most liverworts lie broadside to the substratum. Very rarely is the thallus erect and attached by a narrow stalk.

52. The dorsiventral thallus.-In the simplest forms the thallus is uniform in structure from upper to under side. In others there is a decided difference between the two sides. The upper part is green, while the under is not. In one family there are large air-chambers in the upper part of the 
thallus, from the floor of which arise green filaments (fig. $3^{8}$ ). On the under side, also, are frequently found scale-like outgrowths as in fig. $38, i$.

A part which shows constant differences between an upper (dorsal) and an under (ventral) side is said to be dorsiventral.

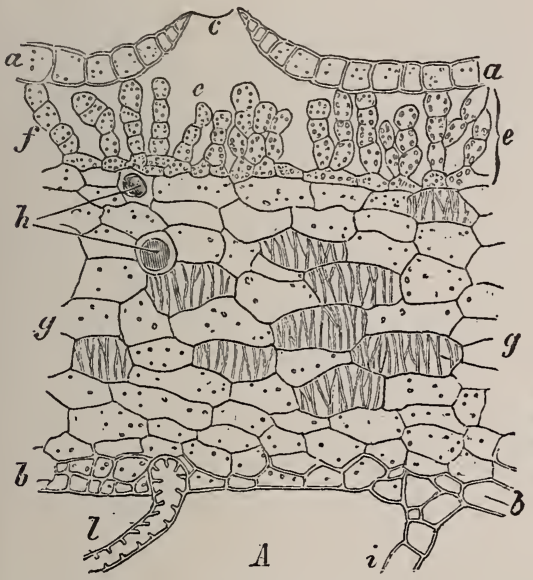

FIG. $3^{8}$

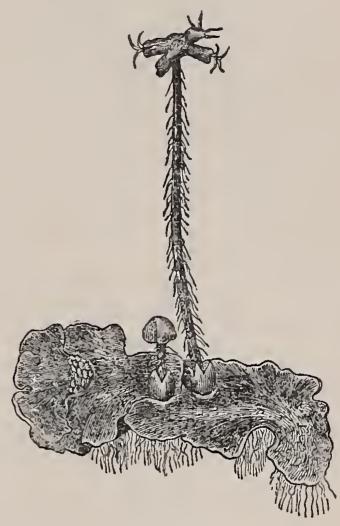

Fig. 39 .

FIG. 38.- Portion of a vertical section of the thallus of Lunularia cruciata. a, dorsal, $b$, ventral epidermis : $c$, an air-pore ; $e$, air-chamber, from whose floor rise green filaments, $d ; f$, partition between adjoining air chambers; $g$, colorless cells contain. ing starch, some showing net-like thickenings of the walls, others with oil-bodies, $h$; $i$, a ventral scale; $l$, a rhizoid. Magnified r ro diam.--After Nestler.

FIG. 39. -Lunularia cruciata, showing horizontal thallus and rhizoids with two erect branches (one young, one mature), for carrying sex-organs. Natural size.-After Bischoff.

These differences are usually called forth by the action of light (see $\uparrow 325$ ).

53. Branching.- - The branching of the thallus is always by forking, in a single plane or direction, as in Fucus, but the branches do not always develop equally. Sometimes special branches, instead of remaining horizontal, grow upright and develop into peculiar forms adapted to producing the sexual reproductive organs (fig. 39). 


\section{EXERCISE XI.}

A thallose liverwort (Marchantia polymorpha).-Examine an entire plant in water. Observe

I. The flattened horizontal body (thallus) with central line, the midrib, and thinner wings on each side.

2. The notched apex (the wings outgrow the midrib somewhat).

3. The mode of branching (forking). Examine the tips and find one just branched. Do not confuse with notch of apex ; when a tip branches there will soon appear two notches. Does the branch appear on the side of the older thallus, or are the branches equal at first? Are they equal when older? ( 53.$)$

4. The green lens-shaped bodies (brood-buds) growing at certain spots along the midrib, surrounded by an outgrowth which forms a cup-like rim about the cluster. Remove a brood-bud and observe its form, especially in full grown ones the two opposite notches, the growing points. (T 297, fig. I77.)

5. The air-chambers (arcola) of the upper part of the thallus, showing through the skin, best seen in older parts and with a lens. What is their form? Are they all alike?

(ब 52.)

6. The openings into the air-chambers, in the- skin over each one, like a little pinhole.

7. Compare the under surface with the upper. Observe the numerous hairs. Discover the difference in place of origin and direction of growth of these. ( 5 I.)

8. Carefully pull off with forceps as many of these hairs as possible and notice the dark-colored overlapping outgrowths along the midrib, curving outward as they are followed forward, attached along their edges. These are the so-called "leaves."

Cut a transverse section of the thallus through a brood-bud cup. Observe

9. The origin of the brood-buds (only the younger still remaining) over the midrib.

ro. The difference between tissue of upper and under parts of thallus. (If fresh plants are available observe especially the difference in color.)

Ir. Demonstration. Cut a very thin transverse section of the thallus. Select a part passing through stoma and show

(I) The air-chamber; its roof, the skin, with chimney-like stoma in center; its sides a vertical plate of cells; its floor, with branched filaments of chlorophyll-bearing cells. (Fig. 38.) 
(2) The large-celled colorless tissue forming the lower half of section; the sections of "leaves" arising near midrib and concave towards center.

54. The shoot.-In the greater number of liverworts the mature regetative body is a shoot, which is differentiated into stem and leaves (figs. 40, 4I). Even in such a body the dorsiventral character is well marked. The stem is slender and bears three (rarely more or fewer) rows of leaves, of which the two dorsal rows are the larger,

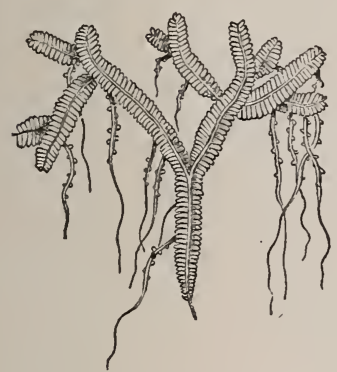

FIG. 40.
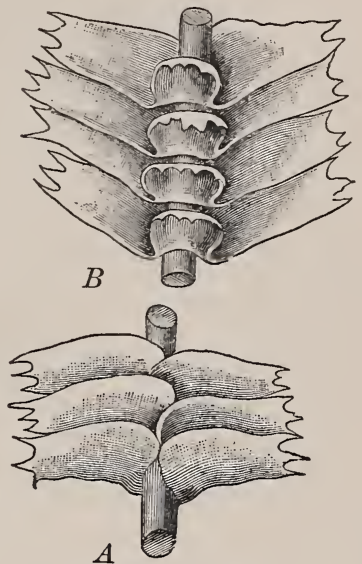

FIG. 4r.

FIG. 40.-Gametophyte of Bazzania Nova-Hollandia. Besides the ordinary branches there are slender ones (flagella) with sparse minute leaves. Natural size.-After Lindenberg and Gottsche.

FIG $4 \mathrm{I},-A$, dorsal view; $B$, ventral view of a piece of fig. 40 , magnified about 12 diam., showing the stem, bearing two dorsal rows of large leaves and one ventral row of small ones.-After Lindenberg and Gottsche.

while the under leaves are much smaller, even to being inconspicuous or wanting. These leaves consist of a single sheet of uniform cells richly supplied with chloroplasts, as are also the outer cells of the stem. Their form is very varied and often of great beauty. They are usually crowded so closely as to overlap each other more or less, and hide the stem completely (fig. $4 \mathrm{I}$ ). 


\section{EXERCISE XII.}

A leafy liverwort (Porclla platyphylla).

I. In what position do the plants grow with reference to the substratum?

Disentangle carefully a single plant.* Observe

2. The growing apex; the dying base; the distinctly dorsiventral habit. Enumerate the differences between the upper and under sides. (ฯ 54.)

3. The mode of branching: a central axis, with lateral branches, themselves with lateral branches; i.e., monopodiai and bipinnate. ( 5 58.)

4. The yellowish or brownish stem, covered with leaves unequally distributed.

5. The two rows of large leaves on the upper flanks of the stem. How do they overlap? Turn the shoot over and note a third row of small underleaves in the center below; also right and left the lobes of the upper leaves. Determine the form of the under and upper leaves. Make an enlarged paper pattern of the latter showing how their ventral lobes are arranged. (Figs. 40, 4r.)

6. Demonstration. Mount a leaf and point out the uniformity of cells and their abundant chloroplasts.

\section{Mosses.}

In the mosses the complexity of the mature vegetative body is somewhat greater. It is always developed as a shoot differentiated into stem and leaves.

55. Rhizoids. - The shoot is anchored, as in the liverworts, by numerous usually much branched rhizoids ( $A$, fig. 42 ; w, fig. 43). Similar filaments may be produced, often in great numbers, along the stem and especially inthe axils of the leaves, or they may even arise from the leaves themselves, when the plants grow in dense patches or in a very moist place.

56. The stem is usually cylindrical and covered by the crowded leaves. In structure it generally shows an advance upon that of the liverworts, which is nearly uniform, in hav-

* If dry, first soften by placing plants in hot water for a few minutes. 
ing the whole of the outer region occupied by a distinct mass of mechanical tissue for stiffening the stem, and, near the center, a strand known as "conducting tissue," which may act as a line of transfer for water or food.

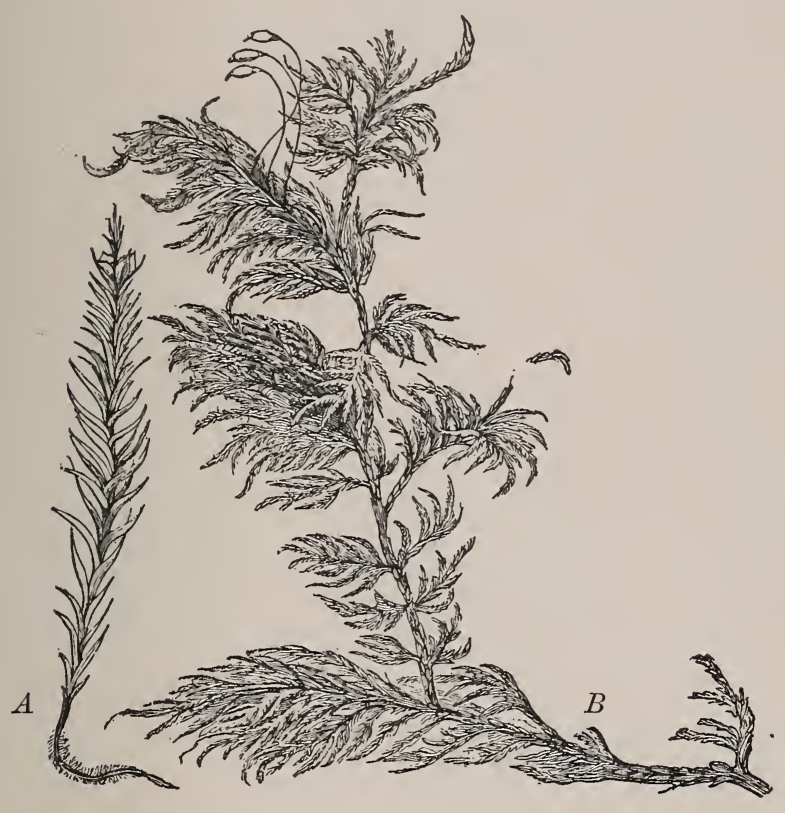

FIG. 42.- $A$, gametophyte of Polytrichum commune, with rhizoids below. $B$, gametophyte of Hylocomium splendens, bearing three sporophytes near top. Natural size. -After Kerner.

57. The leaves are also more highly developed than in liverworts. They are always sessile and are arranged in two (rarely), three, or more vertical ranks along the stem, and consist usually of a single sheet of green cells, the blade (figs. 43,44 ), and a central rib running from base to apex (frequently wanting), which is composed of elongated conducting and strengthening cells (figs. 43, 44). In some the 
amount of green tissue is increased by the formation of vertical plates similar to the blade (fig. 44).

58. Branching. - The stem branches, often very profusely. Sometimes the growth of the lateral branches, as of the original main axis, is checked by the formation of sex organs. In that case a new branch is likely to arise some distance

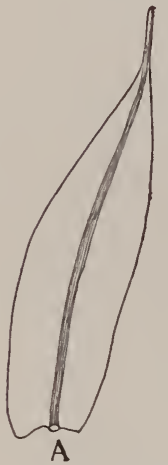

FIG. 43 .

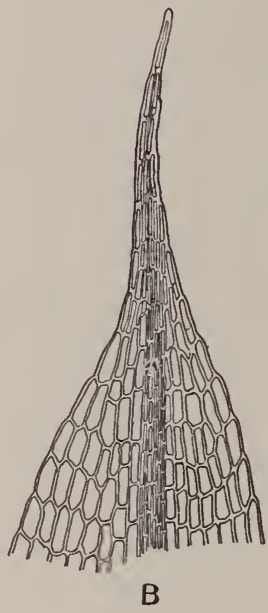

B

(Funaria Americana), showing central rib. Magnified about 40 diam.; $B$, upper portion of the same leaf, highly magnified, showing single layer of cells forming the blade and the narrower cells of the thick rib-After Sullivant.

FIG. 44--Tip of leaf of a moss (Oligotrichum aligerum), showing the thickened rib, and the plate-like ridges on blade and rib greatly increasing the surface of nutritive tissue. Magnified about 75 diam.-After Sullivant.

below the apex, so that the stem is merely a succession of lateral branches (fig. 45). This mode of branching is called sympodial. In other cases the main axis continues its growth unchecked, and more or fewer branches also develop. These lie plainly upon the sides of a central axis. This mode of branching is called monopodial. Often the growth of the lateral axes is definitely limited and their development regular, forming a pinnate branch-system. If the secondary axes 
themselves branch, there is formed a bipinnate or even tripinnate system, as in figure $42, B$.

59. Protonema.-In its early stages the vegetative body of the leafy liverworts and the mosses is either a flat thallus, similar to the mature form of the thallose liverworts, or a branching filamentous body, called the protonema, almost identical with the form of the branched filamentous algæ. Upon this protonema the leafy shoot arises as a lateral bud, which soon outstrips it in growth and develops leaves. The protonema may live for some months, but generally perishes after having produced a few leafy plants.

60. Sporophyte. - The nonsexual phase in the liverworts and mosses has almost no vegetative functions. It consists at maturity of a yellowish or brown spherical or cylindrical case (fig. 46), which is sessile or raised upon a short or long stalk and contains (a few or) hundreds or thousands of reproductive cells called spores. The pointed or swollen base of this

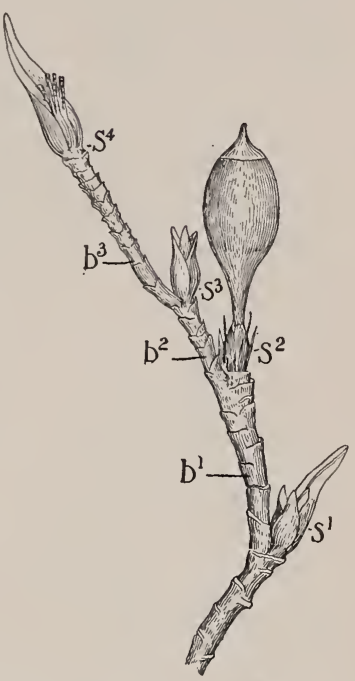

FIG. 45.-Axis of a moss (Orthotrichum) showing sympodial branching. $S^{1}, S^{2}, S^{3}, 1^{4}$, successive clusters of sex-organs, produced at apex, which check the growth of axis. Beneath each a lateral growing point develops, producing successively the branches $b^{1}, b^{2}, b^{5}$. Magnified ro diam. - After Bruch \& Schimper. stalk is called the "foot," and is embedded in the gametophyte $(f$, fig. 47$)$ to absorb food from it.

61. Nutrition.-The surface of the young sporophyte, when large and well developed, as it is in the higher liverworts and mosses, is green. To a limited extent, therefore, it is able to make food; but not sufficient for its needs, for these are great on account of its rapid growth and the amount 

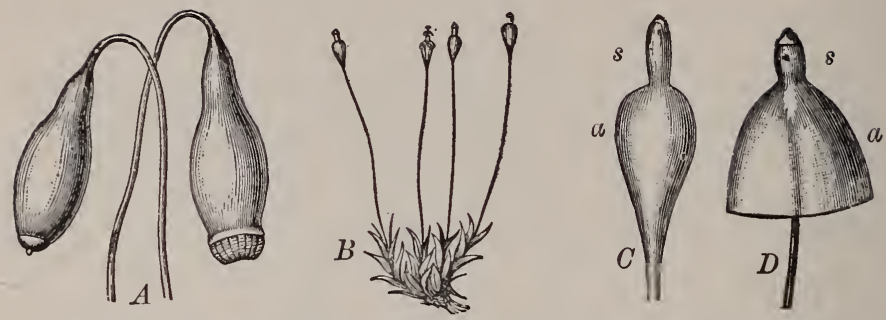

Fig. $46-\lambda$, two capsules of Bryum ; from the right-hand one the lid has fallen, showing the teeth. Magnified 5 diam. $B$, four gametophyte shoots of Splachnum ampullaceum, bearing four sporophytes. Natural size. C, a capsule of one of the same sporophytes, showing enlarged apophysis, $a$, below the spore case, $s$. Magnified ro diam. D, capsule of Splach num luteum, with umbrella-like apophysis, $a$, below spore case, $s$. Magnified 2 diam.

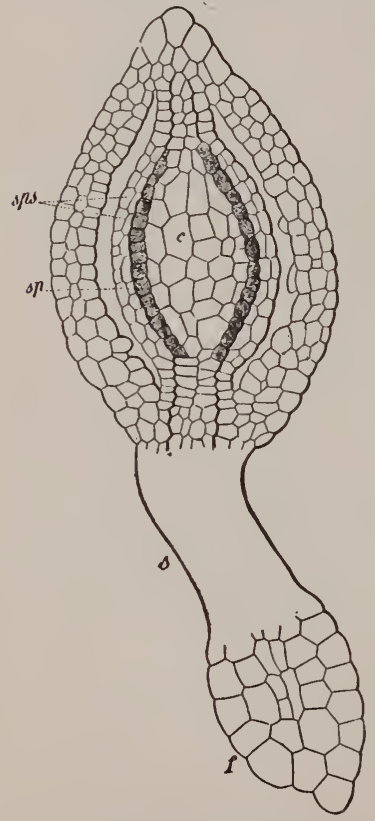

FIG. 47.-Young sporophyte of Phascum cuspidatum. r, columella : $f$, foot, embedded in gametophyte stem ; $s$, seta (cells not shown): $s \not s$, spore case : sp, spore-mother-cells. Magnified 80 diam -After Kienitz-Gerloff. required to supply each spore. The foot, being in close contact with the tissue of the gametophyte, acts as an absorbing organ, receiving food solutions from it. The sporophyte thus lives, in part at least, as a parasite upon the gametophyte.

In some mosses there is a tendency to increase the nutritive work of the sporophyte by developing at the top of the stalk, below the spore case, a mass of green tissue. In Bryum $(A$, fig. 46) this gives the capsule a pearshape, while in Splachnum $(B, C, D$, fig. 46$)$ it is so far developed as to exceed the spore case. In some species it is expanded into a miniature umbrella which, one can imagine, might readily become divided into leaves.

The intimate attachment of sporophyte to gametophyte continues throughout the life of the former. Sometimes the gameto- 
phyte perishes at the close of the growing season, but more commonly it is perennial, growing and branching at the anterior end as the older posterior parts die away.

62. Summary.-Liverworts and mosses show a distinct alternation of generations. The vegetative body of the simpler liverworts is a flat thallus, like that of the larger algæ, but the higher forms have the central part developed as a roundish stem, and the wings so branched as to form separate leaves. The latter form is general in all the mosses, which further have the stem and often the leaves stiffened by the differentiation of mechanical tissues. The non-sexual generation in all is relatively small and depends for its food upon the sexual generation.

\section{EXERCISE XIII.}

A moss (Mnium cuspidatum).-Examine plants with capsules attached. Observe the two connected plants :

I. The leafy stemmed plant or gametophyte. ( $\$$ 50.)

2. The slender plant attached to its tip, the sporophyte, consisting of a wire-like stalk, the seta, enlarged above to form the hanging capsule. (- 6o, fig. 46.)

3. Boil for a few minutes in 5 per cent. potassic hydrate, rinse in water and gently pull sporophyte until it separates from the gametophyte. Observe the smooth pointed end which was sunk in gametophyte. If properly separated no sign of tearing can be seen. (Fig. 47.)

Examine gametophyte in water. Observe

4. The differentiation of the body into stem and leaves.

5. The brown hairs (rhizoids) about the stem, which attach plant to ground. Do they branch? ( $(55$.)

6. The strength of the stem; test it by breaking it with a lengthwise pull. Cut a thin transverse section and observe dark colored mechanical tissues in outer region. ( $\$ 5^{6 .)}$

7. The form and structure of the foliage leaves: note midrib of mechanical cells (test strength); lamina of one layer of cells large enough to be visible under lens; border of mechanical cells, some projecting pretty regularly as teeth. ( $(57$, fig. 43.)

8. Smaller, scale-like leaves on part of the stem. 
Examine sporophyte with mature capsule. Observe

9. The slender seta.

Io. The thin yellow inverted capsule, from whose end a piece has fallen leaving it open.

( 274 , fig. 46.)

II. About the edge of the capsule a fringe of pointed projections, teeth, curved inward, constituting the peristome. Break off these outer teeth and notice the pale fringed membrane within, forming the inner peristome or endostome. (Figs. 46, I48.)

12. Among these, or to be pressed out of capsule, many fine spores.

Examine young sporophytes of this or other mosses. Observe

13. The cylindrical form of the embryo sporophyte.

I4. The hood covering its apex and carried up by it until the developing capsule forces it off.

15. The lid which falls off to open capsule. 


\section{CHAPTER VII.}

\section{FERNWORTS AND SEED-PLANTS.}

\section{Fernworts.}

Among the still more complex plants, the ferns and their allies, the same "alternation of generations" can be seen. The two "generations," or phases, have, however, changed much in relative size. Whereas in the liverworts and mosses the gametophyte is much the larger and more conspicuous, as well as the longer-lived, among fernworts the sexual phase is so much smaller that it is seldom seen; and in some species it is almost microscopic. On the other hand, the sporophyte is the phase which is usually seen and the only part popularly known.

63. The gametophyte. - The vegetative body of this phase of the fernworts in its best developed forms is a small, flattened, green body of oblong, orbicular, or cordate outline, commonly less than half a centimeter in diameter, rarely as much as $2 \mathrm{~cm}$. (fig. 48 ). It is strikingly like a thallose liverwort in general form, being distinctly dorsiventral and having rhizoids on its under side, which fasten it in place. Only the central part of the gametophyte consists of more than one layer of cells. On the under

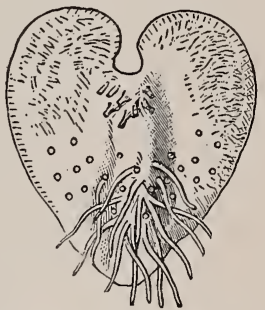

Fig. 48-Ventral side of the gametophyte of a fern, Asplenium. The notched end is the anterior. Rhizoids near posterior end. The small circles show position of male organs ; the chimney-like projections near anterior end the female organs. Magnified 10 diam.-After Kerner. side of this central "cushion," as it is called, are borne the sex organs. 
64. Reduction of gametophyte.-In a few of the fernworts the gametophyte is filamentous, or tuberous, and more or less completely subterranean and colorless; such derive their food from decaying plant-offal.

In higher plants of this group the gametophyte becomes still further reduced in size and structurally simplified, until in some species it is hardly more than a few cells surrounding

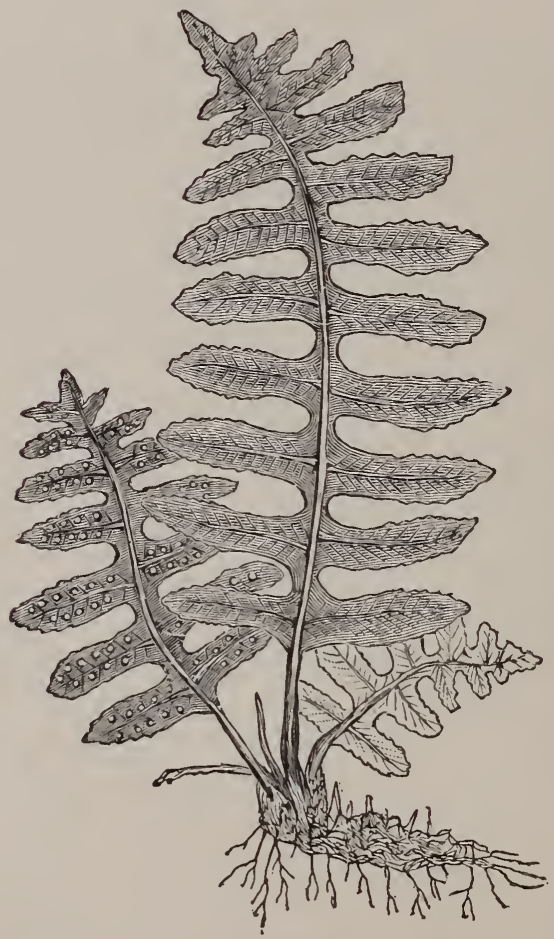

FIG. 49.- Sporophyte of a fern, Polıpodium zulgare, showing horizontal underground stem, bearing secondary roots and leaves. Natural size.-From Bessey.

the sex organs. These reduced forms grow by the use of food stored in the spore from which they originate. The gameto- 
phyte of such species has lost wholly its vegetative character, and is restricted in function to the production of the sex organs.

65. The sporophyte.-In contrast with the smallness and simplicity of the gametophyte is the relatively large size and complexity of the sporophyte (fig. 49). It is always differentiated into stem and leaves, and, with rare exceptions, roots also. It is also noteworthy that, as compared with mossworts, the chief work of nutrition has been shifted from the gametophyte to the sporophyte; and this even when the gametophyte has its largest size and greatest duration, while nutritive work is wholly abandoned in the smaller forms. The sporophyte has also become the long-lived stage, the gametophyte being usually transitory (only exceptionally living more than one season), while the sporophyte lives through one season in the few annuals, and commonly for several or even many years.

66. Members.-The mature sporophyte is differentiated into root, stem, and leaves. The important adaptations of the structure and forms of these members are so similar to those of the seed plants that they will be discussed in connection with them.

\section{EXERCISE XIV.}

\section{Maidenhair fern (Adiantum pedatum).}

I. The Gametophyte.

I. Observe its shape and size ; the notch at the growing point (anterior end); the dying (posterior) end; the thicker central region, with thin wings. ( $(63$, fig. 48 .)

2. On the under side, a cluster of rhizoids near the posterior end.

3. Compare this plant with the thallus of Marchantia.

If gametophytes with young sporophytes attached are available, observe

5. That the young sporophyte is fastened to the under side of the gametophyte. 


\section{The Sporophyte.}

Taking the underground parts in a dish of water, observe

I. The slender wire-like roots. How are they branched? ( $\$ 83 \mathrm{ff}$.) Where are they attached to the stem? Trace an unbroken one to the tip. The following points can only be seen on roots carefully gathered and cleaned. What difference of color near tip? Can you find many fine tangled root hairs? Where present? Where absent? (T 73.)

Cut a transverse section of an old root, mount and observe

3. The outer brown mechanical tissues (also used for storage). ( $(78$.)

4. The central whitish tissue, chiefly the stele, in which the visible openings are the larger vessels. ( $\boldsymbol{\top} 75$.)

5. In what position does the stem naturally stand? Observe its occasional branching ( $\% 89$ ); the surface covered with chaffy scales; the growing apex and dying base.

6. Its nodes and internodes; the nodes are indicated by the attachment of a single leaf at each; the internodes are the intervals between the nodes. How are the leaves placed? (\% 104.)

Cut a transverse section of the stem and observe

7. The outer brown mechanical tissues (also used for storage). ( $\mathbb{T}$ 108.)

8. The circular, oval, or C-shaped white tissues, most of which belong to the stele. Trace the course of the stele through at least two internodes by cutting a series of rather thick $(\mathrm{I} \mathrm{mm}$.) sections, observing the mode in which the stele branches to pass out into a leaf. Cut also a longitudinal section through the base of a leaf stalk and trace course of stele. ( $\mathbb{\text { T }}$ I09.)

Taking a perfect leaf, dried under pressure, observe

9. The stalk or petiole, with its branches. Note the mode of branching; the petiole divides into two equal divergent branches; each of these forks, one branch carrying leaflets while the other again forks, and so on. ( $\Upsilon$ 126, 128.)

IO. The hardness of the mechanical tissues at surface of polished petiole.

II. The leaflets. Note $(a)$ shape as to outline and margin, comparing basal, median, and terminal leaflets of any branch; $(b)$ the veins, containing branches of the stele; $(c)$ the green tissues between the veins ( $\Phi$ I27.)

12. Demonstration. Strip off a bit of epidermis, mount and show $(a)$ the irregular form of epidermal cells; $(b)$ the intercellular openings with guard cells (stomata). ( $($ I $\mathbf{3} 7 \cdot$ )

13. At the edges of the leaflets on the under side crescentic brown spots, clusters of spore cases.

( $(275$, figs. 149, I50.) 
14. Boil a leaflet for a minute in water. With a needle turn back a flap which covers the spore cases; observe that it is a specialized portion of the edge of leaflet.

I5. On the under side of the flap a mass of yellowish spheroidal bodies, the spore cases. Scrape away most of them and notice the relation of their points of attachment to the veins.

Mount some of the spore cases and observe

I6. Their shape; the stalk by which they were attached. (Fig. 236.)

I7. The darker ridge, annulus, which serves to burst them when mature. (Fig. 236.)

18. Study the manner of bursting. Tear a bit of indusium from a dried specimen previously soaked in water, removing most of the sporangia. Allow it to dry while watching it with a lens, illuminating from above.

19. Demonstration. Mount sporangia and spores and show their structure, especially the annulus.

\section{Seed-plants.}

67. Development. - Among the highest plants, those which produce seeds, the differentiation of the body is essentially the same as in fernworts. The alternation of sexual and non-sexual phases is still traceable, though greatly obscured by the extreme reduction of the gametophyte.

This tendency to the reduction of the sexual phase, which was remarked in passing from the mossworts to the fernworts, continues, until in the highest seed-plants the gametophyte is wholly microscopic. Even by the aid of the microscope, it is possible to identify only the sexual organs which it produces, and one or more cells which are, perhaps, the rudiments of its vegetative body.

The sporophyte, consequently, is the only phase of the seed-plant visible to the unaided eye.

The body of the sporophyte exhibits the same members, viz., stem, root, and leaf, having the same general form, and subject to the same modifications, as in the fernworts. An account of the vegetative members of the fernworts and seedplants occupies the following three chapters. 


\section{EXERCISE XV.}

Marsh Marigold (Caltha palusiris).

I. Examine the roots. Observe $(a)$ their surface, wrinkled from shortening; (b) their structure.

2. Cut a transverse section as in fern; observe that mechanical tissues are wanting.

3. Bisect longitudinally the base of a plant. Observe, as shown by the origin of leaves, the variable length of internodes; at base the internodes are very short so that leaves are crowded; in the middle the internodes are long and leaves distant; above, the internodes become shorter until, in the flower, they are not developed and the leaves are very much crowded.

(बi IO4.)

Study one of the well developed foliage leaves ( $\boldsymbol{\top}$ 123). Observe

4. The broad rounded blade with slight branches (teeth) at the margin.

5. The long slender stalk, petiole, gradually passing into

6. The sheathing base, in upper leaves branched to form two stipules. (ब 125.$)$

7. Examine and compare the various forms of leaves: $(a)$ the lowest, having sheathing bases without petiole or blade, passing gradually into (b) the best developed foliage leaves; (c) these near the flowers losing petiole and diminishing blade, becoming bracts; $(d)$ the yellow perianth leaves; $(e)$ next within these the yellowish stamens; $(f)$ the flattened podlike green carpels each forming a simple pisitl.

(Further study of flewer, p. 210.)

68. Summary.--In fernworts and seed-plants the sexual generation is small, often microscopic, while the non-sexual generation is conspicuous and often long-lived. The nutritive work of the gametophyte is either temporary, ceasing when the sporophyte develops green leaves, or is entirely wanting. The sporophyte forms stems, leaves, and roots and does most of the nutritive work. These members are very various in form and are described in the following chapters. 


\section{CHAPTER VIII.}

\section{THE ROOT.}

69. True roots. - It has been pointed out that, among the lower plants, there are very many which possess structures similar in form and function to the root, and by some called by this name. Although these parts serve to hold the plant in place, and perhaps to absorb material from the substratum, they are not to be looked upon as equivalent to the roots of the higher plants either in origin or structure. In the algæ, fungi, liverworts, and mosses, the gametophyte is the prominent phase. In no case does the gametophyte produce true roots. It is not until the sporophyte becomes an independent plant that true roots are found in the vegetable kingdom. It is, therefore, only among fernworts and seed-plants that these organs are to be found. When the sporophyte is developed as an independent plant, it becomes necessary for it to produce some organ capable of holding it in place, or of absorbing materials from the outside, or of doing both. The organ developed to meet this need is the root.

70. Primary and secondary roots.-In accordance with their origin, roots are either primary or secondary. Primary roots are the first formed roots, i.e., those which are developed directly by the young embryo. In both fernworts and seed-plants the primary root is rarely wanting, but often short-lived, dying after the plant has established itself and has formed secondary roots to take its place. In many cases, 
however, the primary root persists throughout the life of the plant.

Secondary roots are later formed. They are roots which arise upon stem or leaf, or even upon the primary root itself. In the last case they are distinguished from branches of the primary root, which arise in regular succession toward the apex, by originating out of this regular order. Secondary roots are also called adventitious roots. They may take their origin at any point upon any of the members. Their point of origin will depend largely upon external conditions. A wound may cause them to appear. 'They are especially likely to be formed upon those parts which are in contact with the substratum, or from those parts which are kept moist. Upon stems they are most apt to appear near the nodes. (See - 104.) If the plant as a whole is surrounded by very moist air, roots may appear at any point of the surface. Secondary roots arising thus upon a part of the plant exposed to the air, and growing for all or part of their existence in the air, are also called aerial roots. Familiar examples are to be seen about the lower part of the stem of Indian corn, the English ivy, the poison-oak, the trunks of palms and treeferns. Secondary roots often arise in regular succession toward the growing apex of the stem, particularly in plants which have creeping or subterranean stems.

71. Growing point.-Primary and secondary roots do not differ materially in their structure. Near the tip they consist of a mass of actively dividing cells, the growing point of the root (compare 87). The real tip of the root is covered by a mass of cells called the root-cap (ep, fig. 50), which is attached only to the growing point. Since the cells of the free surface of the root-cap are older and firmer than the inner ones and the growing point, and lie in front of them, they serve to protect these more delicate parts as the growth constantiy pushes the apex forward through the soil. 
The youngest parts of the root are very much alike, but as they become older they grow unlike. The just mature portion of roots shows three characteristic regions, namely, (I) an outer layer or layers, the epidermis; (2) an inner region, the stele; (3) between these, the cortex.

72. I. The epidermis usually becomes many-layered. At the apex it constitutes the root-cap (ep, fig. $5^{\circ}$ ). On the other parts of the root it sometimes sloughs off entirely, exposing the cells of the cortex itself, as in the monocotyledons (lilies, grasses, sedges, etc.) ; or, more commonly, only the outer layer sloughs off, leaving the innermost as the covering of the cortex. It is too delicate to be distinguished by the unaided eye, except at the tip and further back where it produces root-hairs.

73. (a) Root-hairs. - Those cells which form the surface of the root, whether they be the original epidermis or cortical ones which have been exposed

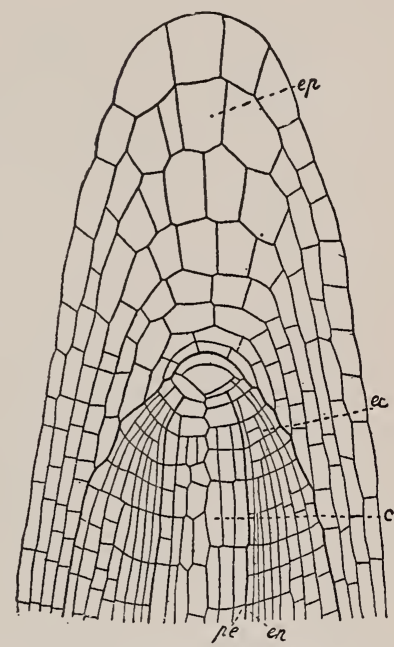

FIG. 50.-Median longitudinal section through the extremity of a ruot of Marsilia. The larger triangular cell near center of figure is the apical cell. The segments from the inner faces may be readily traced backward; thus the dotted line ec points to the fourth, $c$ to the sixth segment from the posterior right-hand face of apical cell. $e p$, root-cap (epidermis); $e c$, cortex; $c$, stele; $e n$, endodermis (part of cortex); pe, pericycle (part of stele) Magnified about roo diam. -After Van Tieghem.

by its loss, usually develop a large number of hairs, known as root-hairs (figs. $5^{\mathrm{I}}, 5^{2}$ ).

These root-hairs are branches of the superficial cells (fig. 52), and may be looked upon as simple extensions of them, as the finger of a glove is the extension of its palm. Only one root-hair arises from a superficial cell. They are usually unbranched and without transverse partitions. 
Only in rare cases are they wanting. They live for a shorter or longer time, but are always, as compared with the duration of the root, quite, transient. The older part of the root, therefore, is without root-hairs because of their death.

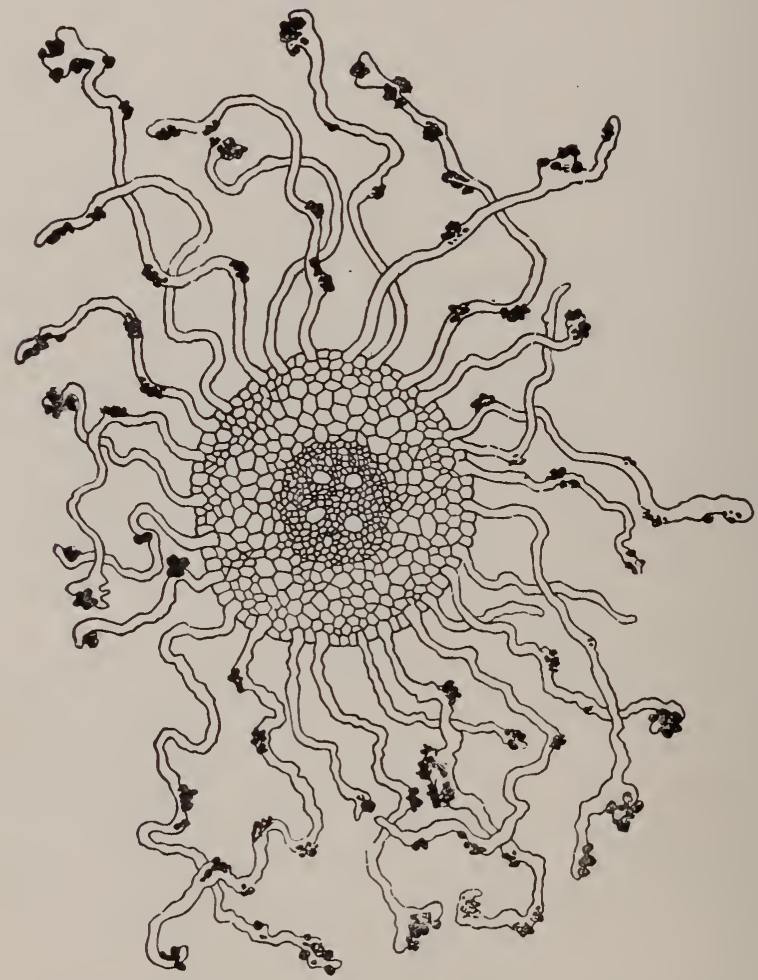

FIG. 51.- Transverse section of a young root grown in soil, showing root-hairs with adherent soii-particles, the cortex, and the stele, Magnified about 20 diam.-After Frank.

The youngest part of the root is likewise free from them, because they have not yet been produced. As the root grows in length, new root-hairs are continually being pro- 
duced and the older ones are dying at an equal rate, so that a zone of hairs is found only upon the younger parts of the roots.

74. (b) The root-cap.-If the finger be supposed to represent the root, a short finger-stall, if it were attached to the tip of the finger, might be fairly taken to represent the position of the root-cap. Only in rare cases is the root-cap entirely wanting. Serving to protect the tenderer portion of the root behind, the root-cap is itself constantly exposed to injury. The outer and older parts of the root-cap are, therefore, either worn away through mechanical contact ; or, dying, they degenerate and break down into a slightly mucilaginous material which facilitates the passage of the root through the substratum. This degeneration or the mechanical wear is constantly repaired within at the growing point. The thickness of the rootcap, therefore, is maintained throughout its existence without considerable change.

75. 2. The stele.-Occupying the center of the root, and surrounded on all sides by the cortex, is an aggregate of tissues called the central cylinder, or stele (figs. $5 \mathrm{I}$, 53). The most noticeable part of this are the groups of elongated cells or cellfusions, * called vascular bundles, or vascular strands. These strands are of two kinds, wood strands, specially for the con-

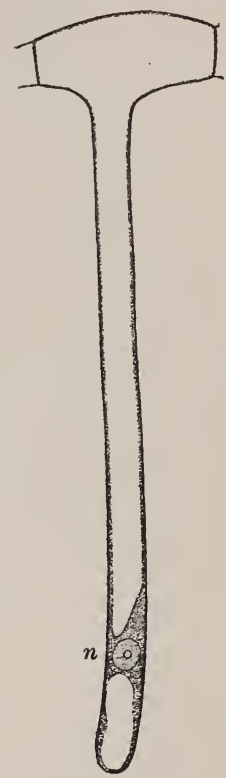

FIG. 52,-A nearly mature root-hair, showing structure and relation to superficial cell of root; grown in water and therefore not distorted as in fig. $5 \mathrm{I}$. $n$, nucleus embedded in protoplasm; vacuole single and very large. Highly $m a g n$ ified. -After Frank.

* These are continuous chambers formed by the breaking down of the partition-walls between the abutting ends of cells. They are usually devoid of living contents. 
ducting of water, and bast strands for carrying foods. (See - $172-174$, I97.) They are so placed that they alternate with each other about the outer part of the stele (figs. $5 \mathrm{I}$, 53). The strands may be in contact with one another in

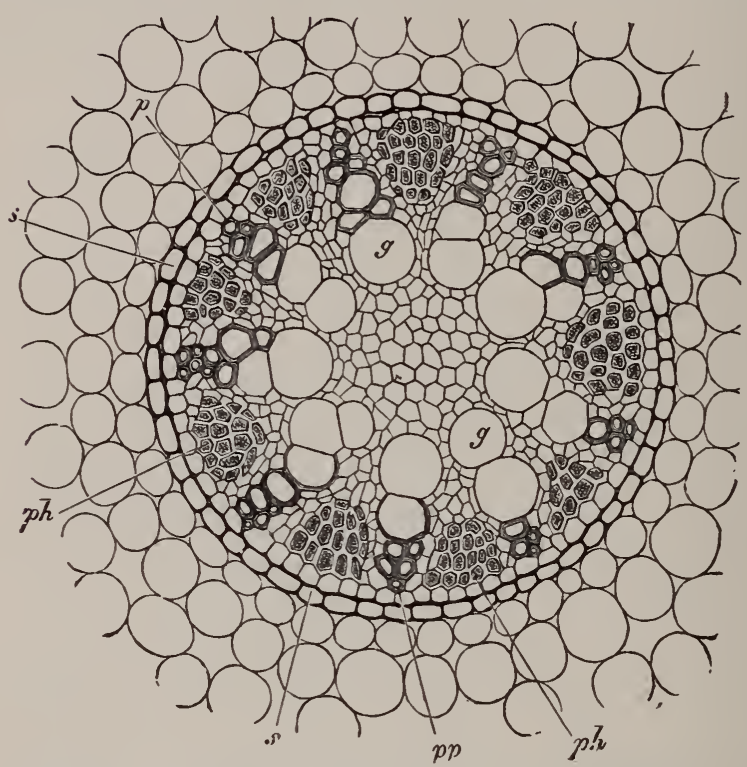

FIG. 53.-Transverse section of the stele and a portion of the surrounding cortex of the root of calamus $s, s$, innermost layer of cortex, adjoining outermost layer of stele ; $p$, wood strands; $p h$, bast strands. In the center of the stele and between the bundles is conjunctive tissue. Highly magnified.-After Sachs.

the center, or the center of the stele may be occupied by a pith (fig. 53).

The number of vascular strands constituting the stele is various, being as few as four or as many as forty. The ordinary number, however, is from eight to twenty. (See fig. 53.)

76. 3. The cortex generally consists of large thin-walled cells which have become partially separated from one another, leaving larger or smaller intercellular spaces (fig. 53). 
77. Duration.-Even when the primary root persists throughout the entire life of the plant secondary roots often appear. When the primary root perishes, its functions must be performed wholly by secondary roots, which are developed in succession upon those parts where they are useful. The secondary roots themselves may be either permanent or transient. In creeping plants particularly, whether growing on land or in water, the functions of the root are likely to be handed on to successively younger roots, the old ones perishing and dropping off. If the roots endure for a. considerable time, they may retain their primitive structure and form, or they may undergo secondary changes which unfit them for absorbing organs, and adapt them to subserve various special functions.

78. Secondary changes.-Shortly after any portion of the root has ceased to increase in length, and, therefore, within the first season, it ordinarily undergoes minor secondary changes which may or may not be followed by more profound alterations. These changes affect its primary structure in various ways and to various degrees according to the parts concerned.

In some cases the older roots differ from the younger in scarcely more than the loss of the external layer of cells, from which the root-hairs arose. The sloughing off of this layer carries with it the hairs themselves and exposes the next inner layer of cells, which had before become slightly altered so as to be rather impervious to water. Upon their exposure, this alteration proceeds further, so that they become almost or quite incapable of absorbing the soil-water to which they may be exposed. It follows from this that it is only the younger part of the root, that is, the portion which has not undergone secondary changes, which is capable of absorbing water. In many roots this is the only change which occurs. In a greater number the root is also strengthened. 
In a large number of roots, the secondary changes result in increasing the diameter, sometimes very greatly, by the formation of concentric layers of new tissue in two or more regions, called the cambium regions.

The outer growing layer, or cork cambium, usually formed in the cortex, produces tissues which are of such a nature as to protect the parts within. They constitute the periderm, and are ordinarily cork-like, i.e., thin-walled and impervious to water. Those cells which lie outside

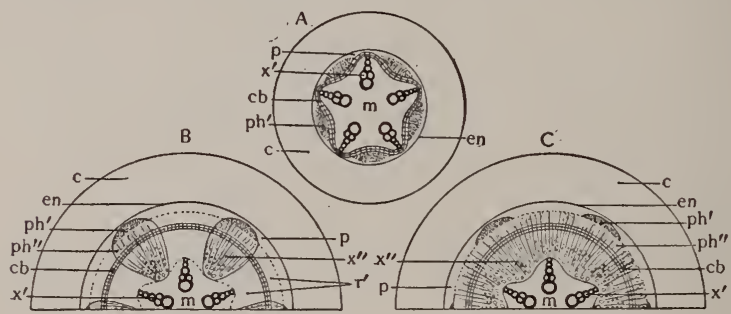

FIG. $54-A$, diagram of primary structure. $B, C$, diagrams showing the results of secondary thickening from the stelar cambium in the two extreme forms $c$, cortex; $e n$, its innermost layer; $p$, vutermost layer of stele ; $p h^{\prime}$, primary bast ; $p h^{\prime \prime}$, secondary bast ; $x^{\prime}$, primary wood ; $x^{\prime \prime} x^{\prime \prime}$, secondary wood ; $c b$, stelar cambium ; $r$, secondary pith-rays; $m$, pith.-After Van Tieghem

a layer of cork are therefore cut off from a supply of food and soon perish.

The inner growing layer, or stelar cambium. is developed within the stele and follows a tortuous course, lying outside the wood strands and inside the bast strands (fig. 54). As a result of tangential divisions in this region, tissues similar to those already existing in the stele are produced.

The relative amount of the new tissues goes far to determine the character of the mature root.

79. (a) Woody roots. - If mechanical tissues predominate, the root will become strong and rigid, as in the case of trees and shrubs. When the root is long-lived, the formation of new tissues is usually resumed with each season, and the central part, especially, shows in cross-section concentric rings indicating the yearly additions. As the root thickens 
the outside parts become fissured lengthwise. Thus, in an old and large root of the woody type, all the parts outside the central wood constitute a bark, which becomes furrowed lengthwise, like the bark of the stems of many trees. Such secondary thickening finally produces in the roots a structure which is almost identical with that of stems which have undergone secondary thickening. (Compare III.)

80. (b) Fleshy roots. - But if thin-walled cells are the chief products, the root often becomes very thick and fleshy, as in the carrot, turnip, radish, sweet potato, beet, dahlia, artichoke, etc. Such roots serve the plant as storehouses of reserve food, and are consequently useful to animals as food. This thickening for storage purposes may affect either the primary or secondary roots, or both.

81. (c) Float roots.-Plants which grow in water or in very wet swamps sometimes modify their roots to serve as floats. In these cases, the voluminous cortex consists of large cells, with huge intercellular spaces which are filled with air. The root thus serves to buoy up the parts of the plant to which it is attached, and assist in its respiration. (See $T$ 202.)

82. (d) Tendrils, thorns, etc.-In a very few plants, aerial roots are modified into tendrils, being slender, sensitive to contact, clasping the objects which they touch, if of suitable size, and thus assisting the plant to climb; in some instances they are altered into thorns, being short, rigid, and sharp-pointed; in others, being exposed to the light, they develop chloroplasts, which enables them to act as organs for the manufacture of food.

83. Branching.-Both primary and secondary roots may branch. The mode of branching is commonly monopodial, i.e., the central axis grows most vigorously, and bears lateral branches upon its sides. The normal branches arise from lateral growing points, which originate in regular succession 


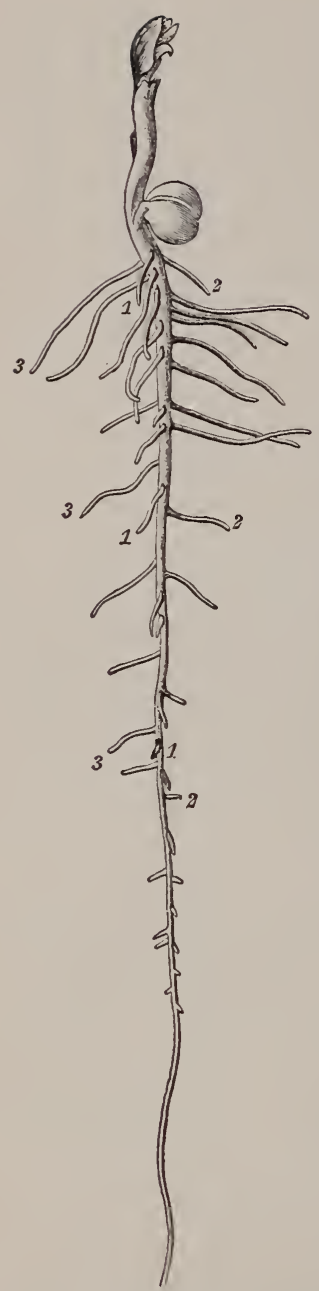

FIG. 55.-Seedling pea, showing three vertical ranks of branches along the main root. These are numbered $\mathbf{1}, 2,3$. Natural size.-After Frank. behind the apical growing point. But sometimes branches appear out of this regular order. Such are called adventitious roots. (See 7o.)

Branches generally originate opposite the wood strands, or with definite relation to them. (See figs. 55, 56.) The number of vertical ranks of branches can, therefore, be predicted with some certainty from the structure of the root, but the longitudinal intervals at which the branches will be formed cannot, because they are unequal (fig. 55).

When secondary roots arise from the shoot, they have a fixed relation to the leaves, or they are formed upon the buds produced in the axils of the leaves, or they may arise at indefinite points along the internodes. In the first case, roots may be produced either opposite a leaf, or in pairs, right and left of the base of the leaf.

84. Origin.-The origin of rootbranches and of secondary roots is rarely external; that is, the root is not commonly produced by growth at the surface of a member. In the great majority of cases the origin of the roots is internal; that is, the formation of the root is begun by the growth in the interior of the member producing it. In most cases growth begins very near to the surface of the 
stele. Soon a growing point is formed (fig. $\left.5^{6}\right)$. The rootlet is thus in its early stage completely hidden, being buried beneath the cortex, through which it gradually makes its way, partly by disorganizing the tissues by pressure, and, probably,

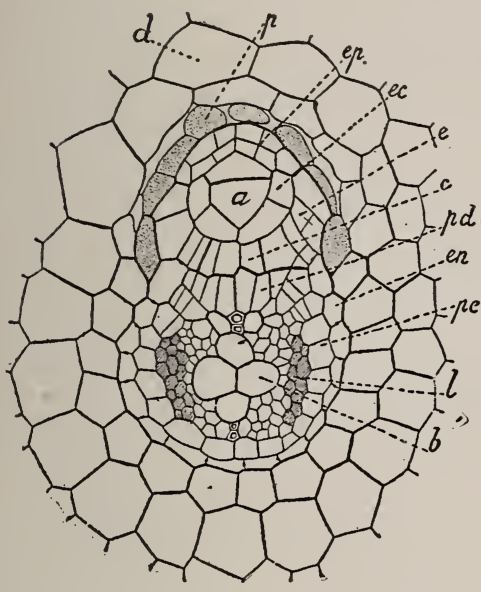

FIG. 56 .

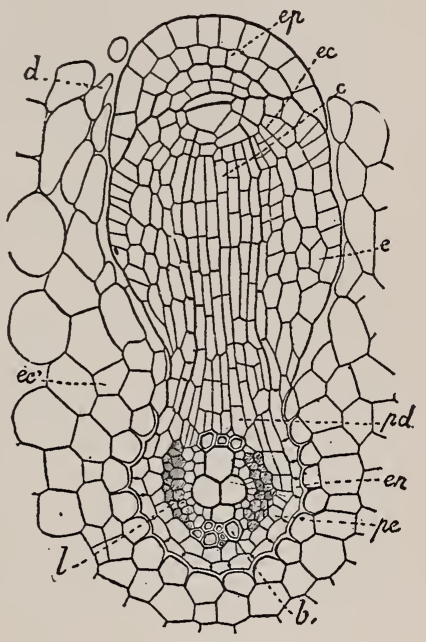

Fig. 57

FIg. 56.-Transverse section of a root of a fern (Pler is cretica), passing through a rootlet which has not yet emerged. Only the stele and three rows of cortex shown. $a$, apical cell of rootlet, forming anteriorly the root-cap, epp, and posteriorly the body of the root, $e c, e, c, p d ; b$, wood strands ; $l$, bast strand with its fellow opposite; $p e$, outer layer of stele; $e n$, inner layer of cortex; $p$, cells partly disorganized and digested; $d$, cells of cortex, which will be disorganized as rootlet advances. Highly magnified - After Van Tieghem.

FIG. 57.-The same as fig. 56 , but older; not quite so much magnified. The rootlet is just emerging from the parent root. $p d, c$, stele of the rootlet; $e c$, its cortex; $d$, disorganized cells of cortex $e c^{\prime}$, of parent root; $b^{\prime}$, secondary wood; other letters as in fig. 56.-After Van Tieghem.

partly by actually digesting and absorbing the material of these cells. When the rootlet reaches the surface it emerges, therefore, from a distinct rift in the cortex (fig. 57).

85. Buds. - New shoots may be formed by the roots, either as a result of injuries, or normally. In a partially developed form, these constitute buds (see 9 9I). Whether formed as 
a result of injuries or normally, they are known as adventitious buds.

They arise in the same places and develop in the same way as lateral roots; that is, they are internal in origin, and, as they continue to grow, burst through the cortex. The shoots so produced grow in the normal manner. Very rarely the growing point of the root, casting off the rootcap, becomes itself the growing point of the shoot. This alteration is usually the result of artificial reversal of the position of the root, being brought about in some potted plants by being turned upside down.

\section{EXERCISE XVI.}

Roots.-Germinate seeds of wheat, corn, white (or any) bean, pea, and white mustard in clean damp pine sawdust or chopped peat moss.

Observe the form and distribution of the root-hairs on younger parts of the root. Let wheat grow for several weeks and observe on what part of the roots the root-hairs are dying away. ( $\$ 73$.

Observe arrangement and origin of branches in the roots of pea seedlings. ( ${ }_{3}, 8_{4}$, fig. 55.)

Grow wheat in soil, planting it about one inch deep. After two to four weeks examine roots, washing away sand carefully. Distinguish primary and secondary roots. $(\varangle 7 \mathrm{\top}, 77$.

Observe roots of sweet potato, beet, or dahlia, thickened for storage. $(\mp 80$.

Examine a smoothly cut end of a root (as thick as one's finger) of any tree (maple, oak, elm, etc.). Observe the bark; the wood with concentric layers (annual rings). (79.) Compare with the stem of same tree. Contrast with structure of a root of lily or marsh marigold.

Examine the root of a lily, or marsh marigold, by cutting cross-sections and by dissection. Observe $(a)$ the central stele, $(b)$ the cortex.

86. Summary.-True roots are found only in fernworts and seed plants. Primary roots are usually transient; secondary roots may be transient or permanent. Both grow at the tip only, which is protected by the root cap. The young parts form numerous root-hairs, which are sloughed off after a short time (a few days or weeks) with the outer surface. The central stele is chiefly for conduction of water and foods in young 
roots. In older roots these functions may be maintained with the addition of mechanical tissues for strength and cork tissues outside for protection. Other roots as they grow older may be transformed into storage places, floats, tendrils, thorns, etc. The branching of roots is usually monopodial. Branches arise in longitudinal rows, originating internally near the surface of the stele. Roots may produce adventitious buds instead of root branches. 


\section{CHAPTER IX.}

\section{THE SHOOT.}

87. Primary shoot.-The first shoot which develops is called the primary shoot. Rarely no primary shoot develops. Sometimes the primary shoot early ceases to grow, and its place is taken by secondary shoots arising from the root.

The tip of the shoot is the region in which the formation of new cells is taking place. This region of young cells has no definite limit below, but passes insensibly into the older, which it produces. The tip of the shoot may be either a sharp cone or a low dome. Between these forms a complete series of gradations exists. Close below the apex the shoot begins to show a differentiation into a central axis and lateral outgrowths. The first of these to appear are swellings which form the leaves. Later, above the leaf rudiments, the rudiments of the lateral shoots may appear. The older leaves upon the sides of the axis outgrow the younger ones and the developing axis, and arch over them in such a way as to form a more or less compact structure, which is a terminal bud. A bud is, then, an undeveloped shoot, whose older leaves protect the younger, and particularly the youngest region, the apex (fig. 58). From the terminal bud arise all the members of the primary shoot.

88. Differences from root.-From what has been said of the origin of the shoot, it will be observed that it is distinguished from the root by not forming in front of the apex a protecting cap. In further contrast with the root, the shoot possesses an uninterrupted epidermis over its entire 
surface, consisting always at first of a single layer of cells. This epidermis persists as a surface covering either throughout the life of the shoot. or for a long period. being replaced only upon the older surfaces of the stem by subsequently formed protective layers. (See II III.)

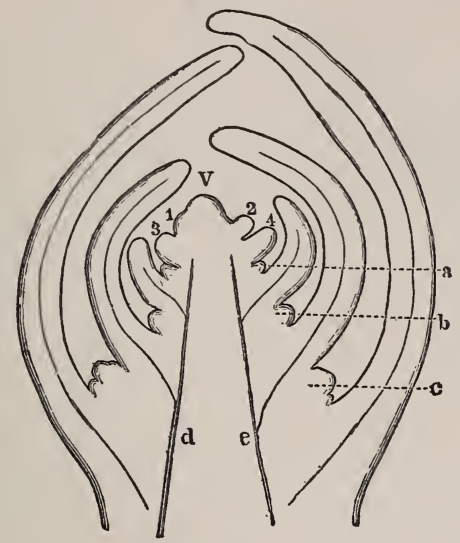

FIG. 58.-Diagram of a section through a bud. $V$, the apex; I, 2, 3, 4, successively older leaf rudiments; $a, b, c$, successively older branch rudiments; $d, e$, vascular bundles. -After Hansen.

89. Branching.-Branches of the shoot arise from lateral buds, which are in all respects like the terminal buds just described. If, for any reason, the terminal bud of the stem is destroyed, or its growth arrested, a branch, developing from a lateral bud near by, may assume the position and habit of the main axis. In many plants the death or arrest of the terminal bud recurs at regular intervals. In such plants, therefore, the main axis is really a succession of lateral branches, i.e., the branching is sympodial (cf. fig. 59 and - 58 ). In some plants, e.g., lilac, two lateral buds standing at the same level may develop, if the terminal one fails. In this case the shoot divides into two equal branches. Ordinarily, however, the terminal bud develops without interruption. In case it is more vigorous than any of the lateral 
buds, the plant will have a central axis, from the sides of which distinctly smaller branches arise. If, however, the lateral buds are almost or quite as strong as the central one, the plant seems to be broken up into branches, and, after it

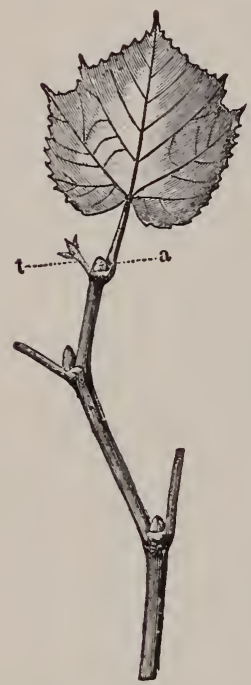

FIG. 59.-Shoot of European linden. $t$, the last internode formed by the bud of present season. This dies and drops off and the shoot will be formed next year by the last auxiliary bud, $n$, which appears to be terminal after loss of $t$. Half natural size - After Frank.

ment (fig. $5^{8}$ ). has attained its mature form, no one can be pointed out as the main axis.* Such branching is monopodial (see $5^{8}$ ). These two types of monopodial branching and the sympodial type are all illustrated in the forms attained by common forest trees. (See frontispiece.)

90. Inflorescence.-Especially profuse branching commonly occurs in the parts of the seed plants where flowers are produced. Such clusters of branches bearing flowers constitute an inflorescence. Each sort has received a special name which indicates the type of branching, and also the relative length of the branches. $\dagger$

91. Lateral buds.-Lateral buds are ordinarily formed in definite relation to the leaves. They stand usually in the upper angle formed by the leaf with the stem. This angle is the axil of the leaf, and such buds are said to be axillary (fig. 6o). Ordinarily a single bud arises in the axil of each leaf. Its origin is always later than that of the leaf-rudi-

There are many cases in which the lateral buds are not

* The obscurity is greatly increased by the death of more branches than survive, owing to various causes resulting in poor nutrition or disease.

+ For these names and further discussion see Gray: "Structural Botany," p. 144; Goebel: "Outlines of Classification, p. 407. 
found precisely in the axils of the leaves, but slightly to one side, or at a greater or less distance above the axil (figs. $6 \mathrm{x}$,

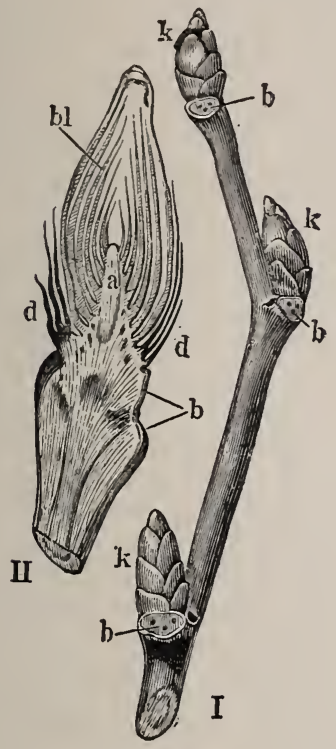

FIG. 6o.

Fig. 6o.-I, terminal shoot of an elm. $b$, leafscars; $k$, axillary buds. Natural size. II, one of the buds cut lengthwise through center, magnified 3 diam. $a$, young axis; $b$, leaf-scar; $b l$, young leaves; $d$, budscales.-After Behrens.

FIG. 6r.-A, twig of red maple with accessory buds in addition to axillary bud. $B$, twig of butternut, with leaf-scar, $a$, small axillary bud, $b$, and larger accessory buds, $c, d$, above axil. Natural size.-After Gray.

FIG 62.-A bit of stem of a honeysuckle (Lonicera xylosteum) bearing large axillary and smaller superposed accessory buds above the axils of the scars, $n$, from which leaves have fallen. Natural size.-After Frank.
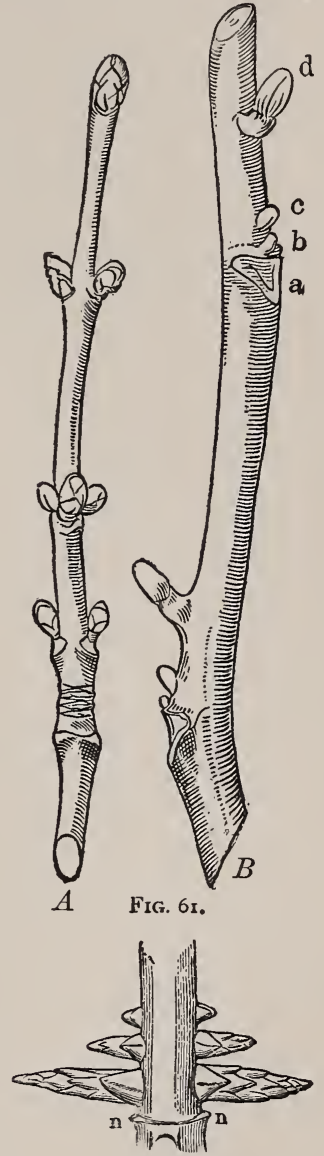

Fig. 62 .

62). Buds are frequently formed without any relation what. ever to the leaf-axil, and even on the leaf itself (fig. I79). Sometimes these extra-axillary buds are produced without the 
action of any extraordinary cause, but more commonly injury of one sort or another acts as a stimulus to the production of such buds. Buds which do not originate in regular succession on the parent shoot (i.e., the younger nearer the apex) are called adventitious buds.

Adventitious buds may arise upon stems, leaves, or roots. They are most commonly and abundantly produced upon stems and roots.

92. Dormant buds.-Many buds continue to grow without interruption from the time of their formation, but more cease to develop after they have reached a certain stage. Such buds may remain dormant for a considerable period, and may even be overgrown and completely enclosed by the wood upon old shoots. The bud in this case grows slowly and maintains itself near the surface of the wood. It is quite possible that these dormant buds should for some reason begin to develop later, when they are liable to be confounded with adventitious buds.

In case they have been buried by the growth of tissues over them, the shoots which they produce will seem to come from the interior of the organ upon which they are borne. This apparent internal origin must not be confounded with the real internal origin of roots.

Since in most cases lateral buds have a definite relation to the leaves, the shoots which arise from them will have a similar relation. But, as many buds are produced which never develop into branches, this relation is often obscure and difficult to see.

93. Special forms.-The primary shoot may grow underground, in which case its stem usually takes a horizontal direction and becomes much thickened for storage of reserve food ( I 96), while its leaves are so reduced as to be scarcely recognizable. Such a shoot is a rhizome. When the primary stem is short, erect, and crowded with thickened leaf bases it forms a bulb, as in the hyacinth and onion. When the 
primary stem is short and thick, and has thin scale leaves upon it, it forms a corm, as in cyclamen and Indian turnip.

Branches of the specialized primary shoot may be like it, as when some branches of the rhizome or corm are themselves rhizomes or corms. Others, however, will be adapted to other purposes, as when aerial branches arise from rhizomes to carry foliage and flowers, or when slender leafless shoots called runners develop from the main axis of the strawberry (fig. I83). Offsets and stolons (figs. I82, 207) are similar branches likewise adapted to propagation. (See 9 30I.)

Branches of the secondary shoots may also be different from their parent axis. In different plants the shoots assume the most varied forms.

Such specialized branches may be confined to a definite region of the plant, or may be distributed over it. The more important of these kinds of branches may now be enumerated.

94. (a) Dwarf branches.-It is not uncommon to find branches specialized merely by their slight development in length and their capacity for being separated readily from the parent shoot. Such short branches are particularly common among the cone-bearing trees. In these plants the short branches carry the clusters of needle leaves (figs. 63 , 64 , I98). After the death of the leaves the branches themselves drop off. Somewhat similar short branches are to be recognized among many deciduous trees, and, in the apple, the so-called fruit spurs are not dissimilar (fig. 65).

95. (b) Flowers.-The most common of the specialized branches among the seed plants are those which constitute the flower. In these the axis usually remains short, the leaves are crowded, and often some of them are highly colored (fig. 66). Commonly these flower branches are short-lived and drop off with the fruit or earlier.

96. (c) Leaf-like branches.-A few plants have developed 


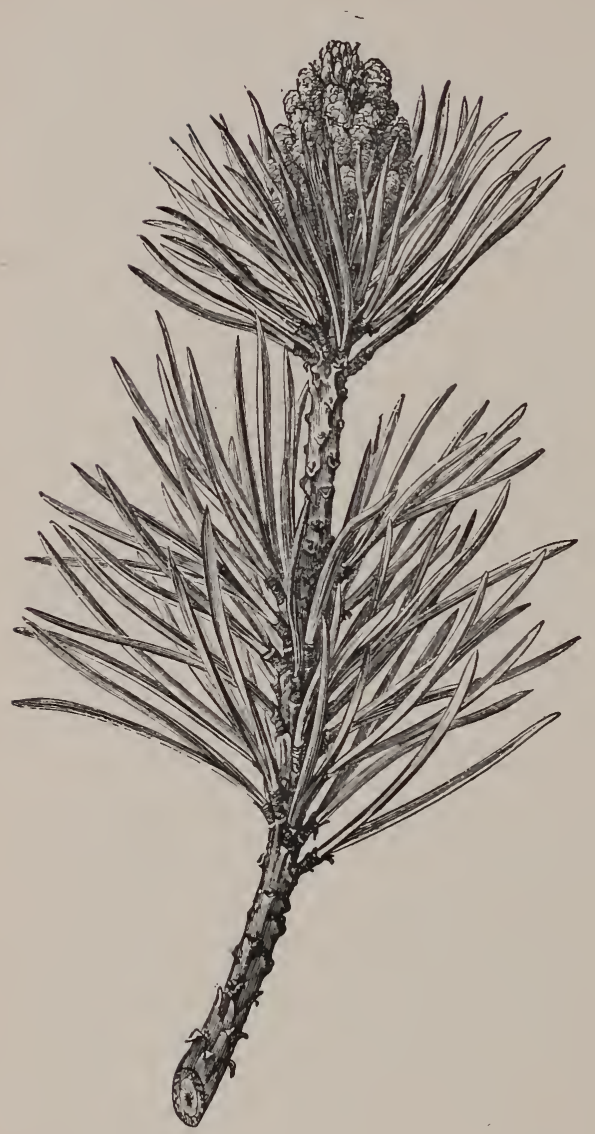

FIG. 63.

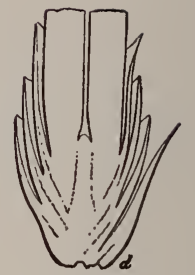

FIG. 64.

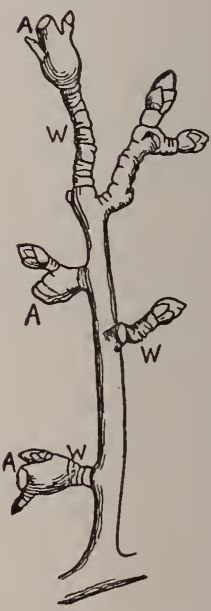

Fic. 65 .

FIG. 63. - A shout of Scotch pine showing two regions of dwarf branches each with a pair of needle leaves, and three regions of flower branches; the flowers have fallen from lower two, showing scale leaves covering the stem. Natural size.-After Willkomm.

FIG. 64.-The base of leaves and dwarf branch of Scotch pine cut through the center lengthwise. Besides the two needle leaves the dwarf branch carries a number of scale leaves, $d$. Between the bases of the needle leaves is seen the conical apex of the dwarf branch, showing their lateral origin. Magnified about 4 diam.-After Luerssen.

FIG. 65.-Twig of apple, bearing fruit spurs. $A$, points at which fruit was detached the preceding year; $W$, leaf scars. Natural size.- After Hardy. 
shoots which repiace leaves in function and resemble them in form. These branches may be either broad and flattened, as in the "smilax" of the greenhouses, or they may be slender and needle-like, as in the common garden asparagus (fig. $6_{7}$ ). In any case, since they replace leaves in function,

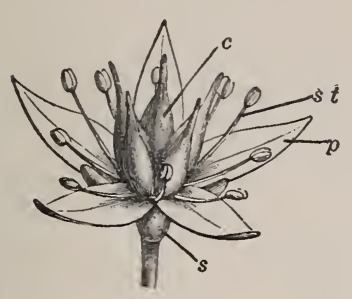

Fig. 66.

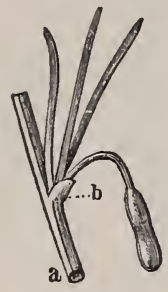

Fig. 67 .

Fig. 66.-Flower of Sedum acre. $s$, sepal ; $\not$, petal; st, stamen; $c$, carpel. Magnified 3 diam.--After Baillon.

FIs. 67.-Piece of a twig of asparagus; in the axil of the scale leaf, $b$, arise a flower shoot, and three leafless needle-like branchlets. Magnified about 2 diam.-After Frank.

they are abundantly supplied with green coloring matter for manufacturing food.

97. (d) Bulblets.-Other branches renain undeveloped as buds, but their leaves become thick and fleshy. These bulblets are easily detached and serve for propagation. (See

299.) They are to be found in many plants. In the tiger-lily they occupy the axils of the leaves (fig. I80), and are modified lateral buds, while in the garden onion they usually replace the flowers.

98. (e) Tubers.-Some underground shoots have their ends suddenly and greatly enlarged, adapting them to the storage of food. They are then called tubers. In the white potato the tuber consists of several terminal internodes of an elsewhere slender underground stem, the "eyes" being lateral buds in the axils of minute scale leaves. In a few plants tubers may even be formed above ground, as in certain polygonums whose flowers are often replaced by little tubers which are readily detached (fig. 68). 
99. $(f)$ Tendrils.-Some shoots take the form of slender, leafless, sensitive tendrils, which assist the plant in climbing

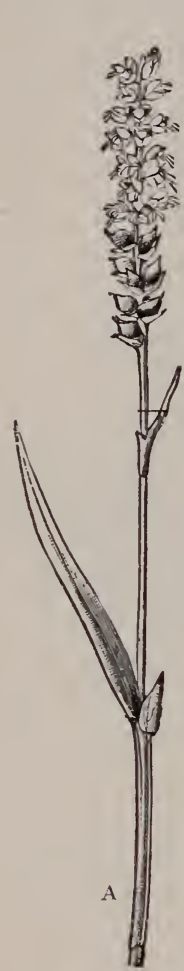

FIG. 68.

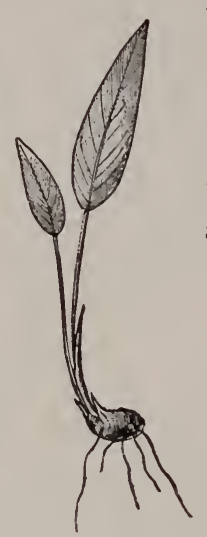

C

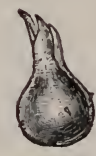

$\mathrm{B}$

by coiling about suitable objects (fig. 69).

100. (g) Thorns. - Many plants produce defensive shoots, which are leafless, rigid, short, and sharp, called thorns, which

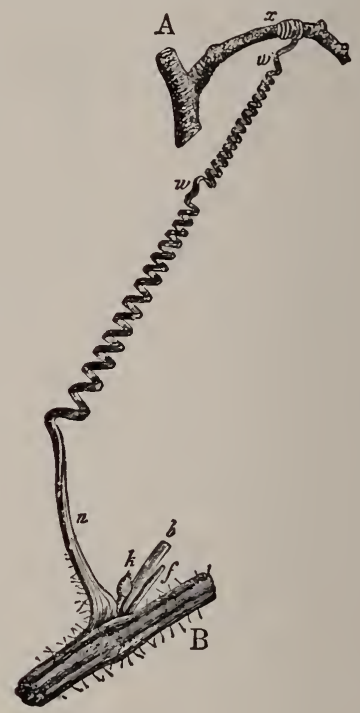

FIG. 69.

F1G. 68.- $A$, upper part of a plant of Polygonum viviparum, showing flower cluster, the flowers in lower half being replaced by tubers. Two-thirds natural size. $B$, a fallen tuber. Magnified about 3 diam. $C$, a plantlet growing from tuber. Natural size.-After Kerner.

FiG. 69.-A portion of the stem of white bryony, $B$, from which a tendril, $u . r$, arises near the leaf stalk, $b$, and the bud, $k$. $u$, rigid portion of tendril; the portion between $u$ and the portion $x$, clasping the support, $\mathcal{A}$, has become coiled into a spiral which reverses the direction of the coils at $w$ and $w$. Nearly natural size.-After Sachs.

may be either simple or branched (fig. 70). The honeylocust furnishes an excellent example of branched, or compound, thorns. 
Leaves themselves may be developed as tendrils or as thorns, so that it must not be assumed from appearance alone that such members are forms of the shoot. Observation of the origin and relation of the members will reveal their true nature. If shoots, they will usually be subtended by a leaf ; if leaves, they will often have a bud or a shoot in their axils. Thorns or tendrils which do not arise at the nodes are reckoned as shoots.

101. Duration.-Shoots are either annual, biennial, or perennial. If the entire shoot dies this generally involves the death of the whole plant, though new adventitious shoots

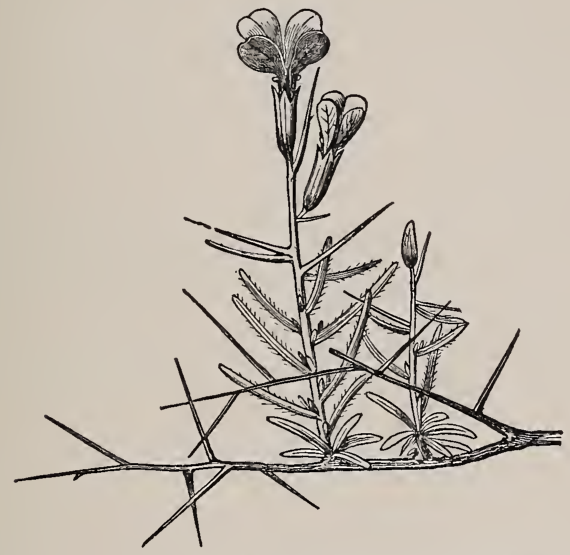

Fig. 70.-Shoots of Vella spinosa, showing thorns. Natural size.-After Kerner.

may arise from the roots, as in sweet potatoes. In many plants, in which the shoot seems to die at the close of the growing season, an underground portion really survives, and sends up the new sloots. Such plants, if they live for two years, are called biennials; or, if they live for several or many years, are called perennials.

The shoot may be composed mainly of soft tissues, and persist underground, where it is protected against unfavorable conditions, such as drought and cold, and especially against 
sudden changes; or it may be composed mainly of mechanical tissues, and be fully exposed, as are the shoots of trees. In these cases the leaves generally perish and drop off annually, but in the "evergreen" plants they live more than one growing season.

\section{EXERCISE XVII.}

Shoots.-Examine the shoots of the linden, elm, maple, oak, and lilac and observe the mode of branching, and the arrangement of the buds. (ब 89).

Study the construction of winter buds of lilac, horsechestnut, or hickory. (This can be done most easily by examining them just as buds are unfolding in spring, or by keeping shoots in a warm room for a few days, when the buds will begin to open.) Observe the form and arrangement of the scales and the way in which foliage leaves are folded. How are these buds protected against water? Against sudden changes of temperature? ( 87, I33.)

Examine the rhizomes of couch grass, mint, solomon's seal or bloodroot; the bulb of the onion or hyacinth; the tuber of the white potato, as forms of underground storage shoots ( 993,98$)$. Do these shoots have buds on them?

Examine the tendrils of the passion flower (or the wild cucumber vine); the thorns of the haws or the honey locust, as special leafless forms of the shoot.

102. Summary.-The shoot grows at the tip, new lateral members being formed in regular succession below it. These young members and the tender tip itself, protected by some older leaves, compose the terminal bud. Similar growing points arise on the sides of the main shoot and exist for a time as lateral buds. Some buds die, and some live but remain undeveloped. Others develop into branches similar to or different from the main axis. Special forms of the shoot are produced to serve special purposes, such as storage, reproduction, protection, climbing, etc. The branches, some or all, and even the main shoot, die after a time. Annual shoots die after one growing season, biennial shoots after two, and perennial shoots after several or many. 


\section{CHAPTER $\mathrm{X}$.}

\section{THE STEM.}

103. Definition.-The shoot is almost always segmented into members of two kinds, the stem and leaves. The stem is the central axis of any shoot, and the leaves are lateral outgrowths, or branches, of it. These two members cannot be accurately defined, but are in most cases readily recognized. Leaves commonly differ from the stem in their flattened form, limited growth, and position, subtending the lateral shoots. (See further p. 96.)

104. Nodes and internodes.-Upon examining the surface of the stem, it is almost always readily distinguishable into distinct regions, the nodes and internodes. The nodes are the narrow zones, often somewhat swollen (whence the name), at which one or more leaves arise. The internodes are the zones between the nodes. Upon watching the derelopment of the stem from the terminal bud, it will be seen that new nodes and internodes are constantly emerging from its base, and that the leaves formed at the nodes are successively expanding. This emergence of the internodes is due to their growth. The amount of growth, however, varies greatly in different plants, and even in different parts of the same plant. In many cases the internodes are considerably and uniformly elongated; the leaves are then distributed along the stem at considerable and regular intervals. In other cases the internodes remain very short, and the leaves are, thcrefore, crowded. They may be so crowded as 
to envelop the stem completely and hide it from view. This is well seen in the scale-like leaves of such plants as the pines

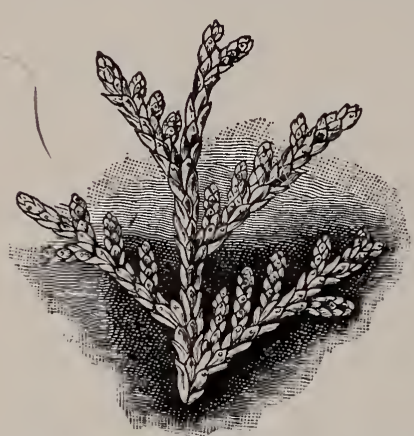

FIG. 71.-A shoot of arbor vitæ or white cedar, showing scale leaves covering stem. Natural size.-After Kerner. (fig. 63), cedars, and arbor vitæ (fig. 7 I). Or, certain of the internodes may elongate, while others remain undeveloped. For example, in the shepherd'spurse, the first internodes remain short, so that the lower leaves are crowded into a tuft or rosette; the following internodes are elongated, the corresponding leaves being scattered at regular intervals; while, still higher, the internodes are again shortened and the leaves brought into close clusters in the flowers.

105. A section of the stem commonly presents an irregularly circular outline (fig. 72). Occasionally the surface of the stem is fluted or channeled, and, if these grooves or channels be few, and the corresponding angles prominent, the section of the stem is polygonal, with three, four, five, six, or more sides (fig. I3I).

106. Habit.-As to habit, stems are commonly erect when enough mechanical tissue is developed to render them. sufficiently rigid to carry not only their own weight, but that of the leaves and other members attached to them. Other stems lie flat upon the ground, to which they may or may not attach themselves by the development of secondary roots. Between these prostrate, or creeping, stems and the erect form every conceivable position exists. The direction of growth is determined largely by the relation of the plant to gravity and light as stimuli. (See $\Upsilon$ 243, 245.) Other stems rise into the air, not by their own rigidity, but by the development of special members for climbing purposes, such as 
recurved spines, tendrils, sensitive leaf stalks, or even by recurved normal branches. (See 99 , I 3 I.) Others wrap themselves about objects of suitable size, and are called twining stems. (See 249.)

107. Primary structure.-If a thin section be cut from an internode which has just reached its full length, three definite regions may be distinguished, viz. : (I) the epidermis; (2) the cortex; (3) the stele (figs. 72, 73).

I. The epidermis is a single layer of cells forming the extreme edge of the section, being, therefore, the layer which

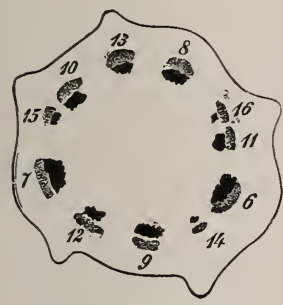

Fig. 72.

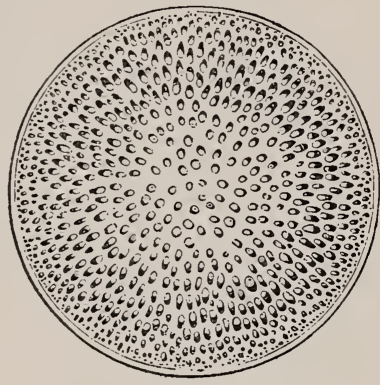

FIG. 73.

FIG. 72.-Diagram of a transverse section of stem of Iheris amara, showing outline, and paired vascular strands. The black is the wood strand; the grav is the bast strand. The outer line represents the epidermis; a circle including the bundles would mark the limits of the stele, with its central pith; the cortex lies between the epidermis and stele.-After Nägeli.

FIG. 73. - Diagram of a transverse section of a palm stem. The epidermis is represented by the outer line ; the narrow cortex lies between this and the inner circle; the stele, with numerous bundles scattered through the pith, is within the cortex.-After Frank.

covers the surface of the stem. Here and there are minute openings which permit communication between the outside air and spaces between the cells of the cortex. These openings are usually bordered by two specialized cells, and are called stomata. (See I I7.) Naturally they are wanting in submerged stems of water plants and in most subterranean stems. The epidermis is often furnished with hairs, scales, and like outgrowths (figs. 74, 75, 200-203). 
2. The cortex consists of several layers of cells, usually thin-walled and not in close contact, and hence abundantly provided with intercellular spaces. These cells usually contain many chloroplasts, to which the green color common to young stems is due.

3. The stele forms the central region. Its most striking parts are several or many clusters of smaller cells, the cut ends of the vascular strands. Occupying the space between the vascular strands is the pith (figs. 72,73 ).

108. The cortex. - In certain plants the cortex undergoes an enormous development, forming in some tubers the

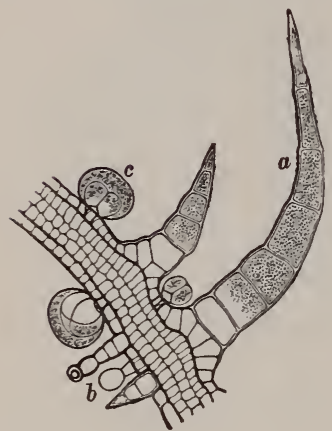

FIG. 74 . greater part of the massive stem; in others it is so reduced that it consists only of two or three layers of cells. With the epidermis it very commonly enters into the formation of outgrowths, such as

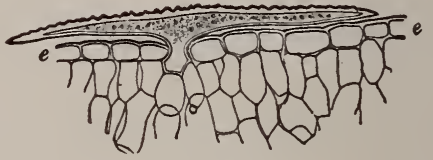

Fis. 75 .

Fig. 74.-Forms of hairs from Plectranthus. $a$, simple pointed hair; $b$, stalked glandular hair; $c$, sessile giandular hair with secretion covering the two glandular cells. Highly magnified.-After De Bary.

FIg. 75.-T-shaped hair of the wall-flower (Cheiranthus). e, epidermis. Highly magnified. - After De Bary.

warts, prickles, wings, etc. Very frequently the intercellular spaces of the cortex are greatly enlarged, forming air passages of considerable size (fig. 76). In other cases the cortical cells, instead of remaining thin-walled, may become greatly thickened in certain regions, or even througheut the cortex. These mechanical cells are likely to be aggregated in clusters or strands, and serve an important purpose in strengthening the stem. 
109. Stele.-The outermost part of the stele often produces mechanical cells with thick walls and small cavities. They are either aggregated in strands opposite to the vascular strands of the stele, or they constitute a complete zone

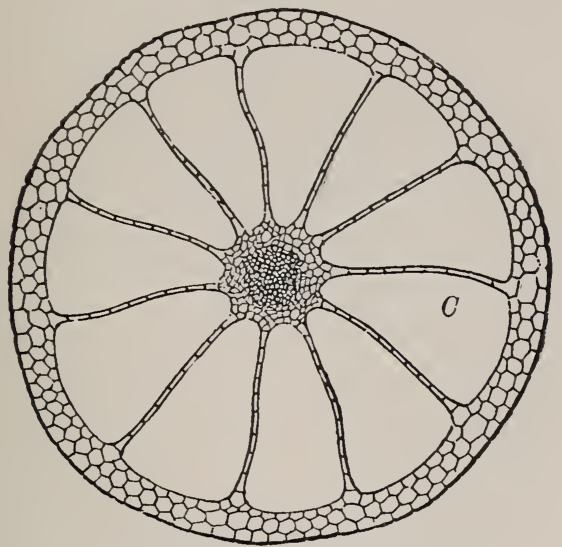

FIG. 76.-Transverse section of the stem of Elatine, showing intercellular canals, $C$. Magnified about 15 diam.-After Reinke.

around it. Many of the most valuable textile fibers, such as those of flax, hemp, and ramie, are obtained from this region of the stem (fig. 77).

In any section of the stem the number of vascular strands in the central cylinder varies greatly, not only in different plants, but even in different parts of the same plant. The strands are commonly arranged in pairs, a bast strand and a wood strand being placed side by side, the former occupying the side next the surface of the stem, and the latter the side next the center (figs. 72, 78). The number and position of these bundles is, however, subject to change. In some cases one of the strands surrounds the other. Commonly it is the bast which surrounds the wood, as in the fernworts. Sometimes independent bast strands are found with which are associated no wood strands. In the bast certain cells 
may develop into fibers, which are quite like the fibers

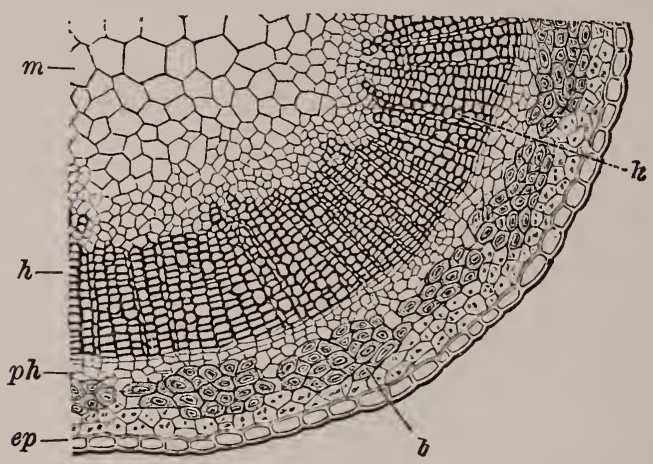

Frg. 77.- Portion of a transverse section of the stem of flax. $m$, pith; $h$, secondary wood forming a cylinder; $p h$, bast ; $b$, strands of mechanical tissue (fibers) among the thin-walled cells, the two sorts making up the cortex; $e p$, the epidermis. Magni-
fied about 25 diam. - After Frank.

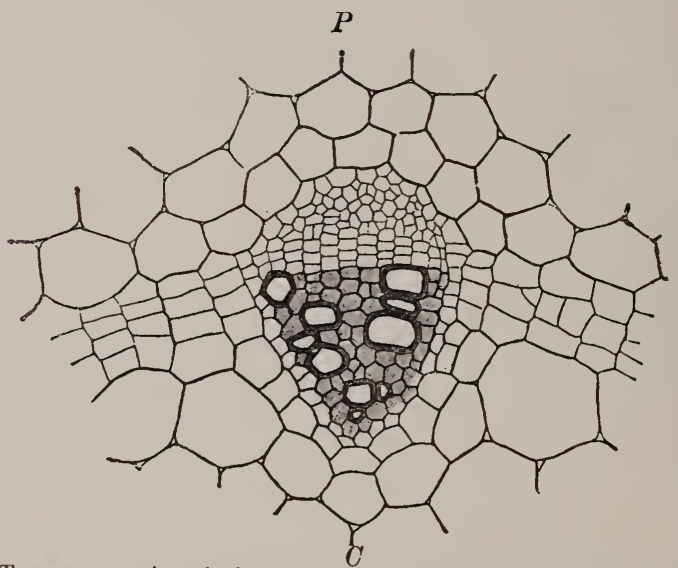

FIG. 78. - Transverse section of a bundle pair from the stem of a begonia. The shaded part is the wood strand; the small irregular cells above are the bast strand; between them is a zone of growing cells, the stelar cambium, which extends also right and left of the bundle pair. The radius of the section passes through $C P ; C$, next the
center. Magnified I5o dram.-After Haberlandt.

occurring in the outer part of the stele. Some of these, also, are valuable in the textile industries. 
The paired vascular strands within the stele occupy various positions, and for purpose of location may be spoken of as though single. If transverse sections of the stem are observed, they may be seen either in a single row, roughly parallel with the surface of the stem (fig. 72), or in several concentric rows (fig. 79), or they may be irregularly disposed throughout it (fig. 73). No one method of arrangement is confined to any of the larger groups of plants, although the first is characteristic of most

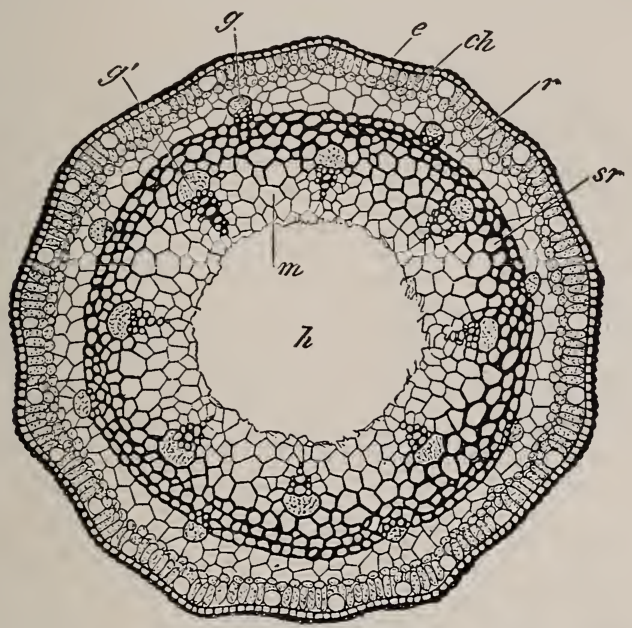

FIf. 79. - Transverse section of the aerial stem of an onion (Allium Schoenoprasum). $e$, epidermis ; $c h$, chlorophyll-bearing tissue of cortex; $r$, colorless tissue of cortex; $g, g^{\prime}$, vascular bundles (wood bundles black, bast bundles dotted); $s r$, mechanical tissues connected into a cylinder; $m$, pith; $h$, pith canal formed by destruction of cells. Magnified 30 diam.-After Sachs.

dicotyledons, while both the second and third methods are common among the monocotyledons. But so many exceptions are found to these last statements that it is best not to indicate the arrangement of the bundles by the terms dicotyledonous or monocotyledonous, as has been commonly done; nor is it possible to maintain the terms exogenous and endogenous, which have long since become obsolete because misleading.

110. Pith.-The pith is frequently found enormously developed in those parts of the stem used for storing reserve food, such as the tubers of the white potato and the yam. In other plants, particularly those growing in water, it suffers 
extreme reduction or is often completely wanting, in which case the bundles of the stele are in close contact, and the cortex usually shows a corresponding increase. In other plants the cells constituting the pith are greatly thickened, so as to form a mechanical tissue.

The thickened areas are usually either opposite the vascular strands, forming a strand closely adherent to their inner faces, or they may extend

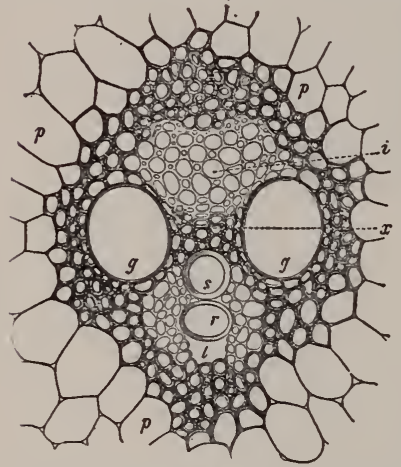

FIg. 8o.-Transverse section of a bundle pair of Indian corn. $\%$, bast bundle; $x, g, g, s, r$, wood bundle; $p$, pith; $l$, an intercellular space formed tissues. The bundle pair is surrounded by a sheath of thick-walled mechanical tissues. Magnified 235 diam.-After Sachs. to their flanks, thus forming an arc embracing each. Sometimes the thickened region becomes extended between the vascular strands and joins other mechanical tissues of the stele, or even those of the cortex, so as to enclose completely the individual strands (fig. $80)$.

In other plants the pith dies early and shrivels up. Very large canals may thus be formed through it, or it may even disappear entirely (fig. 79). Such early disappearance of the pith produces the hollow stem characteristic of the grasses, the sedges, and various members of the sunflower family.

111. Secondary structure.-Some stems retain throughout their entire existence the primary structure which has just been described, undergoing only slight changes which do not materially alter the structure. This permanence of primary structure is frequent in the stems of monocotyledonous plants. But the stems of the great majority of dicotyledonous plants, as well as the conifers, quickly lose their primary structure, adding tissues of considerable amount, so as to bring about a more or less striking rearrangement of the first formed tissues (fig. 8I). This is due chiefly to the 
formation of one or two layers of actively dividing cells, roughly parallel to the surface. When there are two such layers they are concentric. They are formed from existing cells which retain or resume their power of active growth and division. The development of the tissues from the external growing layer, called the cork cambium, results in the formation of secondary cortex, called periderm, while the tissues arising from the internal growing layer, or stelar cambium, form the secondary wood and secondary bast (fig. 8 I).

112. Cork.-The outer tissues of the periderm rarely remain living. The close-set flat cells early lose their contents, and the walls become waterproof, forming cork (fig. 82). Other cells may be altered into mechanical tissues by the thickening of their walls and the death of the protoplasm. Zones of cork often alternate in the periderm with zones of mechanical tissues. Since almost no water can pass through a cork zone, it is evident that all parts lying out-

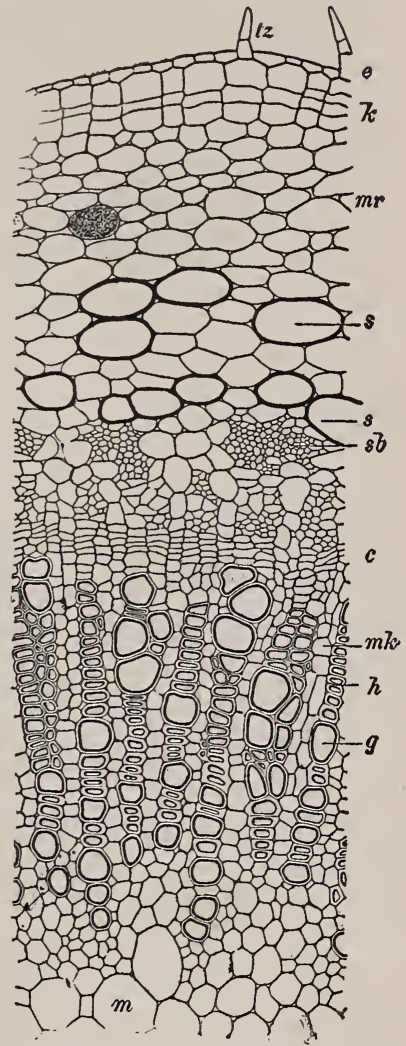

Fig. 81. - Part of a transverse section of a young stem of cinchona in process of secondary thickening. $t z$, hairs ; $e$, epidermis ; $k$, cork-cambium ; $m r$, cortex ; $s$, gum-resin tubes in cortex; $s b$, primary bast strand; $c$, stelar cambium; $g, h$, secondary wood; $m k$, pith rays; $m$, pith The tissue between $s b$ and $c$ is secondary bast. Highly magnified.After Tschirch. side of one are cut off from a supply of nourishment, and must 
therefore perish sooner or later. How much of the stem will thus be killed depends upon the position of the layer of cells which produces the cork.

Annual shoots have usually but a small amount of periderm formed, or sometimes none at all.

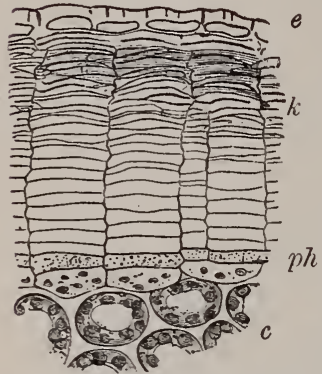

FIG. 82 - Part of a transverse section of young stem of cherry, showing formation of periderm. $e$, epidermis ; $k$, cork; $p h$, cork cambium, with one row of secondary cortex below; c, cortex. Highly magnified. - After Haberlandt.
In perennials, periderm is formed not only during the first year's growth, but the activity of the cork cambium is resumed at the beginning of succeeding seasons, so that annual additions are made to it.

113. Bark. - The dead tissues which accumulate from year to year upon the outside of perennial stems constitute a large part of what is known as the bark. The inner part of the bark belongs to the stele. (See I I I7.) In the bark of most trees one or more cork-forming layers originate in addition to the first, giving rise thus to sheets of cork either concentric with the first, or intersecting it (fig. 83 ).

In the first case the dead outer parts may peel off in concentric sheets, as in the birch. In the second the dead parts break away in the form of scales or flakes, as in the hickory, sycamore, or apple. In many trees the dead outer portions are only gradually worn away by the action of the weather, becoming seamed or deeply furrowed lengthwise.

114. Secondary wood and bast.-The position of the internal growing layer, the stelar cambium, is not subject to the same variations as the external one.

In the many dicotyledons whose stems increase in diameter, the strands of wood and bast are in a single circle. parallel to the surface, the bast bundles in each pair being on 
the outside. The stelar cambium arises between the wood and the bast strands of each pair, and extends across the pith rays which intervene, thus forming a complete zone nearly concentric with the surface of the stem (figs. $78,8 \mathrm{I}$,

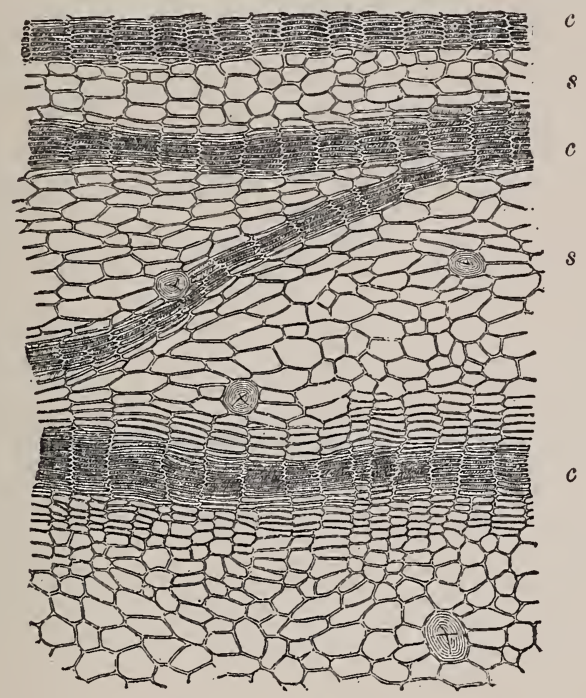

Fig. 83.-Part of a transverse section of the bark of cinchona. $c$, layers of cork formed by a transient cork cambium. $s$, thin-walled tissues, with occasional stone cells. The sheets of cork cells are lines of weakness along which the flakes of bark split off. Magnified $66_{j}$ diam.-After Warnecke.

$84, A)$. On the inside of the cambium there arises, opposite the primary wood, secondary wood. Outside the cambium, opposite the primary bast, there arises secondary bast. Each strand is thus increased in its radial thickness (fig. 8I).

115. Pith rays. - The cambium in the pith between the bundles either produces pith tissue ( $B$, fig. 84 ), or it forms secondary wood and bast corresponding to that produced between the adjacent bundles. In the latter case, therefore, a complete zone or ring of secondary wood and bast is 
formed, so that the pith occupies the center. Upon the ring of secondary wood thus produced the primary wood strand projects into the pith, and upon the ring of secondary bast the primary bast strand projects into the cortex $(C$, fig. 84$)$.

Intermediate between these two methods, it is common to have new strands produced by the cambium formed in the pith rays, these strands remaining separated by narrower pith rays $(D$, fig. 84$)$.
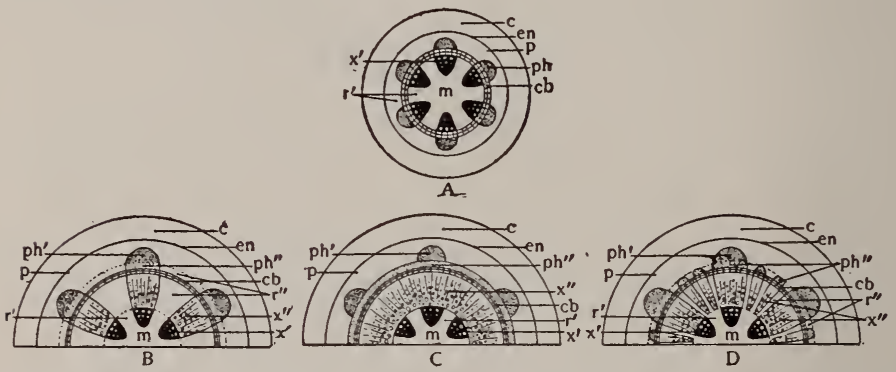

FIG. 84.-Diagrams of transverse sections of stems illustrating modes of secondary thickening. In all $c$, cortex; $e n$, its inner boundary; $p$. limit of stele; $p h^{\prime}$, primary bast ; $p h^{\prime \prime}$, secondary bast ; $c b$, stelar cambium ; $x^{\prime}$, primary wood; $-x^{\prime \prime}$, secondary wood; $r^{\prime}$, primary pith rays; $r^{\prime \prime}$, secondary pith rays. - After Van Tieghem.

The secondary strands thus formed can, of course, have no direct connection with those which enter the leaves. In this they differ from the primary strands, branches from which enter each leaf. (See 1 i 36.)

116. Annual rings. - If the stem is perennial, year after year the stelar cambium resumes its growth, adding layer after layer to the secondary wood and bast. Thus most trees have their shaft-like trunks formed. The cambium forms a line of weakness, and the parts outside separate readily from the wood. They constitute the bark.

117. The bark.-As has been already shown ( $\boldsymbol{\top}$ Ir 3 ) the outer part of the bark consists of the dead, dry, shriveled parts of the periderm lying outside the cork cambium. The inner portions of the bark are composed of the tissues which 
lie between the cork cambium and stelar cambium. This inner part contains a greater amount of water than the outer, and always some living tissues. It may consist of a part of the cortex and both primary and secondary bast. As the tree grows older the bark may come to consist almost wholly of secondary bast. It attains considerable thickness only when the loss from weathering is slow.

\section{EXERCISE XVIII.}

Stems. - Cut cross-sections of the stem of (I) a seedling beam and (2) a young stem of asparagus and compare. Observe in (I) the three regions, epidermis, cortex, and stele ( $\left(\right.$ IO7) $^{2}$. In the stele observe $(a)$ the cut ends of the vascular strands and their arrangement. (Each pair looks like a single strand except in very thin sections.) (b) The central pith. In (2) observe the epidermis, very narrow cortex, and the stele occupying the greater part of the section. In the latter observe the cut ends of the strands, distributed throughout the pith.

Cut a cross-section of the three-year-old shoot of any shrub or tree. Observe $(a)$ the central pith, $(b)$ the wood strands increased in number and thickness until they form a cylinder of wood, in which three annual layers can be observed (how marked?); (c) the stelar cambium, a line of weakness (young cells) outside the wood; $(d)$ the bark, composed of the bast strands on the inside, the cortex (in part) next, and the periderm (brown) on the outside. Compare with the bean stem. How much is the stele? ( (III-II7.)

118. Summary.-The stem shows nodes, i.e., the zones of attachment of leaves, and internodes. The length of the latter determines the distribution of the leaves. Stems may be erect, prostrate, or climbing. They show three regions, epidermis, cortex, and stele; each with great variety of structure in different plants. The stele consists of vascular strands of two kinds, arranged in pairs, and embedded in pith. As stems grow older they frequently increase in diameter by the formation of concentric growing zones in the cortex and stele. The outer one produces the periderm, the inner one wood and bast. In trees and shrubs the wood and bast receive annual additions. They separate readily at the stelar cambium, the outer cylinder being the bark. 


\section{CHAPTER XI.}

\section{THE LEAVES.}

THE leaves are very important nutritive organs in most green plants. They are adapted to catch the sunlight; therefore their form, structure, and position are largely controlled by this relation to light. (See $\boldsymbol{T}_{\text {I }}$ 90, 19I.)

119. Primary and secondary leaves.-Leaves are distinguishable as primary and secondary. The primary leaves are those first developed, usually in the youngest stage, the embryo. In fernworts the primary leaf can be traced back in its development even to the egg. In seed plants they are usually formed before the young plant (embryo) enters its resting state as the seed becomes ripe.

The primary leaves of seed plants are called cotyledons (figs. 85, 86). They are usually transient, and not rarely so distorted by acting as storage places for reserve food that they do not serve as foliage leaves at all. In extreme cases of this kind they remain in the seed coats when the embryo resumes its growth, as in pea and oak.

Secondary leaves are generally numerous and much more conspicuous. It is these which are usually meant by "leares," unless primary leaves are specially named.

120. Development.-If the apex of the shoot be examined, its progressive differentiation into stem and leaves can be observed. Upon the sides of the growing point swellings of various size appear, the smallest being nearest 
the apex (fig. $58,1,2,3,4)$. These swellings are the rudiments of the leaves, into which they become transformed by further development. Similar swellings appear later just above the leaf rudiments, which are at first not distinguishable from them, except by position (fig. $58, a, b, c$ ). These become the branches. Both leaf and branch have their origin usually in the outer layers of the shoot, and can only be distinguished

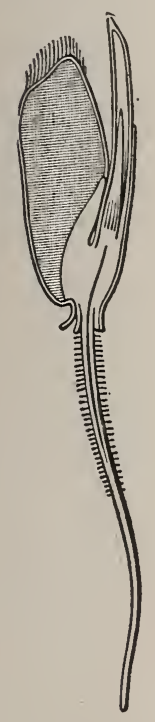

FIg. 85 .
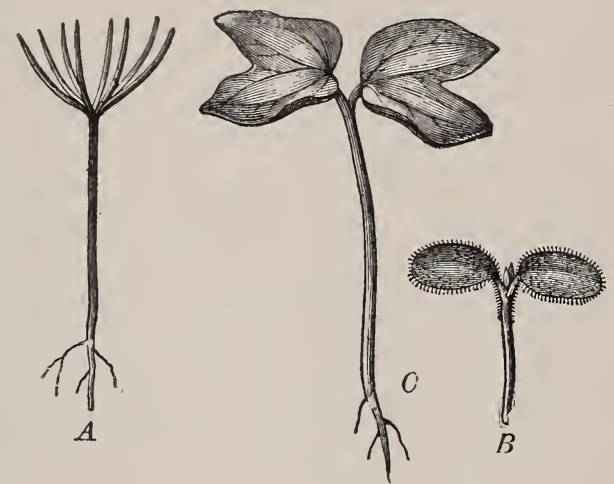

FIG. 86.

FIG. 85-A seedling of wheat, with grain still attached, cut through lengthwise, showing the single primary leaf with its back applied to the store of reserve food in the grain (the shaded part). The first two secondary leaves are also developing, and the primary root has extended. Magnified ${ }_{4}$ diam.-After Kerner.

FIG. 86.-Seedlings, showing primary leaves. $A$, a fir; $B$, the dog-rose ; $C$, a morning-glory. Natural size.-After Kerner.

by the later course of development. The growth of the branch is commonly indefinite, while that of the leaf is generally limited; the branch usually develops leaves and often buds as lateral outgrowths, while the leaf rarely forms buds normally; the axis of the branch is generally radial, like the parent axis, while the leaf is generally flattened and dorsiventral. In most cases, also, the leaf subtends the branch. Both leaf and branch mark those points of the stem known as the nodes. 
121. Arrangement. - Leaves appear in regular succession upon the stem, the youngest being nearest the apex. Their distribution along the sides of the stem, though extremely various, may be reduced to two main types. Either (I) the leaves are formed singly at the nodes, or (2) more than one leaf occurs at each node. When the leaves are single, successive leaves may stand upon exactly opposite sides of the stem, so that the third leaf, counting from below upwards, stands over the first; or the fourth leaf may stand over the first; or the sixth over the first, and so on. A transverse section of an opening bud shows the mode of arrangement, and a study of such sections makes it evident that each leaf appears in the widest space between the two preceding leaves, i.e., where it encounters the least resistance. That this is the determining factor is shown by the fact that the order of arrangement may be artificially altered by pressure or distortion of the bud. When two or more leaves occur at each node, the members of successive circles ordinarily alternate with each other. This alternation is due to the same cause.

122. Form.-Leaves show a great variety of form and structure. Even upon the same plant leaves of various forms occur. The primary leaves are usually different from the secondary leaves, both in form and size. The most abundant form of secondary leaves is foliage leaves. These may be very simple, as the "needles" of the pines, or differentiated more completely, as in the deciduous trees. The mature form of the complex foliage leaf is frequently not attained until several nodes above the point at which the primary leaves arise; and, if only one or two leaves are produced each season, as in many ferns, the mature form may not appear for several years.

123. Foliage leaves.-A well-developed foliage leaf has three parts, the base, the stalk, the blade (fig. 87). The 
leaf base is always present, but either the leaf stalk or the leaf blade or both may be absent. The leaf blade is ordinarily winged; indeed it is for this reason that it received the name "blade." Either the stalk or the base or both may also be winged.

124. I. The leaf base. - The leaf base is generally enlarged so as to form a sort of cushion by which it is attached to the stem. When a broad base is attached over a considerable arc of the circumference of the stem, so that it encircles it more or less, the

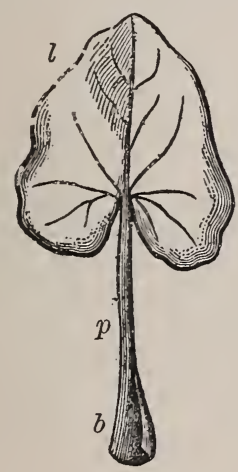

Fig. 87 .

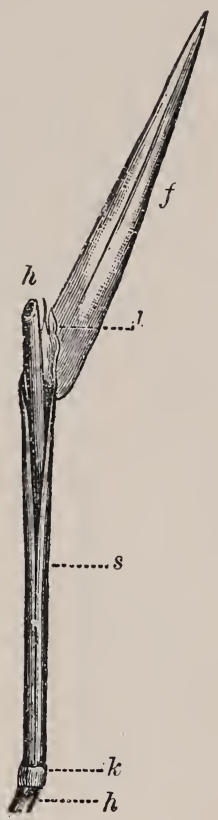

FIG. 88.

Fig. 87.-Leaf of Ranunculus Ficaria. $b$, leaf base; $p$, petiole, or leaf stalk; $l$, lamina or leaf blade. Natural size.-After Prantl.

FIf. 88.-A leaf of a grass, with part of stem to which it is attached. $s$, sheath (leaf base) attached all around node $k$ of the stem $h, h ; f$, blade; $l$, the ligule, an outgrowth from the surface. Natural size.-After Frank.

base is said to be sheathing (fig. 87). In grasses, for example, the leaf base is attached over the entire circumference of the stem, and enwraps it completely for a considerable distance above the node (fig. 88).

125. Stipules.-The leaf base frequently branches. These branches, commonly two in number, are called stipules (fig. 89). They vary from slender, awl-shaped bodies to 
flattened and leaf-like ones. The stipules may remain attached to the base throughout the life of the leaf, or may fall away early. Usually the two are separate, but they may be united with the leaf base itself, forming wings for it, as in roses (fig. 90), or they may be united with one another so as to form a sort of sheath encircling the stem (fig. 9I). When the leaf base is winged, the wings extend downward

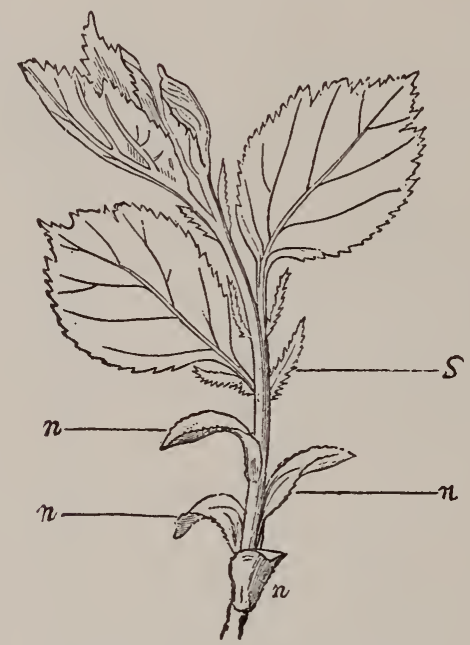

FIG. 89.-A growing shoot of a thorn (Cratagus punctata). $n$, leaves developed as bud scales which protected the parts above when in the bud; $S$, stipules. Natural size.-After Reinke.

as lobes more or less encircling the stem. In many cases the leaf is said to be clasping (fig. 92). These lobes may even unite on the other side of the stem, so that the stem seems to penetrate the base of the blade (fig. 93). When two leaves occur at the same node, corresponding lobes of the leaf bases may unite, so that the stem seems to pass through the center of a leaf which extends equally on each side of it (fig. 94). 
126. 2. The leaf stalk.-The leaf stalk is also known as the petiole. Its form is more or less cylindrical, usually with a groove or channel upon the upper side. Sometimes

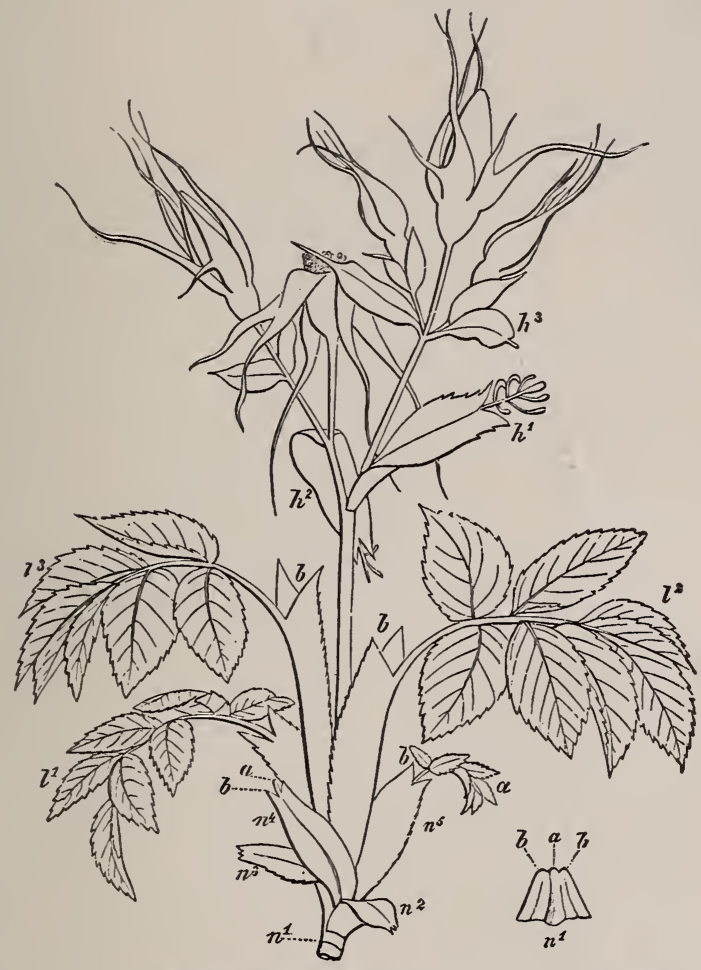

Fig. 90.-A young flowering shoot of dog-rose, showing 1 arious forms of leaves and transition from one to the other. $h^{1}-n^{5}$, scale leaves $;,^{1}-l^{3}$, foliage leaves; $h^{1}-h^{3}$, bracts; the flower leaves not clearly shown. The scale leaf, $n^{1}$, shows a leaf base, winged by stipules $b$, with only a trace of stalk and blade $a$. Trace these parts into foliage leaves, where the blade becomes compound, and subsequent reduction through the series of bracts. Natural size.-After Luerssen.

the petiole is flattened in a vertical plane, as in aspen poplars. When this flattening is extensive, so that the petiole becomes thin and leaf-like and the blade is wanting, it functions as a foliage leaf (fig. 95). Not infrequently, the petiole is 
winged, as in the orange. It may be entirely wanting, in

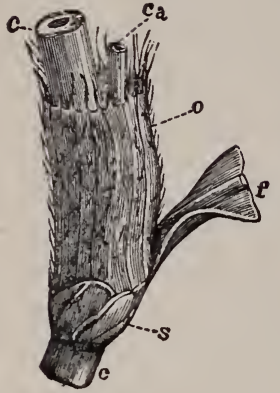

Fig. gr. which case the blade arises directly from the base, as in most grasses (fig. 88).

12\%. 3. The leaf blade.-To this part of the leaf the word "leaf" itself is fre-

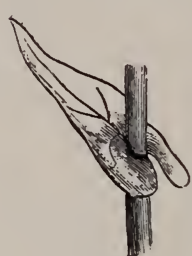

Fig. 92. quently applied. In general, the leaf blade is so broadly winged as to be thin and flat; but all gradations exist between such forms and those that are much folded or crum-

Fig. or. - Stipules of Polygonum forming a pled, thick and fleshy, or
sheath, o, above the sheathing leaf base $s$, of the cut-off leaf $f ; c c$, the stem; $c a$, an axillary even cylindrical.
shoot. Natural size.-After Frank.

shoot. Natural size.-After Frank.
IG. 92.- Leaf of 1 hlirspi with clasping base. Natural size.-After Prantl.

If a thin blade be held

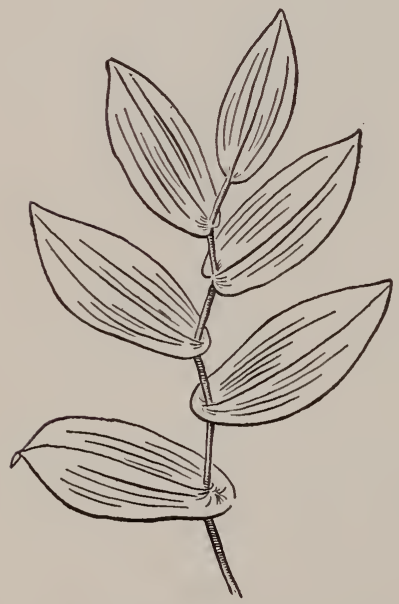

FIG. 93 .

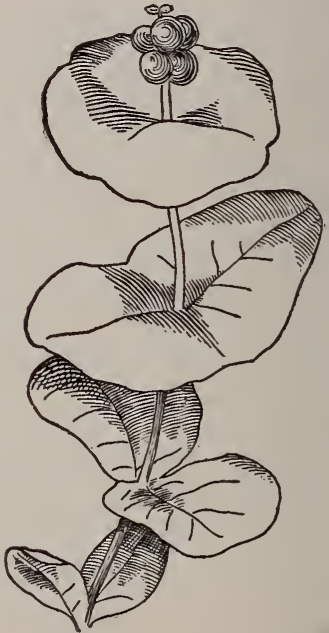

FIG. 94 .

FIG. 93.- Shoot of Uvularia, showing perfoliate leaves below. About half natural size.-After Gray.

FIG. 94.-A shoot of wild honeysuckle, showing upper leaves connate-perfoliate. About half natural size.-After Gray. 
between the eye and the light, two parts become evident: (I) a green tissue, more or less opaque; and (2) translucent " nerves" or " veins." * The larger of these, usually called the "ribs," * frequently form ridges upon the under surface.

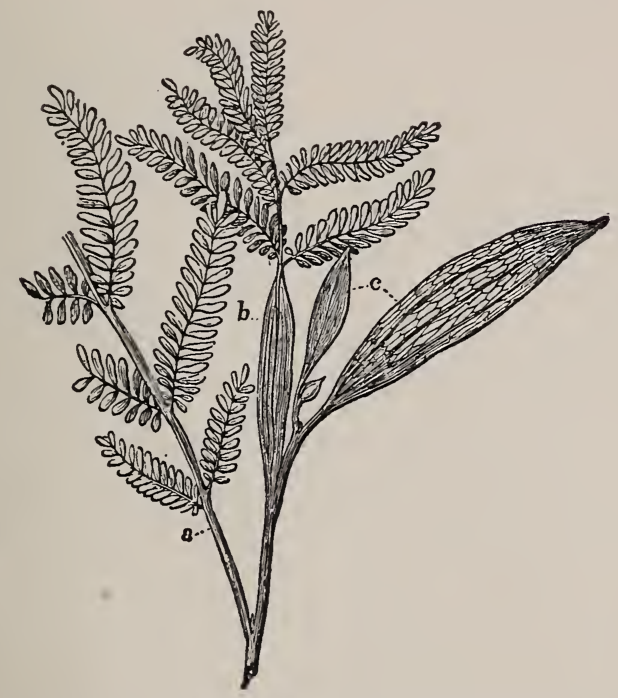

FIG. 95. - A shoot of Acacia, showing at $a$ a twice-branched (compound) leaf with roundish petiole; at $b$. a similar leaf with flattened blade-like petiole; at $c$, phyllodia, i.e., blade-like petioles without true blades. About half natural size (?)-After Frank.

128. Branching.-The outline of the blade is extremely various. It is dependent upon the character and extent of its branching, which may be either slight or extensive. Slight branching gives rise to teeth of various forms (fig. 96). More profound branching is evident in divided or parted leaves (fig. 97). In some blades the branching is so extensive and complete that the green tissue no longer fills the

* These words must not be thought to indicate any resemblance in function to the same parts in animals, but only similarity of position or appearance. 
intervals between the larger ribs, but the blade is made up of a series of independent portions united to a common stalk. Each ultimate branch of the blade is known as a leaflet. Blades in which the green tissue is continuous, even though deeply divided, are

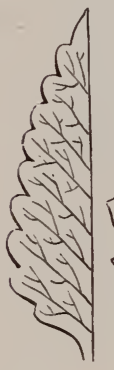

A

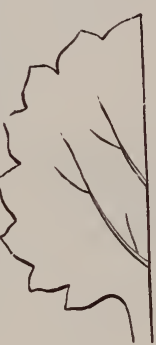

$\mathrm{B}$

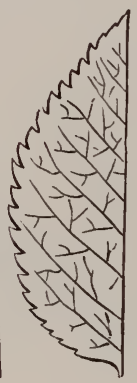

C

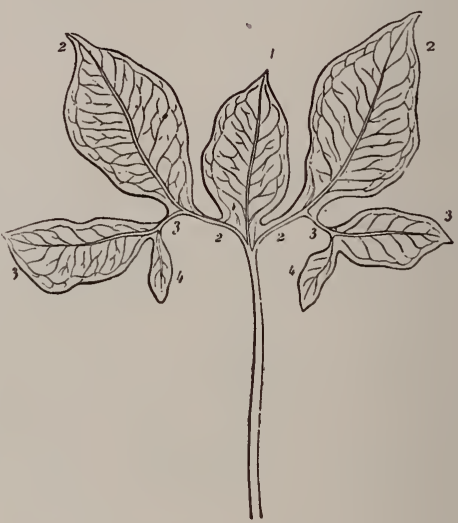

F1G. 97.

FIG. 96 .

FIG. 96.-Diagrams ot slight leaf branching. $A$, leaf with crenate edge; $B$, leaf with dentate edge; $C$, leaf with serrate edge. - After Bessey.

FIg. 97 - Leaf of Amorphophallus, showing sympodial branching. The successive lateral axes are numbered in order. The extent of branching makes the blade divided. Reduced. - After Sachs.

called simple leaves. (See figs. 87, 89, 92, 96, 97.) Those which are branched into distinct leaflets are called compound leaves. (See figs. 90, 95.)

129. Venation.-The ribs and reins, being composed in part of the vascular strands which enter the leaf, and in part of stiffening mechanical tissues, branch profusely and in such a way that no part of the green tissue is far from a vein. In figures 98 and 99, though none of the finest branches are shown, some idea of the complete distribution of the veins may be obtained.

The branching of the ribs and veins agrees in the main with the different modes described for the shoot, 89 , which see. A formal account of venation may be found in Gray's Structural Botany, pp. 90-94.

130. Special forms.-Foliage leaves may be modified to serve special purposes without wholly losing their function 
as foliage. For examplc. the petiole may be made sensitive to contact, and adapted to wrap about slender objects, like a tendril, as in clematis and nasturtium (fig. IOO). Such plants are called leat-climbers.

Some plants develop their leaves into the form of sacs or

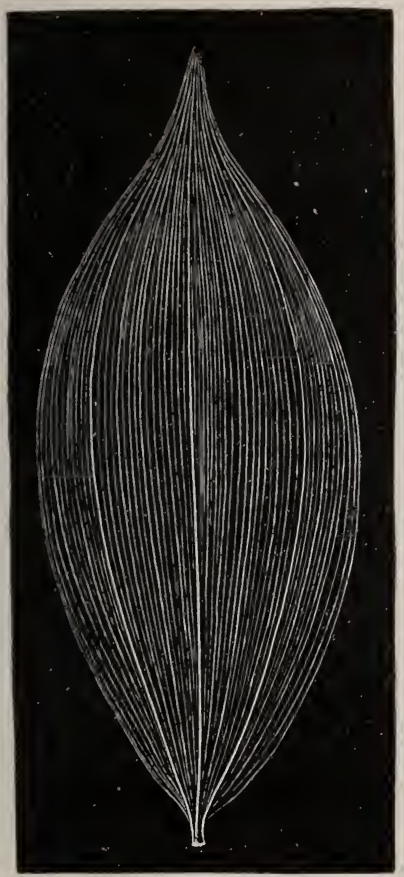

Fig. 98 .

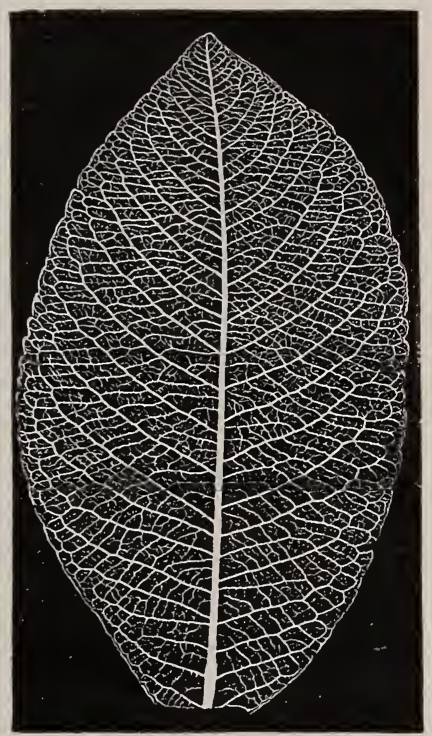

FIG. 99.

FIG 98.-Parallel venation of leaf of Polygonatum latifolium. Natural size.-After Ettingshausen.

FIG. 99.-Pinnately netted venation of leaf of a willow. Natural size.-After Ettings. hausen.

pitchers. These ordinarily represent the blade of the leaf, and are more or less urn- or trumpet-shaped. They may be either without petiole, as in Sarracenia (fig. IOI); or petioled, as in Utricularia (figs. 22 I, 222 ); or the petiole 
may be winged to serve for foliage, as in Nepenthes (fig. 220). A few plants have their leaves modified so as to serve

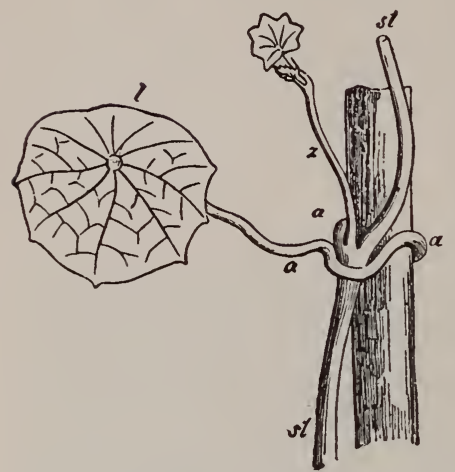

FIG. 100.-Portion of a plant of the dwarf garden-nasturtium (Tropaolum minus) The long petiole $a, a, a$ of the leaf $l$ is sensitive to contact and has coiled about the support and its own stem, st. $z$, axillary branch. Natural size.-After Sachs as traps, which, by their sudden movements, capture small animals (figs. 224, 225,226 ).

But generally the foliage function is subordinated to the other work, and the leaf takes on peculiar forms, the more important of which are as follows:

131. (I) Tendrils. - The leaf blade alone, or some of its branches, or the petiole and blade, may develop as a cylindrical body, without wings and sensitive, known as a tendril. In the pea, the stipules become very large, and take the function of the reduced blade (fig. IO2). In other plants the base may be broadly winged for the same purpose.

132. (2) Thorns.-The leaves may develop into slender conical and sharp-pointed thorns or spines, either branched or unbranched (fig. 228). Sometimes the stipules alone become thorns, as in locust and acacia (fig. 103). Neither tendrils nor thorns can be distinguished structurally from similar forms of the shoot.

133. (3) Scales.-In buds, on underground stems and on various parts of the aerial stem, are found small, scale-like leaves of various shapes (figs. 63, 64, 67, 71, 89, 90, 198). These scales may represent the sheathing base only; they may be the base with the stipules (fig. 90); or they may represent the leaf base and the blade. The petiole in all 
cases is wanting. In addition to the adaptation of their form, scales, especially those that protect buds, are firm and resistant to cold and other unfavorable external conditions. Not infrequently they are supplied with hairs or surface glands, whose function is to produce and excrete resins and

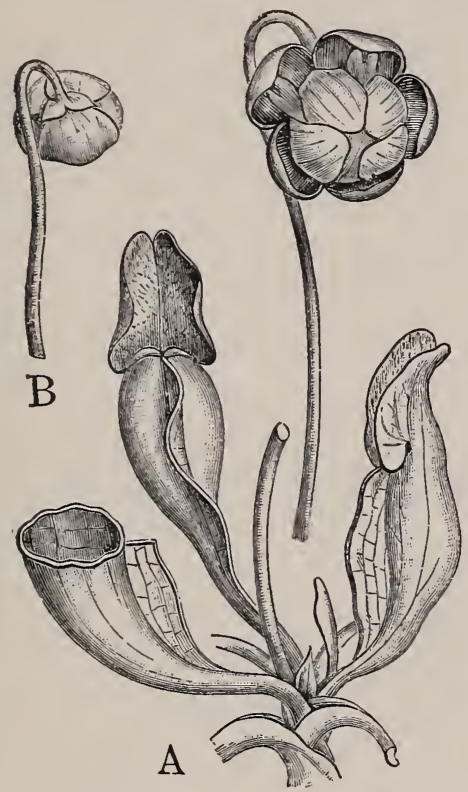

Fig. ror.-Pitcher-plant (Sarracenix purpuren). Leaf above $A$ cut off to show trumpet form One-third natural size - After Gray.

similar materials which make the parts so covered waterproof. The inner scales of buds (fig. 60) are often covered with an abundant coating of woolly hairs, which serve to prevent rapid change of temperature in the interior of the bud.

134. (4) Flower leaves and bracts.-On certain parts of the stem, leaves are commonly profoundly modified to carry the spore cases (c, st, fig. 66). (See p. I96.) Close below these are others which may be highly colored and adapted 
in form to protect the inner ones, and to facilitate the visits of insects ( $s$, p , fig. 66). A shoot whose leaves are thus clustered and specialized constitutes a "flower." The leaves adjacent to the flower leaves are also more or less modified in form and reduced in size. They are called bracts ( $h$ 1, 2, 3, fig. 90).

135. (5) Storage leaves. - Other leaves are utilized for purposes of storage. For this purpose the ribs are reduced in number and size, while the softer tissues of the leaf are often

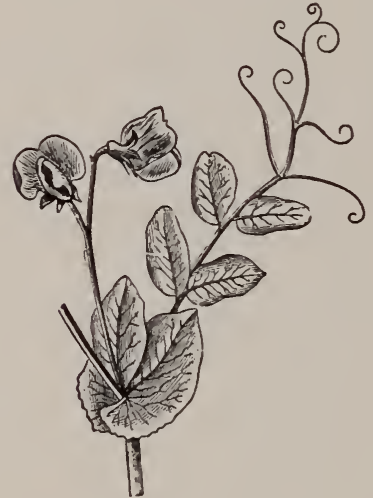

Fig. I02.

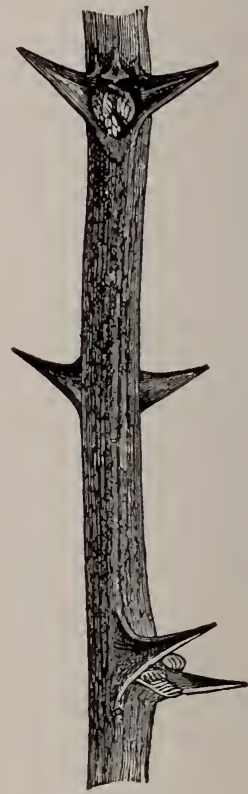

Fig. 103.

F1G. 102.-Portion of shoot of pea, with a pinnately compound leaf whose upper leaflets are modified into tendrils and the stipules greatly developed to serve as toliage About half natural size.-After Frank.

Fif. ro3.- Piece of the stem of locust (Robinia Psendacacia), showing stipules in the form of thorns. Natural size.-After Kerner.

enormously developed, and serve as the receptacles of the reserve food. The primary leaves of the seed plants (cotyledons) are often much distorted by the deposit in them of reserve food for the embryo. When such leaves possess sheathing bases the structure resulting from the union of a number of such leaves upon a short axis is called a bulb. 
(See also 93.) The leaves of buds are sometimes thickened by the deposit of food material, and when such buds loosen from the plant they may produce a new plant, as in the tiger-lily (see - 299). Both base and blade may be used for storage, as in the century-plant; or the entire leaf may serve the same purpose, as in the cultivated cabbage.

136. Structure.-Three regions in each part may be distinguished, as in the root and stem : (I) the epidermis ; (2) the cortex ; both continuous with that of the stem; (3) the steles, continuous with those of the stem when the latter contains several steles, or branches of it when the stem contains a single stele.

The structure of the petiole agrees in all essentials with that of the stem (see I07, ff.). The following is a brief summary of the structure of the blade of a foliage leaf.

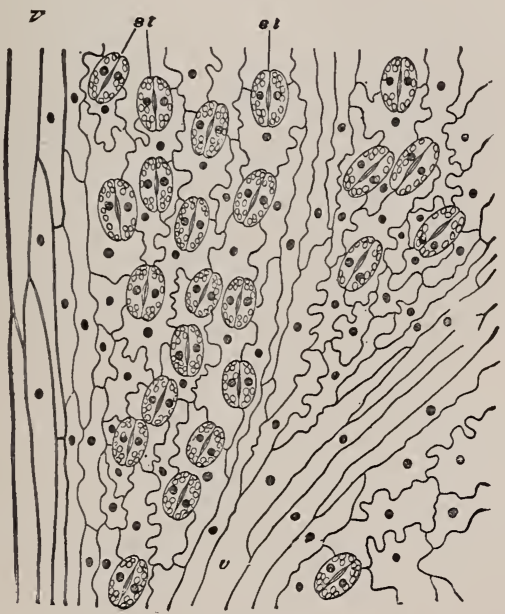

FIG. I04-Surface view of epidermis from under side of leaf of bracken fern (Pteris), showing wavy cells, except over veins, $v$, where they are elongated. st, stomata. The dot in each cell represents the nucleus. Highly magnified.-After Sedgwick and Wilson.

137. Epidermis.-In broad leaves, the epidermis of the blade is made up of tabular cells, often with wavy lateral walls (fig. I04), and, except in shade plants, usually without green color. It usually consists of one layer, but in some plants becomes several-layered, either to serve as ad- 
ditional protection against evaporation or for use as a water-storing tissue. (See 9 342.) Numerous narrow slits, each bounded by a pair of specialized cells called guard cells, are formed in the epidermis. The whole apparatus is called a stoma (figs. 104, 105). The guard cells are crescent-shaped, and are sensitive to various external conditions, especially light, so as to control the size of the slit-like passage between them by becoming straighter or more curved (fig. 105). This passage
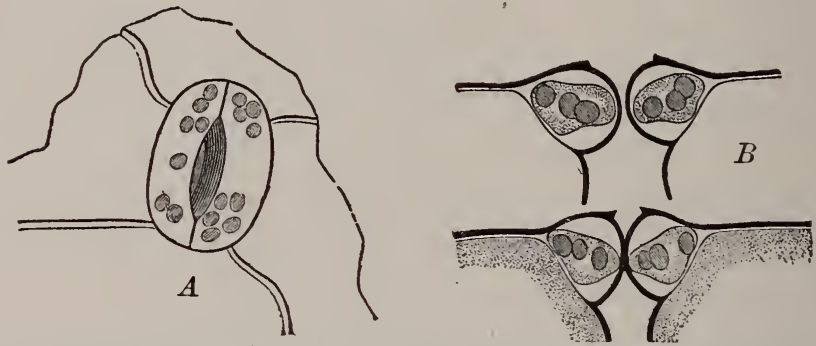

FIg. 105. $-A$, perspective view of a stoma from the under epidermis of the beet leaf, showing the sloping sides of the slit, the crescentic guard cells with chloroplasts. $B$, sections through stomata of beet at right angles to their length. The upper figure shows the stoma open: the lower closed. The black line represents the primary wall, to which additional material, especially in the guard cells, has been added. These thickenings serve by their elasticity to close the stoma. Opening is due to turgor of the guard celis. The chloroplasts and granular protoplasm are shown. Highly mag. nified.-After Frank.

is formed by the partial splitting apart of the guard cells and communicates with extensive spaces between the green cells in the interior.

The stomata are very numerous. In different plants, in the space here enclosed, 30,000 , someto 70,000 in

I sq. $\mathrm{cm}$. the numbers usually vary from 4000 to times, however, reaching as many as 60,000 the olive and rape. They are not equally distributed on the two sides of the leaf, being usually more numerous on the under side, where there are more internal spaces. They may be wanting on the upper side, as in lilac, begonias, and oleander. There are no stomata on submerged leaves nor on the under side of floating leaves. In some plants they are found in clusters, in others uniformly distributed.

138. Cortex.-The cortex of leaves is called the mesophyll. It consists of thin-walled, active cells, for the most part richly supplied with chloroplasts. In very thick leaves the internal cells are colorless. In some leaves the cells of the mesophyll are nearly uniform, but in most 
those near the upper surface are more elongated and close set, forming one or two rows, with their ends outward, while cells near the lower surface are irregular in form, with large intercellular spaces (fig. 106).

The cortex ( $s s$, fig. 106) often develops along the larger steles into one or two strands or a sheath of mechanical tissues. These tissues, to-

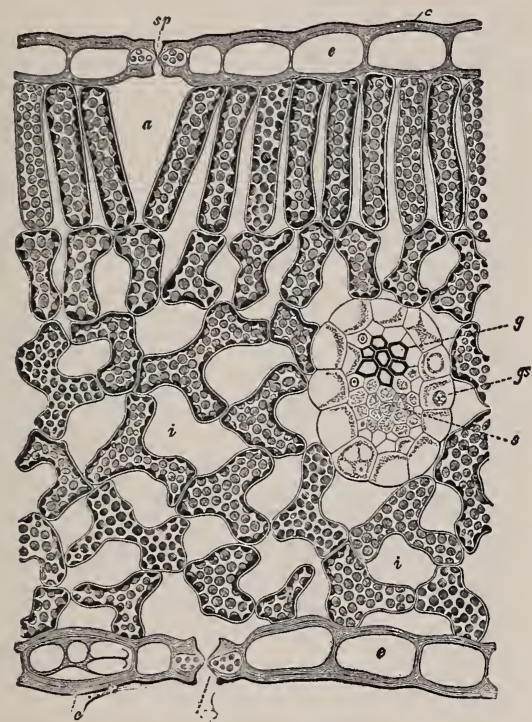

FIG. ro6.-Diagrammatic vertical section of a leaf. $e, e$, epidermis, with cuticle $c, c$, and stomata, sh, st. Between upper and lower epidermis lies the mesophyll, with cells abundantly suptlied with chloroplasts. The upper row of elongated cells is the palisade parenchyma; the rest form the spongy parenchyma, both with many intercellular spaces $a, i, i$, communicating with outside air through stomata. In the mesophyil lies a small vein, here cut across, composed of a ventral wood bundle $g$, a dorsal bast bundle $s$, surrounded by the endodermis $g s$, and the pericycle (between $g$ and $g s$ ). After Sachs.

gether with a stele, constitute the rib or vein, often so massive as to project beyond the other parts in thin leaves.

139. Steles. - The steles are numerous and ramify through the blade. Their structure is essentially as described for the stem ( $\$$ 107). Each of the smaller consists of little more than a single pair of vascular strands. The wood strands alone form the last branches (fig. I07), the bast disappearing earlier. The larger ribs may be accompanied by one or two strands or a complete sheath of mechanical tissues, and the vascular 
strands may be increased by the development of secondary wood and bast. (See I I I 4.)

The growth of the leaves is ordinarily limited, rarely extending over a single season. In a few ferns and coniferous plants the leaves live for two to eight years, and some continue to grow for a longer time than one season.

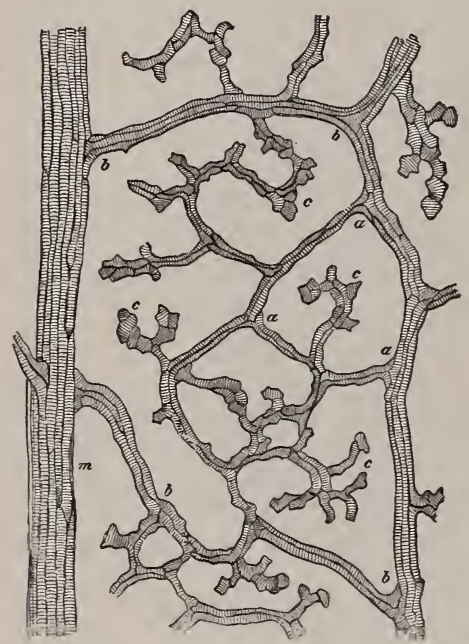

Fig. 107.

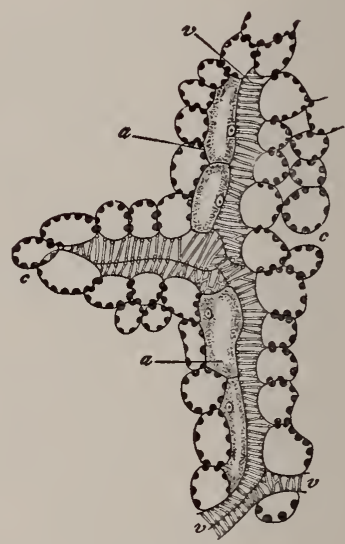

Fig. 108.

Fig. 107.-A few meshes of the finest veins of a leaf of Anthyllis. $m$, main vein $; b, b$, branches; $a, a, a$, a closed mesh; $c$, ends of the finest veins within the mesh. The drawing shows only the wood bundles; the bast bundles accompanying them and the mesophyll cells filling the meshes are not shown. Moderately magnified.-After Sachs.

Fir, 108.-Ending of a vein in the mesophyll of a leaf. $v, v, v$, the spirally thickened cells of the wood; $c, c$, mesophyll cells with chloroplasts; $a$, $a$, cells specialized to transfer water from wood to mesophyll. Magnified 230 diam.-After Frank.

140. Wintering.-In those plants which live from year to year, producing new leaves each spring, the unfolding of these from the winter buds is due chiefly to the enlargement of the rudimentary leaves already formed. New leaves are ordinarily produced before the close of the growing season preceding that in which they are expanded, and are protected in the winter buds. The partly developed leaves in the bud 
may be flat, but broad leaves are commonly folded or rolled in various ways.

141. Production of the other members.-Leaves give rise under certain conditions to roots or to shoots. The number of plants, however, in which this occurs is comparatively limited. Roots arise from leaves in precisely the same way as lateral roots arise from stems $(\$ 84)$, that is, they are internal in their origin, and begin to develop always near the surface of a stele.

When a leaf produces a shoot, it is from the epidermis or from the green tissue underlying it, never from a stele. Shoots thus arise from the part of the leaf corresponding to that from which branches arise upon the parent shoot.

142. Leaf fall.-Leaves, like roots and stems, undergo certain secondary changes, but these are neither so common nor so extensive as in the other two members. One of the secondary changes of most importance is the preparation for the fall of the leaf. This is made by the formation of a transverse plate of cells, some of which may become transformed into cork, making a line of weakness; or, without such alteration, the cells may round themselves off by loosening along a definite line, so that the leaf is held only by the steles. The access of water to this crevice, and its freezing, serve to rupture the remaining tissues, and thus allow the leaf to fall by its own weight, or to be torn off by the wind.

The scar left by the fall of the leaf is protected either by the cork already produced, or by mere drying of the exposed tissues. The leaflets of compound leaves fall in like manner. Sometimes provision for the leaf fall is begun as early as June, as in the Kentucky coffee-tree. In other plants provision for leaf fall is begun late in the season, and in some, such as the oaks, it is very imperfect, so that the leaves are 
finally wrenched off by winter storms, or pushed off in the spring by the developing buds beneath them.

\section{EXERCISE XIX.}

Leaves.-Examine the forms, branching, and venation of such leaves as can be secured. Unfolding buds show modes in which leaves are folded or rolled. Special directions for study seem unnecessary. A demonstration of the structure of a lily or lilac leaf ( 1 136-139) is desirable. (For flower leaves see p. 210.)

143. Summary.-The form, structure, and position of foliage leaves are chiefly dependent upon the amount and direction of light. The first leaf or leaves of the embryo are usually transient; even secondary leaves rarely live more than a single season. They arise in regular succession on the stem and at such points as are least crowded. The parts of a leaf are blade, base, and stalk; any one or two may be wanting. The base is often sheathing or branched to form stipules. The stalk may be winged to act as a blade. The blade is in one piece or more or less branched into lobes or into leaflets. The veins, containing vascular strands, supply all parts with water, and when strong prevent tearing. The leaf rudiment, instead of developing into a foliage leaf, may form a pitcher, a tendril, a thorn, a scale, a flower leaf, a storage place, etc. The internal spaces of the leaf connect with the air through stomata, which are guarded by a pair of valve-like cells. These by changing form can regulate the evaporation of water from the leaf, and also permit ready entrance of air. Leaves often live over winter in a rudimentary condition in the bud. They fall usually because of the formation of a separation layer of cells across the leaf base. 


\title{
PART II. PHYSIOLOGY.
}

\author{
CHAPTER XII.
}

\section{INTRODUCTION.}

144. Division of labor.-The study of the external form and internal structure of plants may be carried on as well upon dead as upon living material. Even the observation of the course of development requires only the examination of the plant as it exists at a particular moment. But the plant may also be studied as a working organism. For this purpose living material is indispensable. The work that plants do, by which they are distinguished from non-living bodies, is extremely varied, and the more complex the plant the more varied it is. In the preceding part the aim has been to show that there exists great variety of form, and that from the smaller to the larger plants there is gradually increasing complexity by differentiation into tissues and members.

Nutrition, respiration, growth, movement, and reproduction are all executed by the single cell of the simplest plant. But with specialization in structure there occurs division of labor. Each kind of physiological work is known as a function, and each part of the organism which does a particular work is called an organ.

145. Physiology and ecology.-Physiology proper treats of the plant at work, discussing the different functions and the way in which these are affected by external forces, such as light, heat, etc. In its broadest sense it also treats of the 
relation of the plant as a whole to external forces and to other living beings, both plants and animals. But it is convenient to separate the latter from physiology proper as ecology.* (See Part IV.)

The study of physiology proper requires methods of controlling these external forces, carefully planned and repeated experiments, and cautious inferences.

The study of ecology requires observation, in the field, of the physical surroundings of plants, of their relation to their neighbors, and of their adaptations to prevent injury by unfavorable physical conditions and the attacks of other beings, and to take advantage of the favorable forces and beneficent agents.

146. Chemical and physical forces.-The functions of a plant may be divided for the sake of convenience into nutrition, respiration, growth, movement, and reproduction. These are largely special modes of chemical and physical action. Nutrition and respiration, for example, consist chiefly of a series of chemical changes; while movement is mainly a result of physical alterations in certain organs. But the action of chemical and physical forces does not suffice at present to explain all the activities of the living plant. Noreover, the peculiar manifestation of these forces which we call life occurs only in connection with the substance which we call protoplasm.

147. The powers of protoplasm.-Although only a portion of any plant is composed of living matter, it is to that living matter only that we are to look for the seat of its powers.

The fundamental powers of protoplasm are four; it is metabolic, irritable, contractile, and reproductive.

148. Metabolism.-Protoplasm is metabolic, that is, it is capable of initiating chemical changes in itself and in sub-

* Spelled in lexicons, œcology, but best usage drops the $o$; sometimes improperly called biology or plant biology. 
stances which come directly under its influence. These changes are of two kinds. They may be constructive, i.e., they may build up complex substances out of simpler ones, and so fit them for use in repairing the waste caused by the activity of the protoplasm; or they may be destructive, i.e., they may break down complex substances into simpler, so setting free the energy necessary for the work of the protoplasm. The substances broken down may be repaired in whole or in part, i.e., may take part in constructive metabolism. Those in which no repair occurs often undergo further destructive changes by which they become converted into materials useless to the plant, and to be gotten rid of. Metabolism, therefore, includes all the chemical changes by which food is either manufactured or utilized, and by which waste materials are produced and eliminated.

149. Irritability.-Protoplasm is irritable, that is, it exists in such a state that it is sensitive to external influences, which thereby affect the various functions of the whole plant. By reason of its irritability, it may even transmit the effects of an external stimulus from one part to a distant part. Moreover, it is capable of initiating similar changes without the action of any observable external influences, and is, therefore, not only irritable but automatic.

150. Contractility.-Protoplasm is contractile, that is, it has the power of altering its form, of shortening in one direction and elongating in another, by virtue of inherent forces whose action is not understood.

151. Reproduction.-Protoplasm is reproductive, that is, it is capable of so directing the chemical and physical forces inherent in it that a new organism similar to that of which it forms part may be produced.

152. Adaptation.-The interrelation of these powers, their harmonious co-working and their variation to suit the varying conditions of the surrounding media (air, water, 
soil, etc.), result in the proper performance of all the functions of the plant. By means of these powers it is brought into relation to the world about it, being adapted to other organisms in whose company it lives, and enabled to withstand the adverse conditions by which it is frequently threatened. Every organism, indeed, must adjust itself first to the external physical conditions, and, second, to other organisms. (See Part IV.)

153. Physical conditions set limits upon the discharge of its functions. Varying amounts of light, of heat, of moisture, determine more or less rigidly how rapidly, or to what extent, each function may be discharged. Every function of the plant is adapted, therefore, to an upper limit, the maximum, and to a lower limit, the minimum, above or below which the performance of the function in question is impossible. Between these limits there lies some point at which it proceeds most rapidly and effectively. This point is known as the optimum.

154. Summary.-Increasing size and complexity permits an advantageous division of labor among different organs. Physiology treats of the work of the plant as a whole; ecology of its adaptations to external conditions and to other organisms. All plant work depends on the living protoplasm. Its power of initiating and carrying on chemical changes in itself and other substances provides for nutrition; its power of receiving impressions from the world about enables it to regulate all its work and adapt itself to its surroundings; its power of contractility enables it to move; and its power of making and separating special parts of its own substance secures a succession of like plants. All work is limited by the physical conditions which surround the plant, and may bring any or all of them to a standstill, because the plant can only adjust itself to them within narrow limits. 


\section{CHAPTER XIII.}

\section{THE MAINTENANCE OF BODILY FORM.}

Every plant is capable of attaining and maintaining a specific form, which is not permanently altered by the direct action of external forces, and is dependent upon the nature of the plant itself.

155. Naked cells. - If the plant consists of a single mass of naked protoplasm, it may assume a spherical or ovoid shape (fig. 109). In attaining this form the physical forces
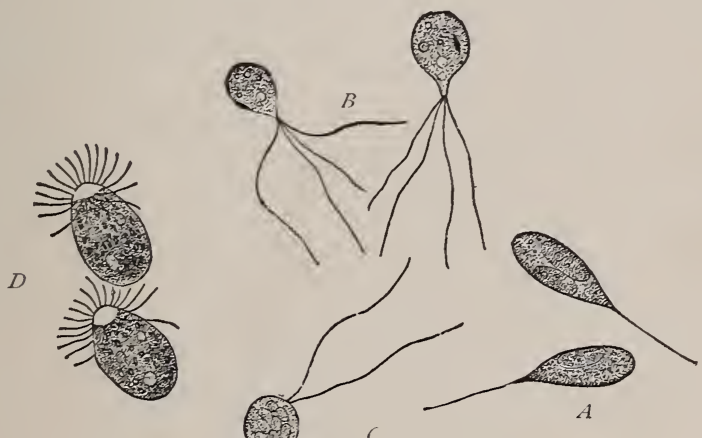

Fig. rog.-Zoospores (naked pro.oplasm) of various kinds, swimming in water by means of one or more cilia. A, Botrydium: $B$, Draparnaldia: $C$, Coleochate: $D$, $\mathscr{E}$ dogonium. Highly magnified.-After Kerner.

play a part, but the form is determined chiefly by unknown internal forces peculiar to living protoplasm. This is particularly well shown when such organisms extend delicate protoplasmic threads, the cilia (fig. I09), and maintain these 
in active motion, or when they extend a large portion of the body for creeping (fig. IIO). The extension of such organs, whether slender or thick, is directly opposed by strong physical forces acting at the surface which tend to contract the body into a sphere, as they do a drop of liquid.
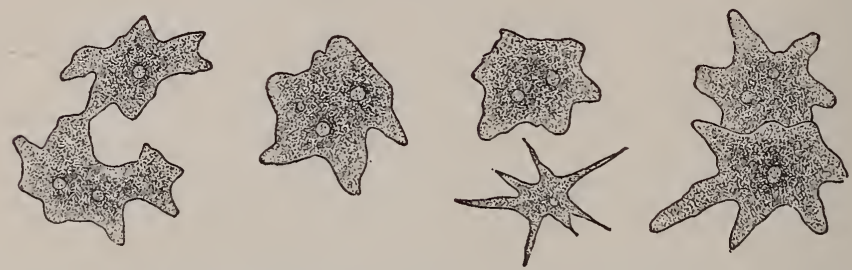

FIG. Iro.-Plasmodia, creeping bits of naked protoplasm, showing varied shapes as parts are protruded or withdrawn. Highly magnified. - After Kerner.

156. Turgor.-If the organism be one surrounded by a cell-wall, or if it be made up of a number of cells united, the cell-wall itself plays a considerable part in maintaining the form. This is due to the condition of the cell known as turgor. When fully mature the cell-wall of each active cell is lined by a more or less thick layer of living protoplasm. In the interior of the protoplasm there exist one or more water chambers, the racuoles ( 4 , and fig. I I 7 ). If such a cell as this be measured in its normal condition, and then surrounded for a few moments by a ro per cent. solution of common salt, re-examination will show that the racuoles have been diminished and the protoplasm shrunken away from the wall; remeasurement will show that the cell has diminished both in length and diameter. In its normal condition, therefore, the wall was stretched by the pressure of the contents within. If a cell which has been thus shrunken by immersion in a solution of salt be again placed in water, it may regain, in the course of a few hours, sts original condition, that is, it may again become turgid. This would be brought about by the entrance of water into the vacuoles to 
replace that withdrawn when the cell was placed in the solution of salt.

If a thin piece of rubber tubing be connected with a pump and filled with water until it is stretched, it increases its diameter and length slightly, and gains, at the same time, a condition of rigidity greater than in its unstretched condition. In a similar way turgid cells are more rigid than those which are flaccid. The union of turgid cells produces a member more rigid than one in which the cells are not turgid. An illustration of this is to be seen in the condition of a wilted, as compared with a fresh, leaf. The turgor of thin-walled cells may play an important part in maintaining the form and position of the parts of a plant.

\section{EXERCISE XX.}

Demonstration. To show the existence of turgor in the individual cell. Mount a bit of Spirogyra under microscope; observe position of chlorophyll bands. Irrigate with 5 per cent. solution of salt and note effect.

(If Spirogyra is not at hand use hairs on stamens of Tradescantia ; or the epidermis, filled with purple cell sap, from the under side of the leaves of the variegated Tradescantia ("wandering Jew"); or the hairs of geranium leaves.)

To show effect of turgor of cells on rigidity of young parts containing no mechanical tissues.

Remove carefully a young plant with vigorous primary root grown in sawdust or moss. Lay in water for a few minutes. Note rigidity. Transfer to 5 per cent. salt. solution for a few minutes. Has rigidity increased or diminished? Remove to water again for $15 \mathrm{~min}$. What is the result?

15\%. Tissue tensions.-But turgor can affect only those cells whose walls are thin and extensible. Those whose walls have become thick and rigid are not stretched by this force. In the larger plants, however, where both thickwalled and thin-walled tissues exist, it is possible that a mass 
of thin-walled cells may, by the united tension of its component cells, stretch those tissues which are not themselves turgid. Such strains in the younger regions, particularly, play an important rôle in maintaining the form of these parts. But the tensions in the older parts are generally due to the unequal growth of different tissues. (See $T 2$ I 8 .)

158. Mechanical rigidity.-The rigidity of the cell-wall itself must be relied upon by all the larger plants. Certain tissues are specialized by having their cell-walls greatly thickened, and such tissue regions constitute a sort of framework or skeleton, which is filled out by the more delicate parts. These mechanical tissues are so distributed within the body as to afford frequently the maximum resistance to bending and breaking strains.

In the accompanying diagrams the position of the mechanical tissues is indicated in transverse sections of a number of different stems (fig. III). It will be seen that they illustrate well-known mechanical principles in
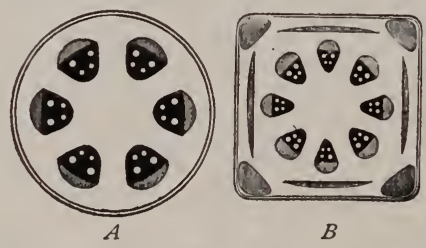

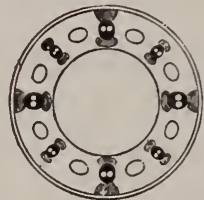

C

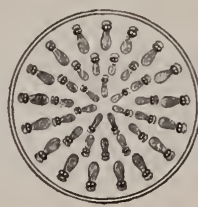

$D$

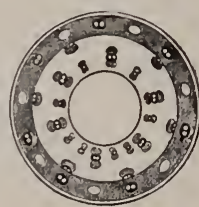

E

FIG. III.-Diagrams showing the arrangement of mechanical tissues and vascular strands in the cross-section of various stems. The mechanical tissue is gray; the vascular strands black, with white dots. $A$, linden (young); $B$, a mint; $C$, a sedge; $D$, a bamboo; $E$, a grass.-After Kerner.

their distribution. The hollow column $(E)$ and the I-beam $(A, B, C)$, two of the most rigid mechanical constructions, are frequently imitated in plants. 
In stems of trees rigidity is secured not by the distribution of the mechanical tissues, but by their massiveness. In them the chief mechanical tissues belong to the wood, which forms a solid column occupying the center of the body. Aquatic plants, which are supported by the medium in which they live, are usually without mechanical tissues.

159. Summary.-Bodily form is maintained by naked protoplasm chiefly by unknown forces inherent in the living substance. In larger plants it is maintained partly by turgor, which develops opposing strains in masses of cells, and partly by the mechanical stiffness of the cell-walls formed by the protoplasm. These rigid parts are either massed or definitely placed in the plant body, so as to carry its weight and meet the strains due to winds, water-currents, etc. 


\section{CHAPTER XIV.}

\section{NUTRITION.}

160. Repair and growth.- Since the body of every plant is constantly wasting away by reason of its own activity, it is necessary that it should be as constantly repaired. It must also, for a considerable time or throughout its whole life, be furnished with material which can be used in the making of new parts. Without an adequate supply of food, therefore, neither repair nor growth is possible. To understand what materials are necessary for repairing waste and forming new parts of the living plant, the constituents of a plant may be determined by chemical analysis.

161. Chemical composition.-The greater portion of the weight of every plant is found to be water. Of the firmer parts it forms as much as 50 per cent, while of the sufter parts it may form 75 or even 90 per cent. The most watery portions of some plant bodies, such as the juicy portions of fruits and the whole body of the algæ, may contain only 2 to 5 per cent. of solid matter.

If the solid matter left after driving off the water at a temperature of $110^{\circ} \mathrm{C}$. is burned, there remains a white material which crumbles under pressure, the ash. The dry matter consists chiefly of three elements, carbon, hydrogen, and nitrogen. The most abundant element in addition to these is nitrogen. When the dry substance is burned these four elements are driven off in gaseous form. An anaiysis of the ash reveals the presence of sulfur and phosphorus in considerable a mounts, and also smaller quantities of the following elements: calcium, magne- 
sium, potassium, iron, sodium, chlorine, and silicon. Of these seven, the first four are found in the ash of all plants, and the remaining three are very common. In addition to the elements enumerated, about 25 others are known to occur in the ash of plants, but only in minute quantities.

\section{A. The water in the plant.}

162. Necessity.-Since water forms such a large percentage of the weight of fresh plants, it is manifest that it must be supplied in relatively large quantities, if the plant is to continue in an active condition. A portion of this water may be used up in the chemical changes occurring in the body, but it is not possible to discriminate between this and the water which is necessary to furnish the proper physical conditions of life. Water is the great solvent in which materials of various kinds enter the plant body, and by which a still greater variety within it are transported from place to place. Before discussing the food of plants, therefore, the relation of water to the plant may be examined.

163. Air, water, and land plants.-Some plants are not in contact with water except at irregular intervals. These are called air plants, and include some algæ, liverworts, mosses, fernworts, and seed plants. All these, however, are able to live only in an atmosphere containing large quantities of water vapor, or in those regions where they are frequently sprayed with water. Water plants float upon the water, or are submerged in it. As distinguished from both air and water plants, are those which have the root system (and sometimes a portion of the stem buried in the soil) continually or intermittently in contact with liquid water, while the shoot system is occasionally sprayed by rain. Such may be called land plants.

164. Solutions in water.-In no case, however, is the water in which plants are immersed, or with which they are sprayed, pure water. It always holds in solution substances 
derived from the atmosphere or from the soil with which it has come in contact. These substances, whether organic or inorganic, enter the plant, together with the water, through those organs which are adapted to absorption.

165. Absorption of water.-In air plants of the simpler sorts, any parts exposed to the moist air or rain can absorb water. In liverworts and mosses the thallus or the leaves are active absorbents. In the higher plants, such as the aerial orchids, the external cortex of the roots is especially adapted to absorb liquid water, or to condense the water vapor of the atmosphere.* In water plants the surfaces which are normally in contact with the water are absorbing surfaces. Such plants may be either wholly without a root system, or it may be only sufficiently developed to anchor them in the mud. In land plants the root system is especially adapted to the absorption of water. Only minute quantities of water are absorbed by the leaves and other aerial parts. The root system of the land plants is developed in contact with the soil.

\section{EXERCISE XXJ}

To show that water is not absorbed by leaves in quantity adequate to supply evaporation.

Cut off a vigorous shoot of a plant with abundant foliage; close end of stem with grafting wax; expose to sunlight until well wilted; then immerse it in water. Does the plant recover its turgidity slowly or rapidly?

166. Soil.-The soil consists primarily of finely divided particles of rock, whose nature and size determine the qualities by which soils are ordinarily distinguished into gravelly, sandy, loamy, clayey, etc. Mixed with these rock particles is more or less material derived from the offal of plants or animals. When decaying plant offal predominates, the soil is known as vegetable mold or humus, which naturally forms

* If such condensation really occurs (as is generally alleged), it does not suffice to keep the plants supplied with the required amount of water. 
the upper layer of the soil of forests. 'To garden or field soils, not naturally rich in organic matter, this is frequently supplied artificially by adding manures and artificial fertilizers.

167. Soil water.-No matter how fine the soil may be, the rock particles are not in close contact, but, on account of their angular outline, leave spaces of greater or less size to be occupied by other materials. If a soil be examined immediately after a heavy rain-fall, these spaces

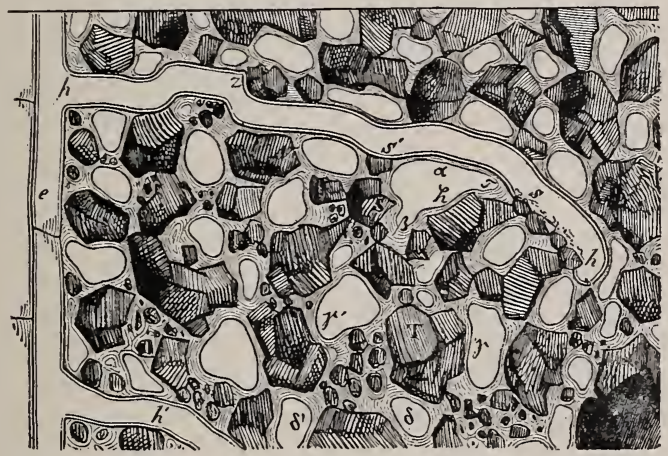

FIG. I12. - Diagram of a portion of soil penetrated by root hairs, $h, h^{\prime}$, arising from root, $e$. At $z, s, s^{\prime}$ the hair has grown into contact with some of the soil particles, $T$, which are surrounded by water films ishaded by concentric lines), $\beta, a, \tau$. The white spaces are air-bubbles, $\delta, \delta^{\prime}, \gamma, \gamma^{\prime}$. When water enters the hair at $\alpha$, the thichness of the film $a, \beta, \tau$ will be diminished, and some water sill flow towards this point, reducing all the other water films in the vicinity. More air enters from above When rain falls, the reverse process occurs; the films thicken, and the air may be entirely driven out, to return as the surplus water drains away.-After Sachs.

will be found completely occupied by rain-water. If the soil be so situated as to be naturally drained, considerable quantities of this water will disappear gradually, and the larger spaces between the soil particles will be occupied partly by films of water adherent to the soil grains, and partly by bubbles of air (fig. I I 2).

168. Salts dissolved.-The water which thus filters through the soil dissolves and retains certain of its constituents. As the rain passes through the atmosphere it also dissolves cer- 
tain substances found therein, notably minute quantities of compounds containing nitrogen, which are useful to the plants for food making.

169. Root absorption.-The structure of the root system has been explained $(72-76)$. The root hairs come into close contact with the soil particles, pushing them aside somewhat, and being in turn more or less deformed by their resistance $(z, s$, fig. II 2$)$. So close does the contact of the root hairs and soil grains become that many particles of the soil are embedded in the walls of the root hairs (fig. $5 \mathrm{I}$ ). The root hairs are not only in contact with the soil particles, but also with the films of water, which occupy the spaces between them ( $\alpha$, fig. II 2 ). They are thus in a position for absorbing water from the adjacent films.

\section{EXERCISE XXII.}

To show the location of root hairs and especially their adhesion to soil particles.

Germinate wheat in sand and when seedlings have several strong roots dig up carefully; shake sharply in water; note where soil clings most tenaciously. Brush away most of this with camelhair brush and examine a bit of this part of root under a low power of microscope. Observe distortion of root hairs, and particles of sand partly embedded in them.

170. Limit of absorption.-Not only is the water immediately in contact with the root a source of supply, but even that in the deep and more distant parts of the soil. For when, by the entrance of some water into the root hair, the thickness of that layer has been decreased, the disturbance of equilibrium causes a flow from neighboring layers; and this goes on until the films of water upon the soil grains become so thin that the water particles are held too tenaciously to be pulled away by the root. There remains in such exhausted soil, which seems dry as dust to the touch, 2 to $\mathrm{r} 2$ per cent. of water unavailable for the plant. 
171. Solvent action.-The root hairs also exert a slightly solvent action upon the soil particles themselves by reason of the carbonic acid and the acid salts which they excrete. By this means various minerals, which could not be dissolved by the water alone, may be brought into solution.

\section{EXERCISE XXIII.}

To show excretion of acid salts by roots.

Fill a wide-mouthed bottle holding $250 \mathrm{cc}$. with tap water; add 2-3 drops of ammonia and several drops of phenolphthalein.* If the water does not now remain pink add a drop or two more of ammonia. Select a vigorous seedling bean grown in sawdust; rinse roots well to remove impurities.

Cut in two a cork which fits the bottle; in the halves cut two corresponding notches of such size that with a little cotton for packing the plant will be firmly held. Place the plant with enough cotton to secure it in the cut cork and set in bottle with roots immersed.

As the plant grows from day to day watch for the disappearance of color in the solution, which will indicate when the alkaline fluid has become acid. Arrange a control experiment in exactly the same way, but without plant. Surround each bottle with opaque shade of heavy paper, to avoid effect of light on the roots and fluid.

To show the corrosion of carbonate of lime by the carbonic acid excreted by the roots.

Cover a polished marble slab to a depth of $5 \mathrm{~cm}$. with clean sand, in which plant corn or beans. After the plants are $10-15 \mathrm{~cm}$. high, remove sand carefully and rinse off the marble. Examine the surface by reflected light. A little graphite rubbed into lines etched by roots will make them more readily visible.

\section{Movement of water within the plant.-Once the} water has gained entrance to the plant, it must move to those parts where it is to be used-i.e., to all the organs of the plant, but especially to the leaves, since from these there is

* An indicator for acids, colorless when a fluid in which it is dissolved is acid, rose pink or darker when alkaline. For use the crystallized phenolphthalein is dissolved in alcohol. 
the largest loss of water by evaporation ( $\Upsilon \mathrm{r} 77)$. From the root hairs the water passes inward through the cortex, and reaches the stele. The forces which determine this movement and its direction are not fully understood. They are comprehended under the general phrase root pressure.

173. Root pressure.-The action of root pressure may be demonstrated by severing a suitable stem close to the ground

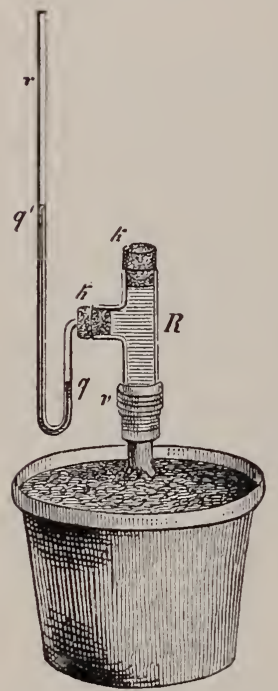

Fig. I13. - Apparatus for measuring root pressure. For explanation see Ex. ercise XXIV. p. 131.After Sachs. and observing that water flows out, after a short time, from the cut end. Careful examination of the cut surface shows that the water is forced out chiefly from the woody parts of the stele, and this continues for a considerable time. The force with which water is extruded may be measured by attaching to the stump, by means of a rubber tube, a pressure gage (fig. I I3). In this way it may be ascertained that in woody plants, such as the birch, the pressure sometimes becomes great enough to sustain a column of mercury about two meters high (2.5 atmospheres).

\section{EXERCISE XXIV.}

Demonstration. To show root pressure as a factor in the movement of water in plants.

Cut off the stem of an actively growing plant (plants of castor bean and tomato $25-30 \mathrm{~cm}$. high are especially recommended) a short distance above the soil and fasten tightly to the stump, by means of rubber tubing, a piece of glass tubing a meter long, and about the diameter of the stump. Wrap joint with tire or electric tape to prevent stretching of rubber and leakage. Add enough water to rise Io $\mathrm{cm}$. above the rubber connection. Keep roots well watered and mark the height of the water in tube from time to time until it reaches the top or begins to fall. Does the water rise from the first? 
A more satisfactory record may be reached by attaching to the stump a T-tube as shown in fig. Ir3. To the horizontal arm attach a mercury pressure gage. (A pressure gage may be readily constructed by bending a glass tube, about $5 \mathrm{~mm}$. diameter $(3 \mathrm{~mm}$. bore) and $80 \mathrm{~cm}$. long, upon itself $30 \mathrm{~cm}$. from one end, so that it forms a $U$ with unequal legs $3-4 \mathrm{~cm}$. apart. Bend $5 \mathrm{~cm}$. of the end of the short leg at right angles, in the plane of the $U$. Tie the legs to a piece of cork between the legs near top, so that the tube will not be easily broken by the leverage of the legs on the bottom bend.) Fill the space between stump and mercury with water. In the third arm insert a short tube drawn out to a slender point to permit the escape of air and extra water. Seal this with a flame after filling. There must be at least $15 \mathrm{~cm}$. of mercury in U-portion of manometer. At beginning mark, with a bit of gummed paper, height of mereury in each leg; measure difference at intervals thereafter until mercury begins to fall.

\section{Route to the leaves.-After entering and traversing} the wood strands of the roots, the water is thence transferred along the stem in the same tissues, which are continuous with those of the root. Since the wood strands form an unbroken line to the most remote parts of the leaves, passing out in the ribs and forming the finer veins, the water may be distributed to every part of the plant body.

Within the wood it travels chiefly in the cavities of the large ducts or vessels, when these are present, though the walls, also, are saturated with it, and permit a slower movement. These ducts, although of great relative length (some up to $\mathrm{I} \mathrm{m}$.), are not continuous tubes like the veins of an animal, nor are they always filled with water. The water is often broken into short columns by numerous gas-bubbles, and in ascending to any considerable height must traverse many cell-walls.

\section{EXERCISE XXV.}

To show roughly the path of evaporation stream in woody plants.

$A$. From a leafy shoot of a woody plant remove a ring of bark $5 \mathrm{~mm}$. wide. With grafting wax protect the exposed surface against drying. Ohserve whether the leaves wilt or not, and if they wilt, the time required.

$B$. With a knife or fine saw cut a little over half through the stem of a plant of the same sort used in $A$; $\mathbf{~ c m}$. above this cut make a similar one 
on the opposite side. The two must be so placed and at such a depth that all the tissues are severed. Support the branch or stiffen it against breaking by bandaging it with strips of wood. Make same observations as in $A$. Examine the pith. Is it alive? Does it contain water? In what tissues, therefore, do you infer water travels to leaves?

To show restoration and maintenance of an interrupted evaporation stream.

Fit a well wilted shoot into the short arm of an unequal U-tube filled with water to the level of the short end. Allow it to stand for half an hour. Does the shoot recover? If not, pour mercury into the longer arm until it stands $10 \mathrm{~cm}$. above its level in the short arm. Does the shoot now recover turgor? Why? Allow it to stand for some days. Does the level of the mercury change?

175. Motive power.-The force by which water is raised in the larger plants remains yet to be ascertained. The water does not flow along the ducts in a continuous current, as the blood in the veins, propelled by a force behind, for root pressure is not adequate to push it to the height attained. On the contrary, during the times of most active evaporation from the leaves, i.e., when the greatest supply is needed, root pressure becomes almost or quite negative. Capillarity is also inadequate. The diameter of the largest ducts is too small and the resistance to the flow consequently too great to permit the movement, by this means, of a sufficient amount of water to supply the evaporation. The most recent researches point to the evaporation of water from the leaves as a very important or even the chief factor in lifting the water. That the movement is not the work of living cells is shown by ex periments in which stems of plants have been subjected to poisonous agents, or heated for many hours to a degree suf. ficient to kill all the living cells, yet without materially affect ing the supply o water to the leaves.

\section{EXERCISE XXVI.}

\section{To show the lifting power of evaporation.}

Cut off under water a shoot from a thrifty plant ; fasten it air-tight in the end of a piece of glass tubing $30 \mathrm{~cm}$. long, or appropriate diameter, 
by means of a piece of rubber tubing slipped over the end of the stem, taking care not to expose the cut end to air. Fill glass tube with water before fitting in plant; erect the whole with lower end of tube dipping in a cup of mercury. Set in light and note height of mercury in I-48 hours.

176. The loss of water.-Water is constantly evaporating from the whole surface of the plant exposed to the air. Since this loss is more or less modified by the vital activity of the plant, it has received the special name, transpiration.

\section{EXERCISE XXVII.}

\section{To show the loss of water by evaporation.}

Clean and dry the surface of a pot in which a thrifty single-stemmed plant is growing; close the hole in the bottom with a cork; with a brush paint the whole surface thickly and evenly with melted paraffin. Cut out a piece of stiff paper which will fit around stem and just cover the soil in pot. Using this as a pattern cut a cover for the soil from a sheet of lead; slit the cover from the central hole to circumference ; adjust it around plant and cement all cracks with grafting wax.* Weigh. Weigh again at intervals of 24 hours, for 4 days.

177. Transpiration.-In the higher plants transpiration from the surface is reduced by the waterproofing of the epidermis, so that most of it takes place from the surfaces of internal cells into the intercellular spaces, wherever these exist. Since the intercellular spaces are connected with each other and also, through the stomata, with the outside air, water vapor is constantly passing off by diffusion (see fig. Iо6). The leaves, affording the largest exposure, are especially organs of transpiration. After they have become fully expanded no considerable amount of water is lost directly from their surfaces.

* Or the pot may be set in a tin or glass vessel which it fits ; this may be covered by sheet rubber tied to the edge and about the stem; or the lead cover may be cemented on as above. 


\section{EXERCISE XXVIII.}

To show the variation in the rate of evaporation due to the difference in structure of the organ. (See also 9339 .)

Compare as shown by shrinkage or by loss of weight. (a) Through cork tissue and without it. Take two potatoes; peel one; expose side by side; compare day by day. (b) Through skin. Compare in same way two apples. (c) Through stomata. Take three equal leaves of oleander ; of one close the stomata (which are on under side only) with a thin coat of grafting wax, or cocoa-butter melted and brushed on (taking care not to kill cells by having wax too hot); coat the upper surface of second in same way; leave third uncovered. Compare day by day.

178. Amount and regulation.-The amount of transpiration, therefore, varies with the structure of the leaf rather than with its area. The temperature, percentage of moisture in the air and movements of the air affect profoundly the rapidity of transpiration. Hence arises the need of regulation by the plant, to prevent excessive loss. The guard cells of the stomata are irritable, so that external conditions affect their turgor. If both are turgid, they become curved away from each other so as to increase the size of the opening between them. If they are flaccid, the thick ridges along the inner face of each cell straighten them, and so close the orifice more or less completely (fig. I05). The presence or absence of hairs upon the leaves, the existence of stomata upon one or both surfaces, the sinking of the guard cells below the general leaf surface, the distribution of the stomata, the thickening of the leaves, their inrolling (fig. 197), or revolution, have a decided effect upon the rate of transpiration, and may be adapted to regulate it. (See $\uparrow 335$ ff.)

\section{EXERCISE XXIX.}

To show that many leaves are not wetted by water.

Immerse various sorts of leaves in water. Does the water wet the surface? What is the cause of the silvery reflection of light from the 
surfaces of some? What relation does this repulsion of water have to blocking of stomata by rain?

Demonstration.-To show the conditions affecting evaporation.

Construct a potometer as follows: Bend the central stem of a T-tube until it is parallel with the cross piece. Fit into the lower opening of the straight leg a capillary tube $3 \mathrm{O}-40 \mathrm{~cm}$. long, with $3 \mathrm{~cm}$. of each end bent at right angles to the main part and in opposite directions. Into the bent leg fit a shoot of a thrifty plant cut off under water, at the same time filling the T-tube with water. (To accomplish this, bend the shoot to be cut off so that the place of the cut is submerged in a deep pan of water. Fit it in tube without exposing cut surface at all to air.) Dip the lower end of the capillary tube in water and allow apparatus to stand until capillary tube fills with water. Remove the water for a moment and allow a bubble $\mathbf{I} \mathrm{cm}$. long to enter ; time it as it moves between a series of equidistant marks on capillary tube. Try the rate under various conditions of light, temperature, and moisture acting on shoot.

To show loss of liquid water when absorption is great and evaporation slow.

Grow seedlings of wheat or oats until 5-10 $\mathrm{cm}$. high ; then cover with a glass bell for an hour or two. Where do drops of water appear? Why?

\section{B. Foods in general.}

179. Foods.-In addition to an adequate supply of water, plants require food. To be a food, the material must consist of certain elements put together in such proportions and in such a way that it can be used, either at once or by the expenditure of comparatively little work upon it, to repair or renew the living protoplasm. All foods are compounds of carbon with two to four other elements. The best foods are very complex in their construction. Only the smallest and simplest plants can live upon the simpler carbon compounds. For most plants the proper foods are precisely of the same nature as for animals, and though each sort of plant has certain kinds of food which it can use best, it may be fed with many different kinds 
Plant foods, like animal foods, belong mainly to three groups, carbohydrates, fats, and proteids. Examples of the first are the sugars, of which grape sugar, fruit sugar, and cane sugar are the commonest; starch, which can be broken up into grape sugar; and cellulose, the material of cell-walls. Examples of the fats are olive oil, palm oil, cotton oil, etc. Proteids are generally recognizable by their property of coagulating upon application of heat, acids, etc. Examples are the albumen of "white of egg," the fibrin of blood, casein of milk, etc. Examples from plants are abundant, but less generally known. Proteids. always, and either carbohydrates or fats, or both, must be available in order that a plant may be properly nourished.

Green plants obtain their food chiefly by manufacturing it out of simple materials taken into the plant body from the soil and air. They are the only living things, so far as known, which have the power of building up foods out of such simple materials as carbonic acid gas and water. They are, therefore, the ultimate source of the food supply of the world.

\section{Nutrition of colorless plants.}

180. Colorless plants. - By this really inaccurate phrase are meant plants which do not possess chlorophyll, though some of them are highly colored by other pigments.

The colorless plants among the thallophytes constitute two large groups, known as bacteria and fungi. Among the seed plants, also, are found some devoid of chlorophyll.

Many plants possessing chlorophyll show to the eye other tints than green, when other pigments are present in such quantity as to mask the green. This is notably the case with the so-called "foliage plants," in which reds, yellows, purples, and browns are common. (See also $\uparrow 9,33,38$.)

Colorless plants necessarily live either upon the material once produced by a living being, oftentimes upon its dead and decomposing body, or in company with living organisms. Those which live upon dead bodies, whether these have lost 
their natural form completely or not, are known as saprophytes. Those organisms which live in association one with another are called symbionts and their relation is known as symbiosis. (See Chap. XXIV.) If one plant preys upon and injures another living plant or animal, it is called a parasite and the being which supports it is called its host. (See \% 44.)

181. Saprophytes.-Saprophytic bacteria live immersed in solutions of food, or surrounded by films of fluid on the surface or in the interior of the solid material upon which they flourish. Saprophytic fungi either form their mycelium upon the surface of the substratum, which contains their food, or, more commonly, they penetrate it more or less extensively by a profusely branched system of hyphæ. A few saprophytic seed plants form at the base of the stem an enlarged, tuber-like mass from whose surface great numbers of profusely branched roots arise. These penetrate the decaying food material in all directions, and act as absorbing organs. A few have abundantly branched underground stems and have no permanent roots.

182. Digestion.-Saprophytes whose surfaces are surrounded by food solutions have only to absorb them. Some, however, have power to convert into material soluble in water the solid insoluble food with which they are in contact. This is brought about in most cases by substances excreted by the living protoplasm. Such chemical changes, by means of which insoluble solid materials are transformed into soluble ones and are dissolved, are identical in nature with those which occur in the digestive tract of the higher animals, and, therefore, may be properly termed digestion.

183. Assimilation.-After the food is absorbed, it undergoes various changes, collectively known as assimilation, by which it is enabled to become part of the living material of the plant body.*

* This is not to be confused with the manufacture of food by green plants, to which the term assimilation is inaptly applied by most writers. 
184. Parasites obtain their food either by growing upon the surface of the host and thrusting into its interior absorbing organs ; or by growing wholly in the interior of the host, breaking out to its surface only to form reproductive bodies.

Parasites may work little apparent harm, or they may bring about local disease and death of the host. Their mode of obtaining food is not essentially different from that of saprophytes. They either digest solid foods, or absorb liquid foods, prepared by the host for its own use. Among the green plants there are some partial parasites, such as the mistletoe, which seem to obtain from their host chiefly the water and salts which they have absorbed. These materials they themselves elaborate into food. (See further 970 .)

\section{Nutrition of green plants.}

185. Raw materials.-In order that the green plants may be able to manufacture their food, they require certain raw materials, which are obtained from the water and air. The water is always a weak watery solution of various mineral salts. From the air (or the water in the case of submerged plants) they absorb a gas, carbon dioxid.

186. Salts absorbed.-Along with the water which is taken into the plant go various amounts of dissolved material, a considerable portion of which consists of mineral salts. When plants grow in humus, or in water or soils containing organic matter, a variable amount of carbon compounds suited for food may be dissolved by the water and be taken up by the plant. To this extent the plant will live as a saprophyte, and no doubt many field and garden plants have been bred to require this sort of life.

Among the mineral salts the most important are the salts of potassium, magnesium, calcium, and iron, which are present in all soils, in greater or less quantity, and are dissolved in surface waters. In the same way 
many additional compounds, of no use in forming food, are taken in. These are all found in the ash, when a plant is completely burned, though not necessarily in the same form in which they were absorbed.

187. Selective action.-The compounds which exist in the water in various, though small amounts are not taken into the plant in the same proportions as they exist in the water. Substances which are utilized by the plant and which, therefore, disappear as such within it by having their chemical composition altered or by being stored up in a different form and so removed from solution, will enter the plant continuously, as long as the supply outside exists. Substances absorbed and not utilized accumulate in the water inside the plant, and these solutions soon attain the same degree of concentration as those outside. Then they are no longer absorbed. It is for this reason that two plants growing upon the same soil may contain very unequal quantities of any important material. Plants thus exert a sort of selective action, but this selection is dependent upon purely physical laws, and is only indirectly under the control of the plant.

188. Carbon dioxid.-Carbon dioxid is a gas, which is always present in the air, in which, however, it exists in small quantities, rarely exceeding one part in twenty-five hundred. An abundant supply of it is constantly being returned to the air by the breathing of animals and plants, by burning of fuel and by slow decomposition of dead bodies of plants and animals. The constant currents in the atmosphere make its distribution practically uniform. On account of its ready solubility, this gas also exists in abundance in soil waters and in the larger bodies of water constituting streams, lakes, or pools. The water which passes through the soil therefore has a larger percentage of this gas than the air, sometimes containing as much as one per cent.

189. Absorption. - Water plants readily absorb the dissolved gas by such surfaces as are exposed to the water. 
Floating plants have opportunity to obtain it both from the water and from the atmosphere. Land plants, although their roots are surrounded by a comparatively concentrated solution of carbon dioxid, do not take up appreciable quantities by these organs. On the contrary, the absorption of this gas seems to depend entirely upon those cells which contain chlorophyll. The stomata, which allow the internal spaces free communication with the outside air, are important organs for facilitating the absorption of this gas. Its continued absorption depends upon its continuous removal from the cell sap in the manufacture of food.

\section{EXERCISE XXX.}

To show the permeability of stomata for air and their communication with the system of intercellular spaces.

Fasten a leaf with a long petiole air-tight in a rubber cork, through which also passes a short glass tube. Fit the cork into a bottle holding sufficient water to cover end of petiole. Attach a filter-pump or airpump to glass tube. Observe whether air bubbles leave the end of the leaf stalk.

Reverse the leaf, so that the blade is immersed, and make same observation. Where do bubbles appear? Is there any difference between upper and lower sides?

190. Photosynthesis. - The process by which carbohydrate foods (sugar, starch, etc.) are produced is called photosynthesis. * The steps in the process are not thoroughly known ; indeed they can only be guessed at, and the theories need not even be stated here. The final product is not necessarily the same in all plants, but in many it is cane sugar. Starch appears later in the form of minute granules in the interior of the chloroplasts. It is probably furmed as a means of removing some sugar from the cell-sap

* This term seems to be more generally approved than photosyntax, which was first proposed as a name for this process. 
and storing the accumulated food for a time. In all green plants oxygen is a by-product. The amount given off about equals in volume the carbon dioxid used in making the foods.

The conditions under which photosynthesis occurs are three: (a) the presence of chlorophyll, (b) the action of light, and $(c)$ the presence of potassium salts.

\section{EXERCISE XXXI.}

Demonstration.--To show that oxygen is a by-product of photosynthesis. Collect the gas mixture evolved from a vessel full of aquatic plants by inverting over them a funnel to whose tip is connected a test-tube filled with water to be displaced by the rising gases. Keep the plants in sunlight. When the tube is filled, test the contents for oxygen by inserting a glowing splinter.

191. (a) Chlorophyll.-Chlorophyll, as has been shown in Part I, sometimes colors the whole protoplasm of the cell, but is more commonly found only in certain special structures, the chloroplasts. The real work of forming the food depends, therefore, upon the protoplasm of the chloroplast. The purpose of the chlorophyll is to absorb certain portions of the light which falls upon it.

192. (b) Light.-The light absorbed by the chlorophyll furnishes the energy necessary to do the work of taking apart the carbonic acid and rearranging the material into a more complex substance. This energy cannot be supplied by the plant itself. An external source of energy is therefore necessary. What this source is is unimportant, provided the energy be sufficient. The light of an electric arc serves the purpose as well as sunlight, if its intensity be equal.

\section{EXERCISE XXXII.}

To show that manufacture of starch occurs only in cells directly illuminated. 
Darken portions of some leaves of a plant previously found to show starch in its leaves * (sunflower, bean, tomato, or nasturtium) by attaching two plates of cork on opposite sides by means of two pins driven through both and the leaf. On the afternoon of the following day, it sunny, cut off the leaves and test for starch as before. What has become of starch in cells under the cork?

193. (c) Potassium salts. - These take no part in the composition of the food produced, and their exact rôle is not understood. It is well established, however, that their presence is essential to the formation of the carbohydrate food.

194. Proteids. - The foods thus formed are sooner or later built up into still more complex foods, the proteids. The process by which this is accomplished is even more obscure than the preceding, neither the steps in the process nor its conditions being known. The formation of proteids occurs abundantly in green leaves while they are illuminated, and therefore making sugar, etc. But even in green plants proteids are made in other parts than leaves, and in darkness. They are also formed by colorless plants. Proteids are used directly in the repair of the protoplasm, and for making new protoplasm.

\section{E. Storage and transfer of food.}

195. Storage and transfer.-Both in the colorless and green plants it is necessary that the foods should be transferred from the point where they are made or absorbed to the place where they are to be used. The larger the plant, the

* To ascertain this, test as follows : Boil a few leaves of various plants for a few minutes. Place in alcohol at about $60^{\circ} \mathrm{C}$. until all chlorophyll is dissolved. (Do not heat over open flame, but set bottle, loosely corked, in a vessel of hot water.) Bring the leaves into a tincture of iodine, diluted to a bright brown, for half an hour. The leaves or parts containing starch will become bluish, dark blue, or black, according to amount of starch present. 
more important (because the longer) does this transfer become. In many plants, also, it is desirable that a supply of reserve food be stored for use when a supply is no longer available from the outside or by manufacture.

196. Storage form.--In the higher plants, storage places are secured by the enlargement of roots, stems, and leaves, to form reservoirs. Similar specialization of parts in the lower plants occurs. The most common form of reserve food, especially in thickened stems, roots, etc., is starch. This is deposited in the form of rounded or oval grains, which often show layers due to different composition and density (e.g., in the potato tuber, $A$, fig. II4), and are sometimes adherent into compound grains, e.g., the oat ( $B$, fig. II 4$)$. Ins eeds also, much reserve
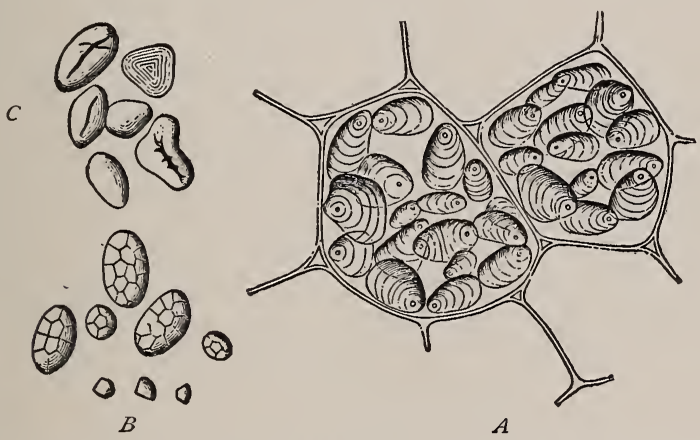

FIG. I 14.--Reserve starch. $A$, two cells of a potato, showing enclosed starch grains.

The other contents not shown. $B$, compound starch grains from a grain of oats. Three of the component granules of a large grain are shown separately. $C$, starch grains from a bean. All highly magnified.-After Kerner.

food may take the form of starch, and fats are common. Fats occur in liquid form, as droplets of various size (e.g., cotton seed), and are only rarely solid. In some seeds the cell walls are enormously thickened, so that the seed is of bony hardness (e.g., the date). Reserve proteids are stored in the form of aleurone grains. These are small granules, often packed in between the larger starch grains, as in the cotyledons of the bean.

197. Digestion and transfer.-When solid foods, insoluble in water, are to be moved from one part of the plant to 
another it must be done by altering them into soluble substances, that is, by digestion. (See 9 r 82 .)

This is accomplished by means of enzymes of different kinds, adapted to effect the alteration of various foods. The most abundant enzyme is diastase, which has the power of altering starch into a sugar. Enzymes fitted to transform proteids are also found in considerable amounts.

When the foods hàve been brought into a soluble condition, they dissolve in the water present. If one cell then contains more of that particular substance, say sugar, than its neighbor, the sugar particles will pass into the neighboring cells until the amount is equal. If this sugar is being used up in growth or repair, or is altered into another substance at any point, a constant stream of particles of sugar moves toward the point at which it is disappearing. Thus from the food sources it is transferred to the reservoirs and stored in suitable form. Thence, when needed, it is redissolved after digestion and carried to the active parts which utilize it. This morement may be hastened if elongated cells are provided along the more important lines of travel. Th.is is done in the bast strands. The movement is made still easier also in these by the perforation of the ends of some of the elongated cells, so that there is less resistance to movement. Foods, therefore, travel chiefly in the bast bundles and in either direction as may be necessary.

\section{EXERCISE XXXIII.}

To show in what tissues food most readily travels.

Girdle as in Exercise XXV $A$ a shoot of willow. Cut it off $5 \mathrm{~cm}$. below ring. Place shoot in water. After some weeks note where new roots are formed. Why?

To show the digestion of starch by diastase.

Powder a handful of malt in a mortar or obtain ground malt. To 25 grams of the powder add $100 \mathrm{cc}$. of water; stir well together; allow mixture to stand (with occasional stirring) one to two hours ; filter ; preserve the filtrate. Take $\mathbf{I} \mathrm{gm}$. of starch and rub it up in a dish with 
5 cc. water; pour this into $95 \mathrm{cc}$. of boiling water, stirring as it enters. With $25 \mathrm{cc}$. of this paste mix thoroughly $5 \mathrm{cc}$. of the filtrate (which contains diastase extracted from the malt). Test a small portion of the mixture at once for starch by adding a few drops of tincture of iodine, and similar portions at intervals of half an hour until starch reaction ceases. Taste the remaining paste. Into what has the starch been converted?

\section{F. Respiration.}

198. Destructive changes.-Coincident with the processes which result in the formation of complex foods and from them still more complex living protoplasm are those which result in its destruction. In the green plants the constructive changes predominate (because of extensive food making), with the result that the plant accumulates additional organic matter; while in colorless plants destructive processes predominate, with the result that the plant increases in bulk, but only at the expense of organic materials previously existent. In all plants, however, both the constructive and destructive changes go on at the same time and without conflict.

199. Respiration.-A series of destructive changes is included under the term respiration. It is a familiar fact that the higher animals cannot live without a constant supply of oxygen and a corresponding excretion of carbon dioxid. This is not so generally known to be true of plants. It is, nevertheless, true that no plant can live without a constant supply of oxygen and a corresponding excretion of carbon dioxid. The processes by which $(a)$ oxygen is obtained, $(b)$ united with the living protoplasm, $(c)$ this substance decomposed, and $(d)$ carbon dioxid excreted constitute respiration.

\section{EXERCISE XXXIV.}

To show evolution of $\mathrm{CO}_{2}$ by respiration of seedlings.

Fill a wide-mouthed glass jar or bottle of I liter capacity one-third full of peas and beans which have been swollen for a day in water, then 
rinsed thoroughly in 5 per cent. formalin and again rinsed in water. Cork or cover tightly. After 24-48 hours remove cover and thrust in a burning match or candle attached to a wire. If $\mathrm{CO}_{2}$ has been produced it will extinguish flame. Test also by lowering into jar a vessel of baryta-water. If precipitate or film forms it shows presence of $\mathrm{CO}_{2}$.

Demonstration.-To show evolution of $\mathrm{CO}_{2}$ by respiration of leaves and flowers.

Provide a piece of plate glass and a bell jar with ground rim, of suitable size to cover a blooming plant growing in a pot. Alongside the pot place a shallow dish of baryta-water; cover both with the bell, daubing its edge with vaseline to make contact with glass plate air-tight. Place in darkness. Note film of barium carbonate on surface of water after a day. Conduct a control experiment, identical but for the absence of plant. Is more or less barium carbonate formed? Why darken?

200. Respiratory ratio. - The ratio between the amount of oxygen consumed and carbon dioxid produced varies somewhat with the age and condition of the plant, as well as with the circumstances under which respiration occurs. Ordinarily the volume of carbon dioxid produced is approximately equal to the volume of oxygen consumed, and the ratio may be expressed thus : $\frac{\mathrm{CO}_{2}}{\mathrm{O}}=\mathrm{I}$.

201. Respiration and photosynthesis. - In the green plants respiration is masked in daylight by photosynthesis. Whenever the green parts are sufficiently illuminated, the carbon dioxid produced by their respiration is consumed in the formation of food. But when these parts are not adequately illuminated, the process of photosynthesis is interrupted, and respiration can be more easily studied. The parts of plants which are free from chlorophyll, such as young flowers, buds, embryos, and the like, and all the non-green plants, allow the respiratory changes to be demonstrated readily.

202. Aeration. - The oxygen consumed comes from the atmosphere, or from that dissolved in water. Certain plants are adapted to aerial respiration, while others are adapted to aquatic respiration, but in either case the gas used is the 
same. In the smaller and simpler plants the protoplasm absorbs oxygen directly through the cell wall. In multicellular plants, however, especially when they become large and complex, only the cells at the surface could do this. The internal cells are too far from the source of supply to allow an adequate amount of oxygen to reach them by travel through other cells. In large plants, therefore, internal spaces are provided, and through these oxygen moves readily. In the land plants the internal spaces open into the air through the epidermis, in which, with the guard cells, they constitute the stomata ( $\Phi$ I37). In the absence of stomata, however, the oxygen may pass through any part of the surface of the plant. In submerged water plants, very large intercellular spaces are formed (fig. 76), permitting the existence of an internal atmosphere of considerable amount, within whose limits gaseous exchanges may occur. Oxygen may reach these intercellular spaces from the water through the superficial cells.

203. Intramolecular respiration.-While free oxygen is ordinarily utilized for respiration, all plants seem to be capable of obtaining their supply for a short time from the living matter of the plant itself. In most plants it can exist for a few hours at most without producing disease and, sooner or later, the death of the plant. It is precisely parallel to the similar method of respiration possible among cold-blooded animals. A few plants of the simpler sort, such as the bacteria, rely wholly upon combined oxygen for their respiratory supply. Such plants have adapted themselves to grow in the absence of free oxygen, which, instead of facilitating their life processes, really checks them.

204. Excretion.-The carbon dioxid produced by respiration, when not used for food making, is gotten rid of by the reverse of the methods described for the absorption of oxygen.

205. Release of energy.-The purpose of respiration is to set free energy required for growth and movement. While 
certain plants are capable of utilizing radiant energy of the sun for food making, all must set free within their own bodies the energy requisite for putting in place particles of new material to form new parts, and for the execution of movements, whether internal, such as the streaming or rotation of the protoplasm, or mass movements, such as those of leaves and other members, or movements of locomotion, such as those of swarm spores and sperm cells. (See $9236 \mathrm{ff}$.) The required energy is set free by the destruction of the substance formed when oxygen united with the protoplasm.

\section{EXERCISE XXXV.}

To show the necessity of respiration for growth.

Germinate a number of beans in sawdust. Select eight with straight roots about $2 \mathrm{~cm}$. long. Clean and dry the surface slightly by brushing with frayed edges of strips of filter paper, taking care not to expose roots so long that they are injured by dry air. With a very fine sablehair brush and thick Chinese (or waterproof black drawing) ink, mark each root by distinct lines into ten spaces $\mathbf{I} \mathrm{mm}$. apart, commencing with tip. This can be done most conveniently by pinning the seedling to a strip of soft wood and laying alongside the root a ruler whose graduated edge has been blunted by a plane until it is about $2 \mathrm{~mm}$. thick.

Pin half the seedlings to a strip of soft wood set into a jar partly filled with wet sawdust, so that the roots will be vertical in damp air. Put the other half into a similar jar and cover them with water recently boiled and cooled. After 24 hours, remeasure and compare total growth. (See also Exercise XXXVI.)

206. Loss of weight.-As a consequence there ensues a loss of weight. If a plant, such as a seedling abundantly supplied with reserve food, be compelled to develop in darkness, and so allowed to make no additional food, it may be easily demonstrated that a large part, often as much as one half, of its weight will be lost (as gases) in respiration. This loss of weight comes primarily from the decomposition of portions of the living protoplasm. These, however, are soon 
replaced by the formation of new protoplasm from the foods. Ultimately, therefore, respiration results in a diminution of the reserve food.

207. A vital function.-Respiration is a function of the protoplasm, and does not occur simply because substances are present in the plant which are destroyed when oxygen is brought into contact with them, as fuel is in a furnace. On the contrary, the oxygen seems to enter into loose combina. tion with protoplasm, forming an extremely unstable compound. This, under unknown conditions, and often some time after its formation, breaks down into simpler substances, so setting free energy. Some of these materials are again used in building protoplasm, while others break down still further, ultimately into water and carbon dioxid. The supply of oxygen is so necessary that if a plant cannot obtain oxygen from the air or water, it will secure it by the destruction of part of its own substance for a time, thus burning the candle of life at both ends.

208. Heat.-While this decomposition of the protoplasm in ordinary respiration is not a true combustion, it nevertheless results, as combustion does, in the evolution of heat. The amount of heat produced is usually not great enough, and its loss too rapid, to make it readily perceptible. Anything which prevents the loss of heat will make its measurement possible. The germination of large quantities of seeds or the blossoming of a number of flowers in a confined space may raise the temperature as much as 15 or $20^{\circ}$ above that of the air.

The heating of hay, grain, and similar substances, which have been stored when moist, is due partly to the respiratory activity of bacteria and fungi, which grow rapidly under these conditions. Fermentation, which also occurs under the same conditions, adds largely to the evolution of heat. 


\section{EXERCISE XXXVI.}

To show the evolution of heat during respiration.

Take three-fifths the amount of dry wheat required to fill two 3 -inch flower pots; swell in water over night; rinse one half in 5 per cent formalin ; kill the other by boiling in water for five minutes. Stop bottom hole in pot with a cork; fill one with dead, the other with living seeds, and bring the two to same temperature by running water through the dead and hot one. Insert a thermometer in the center of each mass of seeds; place both under one box or bell jar. Observe changes of temperature for two days.*

209. Contrast between respiration and photosynthesis. - Since the processes of respiration and photosynthesis in green plants are so frequently confused, a contrast is here drawn between them.

\section{Respiration.}

Occurs in all living cells. Indifferent to or retarded by Requires light. light.

Consumes organic matier. Produces carbon dioxid. Consumes oxygen. Sets free energy.

\section{Photosynthesis.}

Occurs only in green cells.

Produces organic matter. Consumes carbon dioxid. Produces oxygen.

Stores energy.

210. Other destructive changes.-Besides those constituting respiration, a considerable number of other destructive changes occur, which are not so closely connected with the vital functions of the plant. They result in the production of substances which are of no further use in nutrition and only of incidental value for any purpose. Such substances may be stored in some out of the way place; or put into such parts as are transient, so that, by the loss of these parts, the

* Compare thermometers previously to see that they register alike ; if not ascertain the correction. Greater differences in temperature of seeds will be observed if pots are surrounded with cotton batting. 
useless materials are gotten rid of ; or they may be excreted directly. They may be called waste materials.

211. Waste materials.--Among the most important are the carbon acids, such as oxalic, malic, etc., the tannins, the resins, the gums, the volatile oils, and the alkaloids. These substances are either by-products of photosynthesis, or they arise in the course of the assimilation of foods. Oxalic acid is usually gotten rid of by being combined with calcium to form calcium oxalate, which crystallizes either in the form of squarish crystals or as long needles (fig. II5). The resins, usually dissolved in an oil, are generally excreted into special intercellular spaces. Volatile oils, to which most odors of plants are due, are secreted by glandular hairs (e, fig. 74); or are formed in the epidermis itself, as in flowers; or are

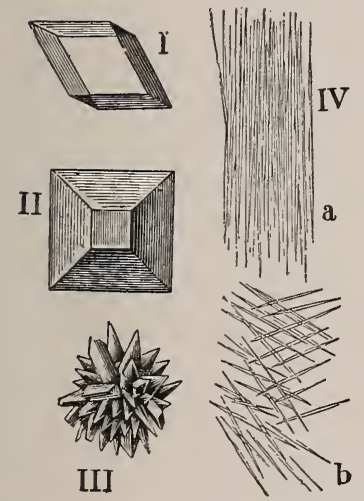

FIG. II5.
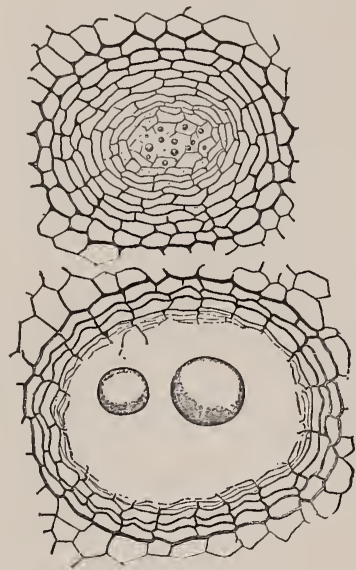

FIG I 6 .

FIG. I15-Crystals found in plants. I, calcium carbonate; II-IV, calcium oxalate; II, octahedron with biunt ends; III, compound crystals from the nectary of a mallow; IV, $a, b$, needle crystals (raphides) from leaf of fuchsia. All highly magnified.After Behrens.

Fig. i 16. - Section through oil-receptacles in rind of orange. The upper figure shows the structure at the beginning of the disorganization of the oil-producing cells; the lower, the final condition, with two drops of oil occupying the cavity. Moderately magnified.-After Tschirch.

produced in chambers near the surface, the cells which produce the oil being disorganized to form the cavity in which the drops lie (fig. II6). Many of the alkaloids, such as quinin, morphin, strychnin, nicotill, etc., 
are important medicines. They occur in the seeds, bark, or leaves, and are gotten rid of when these are dropped.

212. Summary.-The elements required for the nutrition of plants may be determined by analysis. The chief compounds are found to be water and carbon compounds. IVater and the mineral salts dissolved in it are absorbed by land plants from the soil by means of root-hairs. Since the water tends to become equally distributed through the soil the roots draw their supply of solutions not only from parts with which they are in contact, but also from more distant regions. They are also able to dissolve certain solids. The water absorbed moves into the stele, often under pressure, and is carried, by unknown forces, to the leaves, through the wood strands. It is constantly evaporating from the leaves, which regulate the amount in various ways.

Foods are required to repair waste and provide for growth. Colorless plants must absorb these from solution ; if the foods are not already soluble they must be made so by digestion. The foods they use are carbon compounds which have been made by some other living being. Green plants can use ready-made food, or, if suitably illuminated, they can make foods out of carbon dioxid and water, with small quantities of mineral salts. The carbon dioxid is absorbed from air by the leaves. Light furnishes the energy for building up the simple substances into carbohydrates. Proteid foods are also made by working into the carbohydrates additional necessary elements. Foods may be used at once or stored, usually in solid forms, for a longer or shorter time. When needed they are digested and transferred.

Respiration of plants is exactly like respiration of animals. Its purpose is to release energy stored in the living protoplasm to enable it to work, i.e. to grow, move, etc. Respiration consists in the absorption of oxygen, the decomposition of protoplasm, and the excretion of carbon dioxid and 
water. A considerable amount of food is used to repair the necessary destruction in respiration. A plant which is not taking in food from without, or making food, is decreasing constantly in (dry) weight through respiration. Respiration and other destructive chemical changes incident to work result in the formation of a great variety of products called waste products because they take no further part in the processes of repair or growth. 


\section{CHAPTER XV.}

\section{GROWTH.}

213. Definition.-The growth of plants is continued for a much longer time than that of animals. In most cases it is continued in some part throughout the existence of the plant. There are also changes in the form of certain parts, particularly of the lower plants, which must be distinguished from true growth. Growth is a permanent change of form accompanied usually by an increase in size.

214. Formation of new parts.-Each new cell originates by the division of some previously existing cell. The two cells so formed grow until they attain the size of the parent cell, when one or both may continue to grow until they attain a permanent form; then growth ceases. Those cells which do not develop into permanent tissue, but retain their power of division, constitute a mass of tissue at the tip of each branch or root, from which all new parts regularly arise. ( $7 \mathrm{I}, 87$ ). It will be seen, therefore, that every cell of a plant has been at some time in an undeveloped or embryonal condition.

215. Phases of cell growth.-The more striking characteristics of this embryonal condition are the nearly uniform and small size of the cells, and the absence or small size of the water spaces ( $A$, fig. I I 7 ). As the cells which are destined to become the permanent tissues grow older they pass gradually from the embryonal stage into a second phase of 
development, the stage of enlargement. This stage is marked by the rapid increase of the cells in size and a much less marked increase in amount of protoplasm present. The increase in size, therefore, is mainly due to a great increase in the volume of water, which accumulates in one or more large spaces ( $C$, fig. II 7 ). If the organ in question has an elon-

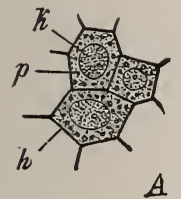

A
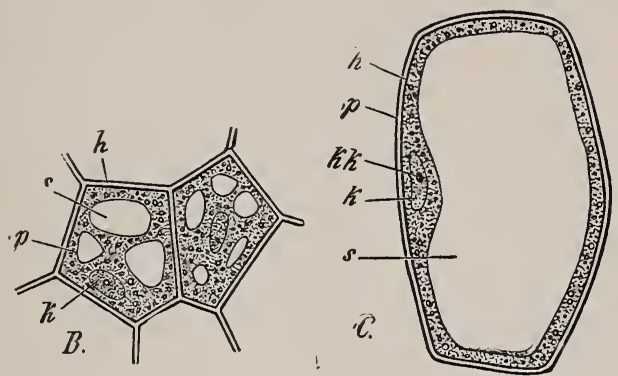

FIG I17-Cells from young and mature fruit of snowberry (Symphoricarpus), seen in section $A$, three young cells, very small, walls thin, nuclei relatively large, vacuoles very minute: $B$, two, somewhat older, larger, walls thicker, nuclei smaller, vacuoles several. $A$ and $b^{\prime}$ magnified 300 diam. $C$, a single cell, mature magnified roo diam.. one thira as much as $A$ and $b^{\prime}$; vacuole single, very large. The volume of $C$ is more than 1500 times one of the cells in $A$. $h$, cell-wall $; p$, protoplasm; $k$, nucleus: $k k$, nucleolus; $s$, vacuole.-After Prantl.

gated form, such as the stem or the root, growth of the cells takes place chiefly in the direction of its long axis. During this phase the cells may attain a hundred or even a thousand times their former volume.

\section{EXERCISE XXXVII.}

\section{To measure the rate of growth in length.}

Construct an auxanometer as follows : Take a board $30 \mathrm{~cm}$. square, a common spool, a wheat or oat straw $35 \mathrm{~cm}$. long, and a piece of glass tubing $5 \mathrm{~cm}$. long, which will just allow spool to revolve easily on it. Close one end of the glass tube by holding it in the flame of a Bunsen burner; when hot spread it enough to stop spoo! from passing over end, by pressing it endwise against a piece of iron. With a fine saw cut a section $5 \mathrm{~mm}$. thick from middle of spool, thus making a wheel. File a groove in edge of this wheel, deep enough to carry a thread. Slip wheel on glass tube and fasten it in board near lower left corner so deep that 
the spool-wheel will revolve smoothly but have no unnecessary play. On the board, with hole for glass tube as a center, mark an arc of 90 degrees. The radius of the arc should be a multiple of the radius of wheel. Divide arc into half centimeters. Attach wheat straw to wheel as a pointer.

To the tip of a growing seedling bean fasten a thread by a slip noose Pass thread over wheel once and to its free end attach a light weight, just enough to turn wheel and pointer when plant is lifted. Set pointer at $o$ and at intervals read the multiplied growth. By taking observation: at regular intervals determine the rate of growth of stem for a week. What regular variation can you discover?

216. Grand period of growth.-The entire duration of growth of an organ is known as its grand period of growth. The growth is not uniform, but is at first very slow, increasing gradually, and then more rapidly, to a maximum, from which it falls rapidly, and then more gradually, until it ceases entirely. The accompanying curve (fig. I I 8 ) represents the

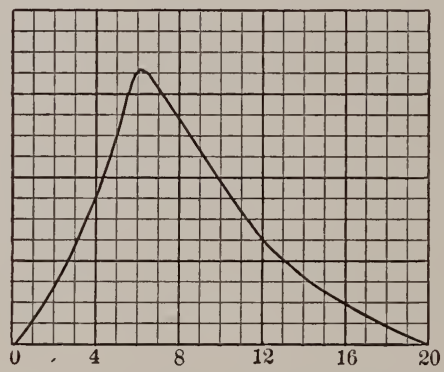

FIG. 118.-Curve representing the rate of growth of an internode of crown imperial for each day during the grand period-in this case 20 days. The height of each vertica! line where it intersects the curve represents the total growth for the corresponding 24 hours. The numbers indicate days. The maximum growth occurred on the 6 th day -After Sachs.

course of growth in length of a short section of a stem. Growth, however, is not uniform from day to day or from hour to hour. If the line should be drawn so as to show these variations it would be irregularly zig-zag, but would follow the same general course as the smooth curve. (See $\mathbf{2 2 2 .}$ ) 
217. Growing region.-The part of any one of the larger plants which is growing in length is limited. The elongating region of a root rarely exceeds a centimeter, and is often not more than one-half a centimeter in length. In stems, however, the elongating part may measure twenty or even fifty centimeters, and in rare cases much more. Figure I I9 shows a root, $A$, upon whose surface marks were made I mm. apart. Twenty-four hours later the root presents the appearance of $B$. Only the tissues in the first five spaces were capable of elongation. The others had passed into the third phase. The second and third millimeters grew most in length. The growing regions of stems may be determined in the same way.

EXERCISE XXXVIII.
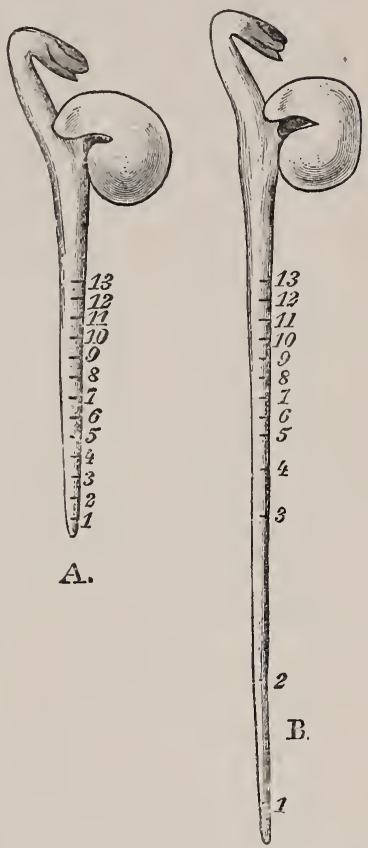

To determine the zone of maximum growth in roots and stems.

$A$. Arrange four seedlings as in - 205, with roots vertical, in moist air.

Which spaces grow most?

$B$. Mark several upper internodes of a bean plant in a similar way, but

FIg. 119. $-A$, a young root of the pea marked with nine lines of Chinese ink into 13 spaces of $\mathrm{I}$ millimeter each. $B$, the same root, 24 hours later, showing elongation only in terminal 5 millimeters. The rate of growth is greatest in the ad and $3 \mathrm{~d}$ millimeters, and slow in the $\mathbf{r s t},{ }_{4}$ th, and 5 th. Magnified 2 diam.-After Frank.

at $5 \mathrm{~mm}$. intervals. After 48 hours observe how many have elongated and which have grown most.

218. Tension due to growth.-The different regions in any organ usually do not grow at an equal pace, and consequently certain parts are under strain, while others are compressed. The curled and crinkled leaves or the curved 
capsules of mosses illustrate this inequality. It may be present, however, without manifesting itself in the external form. If the rapidly growing flower-stalk of the dandelion or the leafstalk of rhubarb be carefully split lengthwise the parts will curve or even curl outward. Separating the pith and the cortex of a young elder shoot from the wood and carefully measuring them shows that the pith elongates and the cortex actually shortens. The experiment, therefore, shows that the pith really grew more rapidly than wood, but were compressed in the uncut stem, while the cortex was slightly stretched. The strains thus set up are spoken of as longitudinal tensions. Similar tensions due to unequal transverse growth may be shown to exist. If a thin transverse slice from the fleshy leaf-stalk of the rhubarb be divided into equal parts by a longitudinal cut it will be found in a few moments that the halves can no longer be made to touch throughout the line of the cut, because it has become convex. Both sorts of tensions will be exaggerated if the parts be placed for a few moments in water.

\section{EXERCISE XXXIX.}

To show the existence of longitudinal tensions of tissues due to unequal growth or turgor.

$A$. Cut a young internode of elder $10 \mathrm{~cm}$. long, making ends as square as possible. Measure accurately. Remuve wood all around and meas. ure pith. Place pith in an atmosphere saturated with moisture and remeasure after I hour. Compare measurements. (If elder is not at hand use young shoots of grape, wild or cultivated.)

$B$. Split a scape of dandelion lengthwise with a sharp knife into four strips. Note immediate effect upon their form. Lay the strips in water for a few minutes. Observe form. Transfer them to 5 per cent salt solution. What effect? What causes these changes of curvature? (The young stems (hypocotyls) of castor bean may be substituted for dandelion scapes, but are not so responsive.)

To show the existence of transverse tensions of tissues due to unequal growth.

$A$. From a piece of willow or poplar stem separate a ring of bark $\mathbf{I} \mathrm{cm}$. 
wide, slitting it on one side only, taking care not to stretch it. Keep it in a moist atmosphere for a few minutes, and then replace it. Does it meet about the wood?

$B$. Cut a slice about $2 \mathrm{~mm}$. thick from the end of a stalk of rhubarb. Bisect this and keep the halves for a few minutes in a moist atmosphere, then place severed edges together. Do they touch throughout?

219. Conditions of growth.-That plants may grow certain conditions are prerequisite. (I) There must be an adequate supply of constructive materials. These may be derived either from food recently manufactured or from that stored in reservoirs, or, in the case of the colorless plants, from that absorbed from without. (2) There must be a supply of oxygen for respiration. This is needed, as previously explained, to set free the energy necessary for growth. (3) There must be a supply of water adequate to supply the material for filling the cells during the phase of enlargement. (4) A suitable temperature is required. The range of temperature within which growth may take place is extensive, and varies with the individual plant. In general, the upper limit may be stated as about $40^{\circ} \mathrm{C}$., and the lower about $0^{\circ} \mathrm{C}$. The minimum of plants of tropical regions is approximately $10^{\circ} \mathrm{C}$., while the maximum for plants of the arctic or alpine regions is much below $40^{\circ} \mathrm{C}$. Between the maximum and minimum temperatures there is an optimum temperature for each plant, at which growth takes place most rapidly. For most plants the optimum lies between $25^{\circ}$ and $32^{\circ} \mathrm{C}$.

220. External conditions exercise a very important influence upon the rate or character of growth by reason of the irritability of the protoplasm. (See further 9 3 7.) Many of these conditions act upon members of the plant so as either to bring about permanently unequal growth in a certain part, or to cause one part to grow more or less rapidly for a time than another. Such variations in growth produce curvatures in the parts concerned and move members connected with them. They are discussed in the chapter on Movements. 
Those conditions which act more generally and uniformly upon a large number of plants serve to determine the form and mode of development of menbers.

221. Light.-The effect of light on growth is different in different plants and even in different members of the same plant. In general light retards growth in length. Stems grown in darkness usually become excessively elongated. Those which under normal illumination have very short internodes, in diminished light may have them well developed, as occurs, for example, in dandelions growing in deep shade.

In general, light accelerates the growth of leaves in area. Leaves of shoots grown in darkness remain small.

Light affects not only the external form but the internal structure. The difference in structure between the upper and lower surface of the thallus of Marchantia $\left(5^{2}\right.$, fig. $\left.3^{8}\right)$ and of the leaves of higher plants (fig. 106) is due to the greater illumination of the upper surface. In diminished light cell walls may not thicken normally, and mechanical tissues are weakened. "Lodging" of oats and such grasses is mainly due to this cause (fig. I20.)

222. Light and temperature.-The combined variation of light and temperature between day and night establishes a daily period in the growth of all plants. The withdrawal of light at night permits an increase in the rate of growth in length, which reaches its maximum in some plants shortly after midnight, in others not until the early morning. During the day its retarding effect diminishes the rate of growth, which reaches a minimum some time in the afternoon. The minor fluctuations in temperature, as well as the generally higher temperature during the day and lower during the night, introduce variations in the rate of growth, which obscure, but do not counteract, the retarding influence of light. (See fig. I $2 \mathrm{r}$ ). This daily period is so impressed upon the constitution of the plant that it maintains it for a considerable time 

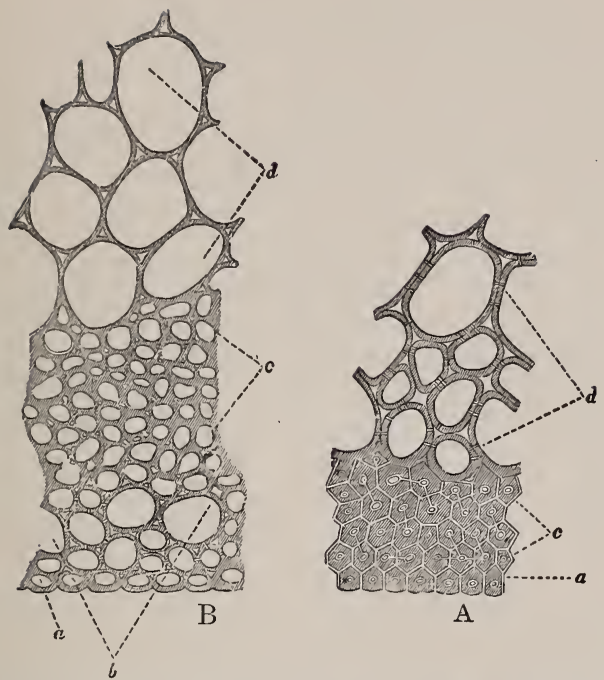

A

FIG. I20.-Part of the transverse sections of the stem of rye. $A$, from a plant grown fully exposed to light: $B$, from a "laid" plant imperfectly exposed to light. $a$, epidermis; $b, c$, mechanical tissues ; $d$, thin-walled tissues. Highly magnified-After Koch.

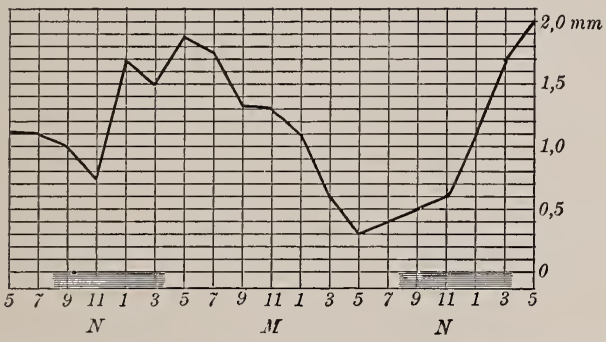

FIG. 121.-Curve showing the daily period in the growth of a stem of rye. The vertical lines represent 2 -hour periods from 5 P.M. of one day to 5 A.M. of the second day, the shaded parts indicating the actual hours of darkness. The horizontal lines represent tenths of a millimeter. The curve is drawn by taking the record from an auxanometer and laying off on the vertical line for each interval the growth shown. The points are then joined. It will be observed that the maximum rate of growth occurs shortly after the period of darkness (5 A.M.) and the minimum rate after the period of most intense illumination ( 5 P.M.). During the experiment the thermometer varied from $18^{\circ}$ to $22^{\circ} \mathrm{C}$ - - After Frank. 
even when kept in complete darkness. Stems of sunflower after two weeks in complete darkness still showed distinctly the daily period.

223. Moisture and oxygen.-The amount of moisture and oxygen present in the medium surrounding a plant pro-

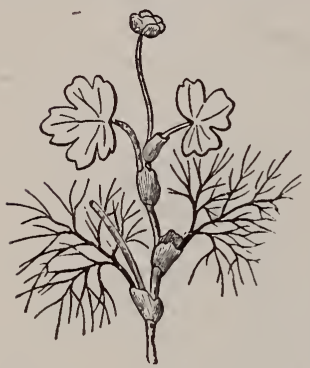

FIG. 122.-A shoot of water crowfoot (Ranunculus aquatilis). The lower leaves have developed under water and are branched into many narrow divisions; the two upper leaves have developed in air and at maturity float on the surface of the water. About half natural size.After Frank. foundly affects its form. Amphibious plants, that is, those which are capable of growing either on land or in water, often show this in a striking way. When grown submerged, the leaves are usually finely divided, while the same leaves, if allowed to develop in the air, have broad blades scarcely more than lobed (fig. I 22 ).

224. Mechanical pressures or strains also exert an influence upon the rate and mode of growth. Compression of tissues retards their growth ; strains accelerate it. Thus, stems enclosed in plaster casts or ligatured grow more slowly in thickness. Tensile strains, such as those exerted by wind or weight, promote the development of mechanical tissues. Petioles, which would break under a strain of $700 \mathrm{gm}$, after enduring a pull of $500 \mathrm{gm}$. for five days, broke only at $1600 \mathrm{gm}$. After five days more under a strain of $\mathrm{I} 200 \mathrm{gm}$. they could not be broken with less than a weight of $6500 \mathrm{gm}$.

225. Variations in rate.-There are not only variations in growth in the course of each day throughout the growing period, but also minor variations independent, so far as known, of external conditions, which are therefore called spontaneous variations. Irregular variations occur from hour to hour in the course of the day. Regular spontaneous variations, also, occur in various organs, particularly in the tendrils of climbing plants, and in the leaves of flowers and buds. These regular variatious, which affect different sides of flat- 
tened organs and different sectors of cylindrical ones, bring about a bending of the entire organ from one side to another. These curvatures produce nutation, and will be further described under movenients.

(See 9 2 4 I.)

226. Duration.-Even when the external conditions of growth are kept as uniform as possible, growth does not continue for an indefinite time. Having passed through the phases above named, it ceases, no matter how favorable the external conditions. Yet some organs, even after growth has ceased, may resume it, under certain circumstances. Thus, the leaf cells which have long since ceased to divide may resume the power of division in the neighborhood of a wound, and by division and the growth of new cells may form a scar covering the wound. The formation of fruits of the seed plants is also a case of resumption of growth after an appropriate stimulus. (See $\%$ 306.)

227. Summary.-Growth is permanent change of form and increase in size. Every part passes successively through three stages of growth, the first marked chiefly by the formation of new cells, the second by the enlargement of cells already formed, and the third by the acquisition of mature characters by these cells. The second stage is the stage of visible and measurable growth. Only a very short part of the root and a limited region of the stem is growing in length. During the stage of enlargement the growth is not uniform. The rate varies on account of internal (unknown) and external (known) causes. Among the latter are light and heat. Light generally retards growth in length, but promotes the growth in area of leaves and other broad parts. It may also produce changes in structure as well as form. Rising temperature (up to a limit) hastens growth; falling temperature retards it. Combined effects of light and heat produce a daily fluctuation in growth. Pressure, amount of water, and oxygen also affect growth. Growth may be resumed by mature parts. 


\section{CHAPTER XVI.}

\section{THE MOVEMENTS OF PLANTS.}

228. Irritability. - Among the inherent properties of protoplasm are irritability and automatism. We know practically nothing of the nature of either of these properties, though upon them depend all the activities of plants. They seem to be merely two phases of the same property. Automatism is the name given to the ability of protoplasm to initiate internal changes without the action of any external force. Irritability expresses the power of the protoplasm to respond or react to the influence of an external change.

229. Stimuli.-The external change which brings about the reaction is known as a stimulus, and its application is called stimulation. External forces which may act as stimuli are light, heat, gravity, moisture, electricity, chemical substances, etc. Most of these act constantly in some measure upon plants. In order that they may act as stimuli, therefore, a change in their intensity or direction must occur. If the change be great or sudden, the reaction is likely to be more marked. Sometimes, however, a slow change will still produce a distinct reaction. For example, the gradual withdrawal of light may cause movements of leaves. (See 255.)

230. Conditions limiting irritability.-Protoplasm is irritable only under certain conditions, which coincide in the main with those that promote the general well-being or life of the organism. But the limits of temperature, moisture, 
and the supply of oxygen, which permit irritability, are much narrower than those which permit life. Thus, irritability may be lost when the conditions are unfavorable, though life may persist under such conditions for a long time. Irritability may also be lost through fatigue, as when, after repeated reaction, no response occurs even to a greatly increased stimulus. Upon the return of suitable conditions, or after sufficient rest, irritability may be regained.

231. Reaction.-The response of the protoplasm to a stimulus is out of all proportion to the physical or chemical action of the stimulus itself. The action of the stimulus upon the irritable protoplasm may be roughly compared to the action of the trigger upon a primed and loaded gun. It sets free forces vastly in excess of those which it exerts.

232. Reaction time.-The observable reaction does not follow instantly upon stimulation. The interval, which is known as the reaction time or the latent period, is ordinarily much longer in plants than in the higher animals. In extreme cases no reaction may be manifest until several hours after stimulation. In other cases, however, as in the wellknown sensitive plant, the movements of the leaves follow almost instantly upon stimulation.

233. Form of reaction.-The character of the reaction is not dependent upon the nature of the stimulus, but upon the nature of the organ itself. It is not in the least understood what the inherent peculiarities are which determine the forn of the reaction. In different organs exactly opposite effects may be produced by the same stimulus, and the same organ at different ages may respond differently to the same stimulus. Thus the young internodes of the Virginia creeper (Ampelopsis) are sharply recurved, but become erect when older. The stalk bearing the flower of the peanut is erect, but as it becomes older it becomes strongly reflexed, and thrusts the fruit under ground. 
234. Localization of irritability.-In multicellular plants irritability to certain stimuli is usually localized in certain organs, and often in special parts of these organs. In many tendrils, for example, the free end is curved and only the concave side is irritable to contact. In the Venus fly-trap, although the whole leaf moves at the contact, only the three hairs upon the upper face of each lobe are sensitive to a touch. (See figs. 224, r 37.)

235. Transmission of impulse.-In these cases, as in many others, the effect of the stimulus must be transmitted in some way from the point of application to the cells which produce movement. At present it is not known how this is accomplished.

The movements of plants may be conveniently considered as (I) movements of protoplasm itself; or, (2) mass movements of multicellular members of the higher plants.

\section{Movements of protoplasm.}

236. Naked cells.-Plants which consist of a single cell may be either naked or furnished with a cell wall. If naked, they may exhibit either amoboid or ciliary movements. Amœboid movements are slow creeping movements brought about by the protrusion of a portion of the protoplasm toward which the remainder gradually flows (fig. IIO). Ciliary movements are due to the extension of one or more very slender threads, called cilia, whose rapid bending in different directions propels the organism (fig. I09). According to the nature of the movements, the course will be zigzag or steady, accompanied by the rotation of the cell on its axis. When the cell comes to rest the cilia are either withdrawn or drop off.

237. Cells with a wall.-Movements of locomotion in plants possessed of a cell wall are either ciliary or creeping. 
The latter are usually due to the protrusion of portions of the protoplasn through slits in the wall, as in some diatoms (fig. I I). The filaments of the water slimes bend from side to side, and so creep over wet surfaces very slowly (fig. 7). Bacteria (fig. 9) and some diatoms move by means of cilia.

The direction of all these movements may be so controlled by stimuli that the organisms move toward or away from the source of stimulus. Thus, ciliated spores of algæ (fig. I09) swimming in a dish of water, will gather next the lighter side.

238. Streaming and rotation.-In multicellular organs it is common to find the protoplasm within each active cell moving about from point to point within the cell. The protoplasm is filled with numerous large vacuoles, so that it forms a next layer the wall, with threads or ribbons extending across it (fig. I23). When currents start along the wall and through the strands, the motion is designated as the streaming of the protoplasm. These currents along any particular portion of the protoplasm may run side by side and in opposite directions.

When the protoplasm surrounds a single large vacuole (fig. II $7, C$ ), the whole mass may rotate, usually in the direction of its long axis. The portion immediately in contact with the wall is motionless, and there must necessarily be a strip between the half moving up and the half moving down the cell, which is also quiet. Such movements are called rotation of the protoplasm. It is not known

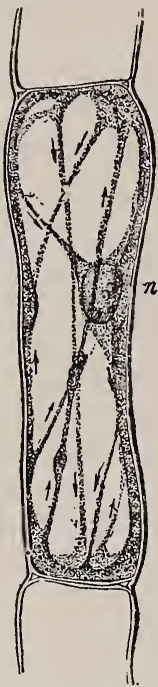

FIG. r23.-A single cell from a hair of Cheladonillm. The arrows show the direction of movement of the protoplasm in the peripheral la yer and in the bands which separate the vacuoles. $n$. the nucleus, with nucleolus. Highly magnified.-After Dippel. whether either streaming or rotation has any immediate relation to the well-being of the cell.

In addition to the mass movements of the protoplasm, the 
smaller protoplasmic bodies within the cell, such as the nucleus and the chloroplasts, are capable of moving about.

\section{Movements of multicellular members.}

239. Forces.-The movements of multicellular parts may be brought about either by special organs known as motor organs, or by the unequal growth of the immature parts. Motor organs are generally responsible for the movements of mature parts, while movements of the younger regions are generally due to growth. The force exerted by the motor organs is dependent upon the altered turgor of the cells of which the organ is composed. If the cells upon one side of it lose their turgidity, those upon the other, being unresisted, will extend and bend the organ toward the side upon which the turgor was diminished. It will be convenient, therefore, to distinguish movements due to growth and movements due to variation in turgor.

240. (A) Movements of growth.-These depend upon some inequality in the rate of growth of the organ concerned. They are of two sorts. (I) Those in which variation in growth is produced by causes not yet known (apparently internal) are called spontaneous movements. (2) Those in which the variation in growth results from stimulation by external agents are called paratonic movements.

241. I. Spontaneous movements.-Among spontaneous movements are those in which the variation in growth occurs upon different sides of a cylindrical organ, or the two faces of a broad one. The opening of all flower and leaf buds illustrates this movement, which is called nutation. During the development of the interior parts, the outer leaves (often scale-like) which protect them grow more rapidly upon their outer (dorsal) surfaces. They are thus pressed together into a compact bud. When the internal parts are suitably de- 
veloped a change occurs in the rate of growth of the outer leaves; their inner (ventral) faces now grow more rapidly and the bud expands. Similar spontaneous variation in the growth of different sides of tendrils produces a nodding or waving motion, or even a rotation of the tip, by means of which they are often enabled to reach a support. In most tendrils the region whose growth is hastened travels irregularly around the axis, so that their tips rotate in a roughly circular or elliptical orbit from the time the tendril is twothirds grown until growth ceases. The further changes in the tendril, by which it wraps the tip about the support and coils the remainder into a double spiral, are paratonic movements induced by contact. The rotating movements by which twining plants climb are also paratonic and not spontaneous.

242. 2. Paratonic movements are also of the highest importance for the well-being of the plants concerned. By means of them the different organs are developed in such situations that they can properly perform their work. The stimuli which influence the rate of growth are chiefly light, gravity, heat, mechanical contact, and moisture. The peculjar states in which a plant or an organ exists when it can respond to the different stimuli have received different names, and those names indicate the nature of the stimulus. A plant or an organ is heliotropic when it places itself in a certain position with reference to the direction of the rays of light falling upon it; geotropic, when it reacts thus to the force of gravity; thermotropic, when it reacts thus to the presence of a warm body; hydrotropic, when it reacts thus to the presence of a moist surface, etc. In each case the plants are said to react positively when the movement is toward the source of the stimulus; negatively, when the movement is away from the stimulus; transversely, when it is transverse to the direction of the stimulus. These reactions are to a certain extent related to one another, and it will be convenient, 
therefore, to consider the effect of each stimulus upon the two common forms of plant organs-namely, the radial (such as stems and roots) and the flattened (such as leaves).

243. (a) Heliotropism.-Heliotropism is the state of a plant or organ when it is irritable to the direction of light rays. Light thus plays an important part in determining the position of organs. As a rule radial organs are either positively heliotropic, as the stems and leaf-stalks, or negatively heliotropic, as the roots. In ordinary light leaves are all transversely heliotropic, assuming a position at right angles to the direction in which the light comes. This is the most favorable position possible for the manufacture of food by the green parts (fig. I24). Intense light, however, may

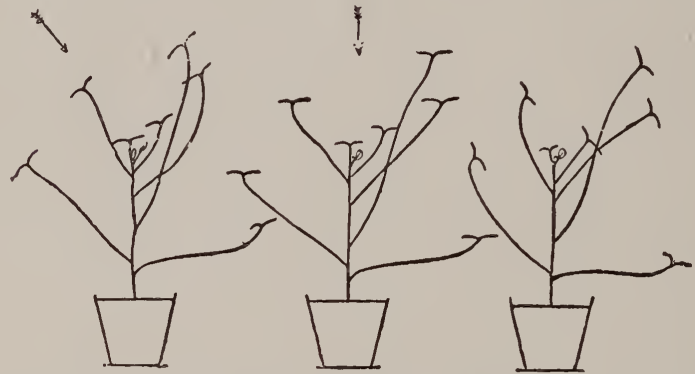

FIG. 124.- Diagrams representing the transverse heliotropism of leaves of the garden nasturtium (Troponlum). Potted plants were subjected successively to light strik. ing them in the direction shown by arrows. The petioles curved so as to place the blades at right angles to the incident light.-After Vöchting.

bring about a different reaction, so that the leaves set themselves edgewise to the light. A fixed light position is usually reached by leaves by the time they become mature, and this is generally at right angles to the source of greatest light. Branches of trees show the leaves so arranged as to size and position that they shade each other as little as possible, forming the so-called leaf mosaics (figs. 1 25, I26). The leaves of window plants also exhibit these movements very strikingly, 
because usually illuminated from one side. Plants kept in darkness have their leaves irregularly placed.

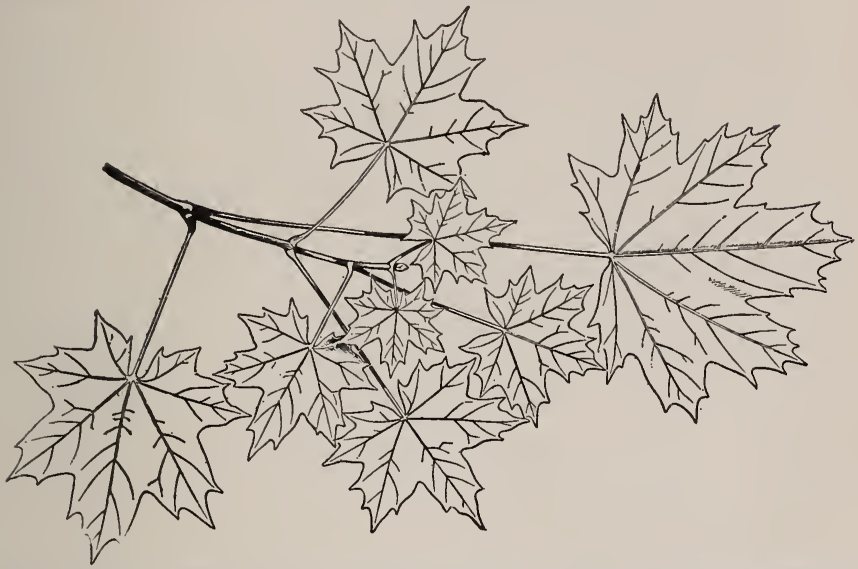

FIG. 125.-Leaf mosaic formed by a horizontal shoot of Norway maple. The lengthening of the petioles of individual leaves to avoid shading of the blade is marked. About one-third natural size.-After Kerner.

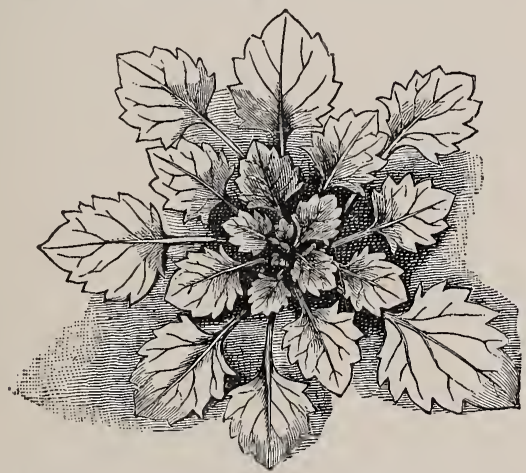

FIG. 126-A rosette of leaves of a bellfower (Campanula pusilla), showing lengthening of petioles of lower leaves so as to carry blades from under upper leaves.After Kerner.

\section{EXERCISE XL.}

To show the effect of direction of light as a stimulus on leaves.

Set a potted plant (geranium, sunflower, nasturtium, or mallow) in the dark for 24 hours; then place it before a window, shading it so that 
light reaches it chiefly from one direction. Mark certain leaves and record the position of the plane of the blade; 24 hours later observe the position and compare with first.

To show effect of direction of light as a stimulus upon stems and roots. Grow seedlings of white mustard thus: Tie loosely over the mouth of a jelly-glass a double piece of fine bobbinet; fill vessel with tap water to the net, on which place seeds; set in dark, replacing water as it evaporates, until seedlings are $3 \mathrm{~cm}$. high, with roots as long or longer. Then place in a box, blackened inside, into which light is admitted through a hole $4-5 \mathrm{~cm}$. in diameter, at right angles to stems and roots. Observe curvatures 24 hours later.

244. (b) Combined movements due to variations in the intensity of light or heat or both are especially exhibited by flowers, whose opening and closing are frequently determined thereby. With some plants the predominant stimulus is heat; with others, light. Closed flowers of the tulip or crocus may be made to open in 2 to 4 minutes by raising the temperature $15^{\circ}$ to $20^{\circ}$. The flowers of the white water-lily and of the dandelion open in sunlight and close in shade. By marking upon their leaves a series of equidistant parallel lines with Chinese ink, and measuring later the distances to which they have been spread, all such movements can be clearly shown to be due to accelerated growth of the outer or inner surfaces, respectively. The protection of the flower parts or their proper working is secured by these movements, which must not be confounded with those due to the direction of light or heat rays.

245. (c) Geotropism.--Geotropism is the state of a plant or an organ when it is irritable to the force of gravity. Since gravity is exerted always in the same direction, it is plain that reactions to this force cannot be studied, as in the case of light, by altering the absolute direction in which gravity acts, but only by so changing the position of the plant that the force acts in a relatively different direction. The reaction to this stimulus and the fixed gravity position must not be confused with the simple effect produced by the 
weight of the parts concerned. Such effects are to be seen in the downward bending of some plants with slender branches, or the curvature of the flower or fruit stalks by the weight of the parts. True geotropic curvatures are brought about by acceleration of the growth of the irritable cells, and the curvatures produced may even be contrary to the direction of the force. If seedlings be grown in boxes upon the rim of a wheel rotating slowly in a vertical plane, so that they are successively subjected to the action of gravity in relatively different directions, it will be seen that while their

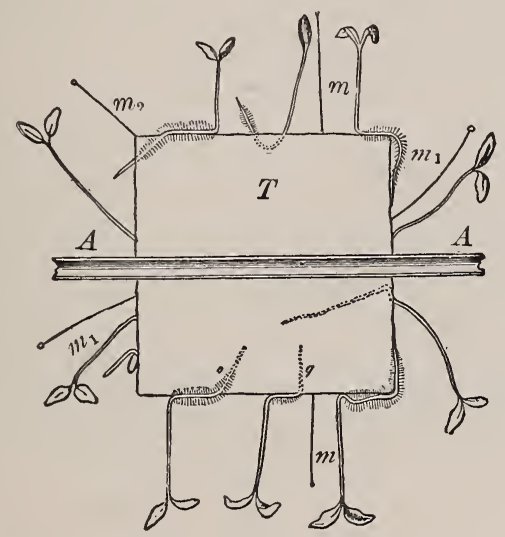

F1G. 127.- Seedling mustard plants grown on a cube of peat, $T$, attached to the slowly rotating axle, $A, A$, of a clinostat. The direction of growth of roots and stems is controlled only by the nearness of moist surfaces, the action of gravity and light being eliminated. Note the variable direction of roots and stems. At $m$ and $m_{2}$ aerial hyphæ of a mold have taken direction as far from the repellant moist surfaces as pos. sible. One half natural size.-After Sachs.

members grow in nearly straight lines, the direction assumed by the stems and roots is quite as frequently abnormal as normal, because the effect of gravity which normally determines the direction of growth of these axes is neutralized, since it now acts upon them from a new direction at each successive moment (fig. I27). If the wheel upon which such seedlings are grown be rotated at a high speed, the cen- 
trifugal force will become a constant one, and, acting in place of the neutralized force of gravitation, will determine the direction which the stems and roots will assume. Since the primary stems of most plants are negatively geotropic, when grown under such conditions they will turn toward the center of the wheel, while the positively geotropic roots grow toward the rim. Similarly, if the wheel be rotated rapidly in a horizontal plane the parts will be controlled by a combination of the force of gravity and the centrifugal force (the latter predominating if the speed is great); the stem will grow inward and upward, while the roots will grow downward and outward (fig. I28).

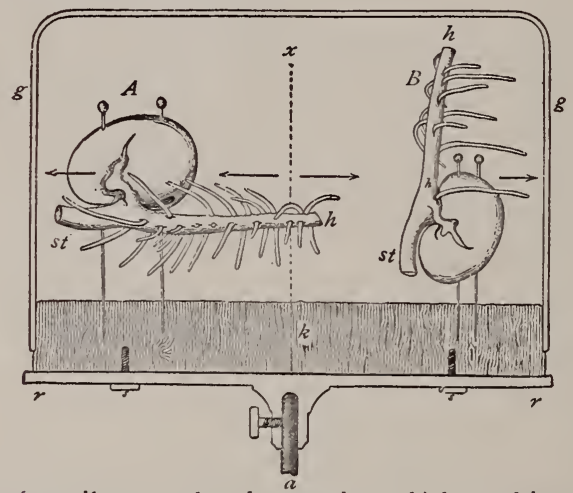

FIG. 128. - Part of centrifuge. $a$, the axle, rotated at a high speed by water or electric motor, to which is attached the circular metal piate, $r, r$, carrying a disk of cork, $k$. To the latter are attached two seedling beans, $A, B$, by means of pins; st, the primary stem; $h$, the primary root. Over the seedlings the cover, $g$, is placed to keep them moist. After a few hours the laterai roots have turned into the direction of the centrifugal force, which was sufficiently powerful to overcome that of gravity except near axis of rotation, $x$. One halt natural size.-After Sachs.

\section{EXERCISE XLI.}

To show the effect of gravity as a stimulus on roots.

Arrange the marked root of a seedling bean as in $T 205$, except that the root is horizontal, and a pin just above the extremity marks its position. After 24 hours observe curvature and which spaces have become curved. Compare with those which have grown most.

To show the effect of gravity as a stimulus on growing regions of upright leaves. 
Support an onion, roots down, in a vessel of water so that it is half immersed, until the leaves are about $10 \mathrm{~cm}$. long. Then turn it so that leaves are horizontal and observe where curvature occurs.

246. Transverse geotropism.-Not all stems, however, are negatively geotropic, nor all roots positively geotropic. The central axis of both root and stem in the majority of plants is so, but lateral branches of both place themselves at an angle to the action of gravity, sometimes at a right angle, at other times at a highly obtuse or acute angle. That is, they are more or less transversely geotropic. Whatever the normal position of any organ, it will be regained by the growing parts as rapidly as possible when the plant is forcibly displaced. This can only be brought about by the curvatures produced by unequal growth of the younger parts.

If a potted plant be laid upon its side for a short time and then erected before any response to the stimulus occurs its growing parts still curve to one side, although not so far as if they had been allowed to remain in the horizontal position.

247. Grasses.-In only a few cases do the maturer parts of plants regain their power of growth under the stimulus of

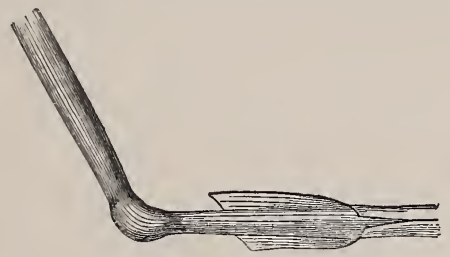

FIG. 129.-Part of a wheat-stalk, showing strong geotropic curvature. The shoot was placed horizontal, and the growth of the basal part of the internode with the leaf-sheath connected with it was stimulated on the under side, the upper remaining short. No curvature occurs in the older part of the internode. About two thirds natural size. -After Pfeffer.

gravity. The basal portion of the internodes of grasses, however, remain for a long time capable of growth; hence, when grasses are blown down or trampled their stems erect themselves by the geotropism of this basal growing zone and of the leaf-sheath (fig. I 29). 


\section{EXERCISE XLII.}

To show the effect of gravity on the growing regions of the stems of grasses.

Cover the bottom of a deep dish about $25 \mathrm{~cm}$. long with a layer of wet sand, and bank this against one end to the top. Into this bank stick horizontally several grass stems having at least one node; cover with a glass plate. After 24-48 hours observe curvature. Cut a longitudinal section of the node and observe what part the leaf-sheath takes in this curvature.

248. oot-cage.-Experiments upon the response of rootlets to the stimulus of gravity when their position is altered

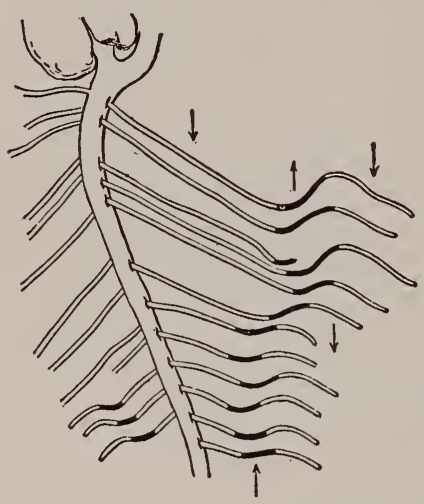

Fxg. 130.-Part of the root system of a broad bean, grown in a root-cage, first in the normal, then in the inverted, and again in the normal position. The arrows show the direction in which gravity acted in the different positions. The black portion of the roots were the parts growing during inversion. Two thirds natural size.-After Sachs. may be carried on by means of a root-cage. It consists essentially of two parallel panes of glass fastened together, between which, in finely sifted soil, the rootlets are grown. By inclining this root-cage at various angles it may be shown that not only the primary root, but its branches, strive to regain their normal angle with the direction of gravity. This is illustrated in figure $\mathrm{I} 30$, in which the dark portion of the rootlets represents the growing parts while the cage was inverted. They then took about the same angle with the horizon as when in normal position.

249. Twining plants. - The movements of twining plants are due to a peculiar reaction to gravity. As the upper internodes of a seedling elongate they soon become too weak to support themselves and bend over, becoming nearly horizontal. When this occurs the growth of the right or left flank of 
the stem near the bend is accelerated (whence the stem is said to be laterally geotropic). The horizontal part is thus swung around, twisting the stem and bringing a new flank under the influence of the stimulus. If in its continued rotation the stem comes in contact with a nearly erect support the free part continues to rotate, growing longer at the same time, and encircles the support. The part below the point of contact now becomes negatively geotropic, and its growth on all sides is equally accelerated. The coils are thereby straightened until the stem clasps the support very closely, from which it is often prevented from slipping by angles or outgrowths of various kinds, which roughen the surface (fig. I3I).

While gravity thus plays a large part in determining the position of both aerial and subterranean organs, it must be remembered that it works conjointly with many other stimuli. The position of the members is, therefore, a resultant

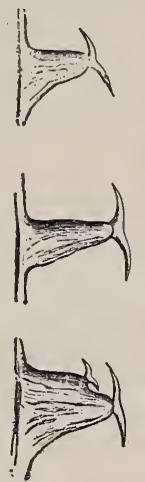

$\mathrm{B}$

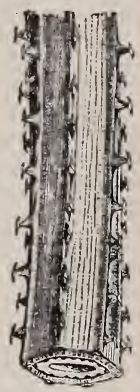

$A$

FIG. 131.- $A$, a bit of the stem of the hop, showing the six angles, each carrying a row of emergences, crowned by a branched rigid hair with very sharp points. Magnified 3 diam. $B$, three emergences more highly magnified.-After Kerner. of the reactions to the various external forces which stimulate them.

250. (d) Hydrotropism.-Hydrotropism is the state of a plant or an organ when it is irritable to moisture. Hydrotropic organs may bend toward or away from a moist surface. Roots are particularly sensitive to the presence of moisture. If a cylinder of wire gauze be filled with damp sawdust and a number of seeds planted near its surface they germinate and the roots start to grow in the normal direction-i.e., directly downward. If now the cylinder be suspended at an angle, as shown in figure 132 , the roots which pass into the air, 
stimulated by the moisture, curve toward the damp sawdust. Upon entering it the stimulus ceases, and they start again to grow downward, being positively geotropic. Again the stimulus of the moist surface overcomes that of gravity, and they turn back to it, often threading themselves in and out of the wire gauze. Since only one-sided action of a stimulus

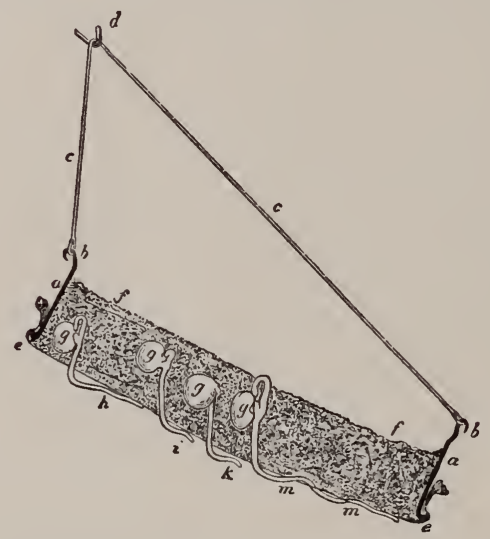

FIG. 132-Apparatus for demonstrating hydrotropism. a, $a$, a zinc disk, with hooks to which is attached a cylinder or trough of wire netting filled with damp sawdust. In this are planted peas, $\rho$, whose roots, $h, i, k, m$, first descend into the air but soon turn toward the damp sawdust again. $m$ has threaded itself in and out of the netting. After Sachs.

determines direction of movement, if the air be saturated they continue to react to the stimulus of gravity alone.

251. (e) Movements due to contact.-Contact, either gentle or forcible, and friction act as stimuli to modify the growth of many plant parts. Only rarely is the main axis of a plant sensitive to mechanical stimuli, except, perhaps, to long continued contact (or pressure) in the case of some twining plants. But in many plants tendrils and leaf-stalks are irritable to contact, even to a degree far surpassing that of our nerves of touch.

If the tip of a tendril ( $\mathbf{2} 25$ ), while still capable of growth, 
come in contact with a solid body, it will quickly become concave on the side touched, and thus will wrap about the object, if it be of suitable size. This curvature is due first to the shortening of the cells upon the concave side and later to unequal growth on the convex and concave sides. Finally this effect extends to all parts of the tendril, which begins to curve. As both ends are fast, it is a mechanical necessity that the curves become spiral coils, both right- and lefthanded, accompanied by a twisting of the tendril on its axis (fig. 69). After the coils are formed the tissues of the tendril become thick-walled and rigid, so that the plant is attached to the support by a spiral spring.

Other tendrils do not nutate, but are negatively heliotropic, and by contact their tips are stimulated to develop disks which apply themselves closely to the support and send into its irregularities short outgrowths from the surface cells. Such plants are adapted to support themselves by walls, treetrunks, etc. The Japanese ivy and one form of the Virginia creeper are notable examples.

The coiling of the leaf-stalks is not unlike the first curvatures described for tendrils (fig. Io०).

\section{EXERCISE XLIII.}

To show effect of contact as a stimulus to tendrils.

Stroke with a pencil the concave side of the tip of a tendril of passion vine, squash, wild cucumber, or balsam-apple, on a warm day or in a hothouse, and observe curvature which follows in a few minutes.

252. (B) Movements of turgor.-The movements already described are confined to members which are growing, either throughout, or in some part. As turgor can affect only tissues whose cell-walls are elastic ( $\left.\mathbf{I}_{5} 6\right)$, the movements produced directly by variation in turgor can nccur only in such. mature members as are provided with special motor organs. In almost all cases these are leaves. Stimuli which regulate 
growth ( $\boldsymbol{\top}_{242}$ ) may also affect motor organs, producing like curvatures. But elongation of any part of a motor organ by increased turgor is reversible, not permanent (cf. 9 2 3 ) ; it is therefore not growth.

253. Motor organs. - The motor organ in leaves is usually the leaf base ( 124 ) or a modified portion of the stalk, sometimes greater but generally less in diameter than the rest. Its

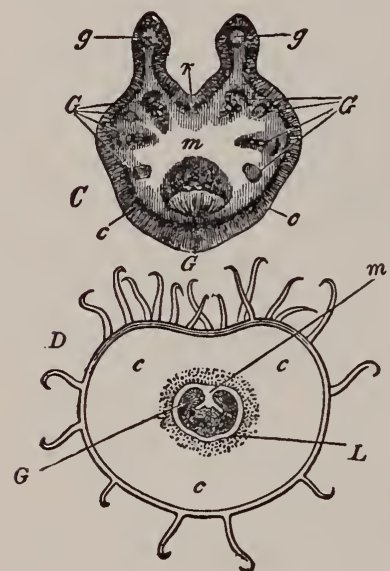

FIG. 133

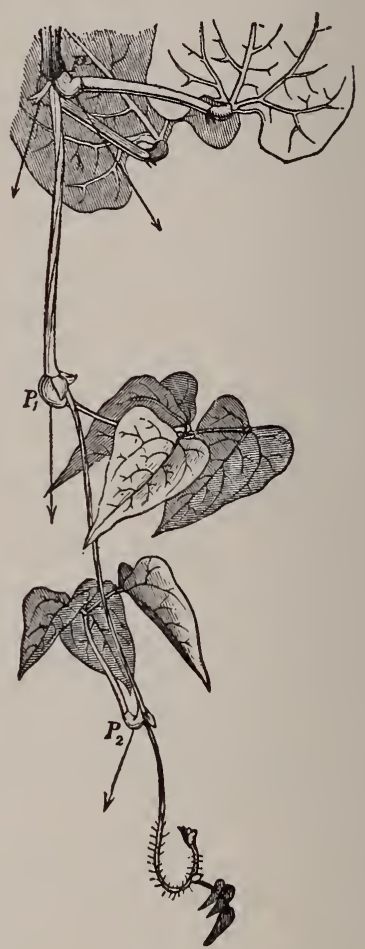

FIG, 134.

FIG I33. - Transverse sections through petiole of scarlet runner. $A$, through the rigid portion; $B$, through the motor organ. $G, g$, vascular strands; $c$, cortex; $m$, pith; $r$, deep channel along ventral side of petiole. Magnified about ro diam.-After Sachs. FIG. 134 . - Portion of a scarlet runner, which, originally growing erect, has been inverted for several hours, resulting in geotropic curvatures of the primary motor organs $P, P^{\prime}$, $I^{\prime \prime 2}$. The lowest pair of leaves show secondary motor organs at the juncture of petiole and blade. Similar ones are present in the upper compound leaves, but are not clearly shown in the figure. 'The arrows show the position of the petioles when the plant was first inverted. About two thirds natural size.-After Sachs.

cortex consists of large cells, and the stele occupies a relatively small part of the transverse section. In other parts of the petiole the stele is much larger, or there may be several 
steles distributed about the center. (See $1 \mathrm{I}^{6}$.) In figure I33, $A$ and $B$ show the contrast. If the leaf be a compound one, there are usually secondary motor organs at the base of the leaflets, as in the leaf of the bean (fig. I34). Variation in the turgor of the cells of the cortex upon one side or the other produces a sharp curvature of the motor organ, which alters the position of the leaf or leaflet (fig. I 34). The concave surface of the motor organ becomes deeply wrinkled transversely, while the convex surface is smooth.

254. Spontaneous movements.-Only a few plants exhibit spontaneous movements by means of motor organs. The lateral leaflets of the telegraph plant $(s$, fig. r 35), under normal conditions of rather high temperature (about $32^{\circ} \mathrm{C}$.), show jerky movements of such direction that their tips describe an irregular ellipse, which is completed in $\mathrm{I}$ to 3 minutes. The leaflets of the clovers and oxal is show much slower movements described in the next paragraph.

More commonly the turgor movements are induced. The most common stimuli are light and contact, although many

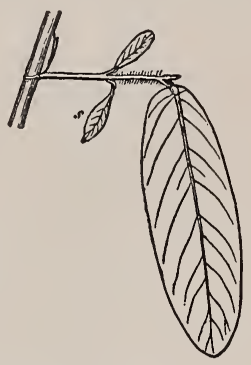

FIG. 135.-Leaf of Desmodium gyrans. Two thirds natural size.-After Sachs. others suffice to induce them.

255. Light movements.-Movements produced by the variations of light have long been known as "sleep movements." They are best observed upon the leaves of the bean family, though many other plants exhibit them. Figure I 36 shows the positions assumed by various leaves toward nightfall. It will be seen that in compound leaves the leaflets sometimes rise, so as to apply their outer faces to each other; others sink, so that the under surfaces are in contact; others become folded in various ways. This position is maintained throughout the night. Upon the increase of light in 
the morning, the day position is assumed. The cutting off of light artificially from any of these plants causes them
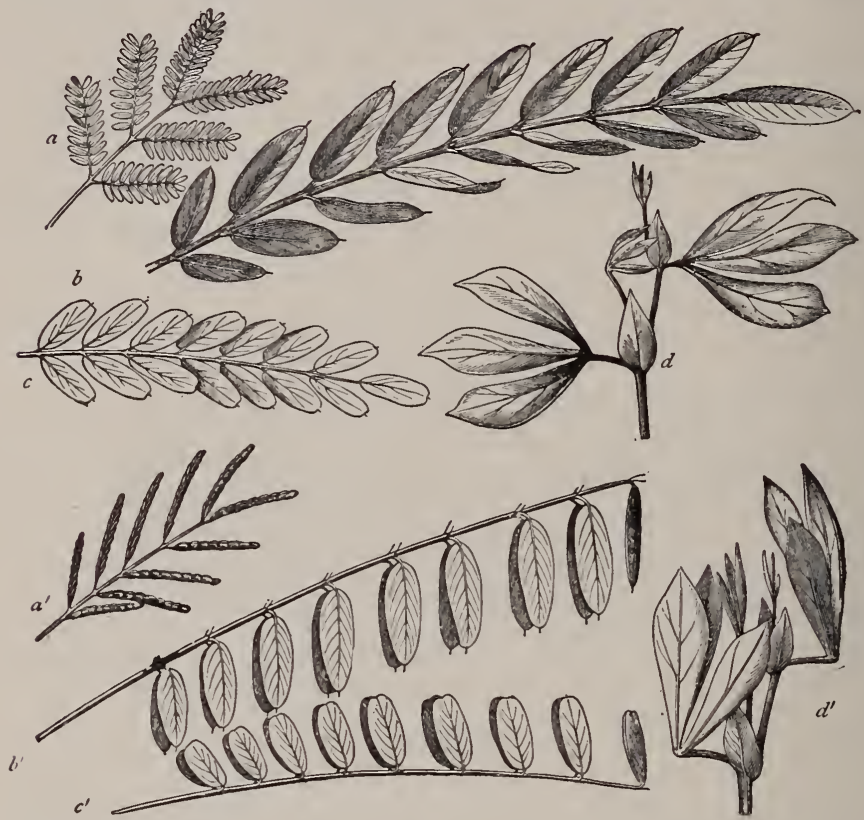

FIG. 136. - Photeolic movements. $a$, leaf of a mimosa in day position; $a^{\prime}$, the same in night position. b, leaf of Coronilla varia in day position; $b^{\prime}$, the same in night position. $c$, leaf of $A$ morpha fruticosa in day position; $c^{\prime}$, the same in night position. $d$, leaf of Tetragonolobus in day position ; $d^{\prime}$, same in night position.-After Kerner.

within a short time to assume the nocturnal position. Their purpose is not certainly known.

\section{EXERCISE XLIV.}

To show effect of intensity of light as a stimulus on certain leaves.

Observe the position of the leaflets of white, red, or sweet clover, bean, locust, or oxalis at 3 P.M., 6 P.M., at dusk (or after nightfall by using a lantern) and at 8 A.M. In the morning darken with a box a plant showing these movements. After an hour or two, observe the position of leaflets.

256. Contact movements. - Some organs are sensitive to contact, as the leaves of Venus' fly-trap, and other related 
plants. The motor organ in the Venus' fly-trap (figs. 224 , r37) is the cushion of tissue running along the back of the leaf between the two lobes. By the sudden variation in turgor of some of these cells the two halves of the leaf are thrown quickly together when one of the six bristles upon its

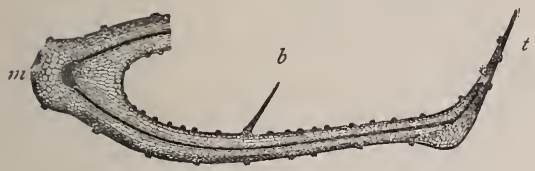

Fili. 137 .
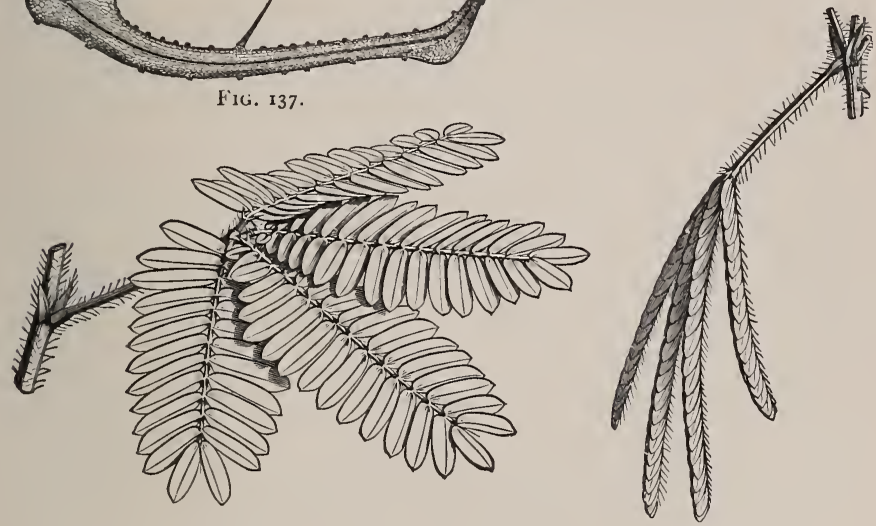

FIG. 138.

FIG. 139.

FIG. 137.-Part of a transverse section of a leaf of Venus' fly-trap. m, the cushion of tissue constituting the motor organ; $b$, one of the sensitive bristles which, upon being touched, cause the leaf to close : $t$, one of the interlocking teeth. The minute projections over inner (ventral) surface are glands which secrete the digestive fluid and later absorb the food. Magnified about 5 diam.-After Kurz.

FIG. 138.-A leaf of the sensitive plant fully expanded. Natural size.-After Duchartre.

FIg. I39.-A leaf of the sensitive plant after stimulation The motor organ at the base of each leaflet has thrown it forward and upward; the motor organs at the base of the four divisions have moved them together. The motor organ at the base of the main petiole has moved the whole leaf sharply downward. Natural size.--After Duchartre.

upper surface is touched. The sensitive plant drops one of its leaflets or the whole leaf quickly when stimulated by contact, heat, or electricity. The position of the leaves when normally expanded is shown in figure $\mathrm{r}_{3} 8$, and their position after stimulation by figure $\mathbf{r} 39$. The stamens ( $\left.\begin{array}{l}\boldsymbol{\top} \\ 287\end{array}\right)$ of some flowers and the stigmas $\left(\mathbf{T}_{2} 8_{3}\right)$ of others are sensitive 
to a touch, shortening, elongating, or bending in such a way as to promote pollination ( 9295 ).

The motor organs of the leaves of a number of the bean and oxalis families also react to more violent mechanical stimuli. Their movements are similar to those described in $\uparrow 255$.

257. Summary.-By irritability, that is, the sensitiveness of protoplasm to external agents, plants are able to regulate all their activity and adjust themselves to the world about them. Under unfavorable conditions this sensitiveness is temporarily lost. If permanently lost, it is death. It is more marked in some parts than others and its effects in these parts are capable of being transmitted to distant parts.

The reactions of plants to stimuli are most easily observed when they result in movements. Movements of the protoplasm itself seem to be automatic, but can be directed by external stimuli. Movements of multicellular plants are due either to unequal growth or to unequal turgor. Light, heat, gravity, moisture, or contact may so influence the rate of growth, or the amount of turgor as to cause curvature of growing parts or of a special motor organ. The parts affected may thus be turned toward or away from the source of the stimulus, or may be placed transverse to it. Movements in response to gravity, light, and heat are most important. These work conjointly to determine the position of organs. 


\title{
PART III: REPRODUCTION.
}

\author{
CHAPTER XVII.
}

\section{VEGETATIVE REPRODUCTION.}

258. Introduction.- - Having considered in Parts I and II the structures and functions by which the nutrition of the individual is secured, Part III is devoted to the consideration of the structure and functions of some of the simpler reproductive organs and the functions by which a succession of similar individuals is insured. (For fuller discussion see Plant Life.)

One of the fundamental powers of protoplasm is its ability to produce new organisms as offspring from the older ones. In the simpler plants the two great functions, nutrition and reproduction, are often carried on by the same cell. This must always be so in the unicellular plants. In the higher plants, however, these two functions become completely separated, organs being specialized for each, so that the functions may be more certainly and efficiently performed.

Any part capable of growing into a new individual may be called a reproductive body, and the part on which or in which it is produced is a reproductive organ. If the reproductive bodies consist of one or two cells only, they are usually called spores. If they are cell-masses, they are generally called brood buds or gemmee to distinguish them from ordi- 
nary buds. In both cases it is necessary that the cells to be separated from the parent should be capable of growth-that is, in the condition known as the embryonic phase ( 2 I 5 ). The reproductive organs produced by some plants are exceedingly complex and varied, while others form reproductive bodies in very direct ways. The reproductive bodies themselves are generally very simple. In addition to complex reproductive organs, there are sometimes accessory parts by which the plant adapts its reproductive functions to the conditions under which it lives. Among these accessory structures are many, as among the flowers of seed plants, by which the aid of other plants or animals is secured.

259. Vegetative and sexual reproduction.-In all the diversity of organs and processes two chief methods may be distinguished, called vegetative reproduction and sexual reproduction.

Vegetative reproduction consists in the formation of reproductive bodies by processes of growth only. The modes in which they arise are varied in detail, but consist essentially in the production by the parent of a body, unicellular or multicellular, which at maturity develops, under suitable conditions, into a new plant. It is scarcely to be doubted that the earliest methods of reproduction were vegetative, and that sexuality has been acquired by a gradual adaptation of cells previously devoted wholly to ordinary processes of growth.

Sexual reproduction consists in the formation of reproductive bodies by the union of two specialized cells, neither of which alone is capable of developing into a new plant.

\section{Fission and budding.}

260. Fission.-In single-celled plants cell division and reproduction are practically identical, since shortly after division occurs the two cells so produced separate and lead 
an independent existence ( $C$, fig. IO). Such a method of reproduction evidently interferes little with the processes of nutrition, which probably are scarcely even suspended during the process of reproduction.

261. Budding.-A slight variation of the method of fission just described is to be found in those single-celled plants, such as the yeasts, whose growth is so localized as to form upon one side a small enlargement which ultimately attains the size of the parent, with which it is connected by a very narrow neck (fig. 29). Across this neck the partition wall is formed in the usual way. This becomes mucilaginous, rendering the adhesion of the daughter cell at this point so weak that it is easily separated from the parent. This method of reproduction is known as budding.

262. Fragmentation.-In those plants which consist of a row of cells more or less closely united, the breaking up of the filaments into separate pieces, either through external force or the death of one of the cells, may produce a number of smaller colonies or of new individuals, each of which may grow to full size. In some of the more loosely organized filament-colonies, such as Nostoc (see $T$ I I, and fig. 6), there are specialized cells whose function seems to be to loosen pieces of definite length, which creep out of the jelly, grow, and thus produce new colonies.

The greater size reached by most multicellular plants soon renders impossible the continuance of this method of reproduction, except among those whose cells are all alike. Should such separation into nearly equal parts occur among more highly specialized plants, it is evident that one portion might easily be left without nutritive organs adapted to its needs. The higher plants, therefore, specialize certain regions or members, where, by division or budding or similar processes, reproductive bodies may be formed. 


\section{Spores.}

263. Sexual and non-sexual spores.-A spore is a single-

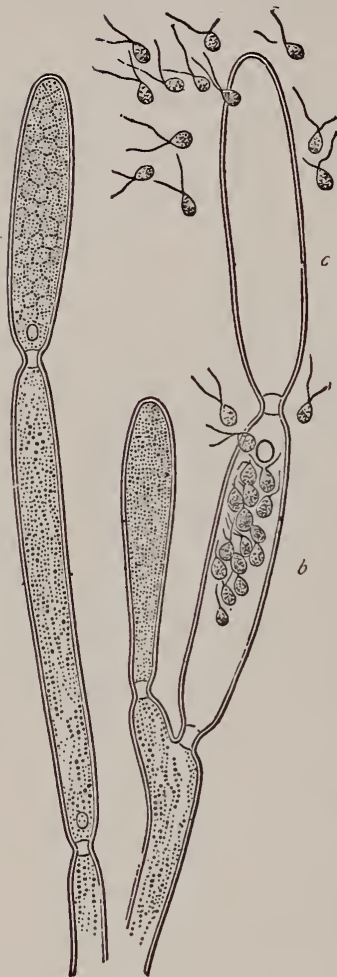

Fig. 140.-Develupment and escape of zoospores of an aquatic fungus (Saproiegniulactea). The ends of two hyphæ are shown, the terminal cells being spore cases. In $a$, the protoplasm is gathering to form spores. From $b$ many of the zoospores have escaped through the perforation in the wall near the upper end of the cell. From $c$ all have escaped but one, which is just slipping through the opening (here in profile). Magnified 300 diam.-After Kerner. celled body capable of producing a new plant. Spores may be formed either by a process of growth or by the union of two cells. The former are called nonsexual spores; the latter, sexual spores. Only non-sexual spores are discussed in this chapter.

264. Motile spores. - Spores may be either naked and motile or furnished with a cell-membrane and non-motile. The former are commonly produced by plants which pass all or part of their lives in water, such as the algæ and aquatic fungi. They are usually pear-shaped and furnished with one or more cilia, by means of which they swim about (figs. I09, I40). When locomotion was supposed to be a distinctive power of animal bodies they were called zoospores, a name still retained. They are also called swarm-spores.

Zoospores are formed either in a general body-cell, not visibly different from the other bodycells, or in a cell specialized in form and structure, the spore case. The entire contents of the spore case may form a single zoospore, or it may divide into several or many. The zoospores are 
set free by the rupture or by the solution of a portion of the enclosing wall (fig. 140). They may begin to move betore the rupture of the wall, in accomplishing which their activity may materially assist. They then work their way out and swim freely in the water. After a time of movement they usually lose their cilia, either withdrawing them into the protoplasm or dropping them off, come to rest, and begin to grow into a new plant.

265. Non-motile spores are formed by all classes of land plants without exception. They are often produced in great profusion, especially by the fungi, the mosses, the ferns, and the seed plants.

266. Form and food.-Their form is exceedingly various. Many are spherical or ovoid, while some are cylindrical or

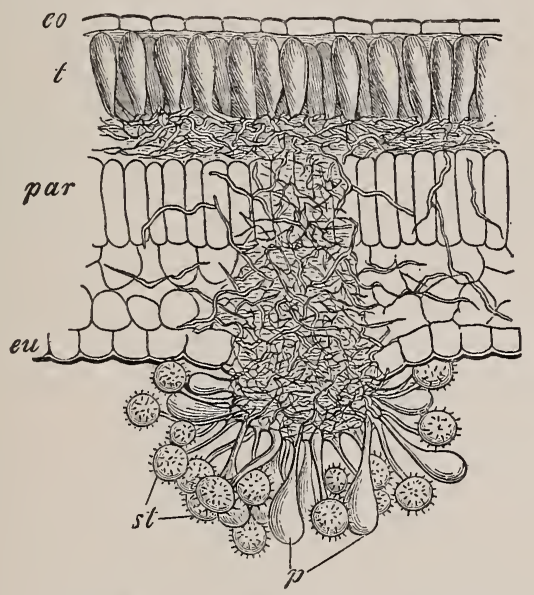

FIG. 141.-Part of a vertical section of a leaf of a willow, attacked by a fungus (Mela $m p$ sora salicina). eo. epidermis of upper side lifted by the young teleuto-spores, $t$, developing from the spore-bed above the ands of the palisade cells of the host $($ par $)$; $e u$, epidermis of the under side, broken through by the spore-bed from which spring uredo-spores, st, and paraphyses, $p$. eo will also finally be ruptured to. set free $t$. Magnified 260 diam.-After Prantl.

even needle-shaped (figs. I4I, I43, I66). Irregular forms, also, are not uncommon. The same plant may produce at 
different stages or in different parts spores which are unlike in form and nature (compare $t$ and st, fig. I4 I). In almost all cases there is a supply of reserve food within the spore, which varies in amount with the conditions under which they are formed. It is ordinarily greater in resting spores than in those intended for immediate growth.

267. Growth. - Spores germinate by absorbing water, thus bursting the more rigid outer layer or layers of the cellwall. The inner layer then grows in area to accommodate the increasing protoplasm, which so controls the mode of growth as to produce a plant of definite form. In many cases the plant produced is essentially like that which gave rise to the spore. In others it is different, but sooner or later in the life cycle the same form recurs.

268. Origin.-Non-motile spores are either free, being produced at the ends of branches specialized for that purpose, or enclosed in a spore case. Often the same plant forms spores by both methods at different stages in its development.

269. Free spores.-The formation of free spores is confined to the lower plants, and is especially characteristic of the non-aquatic fungi. The branches producing spores may occur singly, or, more commonly, they are grouped at certain points, forming a spore-bed (fig. I4 I). If the fungus develops its mycelium in the interior of a host, the formation of a spore-bed is often necessary to rupture the host, so that the spores may be brought to the surface and set free. Thus the spore-beds of parasitic fungi commonly blister the surface of the host by lifting up its outer tissues (eo, fig. I4 I).

Spores may be produced either singly at the ends of the branches, or in chains (fig. 142).

A modification of the production of spores singly occurs when the branch destined to produce them gives rise to two to eight very slender branches, each of which enlarges at the 
tip into a single spore, so that the main branch appears to carry two to eight spores upon slender stalks (fig. 143).

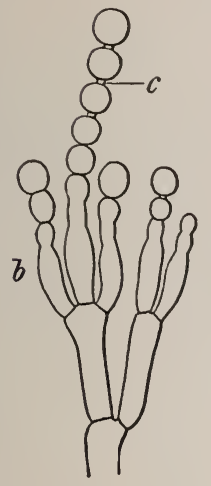

FIG. I42.

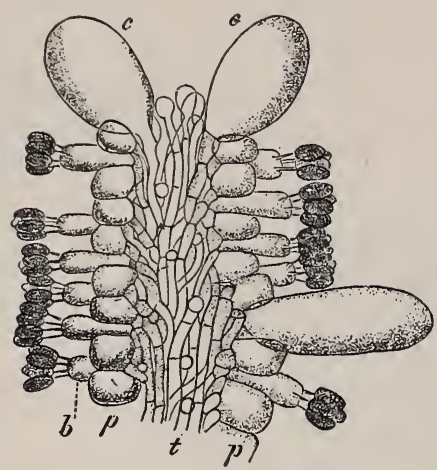

FIG. I43.

FIG. I42.-An outline showing the formation of a spore-chain of the blue-green mold (P'enicillium glaucum). b, branch of spore-bearing hypha, budding beneath two older spores. Across the narrow neck a partition wall is formed, the spores round off, and from this wall a device, $c$, for loosening the spores is developed. The terminal spore is oldest. Highly magnified.-After Frank.

FIG. T43.-Longitudinal section through the edge of a gill of a mushroom (Coprinus) after spore-formation is completed. $t$, interwoven hyphæ of the gill, branching to form the spore bed, composed of sterile branches, $p$, swolien branches, $c$, and sporebearing branches, $b$. The latter give rise to four slender branches, whose tips enlarge to form each a single spore. $\not p$ and $c$ do not produce spores. Magnified 300 diam.After Brefeld.

270. Fructifications.-In the higher fungi whose mycelium is developed within a dead substratum many hyphæ are aggregated to constitute a reproductive structure or fructification, which is the only conspicuous part of the fungus. (For an account of the regetative parts, see $\uparrow 43,47$ ).

The body of the fructification is made up of hyphæ, more or less interlaced and adherent, and is of a form adapted not only to break through the substratum, but also to furnish an extensive surface for the spore-beds (fig. I43).

The fructification may be irregularly lobed, sessile and gelatinous, or much branched and cylindrical or flattened; the shapes being adapted in various ways to form an extensive surface on which spores may be formed (figs. I44, I45). 
271. Simple spore cases.-Spores are also formed loose in the interior of cells. Each spore-containing cell is

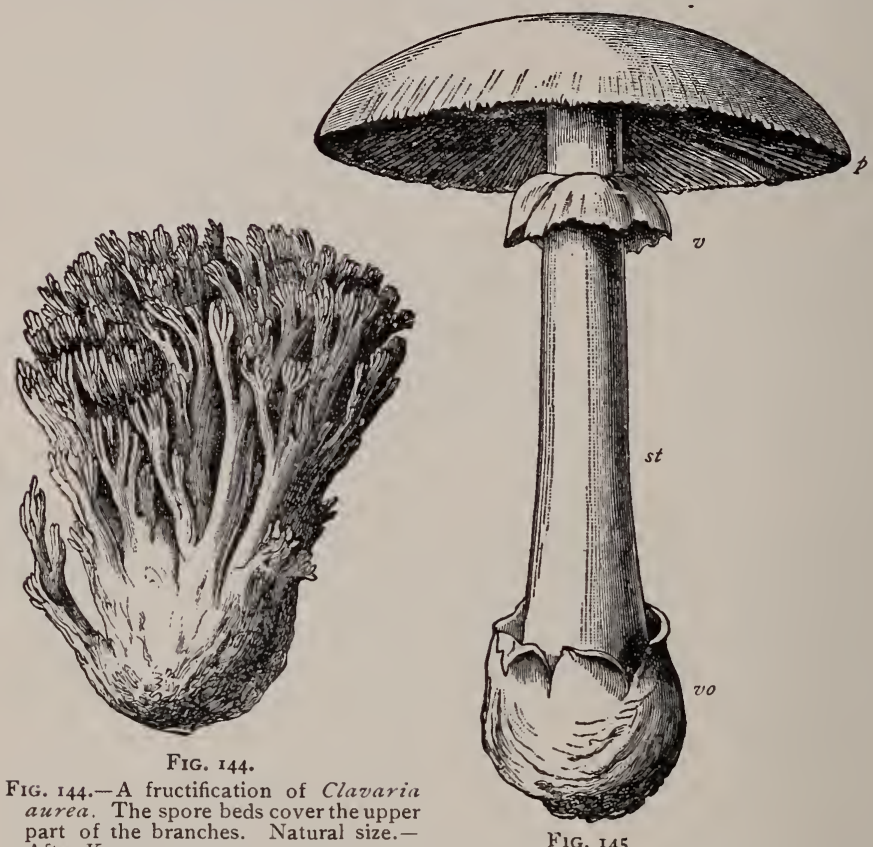
part of the branches. Natural sizeAfter Kerner.

Fig. 145

FIG. 145.-A fructification of a mushroom, A manita phalloides. $p$, the cap or pileus; ", the veil, originally connected with edge of cap, covering the gills which radiate from the stipe, st, to the edge of cap; vo, the volva. The surface of the gills is covered with the spore beds. Most mushrooms showing a distinct volva are poisonous. Natural size.-After Kerner.

called a simple spore case (fig. I46). In the lower plants, the spore case may be merely one of the general body-cells, or it may be specialized in form as well as in function. It may be spherical, sac-like, or linear. The number of spores formed within a simple spore case may be two or more, up to several hundred. Simple spore cases may be formed singly or they may be grouped.

272. Compound spore cases.-In the higher plants, in- 
cluding the mossworts, fernworts, and seed plants, the spore case is always formed of two or more spore-producing cells, surrounded by a covering of cells (one or more layers) which do not produce spores. These spore cases may be developed

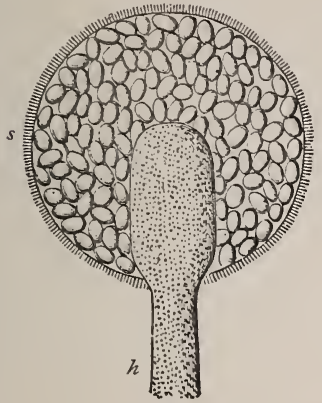

Fig. 146 .

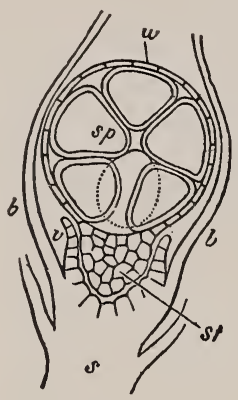

Fig. 147.

FIG. 146.-Longitudinal section of the simple spore case of a mold ( $M$ ucor). The aerial hypha, $h$, has partitioned off a cell, $s$, within which spores are produced. The walls of this spore case are studded with needle crystals of calciuin oxalate. The partition protrudes far into the spore case. Magnified 260 diam.-After Kerner.

FIG. 147.-Longitudinal section of the stem, $s$, of a moss gametophyte, bearing leaves, $b$. Embedded in the stem is the sporophyte, consisting of a stalk, st, and a compound spore case, of which $w$ is the wall, formed of a sheet of cells, enclosing the spores, $s p$ (contents not shown). Magnified roo diam.-After Hofmeister.

either from superficial or from internal cells. As a consequence, the mature sporangia will be either free or more or less enclosed within the tissues of the organ by which they are borne.

273. The sporophyte.-Among the mossworts, fernworts, and seed plants reproduction by spores has become so fixed and important that one stage in the plant is devoted especially to producing them. This phase is different from that producing sex cells, the difference becoming greater the more complex the plant. The stage set apart for spore production is called the sporophyte. In the mossworts the sporophyte has very little green tissue, and therefore carries on little nutritive work, but depends for its supply of food chiefly 
upon the sexual stage, with which it is connected throughout

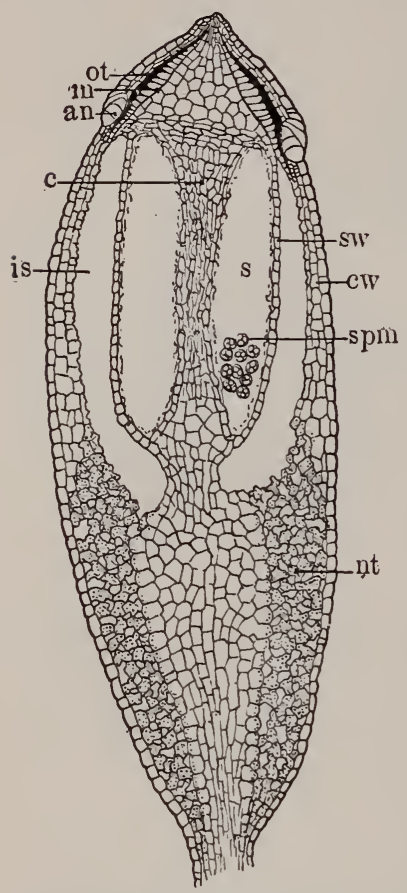

FIG. 148.-Longitudinal section of the young capsule of a true moss (Bryum). $s$, spore case. At this stage the mother cells of the spores, $s p m$, have become free (only a few are shown, still enclosing the spores, which are later releasedi; sw, the wall of the spore case, lined by the remains of another layer of cells now disorganized; $c$, the columella, of partly collapsed cells ; is, intercellular space; crw, wall of the capsule; $a n$, the annulus, a ring of cells which pries off the lid, at whose edge they develop; ot, the outer, $m$, the inner peristome, formed by the thickening of parts of the walls of certain rows of cells; $n t$, nutritive tissue, with chloroplasts and intercelOriginal. lular spaces. Magnified 25 diam.-

its entire existence ( 60 ). In the fernworts and seed plants, however, the sporophyte possesses extensive nutritive tissues, the leaves, stems, and roots belonging entirely to this stage. Sporangia in these plants may be formed either upon the stem or the leaves-never upon the roots.

\section{Liverworts and mosses.} -In most liverworts and mosses the spore case is developed within the enlarged upper part of the sporophyte, to which the name capsule is given (figs. 46, I48, and 59). By the time the spores are mature the capsule has become filled with the loose spores. It bursts at the top or opens by the falling off of the lid-like upper end, and thus allows the spores to escape.

275. Ferns. - In the ferns the sporophyte phase is the plant with roots and leaves. The spore cases are either produced upon the under surface of the foliage leaves or upon specialized leaves. They are usually numerous, stalked, free, and often associated in clusters. The clusters are often arranged in elongated groups or lines (fig. I49). 
Each cluster may be protected by a special outgrowth from the cells in its neighborhood (figs. I 49, r50). Each spore case consists of a stalk expanding above into a body composed of a single outer layer, enclosing at maturity the loose spores (fig. $236)$.

276. Spore leaves.-In many of the ferns the leaves which produce spore cases are not different from the foliage leaves. In others, certain leaves are so specialized for bearing the spore cases that they abandon their nutritive work in part or entirely. To such specialized leaves the name spore leaves is applied.

276a. Differentiation of sp res - Arong higher fernworts the spores are of two sizes: large ones, known as megaspores, and much smaller ones known

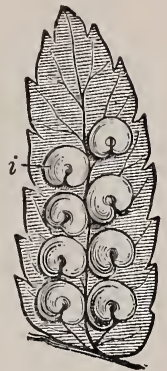

FIG. 149.-A leaflet of a fern (Aspidium) seen from the back. Eight clusters of spore cases are shown, each covered by its own indusium, i. Magnified 2 diam. After Sachs. as microspores (fig. 15I). Each kind, when it germinates, produces a sexual plant. The megaspores give rise to plants bearing female organs only, the microspores to those bearing male organs only. A similar separation of sexes in the gametophytes frequently occurs when the spores

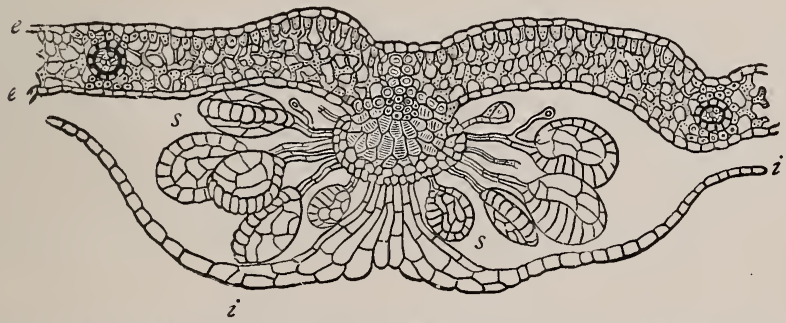

FIG. 150.-Vertical section through the leaflet shown in fig. 149, passing through the center of a spore-case cluster. $e$, ventral epidermis; $e^{\prime}$, dorsal epidermis; between them the mesophyll, showing 3 veins cut across; over the central one is a cushion of tissue from whose surface arise the stalked spore cases $s, s . i, i$, the indusium. Magnified about 30 diam.-After Sachs.

are equal in size, as in Marchantia and horsetails, but it always occurs when they are unequal. A corresponding difference in size is often found 
between the spore cases containing small spores and those containing large spores (fig. I5 I).

In the seed plants this difference in the spores is always found. The

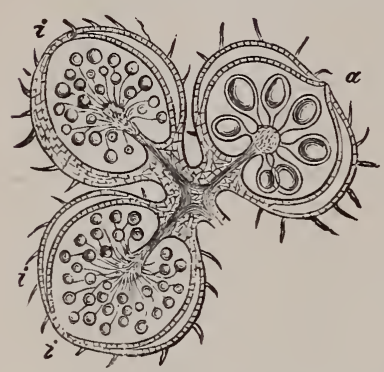

FIG. 151.-Section through three spore case clusters of an aquatic fernwort (Salvinia natans). Each is covered by a double indusium. $i, i$, two clusters consisting of small spore cases, each containing 64 microspores; $a$, a cluster consisting of large spore cases, each containing one megaspore. Magnified ro diam. -After Sachs.

27\%. The spore leaves of the seed plants are usually clustered by the failure of the internodes of the axis to lengthen as much as between the foliage leaves. Very often, also, the leaves adjacent are modified in form and color to adapt them to securing the dispersal of the pollen by various agents, especially insects. Such a shoot bearing stamens, carpels, and accessory leaves is called a flower. As a similar aggregation of the spore leaves occurs in horsetails and many club-mosses it is evident that the flower is not distinctive of the seed plants, though it attains the highest specialization among them. $\dagger$

* These special names were given because the seed plants were first studied, and it was long before the real nature of the parts and their relation to similar ones in the lower plants were known. The terms are still in use, and are likely to continue to be used for convenience.

† It is for this reason that the term seed plants is preferred to flowering plants. 
The parts and functions of the flower of seed plants are now to be discussed.

\section{The Flower.}

278. A flower usually consists of a shortened axis, the torus, bearing several floral leaves (figs. 66, I 52). The spore leaves are known as essential organs, the accessory leaves as the perianth and bracts.

The essential organs are of two sorts, stamens and carpels. In any flower they may be all stamens or all carpels, or may include both sorts. The perianth may be composed of $\begin{gathered}F_{1 G} \text {. 152. } \\ \text { ing a pestle-like pistil. Magnified about }\end{gathered}$ one or two kinds of leaves,

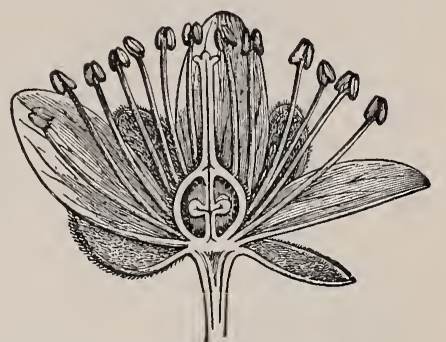
3 diam.-After Kerner.

often bright-colored. If there are two sorts, those next the spore leaves are generally highly colored, and constitute the corolla. Each leaf of the corolla, when distinct, is a petal. The leaves below the corolla are often green. They constitute the calyx, and each, when distinct, is a sepal.

2\%9. Carpels. - The leaves bearing the ovules are called carpels. They may be flattened; or so curved that in the course of their development the edges unite and a cavity is more or less perfectly enclosed; or neighboring carpels may grow together in such a way as to form a case. Such hollow structures, whether composed of one or more carpels, are often somewhat pestle-shaped, whence they early received the name pistil (fig. I 52). A flower whose only essential organs are pistils is called pistillate.

280. Ovules.-Among seed plants the spore cases which the carpels bear are universally known as ovules, a name given to them under the supposition that they were the eggs which, upon fertilization, produce new plants. Though they 
are not in any respect comparable to the real eggs (since they are produced by the non-sexual or sporophyte phase), the name is retained for convenience. The ovules arise usually upon the ventral (inner) face or the edges of the carpels. In the open carpel they are exposed, but in the closed carpels they are completely shut in, except for a narrow opening which sometimes remains, by which the interior cavity communicates with the outside air.

281. Gymnosperms and angiosperms. - When the changes through which the ovule passes are complete, it becomes the

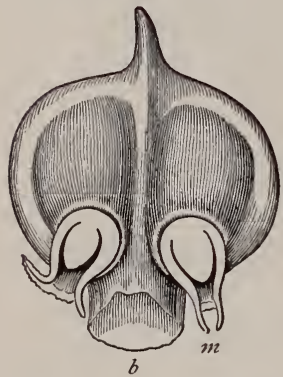

Fig. r53.-A young conescale of Scotch pine showing the two ovules; the latter halved parallel to the scale, showing the body of ovule and the prolonged integument forming the micropyle, $m$. The scale is attached at $b$. Magnified about 8 diam.After Kerner. seed. When the ovules are produced upon the free surface of an open carpel, the seeds are, therefore, exposed. On the contrary, when the ovules are borne within a closed pistil (formed by one or more carpels) the seeds are developed within this case, by which they are protected until mature, or longer.

These two methods of seed production form the basis for the separation of the seed-bearing plants into two great groups, one known as gymnosperms, or plants with naked seeds, the other as the angiosperms, or plants with encased seeds. Open carpels (fig. I53) are found exclusively among the gymnosperms, to which belong the cone-bearing, mostly evergreen, trees, while the closed pistils are chiefly found among angiosperms, to which belong the majority of garden and field plants and the deciduous forest trees.

282. The closed pistils of angiosperms are usually distinguishable into (I) an enlarged basal part, the ovulary,*

* This part was early called the ovary (a name which is still in general use), meaning the organ which produces eggs, under the impression that 
containing the ovules, surmounted by (2) a slender part of variable length, the style, which is terminated by (3) a rough, sticky, or branched part, the sigma. (See figs. I $5^{2},{ }_{5} 6$.)

283. Stigma and style.-The stigma may take the form of a knob, a ridge, a straight or wavy line, or be lobed or branched. However compact, it is usually roughened by the prolongation of its surface cells into rounded, pointed, or hair-like extensions (fig. I 54), which frequently secrete a sticky fluid. Its purpose is to secure the adhesion of the pollen spores brought to it by various agents, among the most important of which are the wind and insects.

The style may be thick or slender, long or short, branched or unbranched, hollow or solid. It is frequently wanting.

\section{Simple and compound pistils.} -When several carpels are present in one flower they may form as many separate simple pistils as there are carpels. If numerous, the axis will be enlarged or elongated to accommodate them. (See T 296, and fig. I73.) Instead of forming separate

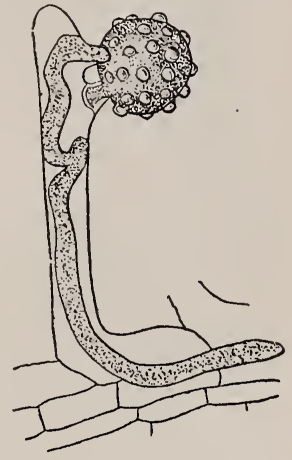

Fig. 154.- One of the hairs from the stigma of corn cockle (Lychnis githago) to which a pollen grain adheres. The pollen tube has penetrated the hair and is making its way down the style. Magnified 175 diam. -After Strasburger.

pistils, the carpels may be united to form a single compound pistil.

The union of the carpels may be only at the base; or it

the ovules ( = little eggs) were like the eggs of birds, an idea which was further carried out in the name albumen given to the food stored in the seed. (See 9 305.) To avoid confusion with the true ovary in which the real egg is produced, I use the name ovulary-i.e., the organ which produces ovules. The word ovule, though as bad in etymology as ovary, is convenient, and does not lead to any confusion. 
may involve the entire ovulary, leaving the styles free; or the union may be complete, with the exception of the stigmas; or it may involve even them (figs. I $55,{ }_{5} 6$ ).

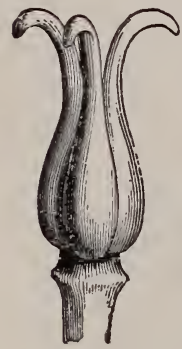

Fici, 155 .

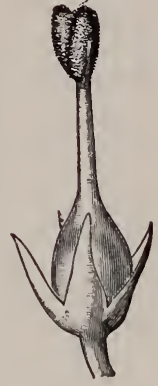

FiG. 156 .

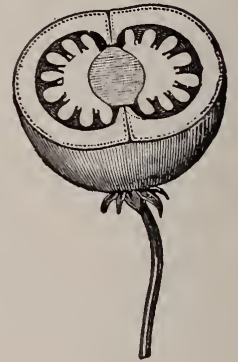

F1G. 157.

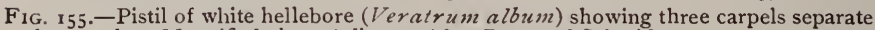
above only. Magnified about 6 diam.-After Berg and Schmidt.

Fig. 156.-Calyx and pistil of the manna ash (Fraxinus ornus) showing calyx leaves united at base and carpels united throughout, the slightly 2-lobed stigma only giving external evidence of their number. Magnified several diam. - After Berg and Schmidt.

$F_{1 G}$ 157.-Pistil of white potato halved transversely, showing two carpels united at center where their edges form a large placenta on whose surface the ovules arise. Magnified several diam.-After Kerner.

285. The ovulary.-The cavity of the ovulary is either undivided or partitioned into as many chambers as there are component carpels (fig. I57); or the normal number of

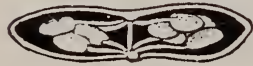

FIG. I58.-A transverse section of the capsule of shepherd's purse. The pistil consists of two carpels, at whose united edges two placentæ are formed carrying the ovules (now seeds). The partition from one placenta to the other is an outgrowth (false partition) and not part of the carpel. Magnified about 6 diam.-Atter Bessey. chambers in the ovulary may be increased by outgrowths from the carpels themselves (fig. I 58).

286. Ovules.-An ovule consists of a central body, the spore case, in which the megaspores are formed. In a few ovules as many as 20 to 40 megaspores begin to develop; in most only one to four. Even when several megaspores begin to form it is rare for more than one to reach perfection; the remainder disappear almost completely. The megaspore never escapes from the spore case; for this reason the megaspore looks more like a cavity in the ovule than like 
a spore. Because an embryo appears later inside this apparent cavity, the megaspore of seed plants has long been called the embryo-sac.

The spore case is surrounded by one or two integuments. These arise as outgrowths from the parts adjacent. If the spore case is to have two coats, the inner appears first as a low ring around its base gradually growing up around it; the outer shortly appears in the same way (fig. I 59). These integuments, as well as the spore case, often grow unsymmetrically, so that at the maturity of the megaspore the ovule is often variously curved (figs. I 59, I60). The megaspore

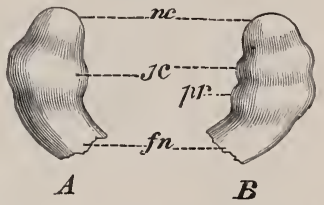

FIG. 159.-Two very young ovules of the California poppy (Eschschaltzia), seen from the outside. $B$, somewhat older than $A$. $n c$, the rudiment of the spore case; $j c$, rudiment of the inner integunient ; pr, rudiment of the outer integument; $f n$, the stalk. Magnified r 40 diam.-After Duchartre. itself may be distorted by this means so as to lose still more its likeness to a spore.

Ovules are borne either upon the axis itself or upon

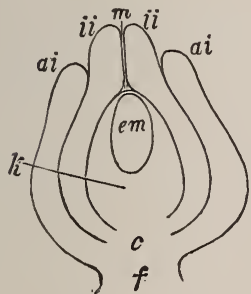

A

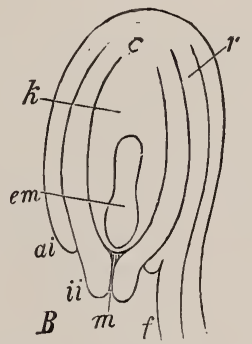

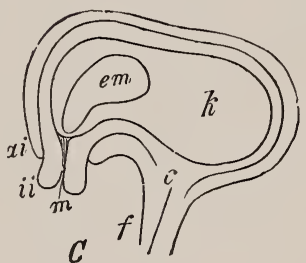

C

FIG. 160.-Diagrams of median longitudinal sections of three sorts of ovules to show curvatures due to unsymmetric growth. $A$, a straight, $B$, an inverted, $C$, a bent ovule. In all: $f$, the stalk; $k$, the spore case; $i i$, the inner integument; $a i$, the outer integument; $m$, the micropyle; $c$, the base of the spore case where the integuments arise (called the chalaza); $r$, the ridge (rhaphe) formed by the union of stalk and outer integument; $e m$, the megaspore. As $C$ develops further $e m$ may become sharply bent on itself.-After Prantl.

the carpels. It is usual for the ovules to arise upon a carpel, either singly or in clusters, from a cushion or ridge, 
called the placenta. The placenta in angiosperms is commonly located at the united edges of the carpel or carpels. If the carpels are united into a compound pistil, the placentas will be either isolated, as ridges upon the inner face of the wall of the ovulary (fig. I 58), or aggregated at its center (fig. I57). Occasionally the ovules arise upon the entire inner face of the carpels, as in the gentians.

28\%. Stamens. - A stamen is a leaf of the seed plants which bears the pollen sacs. The flowers whose essential organs are all stamens are said to be staminate. Rarely a single stamen constitutes a flower. Except for the crowding, the stamens are arranged like all the other leaves of the plant, arising on the axis alternately, or in one or more circles. The stamens exhibit great diversity of form and size. Each usually consists of two parts, a stalk, called the filament, bearing an enlarged portion, called the anther (st, fig. 66).

The anther is usually larger than the filament and commonly two-lobed, having the sporangia located in the thicker parts.

288. Spore cases.-The anther bears from I-I 2 pollen sacs (spore cases) upon its surface, or wholly or partly sunk in its tissues. In most anthers the pollen sacs are either two or four (fig. I6 I). When there are four they are often paired, and each pair may become confluent by the absorption of the partition between them (fig. I62). This occurs about the same time that the outer wall bursts in order to set free the spores. Such anthers, at the time of opening, are apparently two-chambered.

289. Dehiscence.-The opening of the chambers occurs in one of three ways: by pores, by slits, or by valves. (I) A small area of the outer wall is absorbed or breaks away so that the pollen spores sift out through the pore so formed (fig. I63); or (2) a crack begins at one point and extends 
lengthwise of the anther (fig. I $6_{4}$ ); or (3) the break occurs along a line considerably curved, and the flap (valve) thus

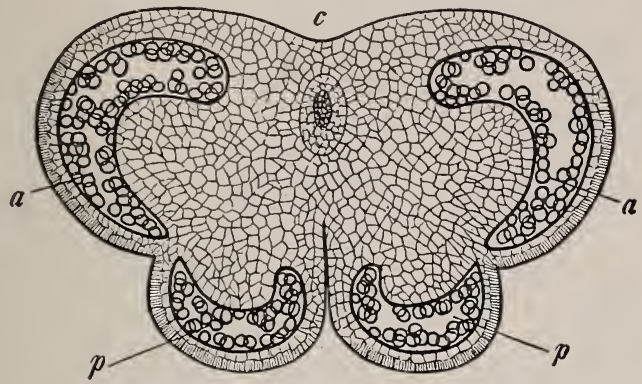

FIG. 161.-Transverse section of the anther of thorn-apple (Datura Stramonium). $c$, connective, with a small stele embedded in parenchyma; $a, p, a, \not$, the four spore cases, arranged in pairs showing pollen grains. When the spore cases break, the walls rupture at the groove between $a$ and $p$. Magnified about 25 diam.-After Frank.

loosened curls up or lifts so as to allow the escape of the spores (fig. 165). All three methods are dependent upon some special structure of the wall of the spore case at the lines of rupture (figs. I6 I, I62).

290. Union.-The stamens are not infrequently united with one another or with some of the neighboring leaves of the flower. They may be united to one another by their filaments only, or by their anthers only, or throughout their whole length. Union with the pistil or pistils is rather uncommon, but union with the corolla or calyx is very frequent. The stamens also branch just as

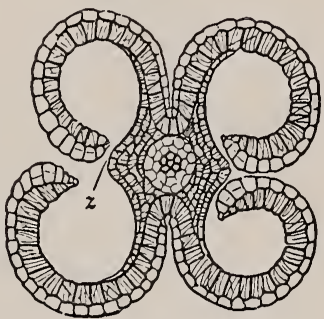

FIG. 162.-Transverse section of bursted anther of a lily (Butomus umbellatus). Sporangia have ruptured at $z$, so that the two pairs have each formed a single cavity. The connective is relatively small ; in the center a single stele. Magnified about 20 diam.-After Sachs. ordinary leaves do.

291. Pollen grains.-The spores produced in the spore cases of the stamens are of various forms, being round, 
ovoid, or even angular, with the surface smooth, grooved, or roughened with few or many bosses, points, or ridges, as in other spores ( $A-D$, fig. I66). They are either dry and powdery when the sporangia burst, or are moist and sticky,

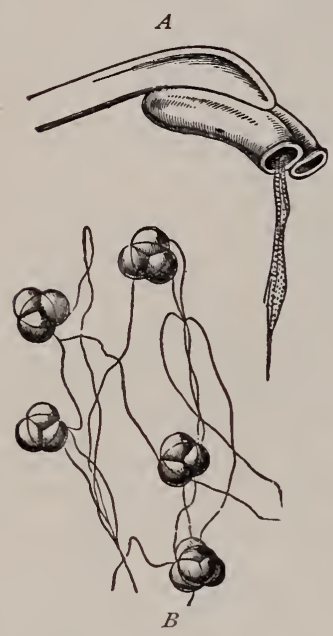

FIG. 163 .

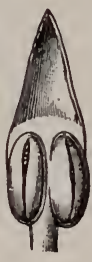

Fig. 164

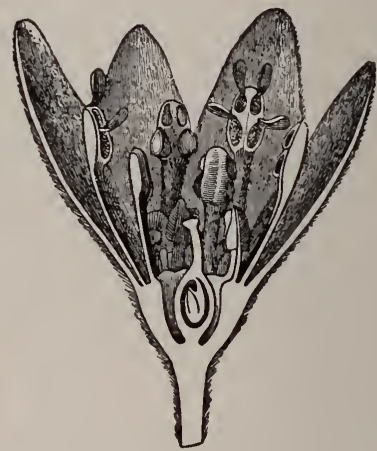

FIG. ${ }_{165}$

FiG. 163.-Anther and pollen of a Rhododendron. $A$, the anther, opening by pores at the end and allowing the pollen to escape. Magnified 8 diam. $B$, pollen grains adherent in fours (tetrads) as formed in the mother cells; the tetrads are held together by a sticky material which draws out into cobwebby threads as they are separated. Magnified 50 diam.-After Kerner.

FIG. 164.- Anther of the sweet violet (Viola odorata), showing the pollen sacs opening by slits. Magnified about 5 diam.--After Kerner.

Fig. 165.-A flower of cinnamon, halved. The calyx and stamens are raised on a cup developed around the pistil. The anthers open by uplifted valves, one for each sporangium, which here are arranged in two stories instead of in pairs side by side. Magnified about 7 diam.-After Luerssen.

adhering to each other in larger or smaller clusters (fig. I63). Sometimes, as in orchids and milkweeds, they are all held together in one mass and are attached to a part of the anther which carries the mass like a stalk or handle (fig. I67). Dry spores are usually adapted to distribution by wind; while the coherent spores are adapted to carriage by small animals, especially insects. (See further T 295.) 
292. Perianth. - The perianth is not present in any gymnosperms ( $28 \mathrm{I}$ ), except in a rudimentary form in a few species of the highest order. In angiosperms the

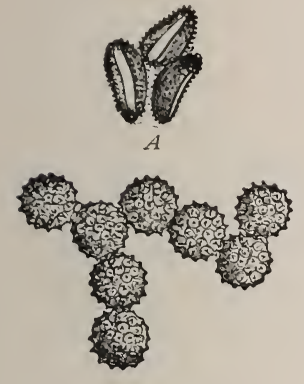

$B$

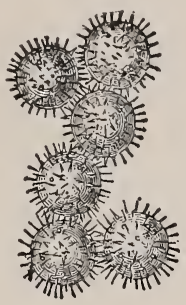

$C$

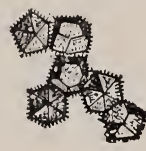

$D$

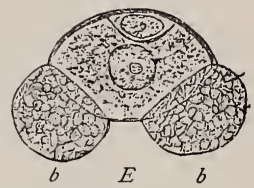

FIG. 166.-Pollen grains. A, white water iily (Nymphcea alba). B, a thistle (Cirsium nemorale). $C$, a mallow (Hibiscus ternatus). $D$, dandelion (Taraxacum officinale). Magnified 200 diam.-After Kerner. $E$, pine, showing bladdery enlargements, $b, b$, of the outer layer of the cell-wall. Magnified 400 diam,-After Stras. burger.

perianth, which is rarely wanting, is primarily for the protection of the stamens and pistils. As in all cases where leaves are produced rapidly and close together on a short axis, they grow during their early stages more rapidly upon the outer face than the inner. They are, therefore, concave inward and closely pressed together, forming a bud. At a certain stage the growth upon the two faces becomes equal, and later is more rapid upon the inner face than the outer. At this time the flower unfolds, the perianth spreading more or less and exposing the stamens and pistils within. These variations in growth are often repeated, the stimulus being light

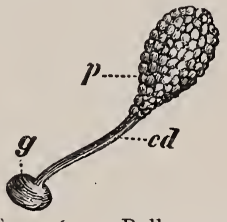

FIG. 167. - Pollen mass from an orchid. The pollengrains are arranged in packets, $\not$, which are aggregated at the end of a stalk, $c d$, terminating in an enlarged sticky disk, $g$, by means of which the pollen mass adheres to insects. Magnified about ro diam.-After Engler. or heat or both, when it is necessary to protect the spores against unfavorable weather. Such flowers open and close several times before their leaves wither. (See also $q$ 244.) 
293. Calyx and corolla.-The leaves of the perianth are usually arranged upon the torus in two or more circles or in a low spiral. They may be all alike or differentiated into two series, an outer and an inner. In the latter case those of the outer row or rows constitute the calyx, and the inner set the corolla.

The calyx leaves, or sepals, are generally green and show a great variety of form. When separate, the sepals are usually sessile and broad, with more or less pointed apex. The sepals are often apparently united, the originally separate portions appearing as teeth or lobes at the rim of a cup or tube, or some similar structure. Occasionally the sepals are not persistent, but fall as the bud opens or shortly thereafter. More commonly, however, the calyx, especially when undivided, remains throughout the entire development of the flower, and often of the fruit.

The inner set of perianth leaves, the petals, constitutes the corolla. The corolla presents a greater variety of form and color than does the calyx.

The corolla is ordinarily not persistent, usually falling or withering shortly after the microspores have been lodged upon the stigma.

294. Irregularity. - The parts of both corolla and calyx are often of equal size and like shape, and may be divided into several like halves by radial planes (figs. I68, I69). But often the symmetry of the calyx, and still more frequently that of the corolla, is so altered by unequal growth of the parts that the flower can be divided into like halves by only one, or at most two, planes; or it may even be entirely unsymmetrical. This unlikeness in the size and shape of the accessory leaves not infrequently extends to the stamens and pistils (figs. I 70, I 7 I).

The irregular form and color of the perianth (when other than green), including the variegation of the ground color 
by lines and spots, seem to be dependent upon the relation of the flower to insects. (See further T 390.)

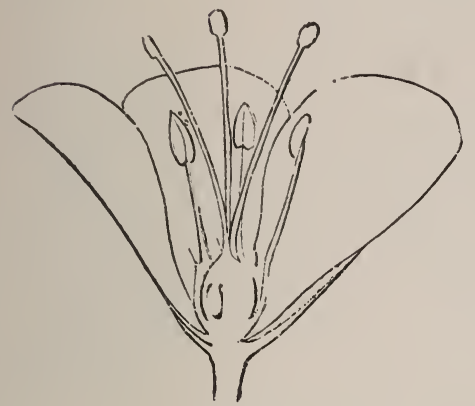

FIG. I68.

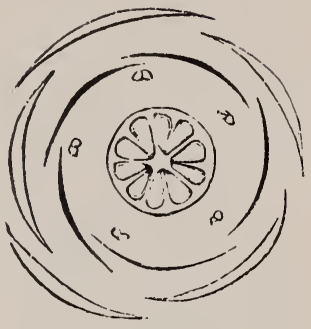

FiG. I69.

FIG. I68.-A flower of the flax, halved; showing radial symmetry. See fig. 169. Magnified 2 diam.-After Bessey.

Fif. 169.-Diagram showing the arrangement of the parts of a flower of flax. Outer circle, 5 sepals; second, 5 petals; third, 5 stamens; fourth, 5 carpels, each divided by a false partition into 2 chambers. Five different radial planes will, therefore, divide this flower into halves.-After Bessey.

295. Pollination.-To bring about the formation of a new plant within the ovule the pollen spores must lodge near

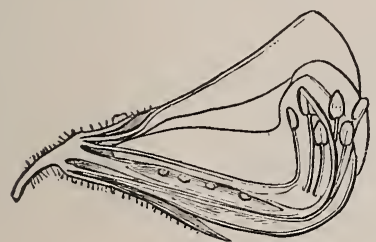

FIG. I70.

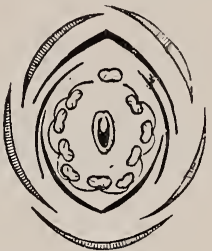

FIG. I7r.

FIG. 170.-An unopened flower of the sweet pea, halved; showing bilateral symmetry (irregularity). Slightly enlarged.-After Bessey.

FIG. 171.-Diagram showing the arrangement of the parts of the flower of sweet pea. Outer circle, calyx (5-lobed) ; second, 5 petals, the two lower united; third, ro stamens, 9 united by filaments, r separate; center, one carpel. Only one plane will divide this flower into halves.-After Bessey.

the ovule and develop. To insure this a portion of the pistil forms a receptive surface, the stigma, to which the pollen spores readily adhere. It is advantageous, also, to have the 
pollen spores of one flower lodged upon the stigma in another flower of the same sort rather than upon the stigma

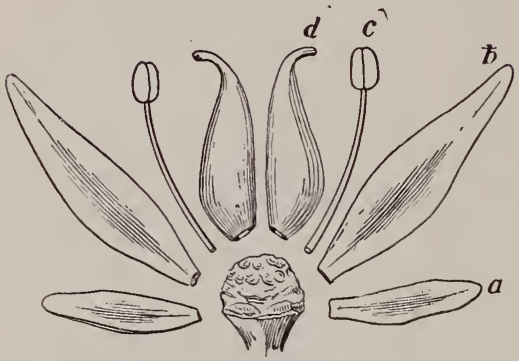

FIG. 172 .

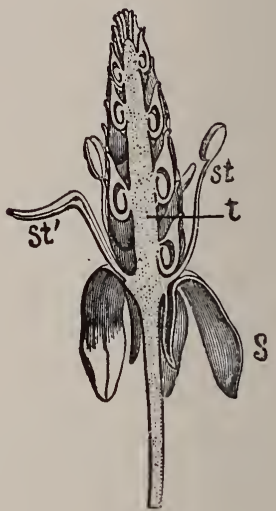

FIG. 173 .

FIG. I72.-The torus of a flower of stonecrop (Sedum ternatum), with the leaves removed to show scars; two leaves of each kind shown. $a$, sepal; $b$, petal ; $c$, stamen; $d$, carpel. Magnified several diam.-After Gray.

FIG. 173.-Flower of mousetail (Myosurus minimus), halved; showing s, spurred sepal ; st, stamen; st', a staminode or sterile stamen, having the position and form of a petal; $t$, elongated torus covered with carpels, some of which are cut through, showing enclosed ovule. Magnified several diam.-After Engler.

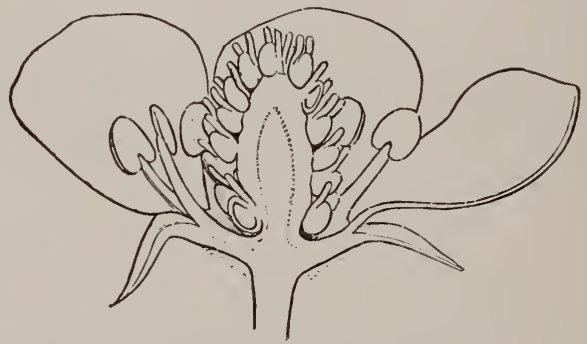

FIG. 174.-Flower of the strawberry, halved; showing elongated and thickened torus, covered with carpels. Magnified about 3 diam.-After Bessey.

of the same flower. The process of transfer and lodgment of pollen on a stigma is called pollination. If the pollen from one flower is carried to the pistil of another, it is called 
cross-pollination.* To secure pollination, and especially cross-pollination, the agency of wind or water or insects is employed. To the peculiarities of these various agents, flowers adapt themselves in character of pollen, color, nectar, odor, form of parts, time of deveolpment of stamens and stigma, etc. For an account of these see $9383-394$.

296. The torus.-In the vicinity of the flower leaves the internodes of the stem are rarely developed, so that the nodes from which the flower leaves arise are close together. More-

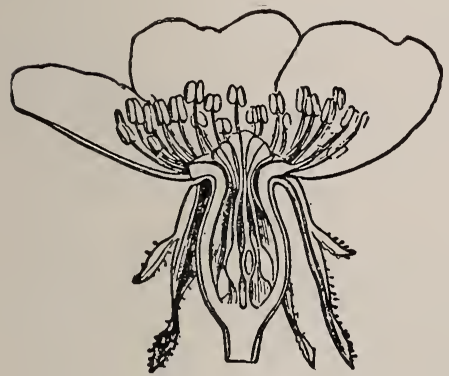

Fig. 175 .

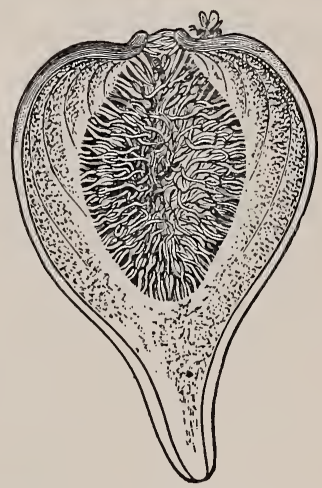

Fig. 176.

FIG. 175.-Flower of sweetbrier rose, halved; showing urn-shaped torus. Compare fig. 9०. Natural size.-After Bessey.

FIG. I76.- The inflorescence of a fig, halved lengthwise; showing common torus on whose interior surface many flowers are formed. Two fig wasps are near the opening of the flower chamber, one outside, while the other has just crawled in among the flowers. Natural size.-After Kerner.

over, the axis is usually enlarged, so as to give greater space for the numerous leaves. This enlarged portion is called the receptacle or torus. When the leaves are removed or fall naturally the torus shows ordinarily a rounded or conical surface, with close-set scars left by their bases (fig. I 72 ).

* Since fertilization of the egg is the ultimate object of pollination and generally its final result, the terms close- or self-fertilization and crossfertilization were formerly used. The word pollination is preferable. 
When a great number of spore leaves are to be borne, the torus is elongated, as in the mousetail (fig. I73); or greatly enlarged, as in the strawberry (fig. I74); or transformed into a cup, as in the rose (fig. I75).

When flowers in large numbers are very closely associated, as in the sunflower and its allies, the receptacles are joined to form a large common receptacle. The receptacle in such plants may be a cone, a dome, or a more or less flattened disk. In the fig the common receptacle is pear-shaped, with the edges almost meeting above and the flowers distributed over the inner face of the fleshy sac (fig. I76).

\section{EXERCISE XLV.}

I. Bisect a flower of marsh marigold lengthwise. Observe the three sorts of leaves, perianth, stamens, and carpels; their relation to each other and their insertion separately on the enlarged stem, the torus. Separate some from an old flower and note the scars left by their fall. (- 278.)

2. Are perianth leaves similar, or of two sorts? 293.)

Dissect off a stamen. Observe the two parts: $(a)$ the slender stalk, filament, and $(b)$ the enlarged part, anther. Note in the anther the two lobes, each with a shallow groove marking the position of the two pairs of spore cases. Tear open the spore case with a needle and observe the innumerable pollen grains which they contain. Examine a naturally bursted anther and determine how they open. ( $\uparrow 287-289$.)

Dissect off and examine a pistil. ( $($ 2 282 .) Observe

3. At the apex the roughened area, the stigma (1 283), sessile upon

4. The enlarged part, the ovulary. Observe its flattened form and the grooves along one edge. Split it along this line, flatten it out carefully and note the ovules attached to the edyes. ( 9 286.)

5. Cut several transverse sections of the pistil and observe the thickened edges of the carpel, forming the placenta, to which ovules are attached. Compare sections. Are all ovules attached to same edge?

6. Study and compare the flowers of the sweet pea (Lathyrus odoratus), apple, fuchsia, and garden lily. 


\section{Brood buds, etc.}

297. Simple forms.-In their simplest form brood buds consist of a single cell, though more commonly they are twoto several-celled. Like spores, they are supplied with reserve food. The shape of brood buds is various. When not furnished with distinct organs, they are club-shaped, lenticular, or spherical. In some thalloid liverworts (Marchantia and Lunularia) they are produced on the surface of the thallus, surrounded wholly or on one side by an outgrowth from the surface forming a cup or a crescentic ledge (figs. 39, I77). In some mosses brood buds arise from the apex of the stem, either in cup-like clusters of leaves or exposed ( $A, A^{\prime}$, fig. I 78$)$; in others they are smaller

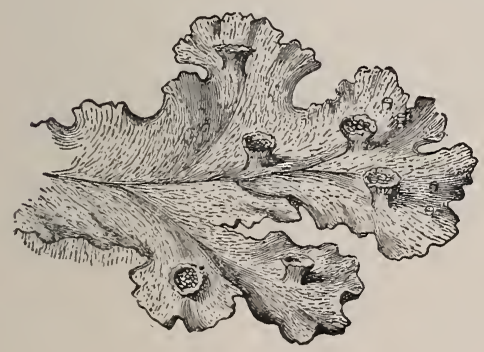

FIG. 177 .

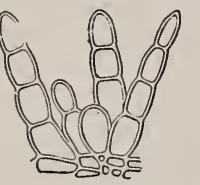

$B^{\prime}$

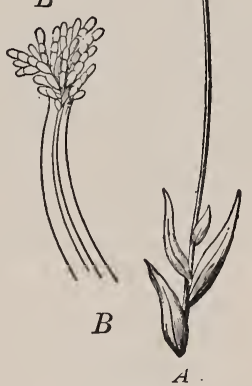

Fig. 178 .

FIG. 177.- Thallus of Marchantia, seen from above, showing the cups containing brood buds. Natural size - After Kerner.

Fig. 178.-Brood buds of mosses. A, upper part of the stem of Aulacomnium androgynum, with a cluster of brood buds at apex (magnified about 8 diam.), one of which is enlarged 120 diam. in $A^{\prime}$. $B$, tip of leaf of Syrrhopodon scaber (magnified about ro diam.) showing brood buds ; $B^{\prime \prime}$ some more enlarged (about 40 diam.).-After Kerner.

and simpler and are developed upon the leaves $\left(B, B^{\prime}\right.$, fig. I 78 ). In all the mossworts they belong to the gametophyte.

298. Shoots. - In fernworts and seed plants the brood buds are especially abundant, and often reach considerable 
size and complexity before being separated from the parent plant. They usually consist of a shert axis with a growing

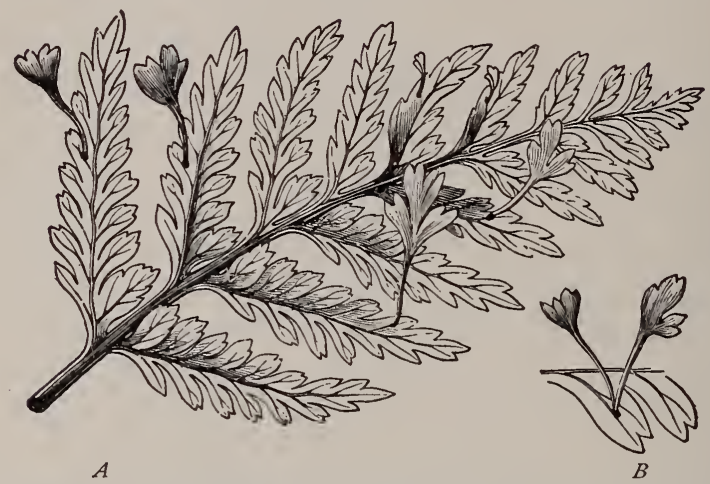

FIG. 179.-Young plants developing from adventitious buds on leaves of a fern (Asplenium bulbiferum), from which they readily separate to form new plants. $A$, natural size. $B$, magnified 2 diam. -After Kerner.

point and at least rudimentary leaves. They generally arise upon the stem, more rarely from the leaves or the root (fig.

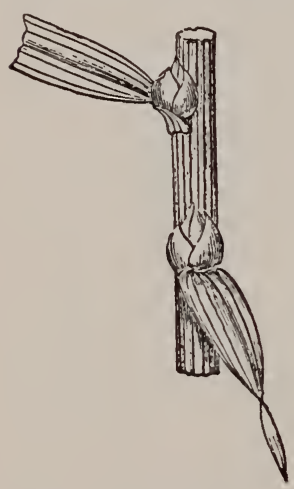

FIG. 180.-Fleshy buds in axils of the leaves of a lily (Lilium bulbiferum). Somewhat reduced.--After Van Tieghem.
I79). Upon the stem they usually take the place of shoots of other forms, developing from axillary buds (figs. 180,182 ). If formed on leaf or root it is always from adventitious buds.

Every possible gradation exists, from the simplest to those with well-developed members, constituting a plant of some size. They may be artificially grouped as follows :

299. (a) Buds.-In these the axis is short and the leaves scale-like. When most highly developed the quantity of reserve food is considerable and the parts of the bud are often distorted by enlargement to contain the food. The fleshy buds which 
readily separate from the axils of the leares of some garden lilies (fig. I So), and those which replace the flowers in some cultivated onions, are well known. (Compare also fig. 68.)

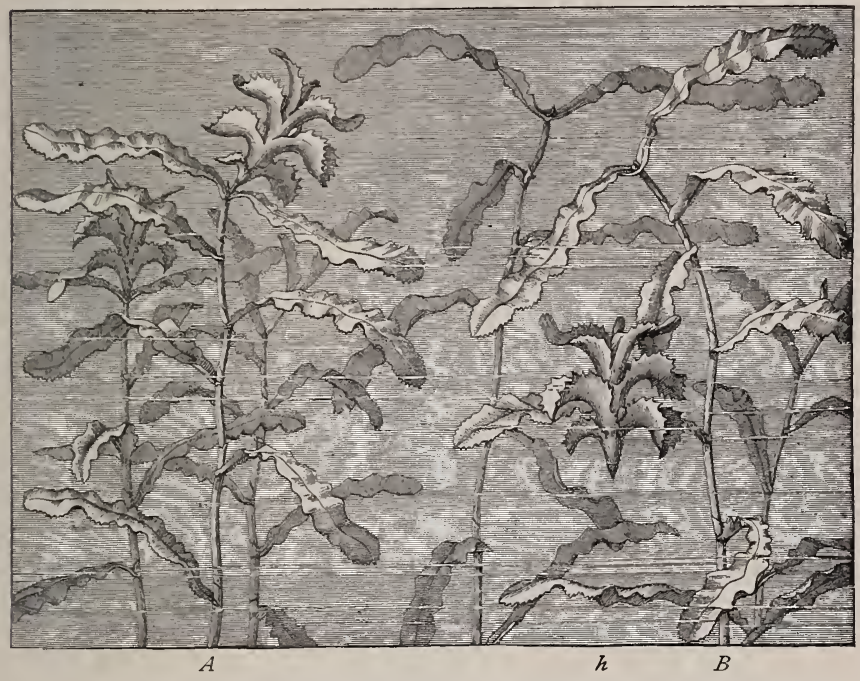

FIG. 181.-Pond weed (Potamogeton crispus). Detachment of special shoots, hibernacula, which are to hibernate under water. The plant $A$ has one of these shoots at the tip; $B$ has just loosened one, $h$, which is sinking to the bottom. Two thirds natural size.-- After Kerner.

300. (b) Winter shoots. - Somewhat similar but more highly developed brood buds are formed at the approach of winter about the base of the stem in many perennials with herbaceous tops. These are separated by the death of the parent stem and produce new plants in the spring. Some aquatics show a similar habit, dropping short shoots to the bottom of the water in autumn, which are to grow in the spring (fig. I 8I).

301. (c) 0ffsets, etc. - Some plants produce special branches, either underground or aerial, which develop at their extremities new plants, or special structures for their 
formation. The house-leek or live-for-ever (fig. 207) and stonecrop (fig. I 82 ) reproduce themselves by offsets. These are short branches with a rosette of leaves at the tip which are readily detached and roll away, to take root at the first opportunity and establish a new plant. The strawberry forms long leafless branches which take root at the tip and produce new plants, the slender runner subsequently perishing (fig. I 83). The white potato forms at the end of slender underground branches elongated tubers upon which are numerous buds, any one of which, nourished by the reserve food in the tuber, may produce a new shoot. The slender stem by which the tuber

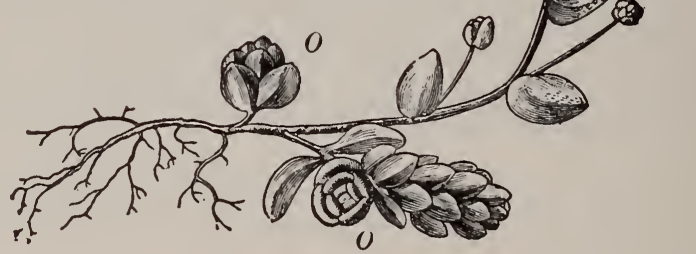

FIG. 182 -A plant of stonecrop (Sedum dasyphrllum) Offsets are produced near the base on short branches $O, O$; at the tip of longer branches, $O^{\prime}$; and in place of the flowers, $O^{\prime \prime}$. Natural size.-After Kerner.

is connected with the main axis perishes at the end of the growing season (fig. 184).

302. (d) Cuttings or scions.-Closely related to this mode of reproduction is that by the separation of fleshy members, upon which later are developed adventitious buds that give rise to new plants. The thick leaves of Bryophyllum are often blown off by storms, and produce new plants from buds formed at the teeth along the edge. Some species of Kleinia, natives of Cape Colony, have fleshy stems, jointed 
at intervals, so that they easily break there. When broken off by an accident, the piece rolls away, takes root from the under side, and sends up shoots from the upper.

Advantage is taken of this power of several parts to form adventitious roots and shoots in the artificial propagation of

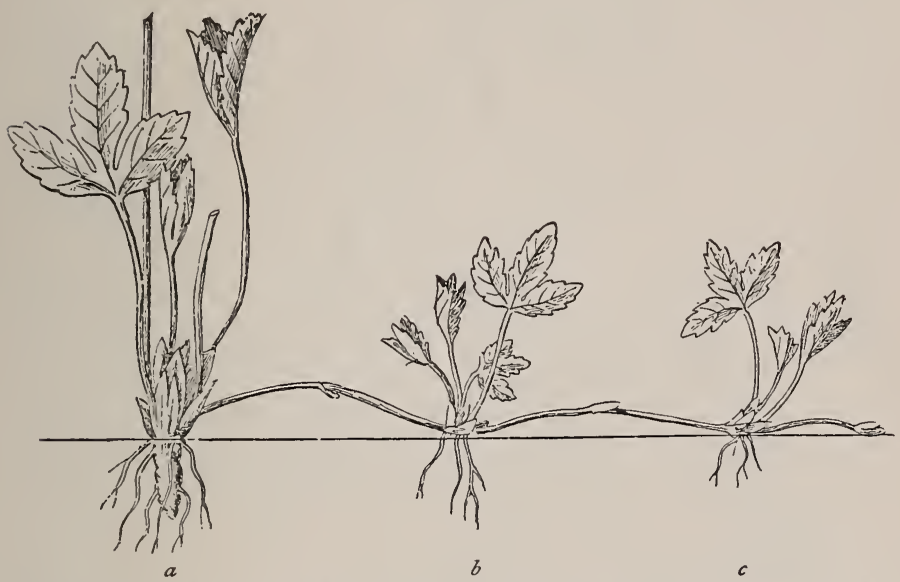

FIG. 183.-Formation of runners in the strawberry. $a$, the mother plant ; $b$, young plant formed at tip of first runner; $c$, plantlet at tip of second; a third has put out from $c$. Slightly reduced.-After Seubert.

domestic plants. Suitable portions of shoots or leaves for the development of new plants under proper conditions are called cuttings, scions, or "buds." They may generally be grown in water or soil ; or they may be securely fastened in a slit or wound in another plant. The latter process is known as grafting or budding, according to the form of the implanted part. Indeed brood buds in general may be looked upon as natural cuttings or scions.

303. Summary.-Vegetative reproduction is usually accomplished by the formation of small bodies which at maturity separate from the parent and grow into new plants. In the simplest plants the process consists of a separation of the 
parent into nearly equal parts, each of which then continues to grow. In most plants the bodies separated are small or minute, compared with the parent. They are either spores

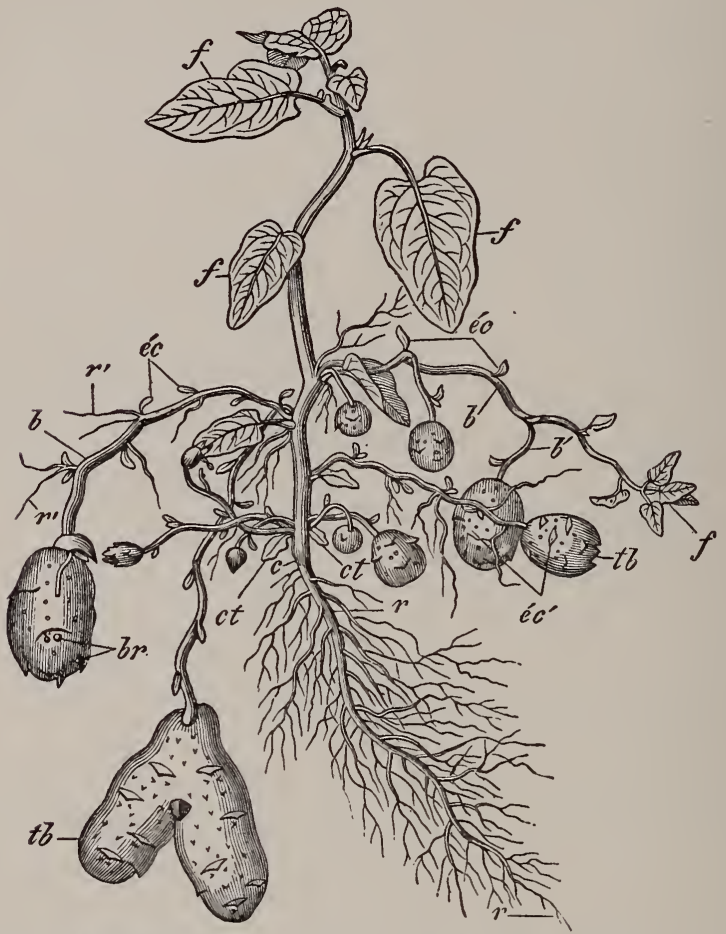

FIG. 184.-A seedling potato plant. $c$ is the base of the stem, below which is the primary root, $r$. The primary leaves $c t$, are still present. The early leaves, $f$, are not so much branched as later ones will be. In the axils of the lower leaves arise the branches $b$, with scale leaves, $e^{\prime} c$, and secondary roots,,$^{\prime}$. The tips of these branches, when illuminated, bear foliage leaves, $f^{\prime}$; but usually they thicken into tubers, $t b$, which have scale leaves, $e^{\prime} c$, in whose axils buds, $b r$, are formed, the so-called " eyes" of the tuber. Natural size.-After Duchartre.

or brood buds. Spores of water plants are often motile; those of some water plants and most land plants are not, but must be distributed by winds, water, or animals. The spores are formed singly or in chains at the tips of special 
branches; or they are produced in spore cases, which break or are broken to set free the spores. The parts producing the spores are usually numerous and are closely associated.

In the fermworts and seed plants the spore cases are usually formed on specialized leaves. When such leaves are clustered on a short stem, and especially when they are accompanied by colored accessory leaves, they form a flower. The accessory leaves form the perianth (calyx and corolla) and the spore-bearing leaves are the essential organs (stamens and pistils). The stem from which they grow, the torus, is often enlarged when the leaves are numerous.

Brood buds are usually larger and more complex than spores. In the lower plants they show no distinct members. In the fernworts and seed plants they often have rudiments of leaves and stems. Similar, but more developed parts, are separated by some plants to form new individuals. Propagation by cuttings, grafting, and budding is merely an imitation of natural methods. 


\section{CHAPTER XVIII.}

\section{SEXUAL REPRODUCTION.}

304. Cell union.-All methods of sexual reproduction consist in the formation of a single cell by the union of two specialized cells, known respectively as the male cell, or sperm, and the female cell, or $\operatorname{egg}$, neither of them capable of growing further without such union.

The organs and processes of sexual reproduction in plants are scarcely visible except with the microscope, and therefore will not be further discussed here. (See the author's Plant Life.)

The cell formed by sexual union is capable of developing into a new plant under suitable conditions. It may grow at once into a new plant, or it may remain dormant for a longer or shorter time. If it remains dormant it forms a resting spore. To protect itself, it thickens its wall, often very greatly.* It may then escape from the parent, but more commonly remains enclosed until set free by the death and decay of the parent. In the other case, the spore develops at once. Except in the brown seaweeds, whose eggs are ejected into the water before union of the sperms with them, the spore remains enclosed in the parent, within which it begins to form a young plant, the embryo.

305. Seed.-In all but the seed plants the development of the embryo is uninterrupted until a mature plant is formed.

* Thick-walled resting spores are also formed vegetatively. 
In seed plants the embryo, which forms within an ovule (see - 280), and stimulates it to renewed growth, develops to a certain stage and then ceases to grow. With suitable protection and food supply, it is then cast off as a seed, and, usually after a dormant period, continues its development until mature. The ripe seed consists of the following parts: (I) In the interior, occupying various positions and of exceedingly variable relative size, is the embryo. (2) Immediately around it lies a tissue containing reserve food, but this may be so shrunken
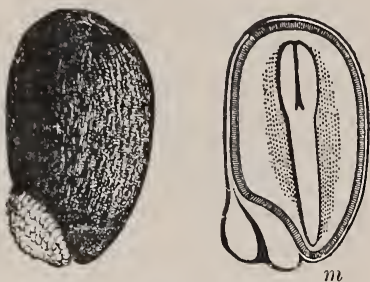

FIG. 185.-Seed of pansy, entire and halved, the latter showing the straight embryo, the endosperm (white and dotted), the seed-coats; $m$, micropyle. Magnified about so diam.-After Baillon.

and emptied as to be recognizable only by microscopic examination. In that case the reserve food will have been absorbed by the embryo itself, which is then likely to be

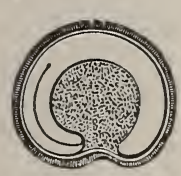

FIG. 186. - Seed of pokeberry (Phytolacca decandra), halved; showing curved embryo next the two seed-coats and nearly surrounding the end os perm. M agnified about io diam. -AfterBaillon. large and to occupy most or all of the space within the seed coats. (3) Upon the exterior one or two seed coats, more or less readily distinguishable from each other (figs. 185,186 ).

\section{Induced result of cell union.}

306. Fruit.--The growth of the embryo excites not only the ovule to further development, but also the carpels which bear the ovules, and not infrequently even more remote parts. The carpels and their contents and adherent parts, when fully developed, constitute the fruit. The carpels are then known as the pericarp. The changes which the parts undergo are chiefly of two sorts-an increase in size and an alteration of texture. The increase in size requires no special explanation. The carpels may become dry at maturity, or may thicken and become soft and fleshy, 
or even juicy. In accordance with these differences, two sorts of fruits are recognized, namely, dry fruits and fleshy fruits. Between these, however, there is no sharp line of demarcation.

30\%. Dry fruits. - If the pistil contain only one or two seeds, it very often does not open at maturity. Consequently, the seed-coats ordinarily remain thin, and the protective function is put upon the pericarp. In some cases the carpels become adherent at an early stage to the surface of the ovule,

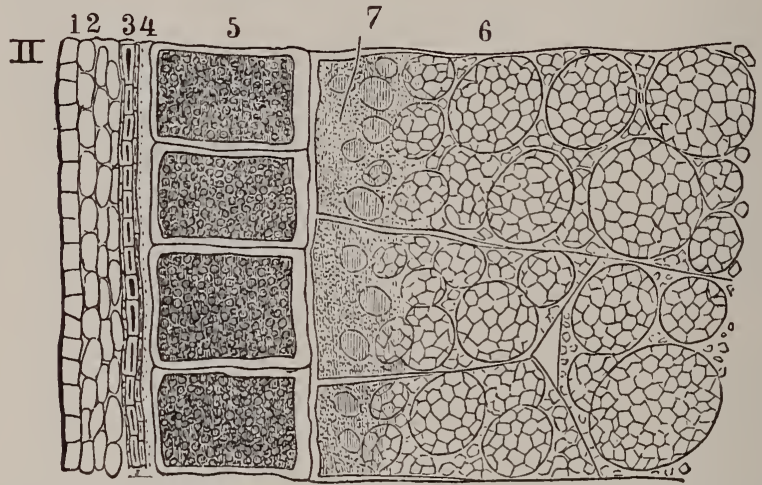

Fig. 187.-A small portion from the margin of a transverse section of grain of oats, I, 2, pericarp; 3, seed-coats; 4, remains of the sporangium; 5-7, endosperm; 5, gluten cells; 6 , cells containing large compound starch-grains (compare fig. I14) at 7 , richer in gluten, with less starch. Magnified about 325 diam. - After Harz.

and at maturity the pericarp is so firmly attached that it can scarcely be distinguished from the seed-coats themselves. Such a change takes place in the fruit of most grasses, and the grain so formed is ordinarily mistaken for a seed (fig. I87). When dry fruits are one-seeded and indehiscent the pericarp usually bears whatever special contrivances are necessary for the distribution of the seeds. (See further $-395 \mathrm{ff}$.) If, however, the pericarp contains many seeds, it generally breaks at maturity to allow the loosened seeds to escape. The extent and position of the opening into the seed chamber or 
chambers are exceedingly various. In some cases the openings are so small as to be mere slits or pores (fig. I88). In others a more or less circular line of breakage forms a little door or valve which opens and closes with changes of moisture (fig. I89). In other cases the pericarp splits lengthwise into

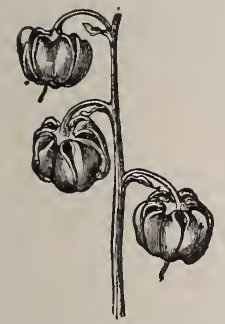

FIG. 188.

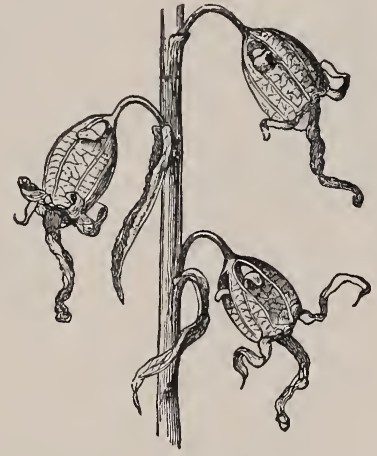

FIG. 189.

FIG. I88.-Ripe capsules of a wintergreen (Pyrola chlorantha), showing dehiscence by pores. The opening is a short split at the middle of the base of each carpel. Natural size.-After Kerner.

FIc. 189.- Ripe capsules of a bellflower (Campanula rapunculoides), showing small reflexed valves. Natural size.-After Kerner.

two or more pieces (fig. I90), or, less often, cracks transversely so as to loosen a lid (fig. I9I).

308. Fleshy fruits. - The changes which produce fleshy fruits consist in a transformation of certain parts of the pericarp into masses of thin-walled juicy cells. Other parts may remain unchanged, or may even become hardened. The inner part of the pericarp sometimes becomes of a stony hardness, while the outer portion becomes soft and juicy. Such changes produce a fruit like that of the peach or the cherry. The pericarp encloses a single seed with delicate brown seedcoats whose protective function has been completely usurped by the stone (fig. I92). In other cases, while the inner face becomes stony, the outer becomes fibrous, tough, and dry, as 
in the almond, walnut, and hickory nut. The outer part in the last even breaks regularly into four pieces. Such fruits

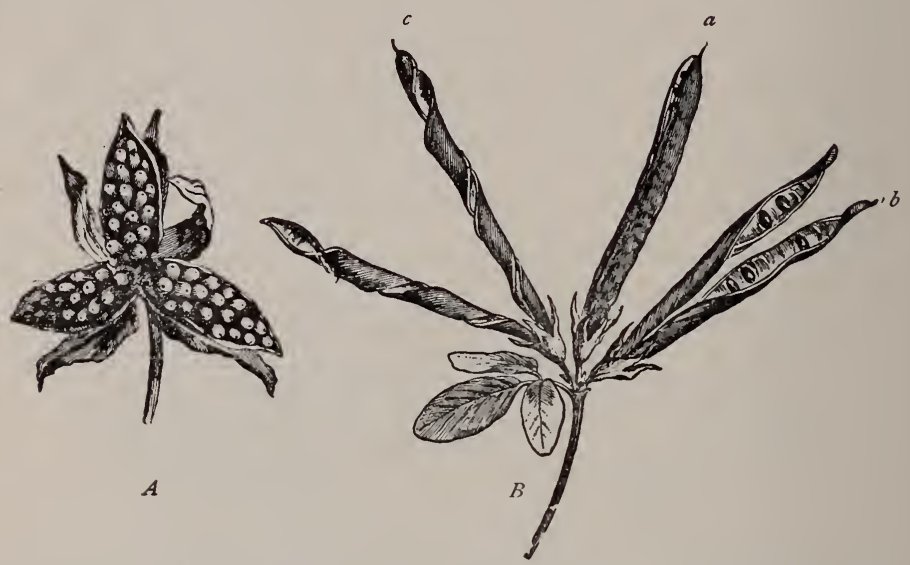

Fig. 19o.- $A$, capsule of violet split open at maturity, the seeds still attached to the placentæ. $B$, three pods of Lotus corniculatus; $a$, just beginning to crack; $b$, split throughout, with the pieces somewhat twisted; $c$, empty of seeds, the two pieces fully dried and twisted. Natural size.-After Baillon.

furnish a transition from the most perfect fleshy fruits to the dry fruits. In other cases the placentas become very much

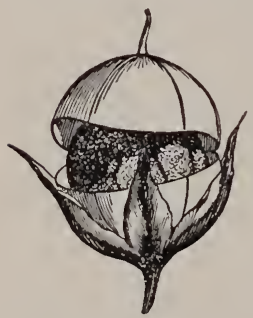

FIG. rgr.-Ripe capsule of pimpernell ( $A$ nagiallis arvensis), opening by a lid. Magnified several diam. - After Baillon. enlarged, and the whole of the pericarp becomes fleshy, as in the tomato. In others the outer part of the pericarp is hard and firm, while the inner becomes pulpy, as in the pumpkin and squash.

309. Accessory fruits.-Parts adjacent to the carpels, either flower leaves or axis or both, stimulated to growth, frequently enter into the formation of fleshy fruits. These may be accompanied by either a fleshy or a dry pericarp. In the wintergreen berry the calyx grows thick and fleshy and surrounds a dry pericarp, which cracks at maturity (fig. I93). 
In the strawberry (fig. I 74) the torus becomes greatly enlarged and fleshy, while the minute, one-seeded, dry fruits are scattered over its surface, imitating small seeds. The fig has the same parts, with the torus concave, instead of convex (fig. I76). The apple consists of a fleshy torus carrying at its free end the withered calyx and enclosing the tough, thin pericarp (fig. 194). In the blackberry the receptacle becomes fleshy, and each pistil forms a minute fruit like a cherry, adherent to its neighbors and to the pulpy torus. The raspberry is like it, except that the adherent mass of fruits separates as a cap from a firm torus (fig. 195).

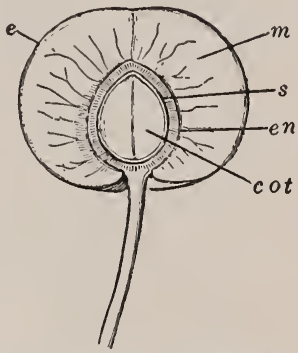

FIG. 192.- Fruit of the cherry, halved. $e$, epidermis of pericarp; $m$; fleshy layer of pericarp ; $e n$, stony layer of pericarp; $s$, seed; cot, one of the pair of thickened seedleaves of embryo. Natural size.-After Focke.

310. Multiple fruits. - If the flowers are crowded, either dry or fleshy fruits resulting from them may be closely crowded at maturity. Under these conditions fleshy fruits frequently become adherent, and may thus constitute a

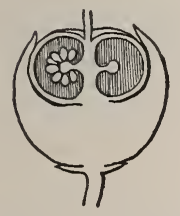

FIG. 193.-Fruit of wintergreen (Gaultheria procumbens), halved,showing thin (dry) pericarp, surrounded by thickened fleshy caly $x$. M a $g$ n if i e d about 2 diam. After Gray. multiple fruit quite similar in form to the fruit formed by the aggregated carpels of a single flower. Compare the multiple fruit of the mulberry (each section from a separate flower whose floral leaves and pistil both become pulpy; fig. 196) with such an aggregate fruit as the blackberry, in which each section is one pistil out of the many belonging to a single flower (fig. 195). The pineapple is similar to the mulberry in origin.

Even more remote parts are stimulated to development by fertilization of the egg. The stem bearing the flower generally grows and becomes stronger, to carry the fruit, especially if large. The 
minute bractlets sometimes become highly developed beneath the fruit. The cup of the acorn and the husk of the hazlenut originate in this way as the nuts form. The similar husk of the beechnut and chestnut encloses more than one fruit.

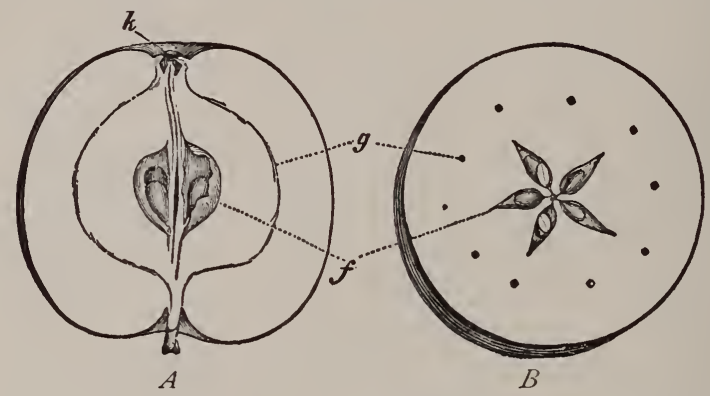

FIG. I94.-Fruit of the apple. $A$, halved longitudinally; $B$, halved transversely. $f$, pericarp, enclosing seeds; $g$, vascular bundles of the flesliy torus entering $k$, the calyx leaves. One half natural size.-After Focke.

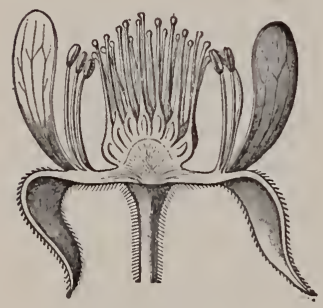

FIG. 195 .

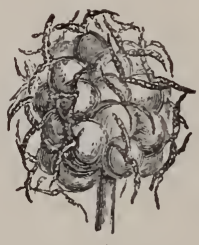

A.

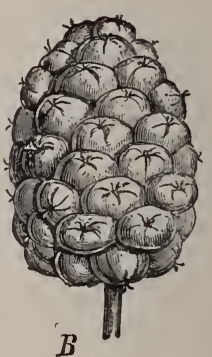

FIG. 196.

FIG. 195--Vertical section of a flower of raspberry ( $R$ ubus id a us), showing numerous pistils which form the caplike fruit over the enlarged torus; stamens, corolla, and calyx all united at base. Magnified about 2 diam.-After Kerner.

FIG. 196.- $A$, pistillate flower cluster of white mulberry; $B$, multiple fruit from same. Natural size.-After Baillon.

311. Distributive arrangements. - The young of all plants must be so scattered as to prevent them from coming into sharp competition with the parents. In seed plants this distribution occurs at the time of maturity of the seed, i.e., when the embryo has become dormant, and the food store and pro- 
tective coverings have been completed. The devices by which seeds are scattered are dependent upon the number and character of the seeds and the nature of the pericarp. Plants adapt themselves so as to employ as distributing agents wind, water, and animals, or they develop special mechanisms for casting off the seed as a projectile. A consideration of these adaptations belongs to ecology. (See Chap. XXVI.)

312. Renewed growth.-After a time, if the seeds become wet and are kept at a suitable temperature, with a supply of air, the embryo resumes its growth, i.e., the seed "germinates." This growth soon bursts the seed coats; the food is digested and absorbed; the young plant sends its roots into the soil and its leaves to the light, and by the time the food store is exhausted, is ready to make its own living.

313. Summary.- Sexual reproduction consists in the union of a male cell and a female cell (neither able to grow further) to form a single new cell capable of growing into a new plant. The processes and organs are not described here. The direct result is the formation of a "resting spore" which remains dormant for a time ; or else the immediate development of an embryo plant. In the latter case the embryo, in all but seed plants, continues its growth, interrupted only by external conditions, until it becomes a full-grown plant. In the seed plant it becomes dormant while still small. Before its growth is interrupted, its development has induced the growth of the ovule, in which it lies, until the two form the ripe seed. Adjacent parts also grow and with the seed constitute the fruit. The changes in the growing parts produce dry, fleshy, accessory, or multiple fruits. The seeds are finally scattered by various ingenious devices. With a suitable supply of heat, air, and water, the embryo resumes its growth and continues to grow until it forms a mature plant. 


\section{PART IV : ECOLOGY.}

314. Definition.-Physiology, in its broadest sense, may be divided into physiology proper and ecology. Ecology is that portion of botanical science which treats of the relations of the plant to the forces and beings of the world about it, as distinguished from physiology proper, which treats of the relations of the plant as a whole to the chemical and physical forces within it. The forces without the plant necessarily limit and modify the action of the forces within it ; consequently it is quite impossible to draw a sharp distinction between those subjects which belong to ecology and those which belong to physiology proper. Parts II and IV, therefore, will be found to overlap in many places. Several of the subjects already treated under physiology belong in part to the present section. For example, the movements of plants are due not to internal causes alone, but to internal causes as modified by external conditions. In this part only a bare outline of the adaptations of plants in form and habit to their physical surroundings and to other living beings can be given. 


\title{
I. NUTRITIVE ADAPTATIONS.
}

\section{§I. ADAPTATIONS OF FORM AND STRUCTURE TO ENVIRONMENT.}

\author{
CHAPTER XIX.
}

\section{FORMS OF VEGETATION.}

315. Adaptation.-The various physical conditions which make up the "climate " of any particular region of the earth's surface, together with the nature of the material upon or in which the plant grows, largely control the form and functions of the plants found in that region. Stated in other words, plants, in order to exist at all, are compelled to adapt themselves to the places in which they grow. This compulsion is on pain of death.

316. The struggle for existence.-The competition between plants is intense. Only a very small portion of the seedlings which start in any particular area can come to maturity. Far the greater number will be killed by being robbed of light and of water by the overshadowing leaves and interlacing roots of their companions. Since such competition exists, it is evident that only those best suited to the conditions under which they grow will have any chance whatever to survive.

Not only are individuals subject to this competition, but all individuals of a particular kind (a species) may be destroyed in any region through the competition of other 
species better suited to the conditions of that region. Through this competition between species one kind may be forced to migrate to some different region in order to maintain itself. The capacity of a plant to adapt itself to different surroundings determines the possibility of its occupying a new region, for here it must come into competition with other sorts, and can only maintain itself if it is capable of so modifying its form and structure as to adapt them to the new conditions, and that, at least as well as the occupants it finds in possession. In the beginning it was probably by competition between species that water plants were gradually forced to adapt themselves to an amphibious life, and then to a terrestrial life, all the while advancing in complexity ; later some green plants adapted themselves to a parasitic or saprophytic life; plants of moist regions gradually moved out and occupied even the deserts; plants loving the shade adapted themselves to the direct light of the sun; and so on, until all parts of the earth's surface and even considerable depths of the ocean have been occupied.

31\%. Environment.-In order to understand the variety of factors which are acting upon any particular plant, it will be instructive to consider the conditions which surround the ordinary land plant. A portion of such a plant is embedded in the soil, and the remainder rises into the air. The subterranean part is profoundly influenced by the size and form of the soil particles, as well as by their chemical composition. It is exposed to contact with water varying in amount, sometimes from day to day and always from time to time during the year, holding many substances in solution in varying amounts and kinds at different periods. It is subject, also, to variations of temperature from day to day and from season to season.

The aerial part of such a plant is exposed to greater or less variations of temperature from hour to hour, from day to 
night, from day to day, and from season to season. It is exposed to light varying in intensity from day to night, and from day to day, and to light differing in direction from hour to hour of each day. It is enveloped by fogs or mists, or is pelted by rain, hail, sleet, or snow, and sometimes completely buried in ice or snow.

A plant has little or no power to alter any of the agents which act upon it, but it must be able to withstand the injurious ones, or even to turn them to its advantage. It would be difficult to conceive a more complex set of factors to which adjustment must be effected; and the more, since these conditions are combined with each other in an infinite variety of ways. Because the physical conditions vary in different parts of the earth's surface, the vegetation in each region differs from that in others.

In any particular locality certain conditions of water, soil, air, temperature, light, and rainfall are likely to be associated. It is possible, in a somewhat arbitrary way, to recognize four general sets of conditions to which plants must adapt themselves, in each of which the relation to water is the dominant factor. It should be understood clearly, however, that these sets of conditions pass into each other imperceptibly. Corresponding to these four sets of external conditions, we may recognize certain characteristics in plant form and structure, which are likely to be associated, and it thus becomes possible to distinguish four forms of vegetation corresponding to the four sets of external conditions.

318. The first set of conditions consists of those characacterized by no extremes. Both the air and the soil are moderately moist; the rainfall is distributed through the year, or at least through the growing season ; there is no excess of salts in the water or in the soil ; the soil is usually enriched with organic matter, often in considerable amount. The plants which grow under these conditions are the ones most familiar 
to people in the fertile regions of temperate climates. These may be reckoned as the average, or mean, plants, and are therefore called technically mesophytes.

319. A second set of conditions is characterized by deficient water supply throughout the year, the amount of water present in the soil often being less than I0\%. Such regions may be considered as regions of continuous drought. The plants adapted to these conditions are known as drought plants, or xerophytes.

320. A third set of conditions, prevailing over comparatively limited regions, is characterized by an excess of salts in the soil or water. These salts are chiefly common salt, gypsum, and magnesium chloride. Plants which can live under these conditions are known as salt plants, or halophytes.

321. A fourth set of conditions is characterized by an excess of water. The plants grow wholly or partly surrounded by water, or their roots are embedded in a soil supersaturated with water, that is, containing at least $80 \%$. Such plants are called water plants, or hydrophytes.

It will be noticed that the first three groups, namely, mesophytes, xerophytes, and halophytes, are essentially land plants in distinction from the fourth group, which are water plants.

322. Summary.-In order to exist at all, plants must adapt themselves to the places in which they live. Competition for light, water, and soil room is intense because of the number of individuals. Competition of better adapted kinds may exterminate or force migration. The factors to which plants must adjust themselves are many. Each factor is more or less variable and different factors may be combined in any ratio, producing almost infinite diversity. Plants differ, chiefly because of this diversity of conditions under which they grow. For convenience the water relation is used to group plants into four vegetation forms, mesophytes, xerophytes, halophytes, and hydrophytes. 


\section{CHAPTER XX.}

\section{ESOPHYTES.}

323. I. Mesophytes show certain general relations to external conditions, many of which are also shared by other forms. Except to these minor variations in the environment, they show no special adaptations; or, rather, they are looked upon as the normal plants, and the ways in which others differ from them are spoken of as special adaptations. In reality, however, the general methods by which they adapt themselves to their environment, which are now to be considered, are quite as much special adaptations as those shown by plants living in extreme climates. These adaptations will be discussed in relation to each of the main factors of the environment.

324. I. Air.-The composition of the air varies little from place to place. It is only in those regions in which it is rendered impure by artificial means, such as the vicinity of cities and factories, and in the few isolated regions in which it is vitiated by natural means, as in volcanic regions, that any special adjustments may be looked for. Artificial vitiation of the air kills off certain plants. A few plants have adapted themselves to air in the neighborhood of fumaroles, where they are subjected to vapors containing large amounts of sulfurous acid. Whatever special adaptations are found are internal, since only the very simplest plants find it possible to live in such conditions. 
The movements of the air, however, influence profoundly the form of plants. This they do indirectly by the shifting of sands in sandy regions, and by their effect upon the precipitation and upon the moisture of the atmosphere. Winds increase evaporation from the soil and from the surface of plants, and thus directly influence form. Trees growing in wind-swept regions are always low, bushy-branched, with the trunk and limbs inclined to leeward. The twigs on the windward side are often dead. Forests in wind-swept regions often thin out to windward, the trees becoming smaller and smaller, finally being replaced by bushes which become sparser until no woody vegetation is present. The leaves upon such plants are small and often peculiarly spotted. These effects upon the form have been ascribed to the mechanical action of the air, to the presence of salts when in the neighborhood of the ocean or salt lakes, and to the reduced temperature; but probably none of these causes is to be looked upon as so efficient as the drying brought about by the prevalent wind.

325. 2. Light._Light affects plants directly through its influence upon their nutrition and upon the evaporation of water from their surfaces. In this way it affects (I) the rate of development. For example, the blossoming of flowers and the production of leaves occur earlier upon the sunward side of a tree or shrub than upon the other side. In the same cultivated crops of the north and south there will often be several days difference in the total number between sowing and maturing. Thus barley at northern Norway, in $68^{\circ}$ $\mathrm{N}$. lat., matures in 89 days, while at Schonen, in $56^{\circ} \mathrm{N}$. lat., it matures in roo days. Since the total hours of illumination must be about equal, the longer days of the north enable the plants to produce more food, and so to mature more rapidly. The forcing of vegetables under glass by the aid of electric light during the night depends upon the same principle. (2) 
The form of plant parts is directly influenced by light. Plants accustomed to the direct sunlight and those accustomed to shade show profound differences in habit. Light plants are stocky and compact; their stems are inclined to be woody, the leaves are usually folded or crisped and often set at an acute angle with the direction of the light, and the surfaces are frequently hairy. In contrast, shade plants are slender and sprawling; their stems often thin and weak; the leaves flat and smooth and set transverse to the direction of the lightrays, while the surface is slightly, if at all hairy. (3) In internal structure, also, there are decided differences, particularly in the leaves. These differences affect the skin, the number and distribution of the stomata, the form of the cells, and their contents. The sum of the differences distinguishes an upper (illuminated) from an under (shaded) side.

326. 3. Temperature. - Temperature exercises an important influence upon plants, both upon their aerial and subterranean parts. The temperature of the air is really much more important in controlling the adaptations, and consequently the geographic distribution, of plants than is light. The reason for this is to be found in the much more unequal distribution of temperature in various regions of the earth's surface. Moreover, temperature affects every vital function of the plant, for each of which a maximum, minimum, and optimum point may be determined. (See $T$ r 53, 2 r9.) The variations in temperature to which plants are subjected require special adaptations.

327. (a) Protection against changes of temperature.These adaptations are to be found in the presence of special substances, such as oils or resins, which reduce the liability of the parts containing them to freeze; in the reduction of the amount of water in the plant so that less damage results from freezing; and, finally, in the presence of poor conductors of heat, such as scale-leaves and hairs in profusion, 
a jacket of old withered leaves, etc., all of which insure slow thawing if the plant is frozen. The winter buds of trees in temperate climates illustrate all of these adaptations.

328. (b) A dormant period is necessitated by low temperature during part of the year in temperate and arctic climates. The period of vegetation in the higher latitudes is often very short. The same conditions prevail at high altitudes, with the same effects. In these regions, therefore, the plants are almost all perennials. In many cases the rudiments of flowers are formed in the year preceding that in which they are developed, in order that full opportunity may be given for the ripening of the seeds and fruits in the short growing season. Some plants adapt themselves to short periods of vegetation by the presence of evergreen leaves, which are ready at the first opportunity to resume their work of food manufacture.

329. (c) The form of plants is modified by the temperature of the air and soil. Low temperatures are also likely to bring about the formation of dwarf plants.

330. (d) The rate of development is strikingly influenced by variations in the temperature of the soil. The soil heat is chiefly derived from the sun. The amount of heat absorbed varies with the exposure of the soil, its color, porosity, amount of water, and the duration of illumination. The influence of the temperature of the soil is mainly indirect, acting through its effect on the water supply of the plant.

331. 4. Moisture and precipitation. - The amount of moisture in the atmosphere largely determines the amount of evaporation from the surface of the plant. The relative amount of moisture in the atmosphere is exceedingly variable, and bears a direct relation to its temperature. Indeed, so closely related are the conditions of temperature, light, and moisture in the air, that the adaptations of shade plants, mentioned above, may be considered as the sum of the 
effects due to these three factors. It is difficult, if not impossible at present, to say which are the effects of light and which of evaporation.

Precipitation affects plants chiefly as it influences water supply. A few plants only of the higher forms are able to absorb moisture directly from the air, except as a last resort. (See r65.) Many of the lower plants, such as the algæ, lichens, and mosses, absorb rain instantly by their aerial parts. Some plants have adapted themselves to frequent and prolonged rainfall, bearing it often for months at a time; other plants under such conditions lose their leaves very quickly. Rain-loving plants have their leaves furnished with elongated tips or with grooves and hairs to carry off the rain quickly. Their surfaces, also, are not readily wetted by water. Others protect themselves against the rain by adjusting the direction of their leaves to it so that a heavy, splashing rain strikes them at an acute angle. Others, by a movement of their leaves as soon as the sky is clouded, avoid injury from heavy rains. The branching of leaves in certain cases may be looked upon as a protection against heavy rainfall.

The snow cover through cold periods is for many plants essential as a protection against low temperatures during the dormant period. Others have adapted themselves to growing even in the midst of snow, putting forth their leaves and blossoms while still surrounded by melting snow.

332. 5. Soil.-Both the chemical composition and the physical properties of the soil affect plants. The latter are, however, by far the most important. Here, again, the reason is to be found in the relation of the physical qualities of soil to the water supply.

The water which permeates the soil takes up from it certain substances, and becomes thus a dilute solution of various salts. That the salts thus present in the soil water may affect 
the form of the plant is strikingly shown in the occurrence of certain species of a genus only upon soils containing lime, while others of the same genus are found only in soils free from lime. When the local distribution of corresponding species of the same genus within the same region is determined by the presence or absence of lime in the soil, comparison of them indicates the general effect of lime salts upon the plant. Plants growing upon lime are usually stronger and more densely hairy, often hoary, while those on other soils are smooth or furnished with glandular hairs. The lime-loving plants have bluish-green leaves, as contrasted with the grass-green. Their leaves are also more numerous and more deeply branched, the flowers larger and their colors duller and paler.

333. Summary.-Mesophytes have a moderate water supply. Arbitrarily selected as the norm, their adaptations are nevertheless as numerous and important as those of other plants, but less striking only because they are familiar to the eye. Thus they adjust themselves in form and structure to the wind, the light, temperature, moisture and rainfall, and the soil. The light influences the rate of growth and development, and especially internal structure, often inducing a two-sided structure, as in leaves. Changes in temperature call out protective adaptation against sudden changes, and a dormant period (during winter), and also affect the form of plants, as do moisture of the air, rain and snow. The substances in the soil may also modify the form of a plant. 


\section{CHAPTER XXI.}

\section{XEROPHYTES AND HALOPHYTES.}

334. II. Xerophytes. - The plants of dry regions blend by imperceptible gradations with the mesophytes. They reach their best development in desert and rocky regions. Some, especially of the lower forms, grow in such situations that they must adapt themselves to become so dry at certain periods that they may be powdered. Such, for example, are a few algæ, many lichens, mosses, and a few fernworts. Adaptations in these cases must be looked for in the character of the cell contents.

Other plants must adapt themselves to endure dry periods, such as those occurring from day to day, or between the wet and dry seasons, by retaining in their bodies sufficient water to sustain life. The following are some of the chief methods by which plants adapt themselves to periodic or continuous drought.

\section{A. Adaptations for reducing transpiration.}

335. I. Periodic reduction of surface exposed.-The dying away of an annual plant after forming its seed may be looked upon as an adaptation of this sort. Little evaporation occurs from the surface of the seed, which is thus adapted to withstand prolonged dryness. Perennial plants accomplish the same results when their annual shoots die off and leave only the rhizomes, tubers, and similar parts buried in the soil. 
Perennial plants with perennial shoots may drop their leaves during the dry period and form them again upon the return of the growing season. The fall of leaves in our woody vegetation is a similar adaptation to the cold season. The rolling or curling of leaves is a common mode of avoiding evaporation. It is common in grasses (fig. I 97) and mosses.

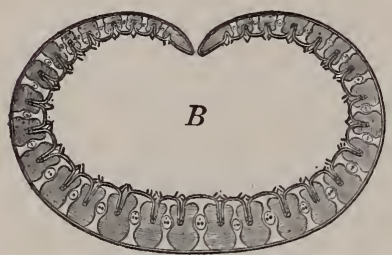

336. 2. The constant reduction of exposed surface.-This may be secured among the leaves by reducing them either in area or in number or both, or by much branching, with little

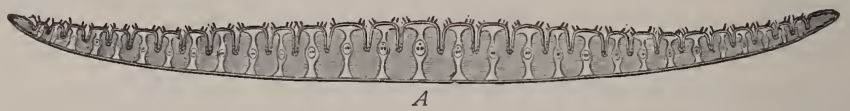

FIG. 197.-Transverse sections of a grass leaf (Lasiagrostis). $A$, open; $B$, rolled, when dry. The white plates are the ribs of mechanical tissue above and below a stele, one in each ridge; the shaded areas are green tissue. The stomata are located low on the sides of the narrow grooves between the ridges, so that when the leaf is rolled, evaporation through them is hindered. Magnified 16 diam.-After Kerner.

green tissue. Plants with bristle-shaped or needle-shaped leaves (figs. 63, I98), those with permanently rolled leaves (permanent form similar to temporary rolling shown in fig. I97), or thase with scale-like leaves (fig. 7I) show the various phases of such adaptations. Extreme reduction of surface is secured by suppression of leaves. In this case any further adaptation depends upon the stems, which must also provide for nutritive work. These may take the form of leaves (see 96 ) ; or the branches may be thick, rigid, and fleshy (fig. I99); or they may be thread-like or needleshaped, as in the asparagus (fig. 67); or the stems themselves may reduce their area by becoming fleshy and cylindrical, prismatic, or spheroidal, as in the various forms of Cereus and melon cactuses.

337. 3. Movements of parts to reduce the illumina- 
tion.-Certain leaves are adapted to a permanent profile position, that is, with the edges turned toward the sky, instead of the surfaces. (See 9 243.) Others assume a profile position when the illumination becomes too intense. These positions, by placing the leaf surface oblique to the direction of the light rays, reduce the amount of evaporation very considerably.

338. 4. Coverings, consisting of living or dead scale-leaves, stipules, leaf-bases or entire leaves, reduce transpiration by obstructing the free exchange of air, or by holding water and so keeping moist the surfaces they cover.

339. 5. Structural modifications.-These may occur either in the epidermis or some internal tissues. (a) The epidermis may greatly reduce evaporation by the formation of hairs in such profusion as to form a cover for the surface (figs. 200-202). Hairs intended to protect from evaporation are usually dead and filled with air. Reflecting light

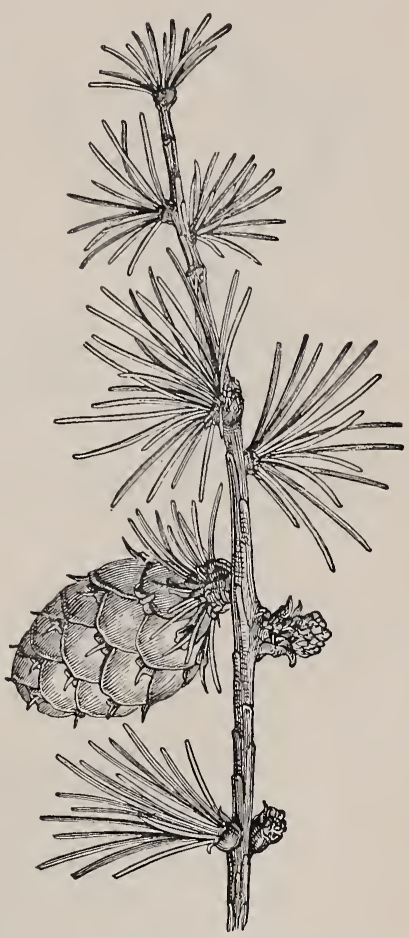

FIG. 198.- Shoot of larch, with ripe cone; showing needle-shaped leaves on dwarf branches; scale leaves on $\mathrm{m}$ a in axis. Natural size. - Afte $r$ Kerner.

from many points, they look white, and the surface seems hoary, or woolly, or silky. Hairs in the form of scales which overlap reduce the rate of evaporation by covering the stomata (fig. 203). Further adaptations of the epidermis are to be found in the water-proofing of part or all of the outer wall of the epider- 
mis (ep, fig. 205); the development of two or more layers of epidermal cells (fig. 208); or the excretion of wax or of varnish upon the surface of the epidermis. The latter often

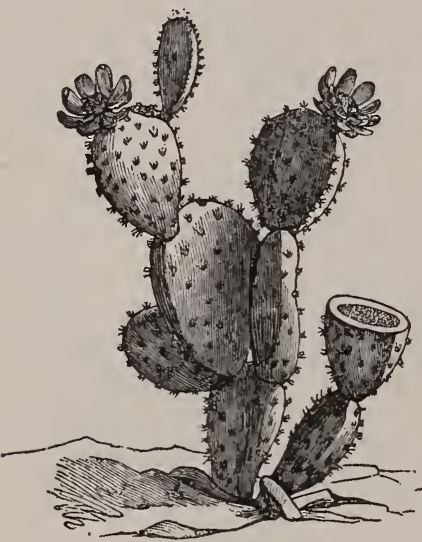

FIG. 199.

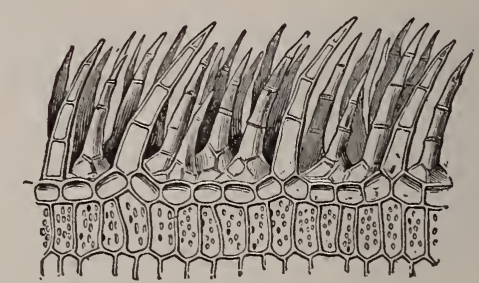

FIG. 200.

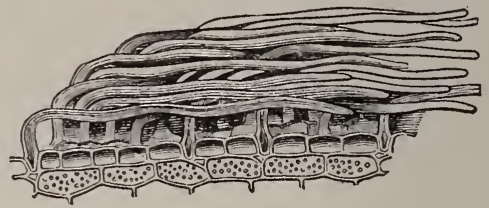

FIG. 201.

FIG. 199.-Prickly pear (Opuntia vulgaris) with flattened jointed stem and no leaves. About one fourth natural size.-After Frank.

FIG. 200.-Multicellular hairs of edelweiss. Magnified about 50 diam.-After Kerner. FIg. 20r.-Silky unicellular hairs of Convolvulus Cneorum. Magnified about 50 diam. - After Kerner.

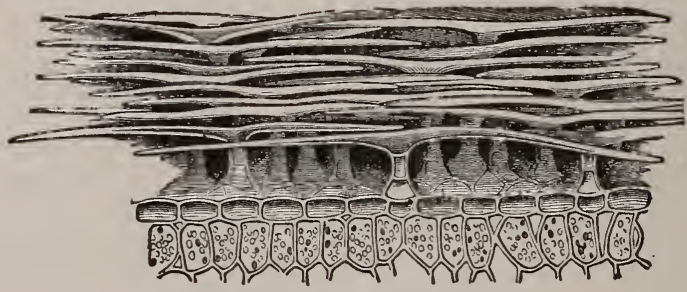

FIG. 202.-T-shaped hairs of Artemisia mutellina. Magnified about 50 diam.-After Kerner.

becomes very thick, giving to the leaves a shiny appearance. Wax is usually in the form of a bluish-white powder, which can be readily wiped off with the fingers, as from the surface of fruits, such as plums or grapes, the leaf of cabbage, or the 
stalk of sugar-cane (fig. 204). The interior layers of the wall of the epidermis are sometimes converted into mucilage,

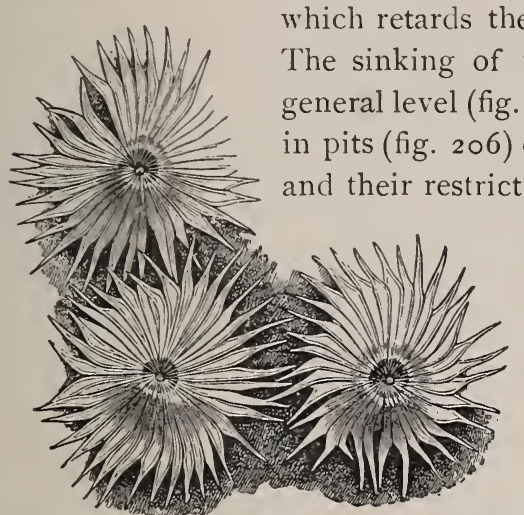

FIG. 203.-Shieldlike scales of an oleaster (Elaagnus angustifolia), seen from above. Nagnified about 5o diam.-After Kerner.

the leaf (fig. 206) may be looked upon as further epidermal adaptations to reduce evaporation. In the leaves of some xerophytes the guard cells of the stomata are motile only when y o ung, becoming thick-walled and fixed when the leaf is mature. The stoma itself sometimes becomes closed. also. (b) The internal

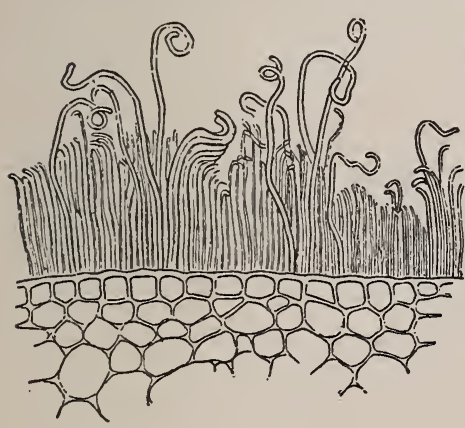

FIG 204.

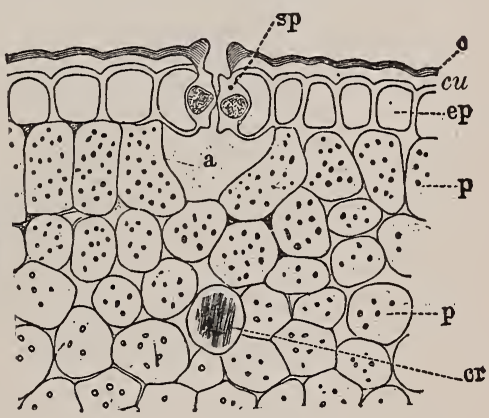

Fig 205.

F1G. 20.4.-Portion of a transverse section through a node of sugar-cane, showing rods of wax secreted by the epidermis. Magnified 142 diam. After De Bary.

F1G. 205.- Transverse section of a portion of the margin of a leaf of Aloe socotrina. $c$, thick cuticle ; $(u$, cutinized layers of wall of epidermis, $e p ; p$, green cells; $c r$, a crystal cell witl needle crystals of oxalate of lime; sp, guard cells of stoma, sunk below surface; $a$, intercellular space under stoma. Magnified about 175 diam.After T'scliirch. 
tissues of the leaves may be more compact. This reduces transpiration by restricting the area of the air passages.

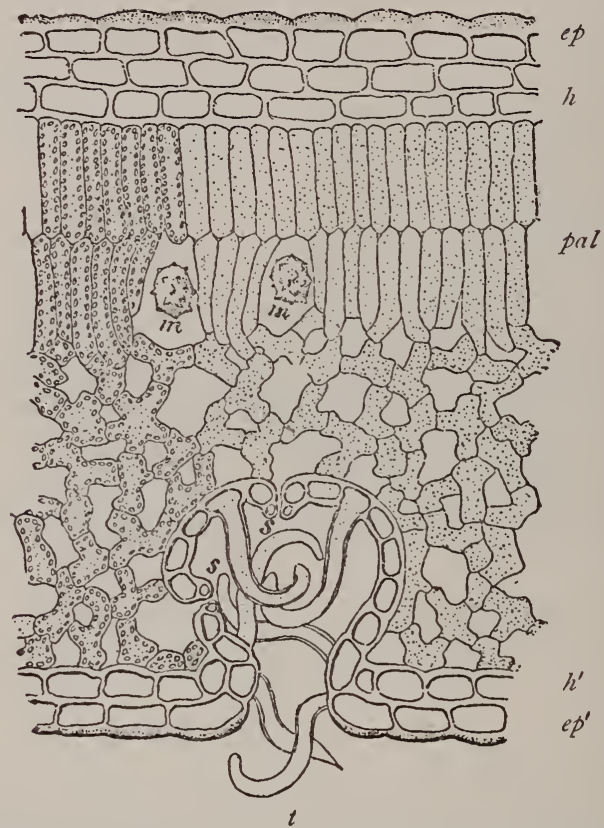

FIG. 206.-Portion of a vertical section of a leaf of oleander. ep, epidermis of upper face; $e \phi^{\prime}$, same of lower face with stomata, $s$, in deep pits with numerous hairs, $t$; $p a l$, palisade cells in two layers; sp, spongy cells ; $h, h^{\prime}$, cells adapted to water storage. Chioroplasts shown only in left-hand side of the figure. NIagnified about 175 diam.-After Van Tieghem.

\section{B. Adaptations for taking up water.}

340. Absorption.- - $r$. Some plants are adapted to immediate absorption of moisture in the air or of liquid water falling on their aerial parts. Such are, usually, the algæ, lichens, and mosses which grow in exposed situations. 2. Certain of the higher plants are furnished with hairs adapted to the prompt absorption of rain or dew, e.g., Spanish moss. 
3. Other plants adapt aerial roots to the absorption of moisture from the air, as well as falling water. (See I 65.) 4. Many are surrounded by the bases of dead leaves, which act as a sponge for absorbing water, and supply it gradually to the stem or younger leaves. Living leaves, sometimes singly, sometimes in clusters, form cuplike or tubular structures, acting as water receptacles, from which it can be absorbed as required. Such adaptations occur chiefly in epiphytes. (See 357.) 5. Many xerophytes develop exceedingly long tap roots, which penetrate the soil deeply to a permanent water supply.

\section{Adaptations for storing water.}

341. r. Special cell contents.-The simplest of these adaptations is the presence of mucilage. The presence of acids, tannins, and certain salts perhaps aids in the retention of water.

342. 2. Water-storing tissues. - (a) Fleshy plants, or succulents, are those which thicken their parts by the development of cells, which contain a large quantity of water, and usually much mucilage. These mucilage-containing parts form a reservoir for the storing of water. In such plants the epidermis is very strongly waterproofed ; the stems are thick, cylindrical, prismatic or spheroidal; the leaves are wanting, or they are thick and

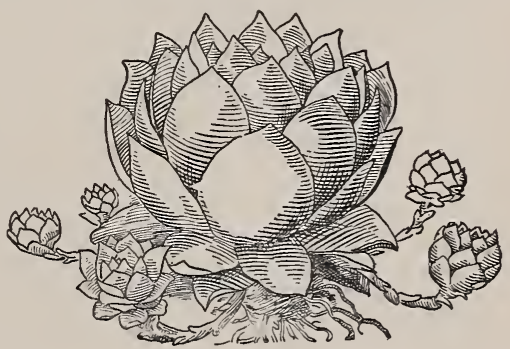

FIG. 207.-A plant of houseleek (Sempervivum tectorum), showing fleshy leaves arranged in a rosette, with offsets formed at the ends of special branches. These become detached and form independent plants. About one half natural size.After Gray.

fleshy, cylindrical or broad (fig. 207), and arranged in rosettes. 
(b) In non-succulents, the epidermis itself may be greatly developed as a water-storing tissue, or it may form great num-

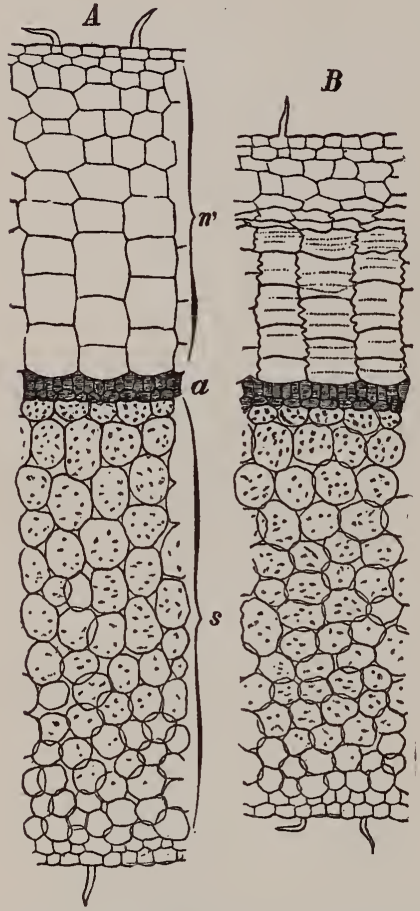

FIG. 208.-Strip from a vertical section of leaf of Peperomia trichocarpa. .4, from a fresh leaf; $w$, water-storing tissue, composed of the multiple epidermis of the upper side ; $a$, chlorophyll-bearing cells ; $s$, spongy parenchyma with sparse chloroplasts and much water. $B$, the same after four days' transpiration at $18-20^{\circ} \mathrm{C}$. The tissue $w$ is much collapsed, the walls being plaited; $s$ also shrunken, but $a$ as before. Magnified about 50 diam.-After Haberlandt. bers of bladdery hairs which are richly supplied with water, as in the well-known "ice-plant," on which the hairs glisten like ice.

In the first case, the epidermis, instead of forming a single layer of cells, may develop into several layers, the lower ones large and thin-walled, as in begonias, figs, and peppers (fig. 208). The cells immediately under the epidermis sometimes become transformed into a water-storing tissue, as in the oleanders (fig. 206); or strips of tissue extending from the upper to the lower side of the leaf may act as reservoirs of water.

343. 3. Tubers and bulbs. -These forms of the shoot, which are richly supplied with water, may also be counted, in part at least, as an adaptation for waterstorage.

344. III. Halophytes.-

The salt-loving plants, though they may grow where water is abundant, are strikingly similar in most of their characters to the xerophytes. This similarity is to be explained prob- 
ably by the difficulty of securing a suitable water supply. They grow near the ocean, upon the shores of salt lakes, by salt springs, and in the interior of the great continents in old lake basins in which the salts have accumulated by the rains. A few of the halophytes are trees and shrubs, with leathery leaves, but almost all are succulents. In habit they are generally low, often creeping, with thick, fleshy, and more or less translucent leaves and stems, containing comparatively little chlorophyll and abundantly supplied with water, and the surface generally smooth.

345. Summary.-Drought plants adapt themselves to a scanty supply of water by $(a)$ reducing the transpiration, $(b)$ providing means of securing water, or $(c)$ by storing water. Reduction of transpiration may be secured by periodic or permanent reduction of evaporating surface, by avoiding direct light, by water-proof or wax-covered skin, by mucilage in the cells; or by obstructing the stomata with coverings of scales or hairs. Adaptations for securing water are special absorbing organs on aerial parts, cuplike parts for holding water, and long roots to reach deep soil water. Adaptations for water-storage are water-holding substances in the cells, cell specialized as water reservoirs, and thickened shoots such as tubers and bulbs.

Salt plants are mostly succulents, and show adaptations similar to the drought plants. 


\section{CHAPTER XXII.}

\section{HY DROPH Y T ES,}

346. IV. Hydrophytes may be divided into three groups : I. Slime plants, which grow in the mud or slime at the bottom of bodies of water. Here belong many algæ, especially diatoms, many species of low fungi, and-bacteria in great numbers. 2. Submersed plants, either free or attached. Many algæ, including both the diatoms and the filamentous algæ, are found floating in the water at various heights, sometimes near the surface, sometimes more deeply submersed. Since their substance is heavier than water, their capacity to sustain themselves depends upon the production of gases in the interior of the cells, or upon the presence of gases entangled anong their filaments. A few of the higher plants are also found submerged and free, such as the bladder-worts. The number of free-floating plants of the larger kinds is small compared with those attached. The higher algæ, moss-worts, fern-worts, and seed plants are usually fastened in the mud or to sticks and stones. The thallus of the algæ is usually profoundly branched and the shoots of the mosses are richly supplied with leaves. All of the submerged fernworts and seed plants are characterized by a very delicate epidermis, the absence of stomata, and the extensive surface due to the very profuse branching of the stems or leaves, or to the great number of these, or to both. In all cases the extensive green surface may be looked upon as an adaptation to securing carbon dioxid and the manufacture of sufficient food by means of the weak light in a situation where there is 
no danger from lack of water. 3. Floating or partly submersed plants, either free or attached. Many of the filamentous alge and diatoms float free at the surface. The chief characteristics of the higher floating plants which root in the mud are these : their floating leaves are simple, little branched or not at all, roundish or elliptical in form, leathery, and the surface not easily wetted; stomata are present only on the upper surface, and the leaf stalks are adapted in length to the depth of the water in which they grow; the woody tissues are either entirely absent or poorly developed, because there is no occasion for the transportation of water, nor need of rigidity, since the medium in which they grow supports most of the weight.

347. Light.-Green water plants are limited in their distribution by the depth to which light can penetrate water. This does not exceed, even in pure waters, four or five hundred meters. No seed plants have been found at a greater depth than thirty meters, and few algæ at a greater depth than forty meters. Plants which are brought up by dredging from lower depths than this are usually those which have been detached and sunk.

348. The temperature of the water is very much less subject to variation than that of the air, never falling, except at the surface, below $0.5^{\circ} \mathrm{C}$.

349. The movements of the water are of much importance to plants in bringing air and food materials to them. These movements are wave movements, or surf, and currents. Plants growing within the limits of wave action are often damaged or torn away by the waves. The Sargasso Sea is marked by an accumulation of such plants, mainly of brown algæ, which have been swept to the quieter parts of the North Atlantic by currents after having been detached by the waves. Such plants may often live for a long time and may even continue their development. 
Plants adapt themselves to currents, such as those in freshwater streams, by their slender form, which is characteristic of plants in flowing waters, as seen in filamentous algæ and the much-divided leaves of higher plants. Currents of water act as a stimulus upon certain plants, producing a direct reaction in the mode of growth.

350. The composition of the water affects chiefly the distribution of plants, in a manner similar to the presence of salts in the soil. In the ocean waters the percentage of salts is extremely variable in different regions; in some places it is as low as 0.5 per cent., while in others it reaches 4 per cent. In fresh waters the differences in kind and amount of dissolved salts are chiefly due to differences in the soils which the streams drain.

351. Summary. - Water plants may grow in the mud or slime at the bottom ; submersed, and either free or attached; or floating and either free or attached. The light, temperature, movements of the water and the composition of the water are the principal factors to which water plants must adapt themselves. 


\section{§ II. ADAPTATIONS TO OTHER PLANTS.}

352. Plant associations.-Each set of external conditions brings about the association of certain plants with one another, because they have adapted themselves to those conditions. The four groups just considered may be looked upon as plant societies of the most general kind. Within each of these four it is possible to distinguish a number of smaller societies determined by a more limited range of conditions.

Besides these plant associations, however, there are those which are determined by the relation of the plants to one another, as affording mechanical support, or assistance in the work of nutrition. The plant associations of this kind only are now to be considered.

\section{CHAPTER XXIII.}

\section{ADAPTATIONS TO OTHER PLANTS AS SUPPORTS.}

Certain plants serve others as carriers, acting purely as mechanical supports. To these supports plants have adapted themselves in various ways. In many instances dead objects of similar form may serve the same purpose. The supported plants are, therefore, partly independent of the others, though in most instances in nature they rely upon living supports.

353. I. Climbing plants.-Climbing plants are those that develop lateral organs, sensitive to contact, which become recurved or coil about a support of suitable shape and size, or form adhesive disks by means of which they cling to rough 
surfaces. These lateral organs take the place of leaves or of lateral shoots, and are known as tendrils (figs. 69, Iо2). (For their form see $\uparrow 99$, I $3 \mathrm{I}$; for their action, $225,25 \mathrm{I}$ ).

354. 2. Clambering plants are those which form lateral organs not sensitive to contact, and by means of them support themselves on adjacent plants. Recurved leaves, shoots, and prickles (fig. 99) may serve these purposes.

355. 3. Twining plants are those which have adapted their shoots to winding about a support of suitable size.

(See 249.)

356. 4. Root climbers have adapted their aerial roots to attaching the plant to rough surfaces. (See 82.) Such structures are found only in fernworts and seed plants.

35\%. 5. Epiphytes.-This name is rather loosely applied to those plants which are attached only to other plants, though they derive no food from them. All kinds of plants have representatives in this group. Algæ, diatoms, and other small water plants attach themselves to other algæ and the higher water plants. Lichens, liverworts, mosses, ferns, orchids, bromelias, etc., are abundant upon trees. Epiphytes are attached by hair-like rhizoids, or by hold-fasts, which apply themselves to the roughnesses or even penetrate the outer dead parts of the supporting plant, but do not absorb from the living tissues either water or food materials. The water supply is provided for ( $\mathrm{I}$ ) by adaptations for absorbing rain or dew, mists, or even dampness, instantly, either by the surface, as in algæ, mosses, and lichens, or by means of hairs, as in the Spanish moss and other seed plants ; (2) by adaptations to catch the water in living or dead leaves and hold it, either by capillarity or as a vessel, long after precipitation has ceased. Many of the simpler epiphytes are adapted to become dry without injury, while the larger ones are inhabitants of moist tropical regions, where the danger of drying is avoided and it is possible to obtain an adequate water supply. 
Their food materials are derived entirely from the air and the water which falls upon them, while the mineral salts are obtained from the dust which has been carried by the air and accumulated upon the surface of the supporting plant, or among the mass of dead and decaying leaves and other débris about the base of the epiphyte. Organic matter from the decay of the older parts may also be reabsorbed.

An adaptation to this mode of life is marked in the reproductive bodies. Of all epiphytes the seeds or spores are either light and carried by the wind; or the seeds are sticky and carried by birds and other animals; or they are eaten by birds and voided upon the trees where they are adapted to germinate.

358. Purpose.-In most cases, the use of other plants as supports has been adopted to secure for the smaller and weaker plants proper exposure to light for making food. For example, so dense are the tropical forests that only by climbing to the tree-tops or perching on the branches can the lowlier plants secure an adequate amount of light. Even in the temperate zone the advantage in climbing for light is obvious.

359. Summary.-Plants rooted in the soil adapt themselves to use others as mechanical supports by the development of tendrils or aerial roots for climbing; recurved leaves, shoots, or prickles for clambering ; and long, swinging sensitive shoots for twining. Others use their neighbors as the sole support, being perched upon them but deriving no food from them. (Those which do absorb food are parasites. See - I 84). In most cases the purpose of such adaptations is to secure light. 


\section{CHAPTER XXIV.}

\section{SYMBIOSIS.}

360. Living contact.-Not only are different species associated through the influence of similar surroundings which they find congenial, but certain plants adapt themselves to such an intimate relation with others that they live in immediate contact with them. This intimate association is known as symbiosis. When the parties to symbiosis stand to each other in the relation of partners, each furnishing certain materials or conditions advantageous to the other, the association is called mutualistic symbiosis or mutualism. When the relation of the parties is that of master and slave, one individual deriving advantage from the labor of the other and in return furnishing it suitable conditions for existence, the association is a form of mutualism known as helotism. Finally, when the relation of the parties is that of an unwilling host and an unwelcome guest, one individual being fastened upon by the other from whose presence it is unable to free itself, the symbiosis is called parasitism. (See $\uparrow$ 44, 45, 46, 184.)

\section{A. Mutualism.}

361. I. Between plants of the same species.-Mutualism may occur between individuals of the same species. Illustrations of this are to be seen in the massing of the lower algæ into colonies, in some of which certain individuals may be differentiated from others for the purpose of carrying on 
a function of advantage to the colony. (See - Io, I I, I 7. ) In a somewhat similar way certain bacteria are found always massed into colonies of characteristic outline, of which one form is shown in fig. 209. In the higher fungi,

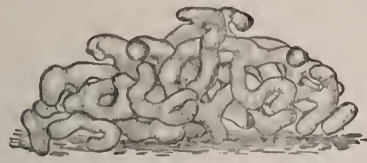

$\therefore$

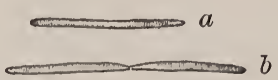

$B$

FIG 209.- - w, worm like colonies of Chondronyces serpens, composed of numerous rod.shaped individuals, $B, a$, which multiply by fission, $b$, and secrete a mass of jelly which holds them together. $A$, magnified 45 diam.; $L$, 750 diam.-After Thaxter.

also, the mycelium may be looked upon as a thallus formed by the aggregation of many individuals ; for, while it is possible to have mycelium produced from the development of a single spore, it is not common. The mycelium is generally the result of the union of hyphæ (see 43) arising from many spores. Even in such cases the mycelium may constitute a single body, and may give rise to a single fructification.

362. 2. Between plants of different species.-Mutualism is more common between plants of different species. It takes the following forms:

363. (a) Lodgers. - The higher plants often shelter various species of lower ones within their internal chambers, or in pockets formed by lobes or bladklers of various sorts. 'This relation is especially common between water plants and algæ. Species of Nostoc live in the air spaces of liverworts and duckweeds, in the roots of some land plants, and in the leaf-lobes of liverworts. Some species of the higher algæ, also, are frequently associated with other species to which they attach themselves. That they are not merely epiphytes (see 957 ) is shown by the fact that certain algx are found only upon certain other kinds, and do not grow indifferently 
upon any plant which would furnish them similar external conditions (fig. 2 Io).

364. (b) Mycorhiza.-Mutualism between the roots of the seed plants and certain fungi is common. Such a combination of root and fungus is called a mycorhiza. The fungus

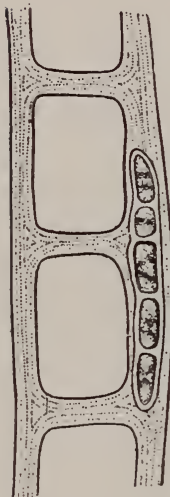

FIG. 2 Io.

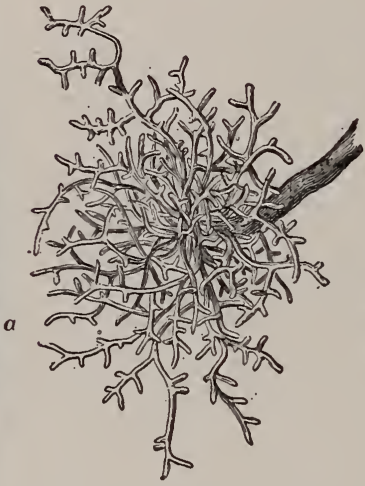

FIG. 21 r.

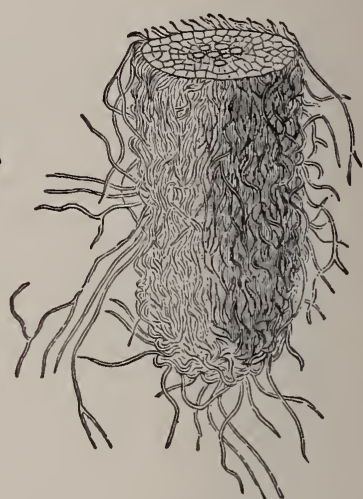

FIG. 212.

FIG. 210.-A portion of a filament of an alga (Ectocarpus) showing at $a$ another alga (Entoderma Wittrockii) which has embedded itself in the cell-wall. Magnified 480 diam.-After Wille.

Fici. 21r. - A tuft of rootlets of white poplar forming mycorhiza. Natural size.After Kerner.

FIG. 212.-Tip of a rootlet of beech (Fagus sylratica) with fungus mantle, the loose hyphæa acting as absurbing organs in place of root hairs. Magnified roo diam.-After Frank.

forms a jacket over the outside of the root (figs. 2 I I , 2 I 2 ), taking the place and work of the root hairs by means of strands of hyphæ extending from the surface of the fungus jacket (fig. 212); or it grows inside the cortex and epidermis, forming knotted masses (fig. 2I3); or it is confined to certain definite portions of the roots, forming upon them swellings from the size of a hazelnut to the size of a man's head. The first form is especially common upon the roots of the oak, elm, walnut, apple, pear, maple, ash, and related trees. It has also been found upon the roots of a large number of herbaceous plants. The second form belongs chiefly 
to the heaths and orchids. The third form grows upon alders, bayberry, etc.

365. (c) Root tubercles of Leguminosæ.-A peculiar case of mutualism appears in the bean family between the roots and bacteria. The latter produce upon the roots small swellings from the size of a grain of wheat to that of a hazelnut (fig. 2I4). The presence of these bacteria, in a way yet unexplained, certainly enables the plant to use free nitrogen from the atmosphere, while other plants are required to obtain it from the soil in combination with other things. The enrichment of the soil by growing clover and similar crops upon it and plowing them under is explained by their ability thus to accumulate nitrogen from the air.

366. 3. Between plants and animals.-Mutualism also occurs between plants and animals. Various species of plants attach themselves to animals by which they are carried about. The plant is thus aided in obtaining the ma-

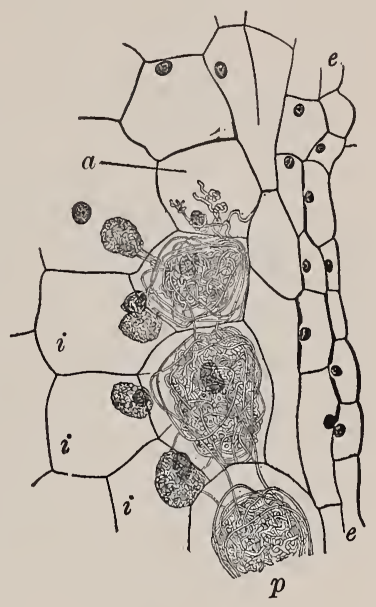

terials for food, and not infrequently the plant conceals the animal from another which seeks it as prey. In this way certain crabs are hidden by algæ attached to them.

\section{B. Helotism.}

367. I. Fungi and algæ.-Helotism exists between fungi and algæ, constituting the bodies known as lichens, in which 
the fungus is the master and the alga the slave. (See 94 , and figs. 2 I 5, 2I6.) The same fungus may be found enslaving more than one species of algæ even within the same

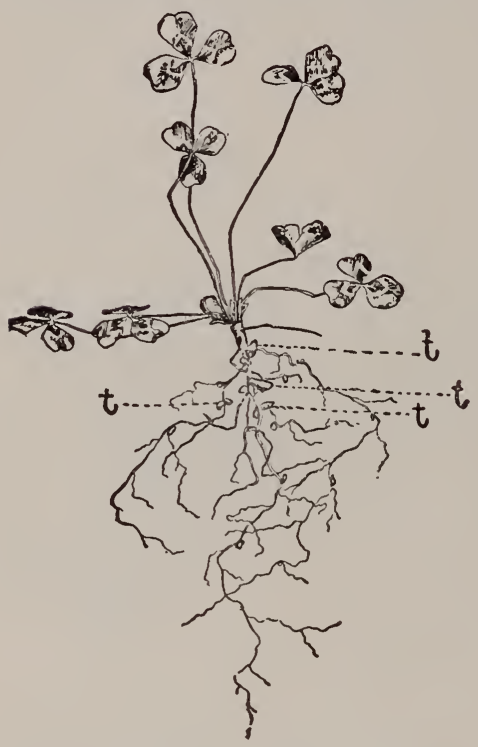

FIG. 214. - A young clover plant, showing tuberGoff. cles, $t$, on the roots. Natural size.-After

nucelium. The protonema of mosses (see 59) or even the leaves of some small plants may be surrounded by a mycelium. The enslaved green plants are generally unicellular or filamentous algæ. If the latter are the species whose colonies produce voluminous gelatin, the texture of the lichen body is gelatinous; otherwise it is tough and leathery. Some of the fungi which ordinarily associate themselves with algæ to form lichens may exist free as saprophytes. The alga itself influences the form of the thallus more or less profoundly according to its relative amount. The same fungus associated with different algæ produces lichens which are described as different species, or even as different genera.

368. 2. Animals and algæ.-Helotism exists between animals and algæ. Various simple animals, such as radiolaria, stentors, hydras, sponges, echinoderms, and worms, enclose algæ in their bodies and utilize the products of their food manufacture. The algæ thus enslaved are all minute unicellular forms which multiply within the animal body by fission ( 260 ). 


\section{Parasitism.}

369. I. Fungi.-A very large number of colorless plants have adapted themselves to live upon living plants or animals which they force to act as their unwilling hosts. By the presence of the parasite the normal functions of the host or its normal growth or both are more or less seriously interfered with, so as to produce disease, slight or grave, local or general, according to the circumstances. Many animals are thus preyed upon by bacteria

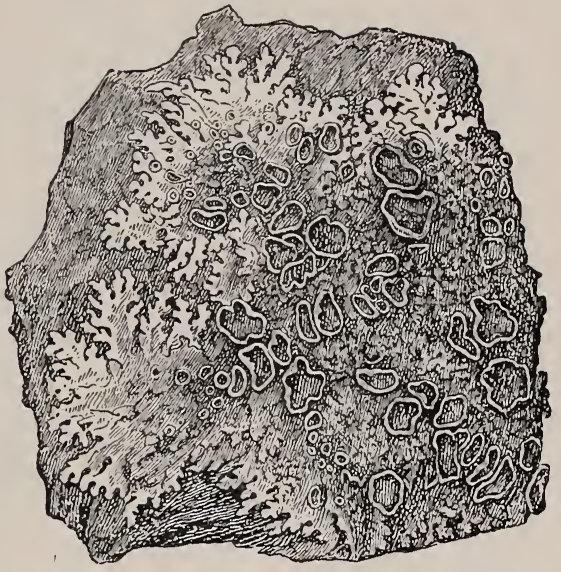

FIG. 215.-A lichen (Parmelia conspersa) growing on a stone, showing the leaf-like thallus (mycelium), with many cup-like fructifications. Natural size.-After Frank.

and fungi. Most communicable diseases, such as typhoid

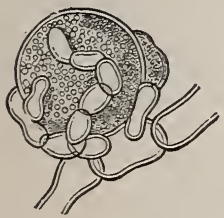

Fig. 2i6.-Hyphæ of a lichen, Cladoniır furcata (see fig. 36), enveloping an alga, Protococcus. Magnified 950 diam.After Kerner. fever, diphtheria, and tuberculosis, are known to be due to the transfer of the parasite from the diseased individual to the healthy one. In a similar way bacteria live as parasites upon green plants, causing disease and often death. The number of bacterial diseases among plants is relatively small, for comparatively few bacteria have been able to adapt themselves to living in the acid cell sap of plants. The number of diseases of plants due to parasitic fungi, on the contrary, 
is very large. (For the mode by which parasitic fungi gain entrance to the bodies of their hosts, see $\uparrow 45 \cdot$ )

$B$

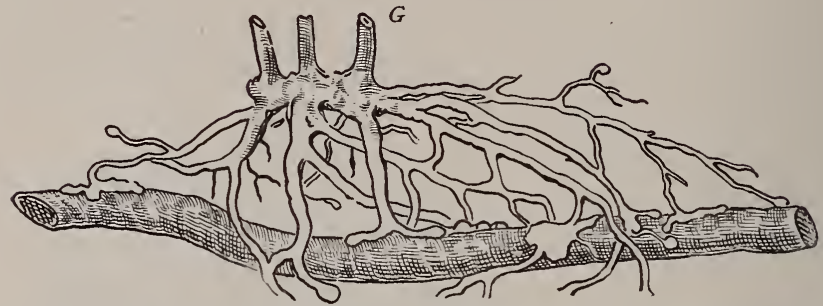

FIG. 2I7.- Roots of a yellow Gerardia, $G$, attached to the root of a blueberry bush, $B$. They enlarge at the points of contact and there send haustoria into the host root. Natural size.-After Gray.

370. 2. Seed plants.-A few seed plants have adapted themselves to a parasitic life upon others. Some may be

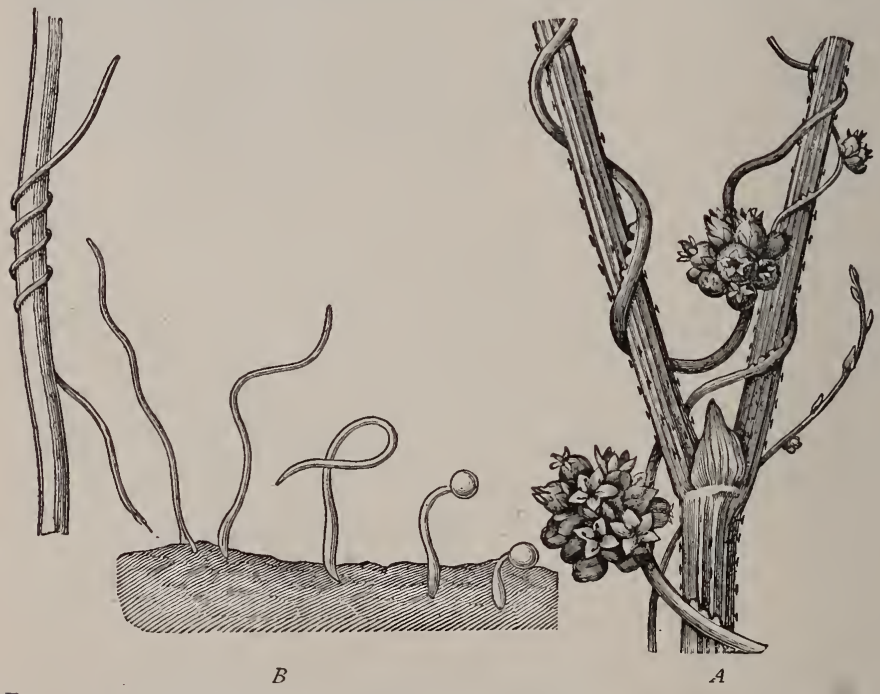

FIG. 2 8.-A, European dodder twining about a hop stem. All but the uppermost coils show the groups of wartlike swellings from which haustoria penetrate the host stem. Natural size. $B$, Germination of same. The various stages are arranged in order from right to left. In the last stage the seedling has found a suitable support and has absorbed all the reserve food in the thickened lower end, which has withered and died, freeing the plant from the ground. Magnified about 2 diam.-After Kerner. 
reckoned as semi-parasitic, having still green leaves and true roots. In addition, however, special organs are developed for attaching the parasite to the roots of other plants, from which at least a water supply and probably food materials are absorbed (fig. 217). Other semi-parasites, such as the mistletoe, attach themselves to the host above ground, and have no true roots of their own. Some parasitic seed plants twine about their hosts, and send into them absorbing organs by means of which they derive all their food from the host. Such is the yellow parasitic vine known as dodder (fig. 2 I8, $A$ ). These plants germinate in the ground, and as seedlings possess true roots, but after attaching themselves to the host the lower part of the stem dies away so that the true roots are transient (fig. 2 I $8, B$ ). Some parasites have the body so reduced that it merely forms a network or a hollow cylinder outside the wood of the host and under the bark. From this curious body the few flowers break through the bark and appear upon the surface of the

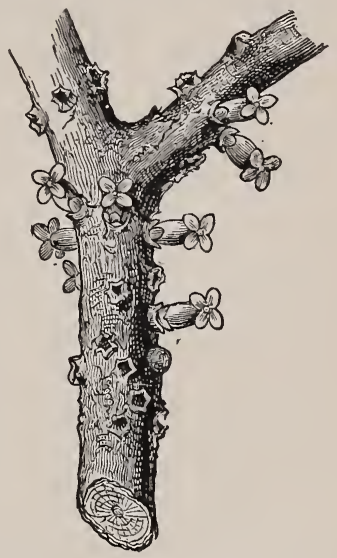

FIG. 219.-A twig infested with a parasitic seed plant (Afodanthes) whose body is hidden under the bark of the host, through which a short branch bearing a few scale leaves and a single flower bursts. Natural size.-After Kerner. root or stem of the host, quite as though they were a part of it (fig. 219).

371. Summary.-Plants may live in such relations that one is directly dependent upon the other for its food supply, or they are mutually dependent for food or advantageous conditions. Animals may likewise be directly dependent on plants associated with them. Mutual dependence may exist between plants of the same species, but is commoner between plants of different kinds. One kind may lodge in cavities or 
internal chambers in the other. Fungus filaments associate themselves with roots, particularly of trees. Bacteria, in connection with roots of the bean family, enable them to acquire nitrogen from the air, as other plants cannot. Fungi and algæ, in the relation of master and slave, form the lichens. Algæ are similarly enslaved by a few animals. A great number of fungi and bacteria attack other plants and also animals, causing more or less extensive deformity and disease. Only a few seed-plants live as parasites upon others. 


\title{
§III. ADAPTATIONS TO ANIMALS.
}

\author{
CHAPTER XXV.
}

ANIMALS AS FOOD, FOES, OR FRIENDS.

\section{Carnivorous plants.}

372. Nitrogen supply.-The ordinary source from which green plants obtain nitrogen for the making of their food is the nitrogen compounds dissolved in the soil water. Plants which live where the soil water contains little or no nitrogenous material are forced to resort to another source of supply. Some plants solve the problem by entrapping animals, deriving from their bodies the desired nitrogen compounds. Such plants are called carnivorous plants, or, since the bulk of their catch consists of insects, insectivorous plants. The catching of animals is done

373. I. By pitfalls and traps.-(a) The various pitcher plants furnish a fine example of well-devised pitfalls. The leaves of these plants have a deep, trumpetlike-tube making up the body of the leaf; or they carry at the end of a long petiole a deep cup with a lid, as in the tropical pitcher plants (fig. 220; see also fig. IOI). The tube is one-third or half full of water, in which are always found numbers of dead or dying insects. The sides of the tube without are often made attractive by gaudy colors or by lines of sweet secretion, which draw both flying and crawling insects. Within, its surfaces are either excessively smooth, so as to afford no foot- 
hold to an insect attempting to crawl out; or covered by stiff, downward-pointing hairs to oppose its passage; or the side of the tube is filled with thin translucent spots through which the captives vainly strive to fly, while the real opening

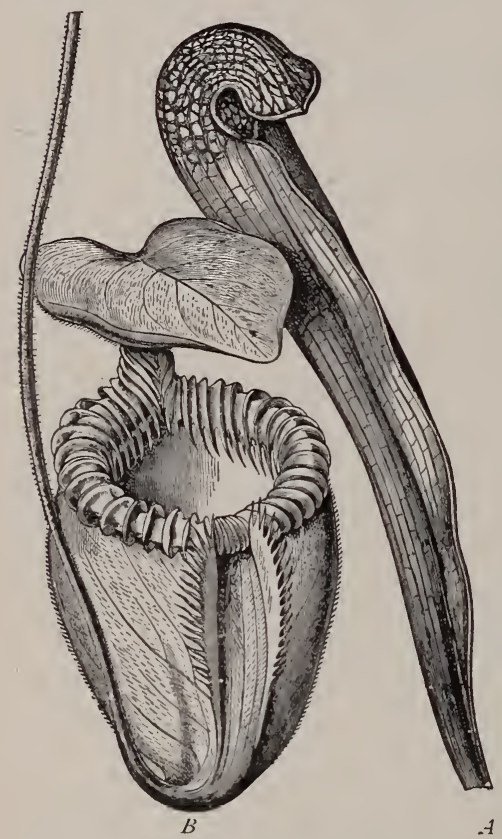

FIG. 220.-A, trumpet-shaped sessile leaf of Sarracenia variolnris, showing thin membranous windows in the meshes of the veins of the hood which arches over the mouth of the trumpet. $B$, cup-shaped petioled leaf of $\mathrm{Ne}$ penthes villosa, with elevated lid and margin
ribbed. One-third natural size.-After Kerner. is concealed. By one or other of these means the prey is prevented from escaping, and sooner or later is drowned in the liquid. In this liquid digestive substances or bacteria quickly dissolve the softer parts of the insect bodies, and the soluble portions are absorbed by the leaf.

(b) The bladderwort, which abounds in quiet pools, furnishes an excellent illustration of traps (figs. 221,222 ). Upon the leaves are numerous minute bladders, each with a small opening about which divergent hairs serve as guides to the entrance. The entrance is lightly closed by a flap of membrane, which is readily lifted by minute water animals. After they have passed through the opening the membrane drops behind them, and is stiff enough to prevent their escape. Death ensues sooner or later, and absorbing hairs on the inner face of the trap take up the nutritive materials. 
ANIMALS AS FOOD, FOES, OR FRIENDS. $26_{3}$

374. 2. By adhesive surfaces.-Animals are also captured by adhesive surfaces. These surfaces are covered by a

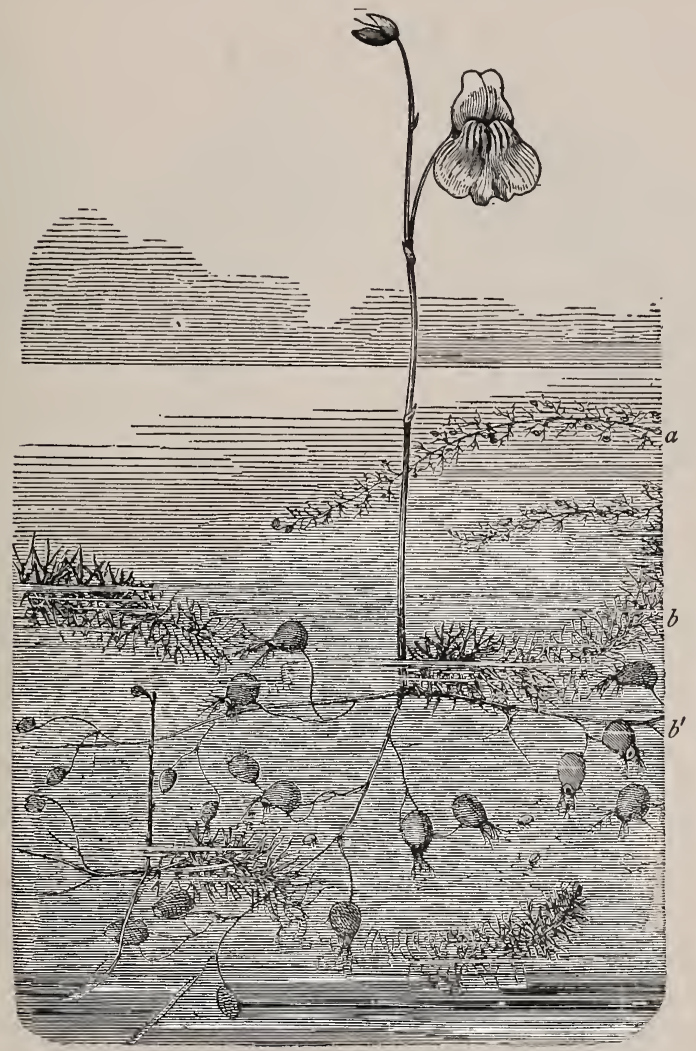

Fig. 22r.-A bladderwort (Utricularia Grafiana), showing an aerial flower stalk carrying an open flower and a second one above from which the corolla has fallen. Some stems bear numerous, finely branched leaves, $b$, and others the large bladders, $b^{\prime}$. See fig. 222. A shoot of a smaller species is shown at $"$, with bladders and leaves on same stem. About two-thirds natural size.-After Kerner.

sticky fluid secreted by numerous glandular hairs, and upon these many small insects may be found dead. In many 
cases the softer parts of the insect bodies are digested and absorbed. It should be noted, however, that adhesive sur-

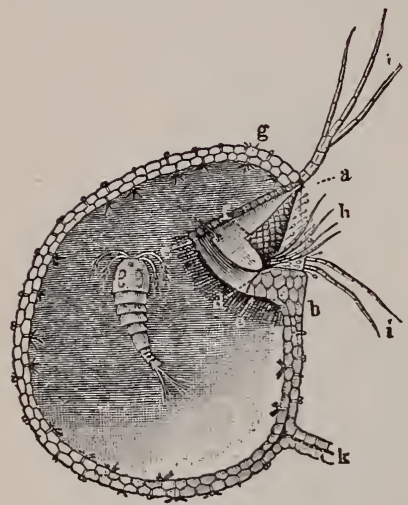

Fig. 222 .

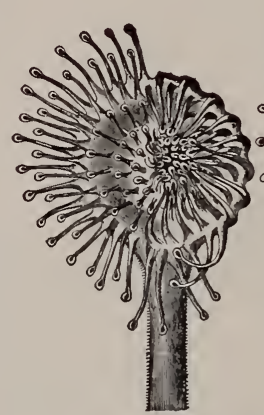

B FIG. 223.

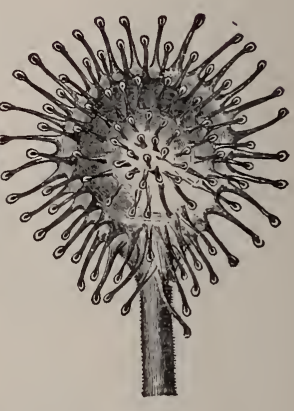

A

Fig. 222.-A bladder of Utricularia vulgaris, halved lengthwise, with an imprisoned crustacean, Cyclops. $a$ to $b$, opening, with hairs, $h, 1$, about it ; $b$ to $c$, cushion-like rim, $b-c$ part cut through, $d$-e surface on which the flap, $f$, rests, opening inwards only ; $g$, wall of bladder set with absorbing hairs within and glandular hairs without; $k$, the stalk (secondary petiole). Magnified 20 diam.-After Colnn.

FIG. 223. - Two leaves of sun-dew (Drosera rotundifolia). $A$, in expanded position showing the tentacles $B$, shortly after the capture of an insect. The tentacles on the right half are inflexed to bring the glandular tips in contact with the prey. Magnified $2 \frac{1}{2}$ diam. - After Kerner.

faces are also merely protective against the visits of unwelcome guests, who steal nectar or pollen. (See -394.$)$

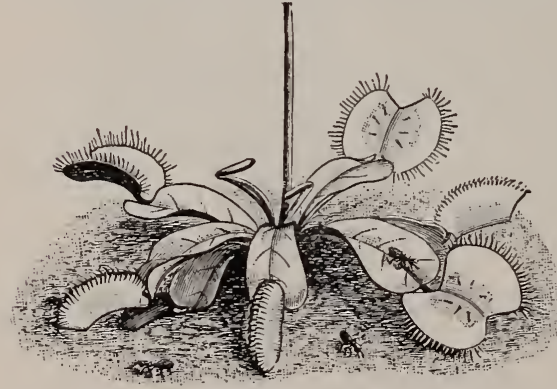

FIG. 224.-Cluster of leaves at the base of flower-stalk of Venus' fly-trap (Dioncea muscipula). One-half natural size.-After Drude.

and surface of the leaves covered with many outgrowths, 
each of which is tipped by a large gland (fig. 223). The clear, glistening fluid, a large drop of which is secreted by

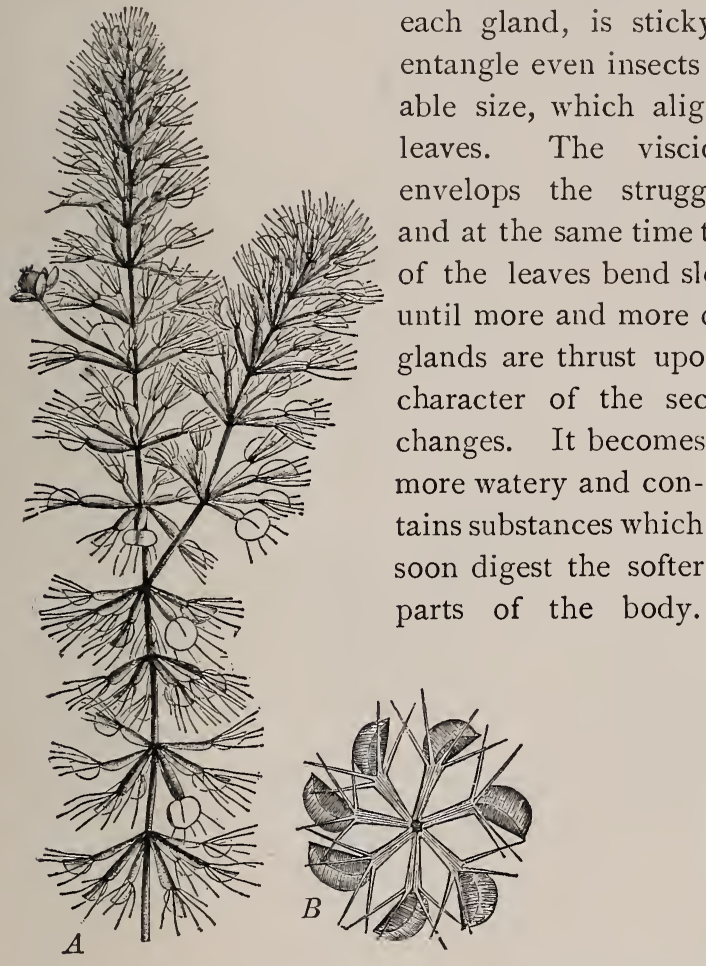

FIG. 225.

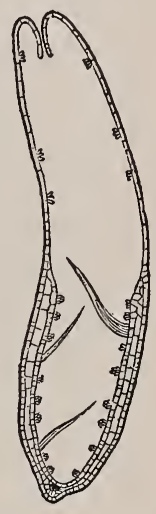

FIG 226.

F1G. 225.-A, blooming plant of Aldrovandia vesiculosa. Natural size.-After Drude. $B$, a single circle of leaves seen from the center above, showing stalk and two semicircular lobes. Magnified $x_{\frac{1}{2}}$ diam.-After Caspary.

Fiv. 226.- Transverse section through closed trap of Aldroz'andia, showing on inner face long sensitive hairs and many absorption hairs. Only the central part is three layers of cells thick; a broad margin is only one cell thick. Compare appearance in $B$, fig. 225. Magnified 20 diam.-After Caspary.

These are absorbed, and play an important part in the nutrition of the plant.

Dioncea (fig. 224) and its water mate, Aldrovandia (fig. 225 ), have leaves whose blades are somewhat like a spring trap. The blade is two-lobed, with a hinge along the middle 
(figs. 137,226 ). The hinge is in reality a cushion of tissue upon the back, which quickly throws the two halves of the leaf together when the sensitive hairs on the inner face of the trap are touched. The movement is sudden enough in Dioncea to catch the slow-flying insect, or, in Androvandia, the minute water animal. The prey is prevented from escaping by the interlocking, tooth-like lobes along the edges of the leaf. Digestion and absorption of the foods follow.*

\section{Herbivorous animals.}

376. Protection.-While a really insignificant number of minute animals are eaten by plants, a very large number of plants find it necessary to protect themselves in some way against destruction by browsing animals, insects, snails, and slugs. Since the animal world relies for its food supply ultimately upon the green plants, it is plain that no such protective measures are completely effective. The protection, therefore, may be looked upon as a protection against extermination rather than against injury. As protective adaptations against browsing animals are usually reckoned :

377. I. Armor, in the form of hard, leathery, sharpedged, woolly, bristly, or sticky parts, especially leaves (figs. 200, 201, 202, 22 7); or thorns (figs. 103, 228), prickles, or stinging hairs (fig. 229).

378. 2. Distasteful or injurious substances, such as volatile oils, camphors, acids tannins, alkaloids, etc. The

* Travesties upon these strange methods of nutrition appear periodically in newspapers, and plants of remarkable size and forbidding aspect are represented as capturing birds, animals, and even men, that venture into their neighborhood. It should be noted, therefore, that in all cases the plants which capture animal food entrap only the smaller animals, scarcely any of them, except those caught by the pitcher plants, larger than the common house-fly. 
milky juice of plants like milkweeds, which often contains acrid substances, may also be protective.

379. 3. Mimicry. - Certain plants which are not distasteful or disagreeable have adopted the same form of leaves and stem and the general habit of those which grazing animals have found distasteful. This mimicry causes them to be avoided, as well as the really hurtful ones which they imitate.

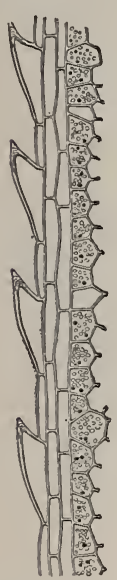

FIG. 227.

380. 4. Ants.-In the tropics particularly, certain plants secure them-

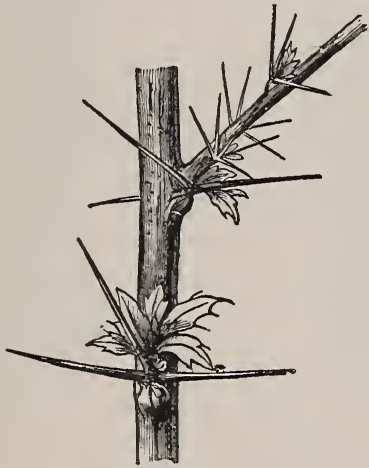

FIG. 228.

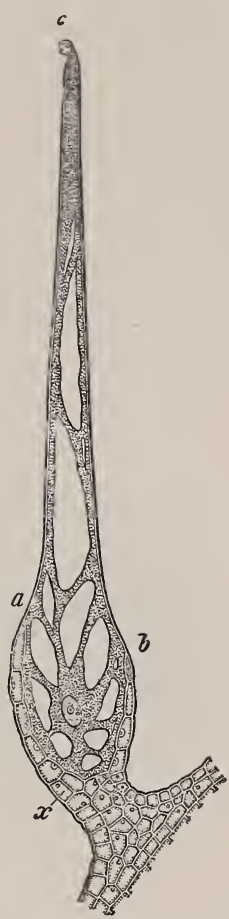

FIG. 229.

FIG 227.-Edge of a leaf of a sedge (Carex stricta), showing alternate epidermal cells pointed and underlaid by two layers of mechanical cells. Magnified 200 diam.-After Kerner.

FIG. 228.- Part of a shoot of barberry in spring showing leaves of preceding year as persistent three-pointed thorns, in whose axils the buds are developing into the season's shoots. Natural size.-After Kerner.

FIG. 229.-A stinging hair of the nettle (Urtica), in longitudinal section. $x$, emergence in which the single-celled hair $a b c$ is sunk below $a b$. The knoblike apex $c$ is easily broken off because the cell wall just below it is thin and brittle. The oblique cutting edge left pierces the skin like a hypodermic needle and some of the acrid cell contents enters the wound, causing intense itching. Magnified 60 diam.-After Frank.

selves from the attacks both of browsing animals and leafcutting insects by encouraging the presence of colonies of warlike ants upon them, and making provision for 
their defenders' wants. A very large number of species* protect themselves in this way. For the ants the plants provide (a) nectar, similar to that secreted in the flower (i.e., a watery solution of various sugars), but secreted by nectaries outside the flower; $(b)$ fodder, in the form of hairs (fig. 230), often of peculiar from, richly supplied with nutritive substances, growing from special parts of the surface, which are regularly eaten by the ants and grow again, so

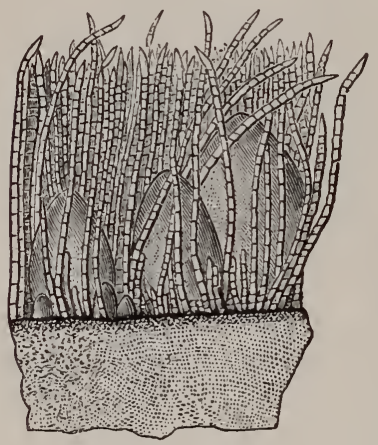

FIG. 230.

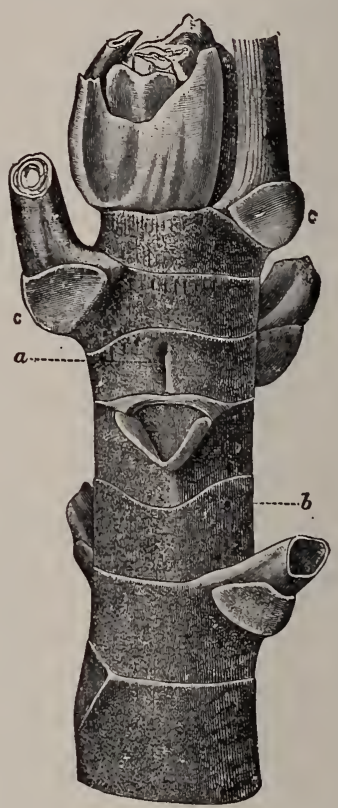

Fig. 231.

FIG. 230.-Bit of a section through the cushion (c, fig. 23I) at base of leaf of Cecropia, showing the veivety hairs with which it is covered, and among them the egg-like bodies, rich in proteids and fats, which the ants collect and carry into their nests in the interior of the stem. Magnified about ro diam.-After Schimper.

Fig. 23r.-Apex of the hollow stem of a young Cecropia. a, the thin spot above a leaf, which at $b$ has been gnawed through by the ants to make their nests in the cavity of the stem; $c$, the cushion at base of leaf stalk where food bodies grow. See fig. 23o. Two-thirds natural size.-After Schimper.

that a constant supply is at hand; $(c)$ dwellings of various sorts. Certain plants have the stems hollow throughout, with special modification of the structure at certain spots, so that an entrance to these hollows may be readily made (fig.

* More than three thousand are listed by Delpino. 
23I). In others, portions of the internodes are much enlarged and hollow; sometimes only the internodes in the region of the flower clusters are thus transformed. In other plants chambers are produced by the bladdery enlargement of the under part of the leaf near the midrib (fig. 232 ). In some acacias the stipules are developed as large hollow thorns, which the ants inhabit.

381. 5. Crystals. - Plants protect themselves against soft-bodied animals, such as snails and slugs, by means of the sharp-pointed crystals which are present in the leaves of many species. According to Stahl, all tissues containing these crystals are avoided by such animals, but will be readily eaten by them after the crystals are removed.

382. Summary.-Carnivorous plants use small animals, especially insects, as food, capturing them by pitfalls, traps, or adhesive surfaces, and either

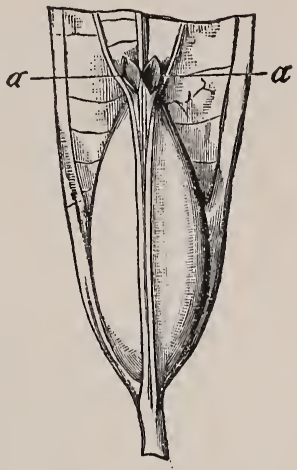
FIG. 232.- Under side of the base of the leaf blade of $T o$ coca lancifolia, showing bladder on each side of midrib, each with entrance at $a, a$. Natural size (?).-After Schumann. digesting and absorbing the useful parts, or after the slower decay, absorbing certain substances. Many plants protect themselves against browsing animals by armor, by distasteful or injurious juices, by mimicking distasteful or hurtful plants, or by harboring fierce ants which attack anything that disturbs the plant they have made their home. For the ants some plants provide not only shelter but food. 


\title{
II. REPRODUCTIVE ADAPTATIONS.
}

\author{
CHAPTER XXVI.
}

\section{PROTECTION AND DISTRIBUTION OF SPORES AND SEEDS.}

THE present knowledge of reproductive adaptations among the flowerless plants is very imperfect, though probably many exist. This chapter, therefore, must discuss chiefly the adaptations in the more complicated reproductive structures of seed-plants which have been most studied, with only incidental allusions to such arrangements in the lower plants.

\section{Protection against bad weather.}

383. By movements._-Pollen unfitted to resist low temperatures or wetting must be protected from rain, cold, and similar conditions. When nectar is secreted in the flower as an attraction to insects it is liable to be washed out by rain unless access of water to the interior of the flower is prevented. To avoid these dangers, many plants upon the approach of unfavorable weather bend their leaves so as to close the flower (fig. 233), or arch the stalk so as to turn the blossom into such a position that the rain or snow will not reach the sporangia or the nectaries. These movements of the leaves and stalk are combined in various ways to meet the needs of each particular form. All of them are growth 
movements, brought about by variations in light and temperature, which act as stimuli. (See 244.)

II. Adaptation to distribution of spores.

The fact that spores are found in every group of plants from the lowest to the highest makes it probable that a great

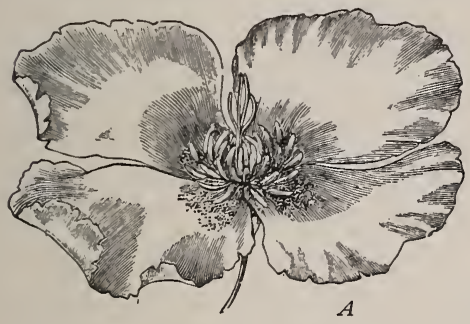

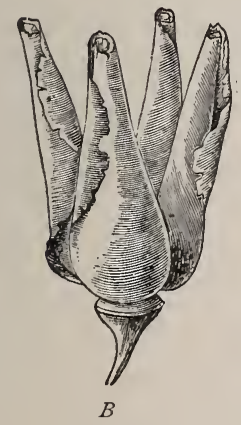

FIG. 233.

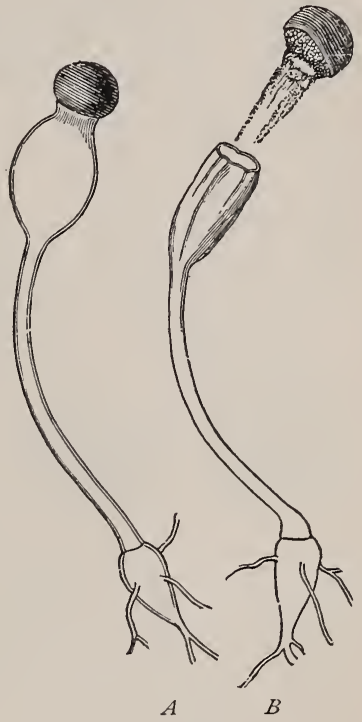

FIG. 234.

Fig. 233.- $A$, flower of California poppy (Eschscholtzin), opened in sunshine; $B$, the same, closed in wet weather. Natural size.-After Kerner.

Fig 234.- $A$, aerial hypha of Pilobolus crystallinus, with spore case. The hypha is swollen beneath the spore case and very turgid. $B$, the same with spore case torn off at base and being shot away by the violent escape of the mucilaginous contents of the hypha. Magnified about ro diam.-After Kerner.

variety of ways will have been adopted by plants to secure their distribution. The more important ways may be grouped as follows :

384. I. By turgor and tension.-Among the fungi, spores are often forced out of the spore case by the pressure upon 
it of neighboring parts, increasing until the spore case ruptures suddenly and the spores are shot out like projectiles. In some plants the whole spore case is thrown off in this fashion, often to the distance of a meter or more (fig. 234). The fungus which attacks and kills house flies in summer

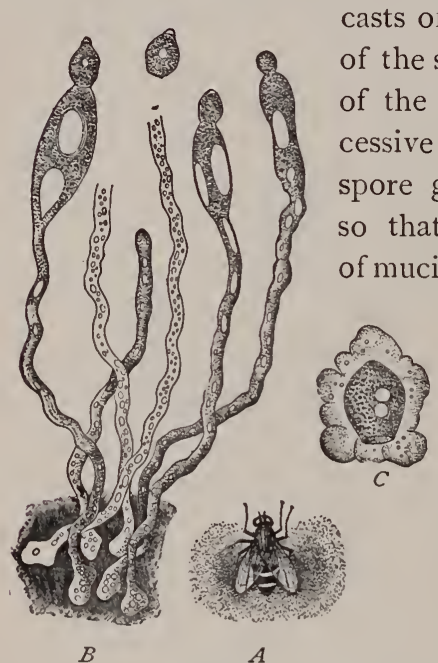

FIG. 235. $-A$, a fly killed by the fly fungus (Empusa Muscue), stuck to wall by hyphæ and surrounded by a halo of the spores. Two-thirds natural size. $B$, hyphæ projecting into the air from the body of the fly, from whose tips spores are being shot off. Several are shown in various stages of development. The turgor of the enlarged end of hypha finally ruptures the attachment of the spore and it is shot off surrounded by the mucilaginous contents which cause it to adhere to any object struck. Magnified 200 diam. $C$, a spore enveloped in mucilage. Magnified 420 diam.-After Kerner.

the teeth, by their form and hygroscopic curvatures, serve to sling out the spores to a short distance. In many ferms the spore cases are furnished with a spring-like structure (the annulus) along the greater part of the edge, which tends to straighten itself upon drying, thus rupturing the spore case. 
After bending backward for some distance until the tear gapes wide, the spring suddenly straightens and hurls the spores to a considerable distance (fig. 236 ).

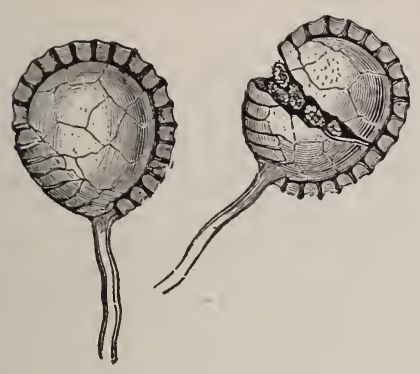

$B$

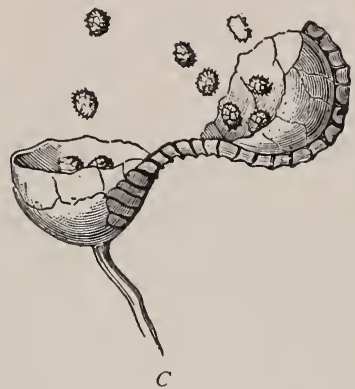

C

Fig. 236.-Spore cases of the male fern (Aspidium Filix-mas) scattering the spores. $A$, closed; $B$, burst by the drying of the annulus ; $C$, the annulus after becoming strongly recurved is just returning to a nearly straight form and the spores are thereby being hurled toward $B$. Magnified about 65 diam.-After Kerner.

385. 2. By water.-In perfectly quiet water, distribution of spores depends solely upon their own motor organs. Only zoospores (see -264 ) are so furnished. For these a film of water is sufficient, and they may swim some distance over what appear to be merely moist surfaces. Most of the algæ and fungi living in water form zoospores. Their production is often controlled by external conditions, the formation of new individuals being thus provided for when the old are threatened with destruction.

In flowing water and by currents, non-motile spores are readily distributed, and even relatively heavy spores may be carried long distances by water currents. The pollen of aquatic seed-plants is sometimes carried to the stigma by water currents, as in Vallisneria (fig. 237).

386. 3. By air currents.-Spores may be readily carried by the air on account of their small size and their ability to withstand dryness. Most spores float in the air for some time as dust particles, and the slightest current is adequate 
to lift many and carry them along. Spores of most nonaquatic fungi, mosses, and fernworts are distributed by air currents. The pollen of some seed-plants, especially the common forest trees, is carried in this way.

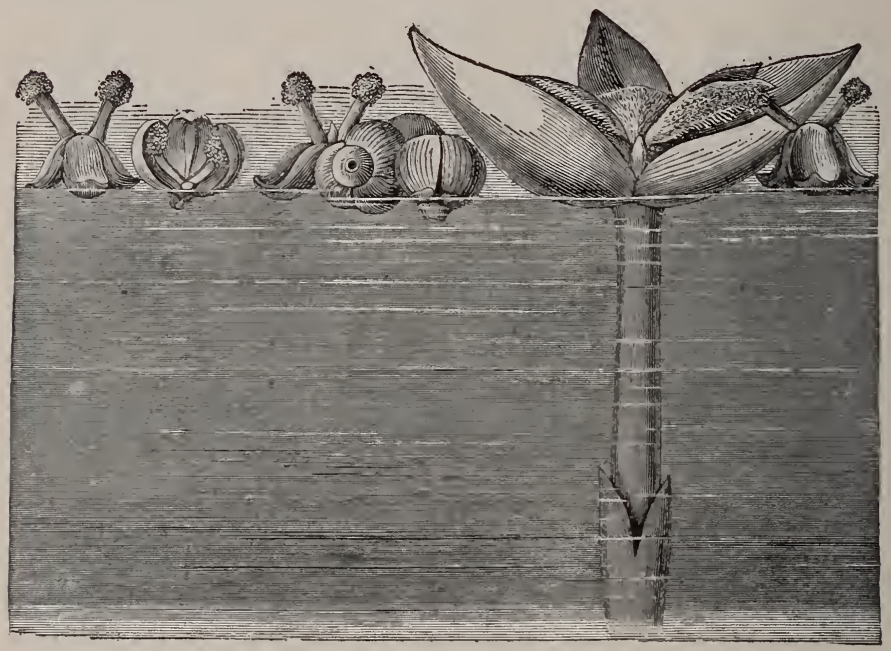

FIG. 237.-Pollination of eel-grass (Vallisneria spiralis). The large flower is a pistillate one, with stigmas fringed on under side. About it are floating staminate flowers in various stages of development, having broken from submersed stems which bore them. The ones on the right and left have the boat-shaped perianth lobes turned back, stamens mature, and pollen exposed; one has floated so that the pollen is brought into contact with the stigma of the pistillate flower. Nagnified ro diam.After Kerner.

387. 4. By animals, especially insects.--It is the seedplants, particularly, which have adapted themselves to the distribution of spores by this means. The pollen must be carried to the ovules of gymnosperms or to the stigmas of angiosperms and lodged there. It has been clearly shown not only that adaptations for securing this result have been developed, but also that there have arisen various ingenious adaptations to secure cross-pollination and to prevent closepollination. (See $\uparrow$ 295.) Some of these may be here enumerated. 
388. Adaptations for cross-pollination.-(a) The separation of the stamens and pistils, staminate flowers and pistillate flowers being produced upon different parts of the same plant or even upon different plants of the same species; $(b)$ the early ripening of the stamens so that they discharge their spores before the stigma of the same flower is exposed or receptive, or vice versa; $(c)$ arrangements preventing the pollen from reaching the stigma of the same flower, which vary according to the different modes by which the transfer of the pollen is made; $(d)$ the failure to form good seed when close-pollination happens.

389. Adaptations for close-pollination.-But close-pollination, even though it results in weaker offspring, is better than entire failure to produce progeny. Therefore, some plants permit close-pollination in the event of failure to secure cross-pollination, while a few have adaptations which insure it. Our common violets produce in the late spring and early summer inconspicuous blossoms which do not open, containing stamens with few pollen grains. These flowers, however, produce seed abundantly, and always by closepollination. Various other species have similar arrangements.

390. Adaptations to insects.-The adaptations to secure cross-pollination through the visits of insects are so numerous and so varied, and the advantage in the number and weight of seeds produced is so marked, that for most seed-plants cross-pollination must be considered the far more desirable process. Flowers are adapted to insect visitors in the following ways :

391. (a) Food, etc.-They provide for their visitors edible substances, such as nectar and pollen, * material for nest building, shelters, or breeding places.

* The pollen is often produced in great excess of the plant's own needs. 
392. (b) Advertisements.-They advertise the presence of such attractions in two ways, which are sometimes combined, and insects accustomed to visit flowers quickly learn to know what the advertisements mean. (i) By color. Flowers are so colored as to attract notice; and this is further secured by the large size of individual flowers or by massing many small flowers into close clusters. (ii) By odor. Odors are due to volatile oils, usually in the petals or sepals, often curiously localized. Dusk- and night-blooming plants often have heavy odors.

393. (c) Form and position of parts.-Many plants by the form of their flower-leaves provide landing places for welcome visitors. Guides to the location of the nectar, in the form of grooves, folds, hairs, lines of color, etc., are often present. The form and position of the stamens and pistils are often such as to insure the desired transfer of pollen. These positions may be permanent or they may be secured by movements at opportune times. Among the movements are those due to turgor and those due to the presence of motor organs. In a very large number of cases, by the form of the flower-leaves and the essential organs the plant is adapted to visitation by particular insects, and if these are not present, or if their access is denied, constant failure to set seeds is the result. Thus one may distinguish plants adapted to bees, moths, butterflies, flies, birds, or even snails.

394. (d) Exclusion of unwelcome visitors. - In addition to provision for welcome guests must be enumerated the methods of excluding unwelcome guests, which on account of their size and habits are unable to bring about the desired transfer of the pollen, while at the same time they rob the plant of nectar or pollen prcvided for more acceptable visitors. (i) Various obstructions within the flower may render access to the nectar impossible to the smaller and weaker insects, while allowing others to reach it. Such obstructions are formed 
by folds, hairs, and other outgrowths upon the flower-leaves or on the essential organs (fig. 238). (ii) Obstructions out-

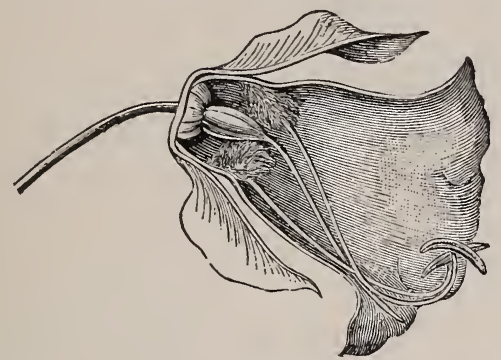

Fig. 238.-Flower of Cobar scandens, halved; showing turts of hairs on the base of the filaments, of which there are five; these close the bottom of the corolla cup, where nectar is secreted, against intruders. Three-fifths natural size.-After Kerner.

side the flower may exclude crawling insects. Such are sticky surfaces and hairs (fig. 239), moats about the stem formed by cup-shaped leaves holding water, or those formed by water in which swamp plants grow. (iii) The time of blooming also prevents the visits of any insects except those flying at that particular season.

\section{Adaptations to the distribution of seeds.}

395. After the ripening of the seed various devices and forces operate to scatter them at as great a distance as

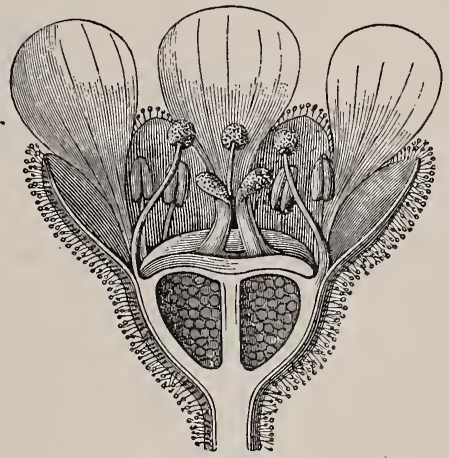

Fig. 239.-Flower of a saxifrage (Saxifraga controversa), protected against invasion by the numerous sticky glandular hairs on the flower stalk, ovulary, and calyx. Magnified several diam.-After Kerner.

possible from the parent, so that the young plants will not come into competition with the old ones or with each other. This object, which is secured in lower plants by the distribution of the spores, can only be attained in seed-plants by 
scattering the seeds, which contain the young plants in a dormant condition.

The methods by which distribution is secured may be grouped as follows:

396. I. Distribution by tension and turgor.-Some plants (e.g., witch hazel) as they ripen the seed vessel, alter its tissues in such a way that the contained seeds are compressed as

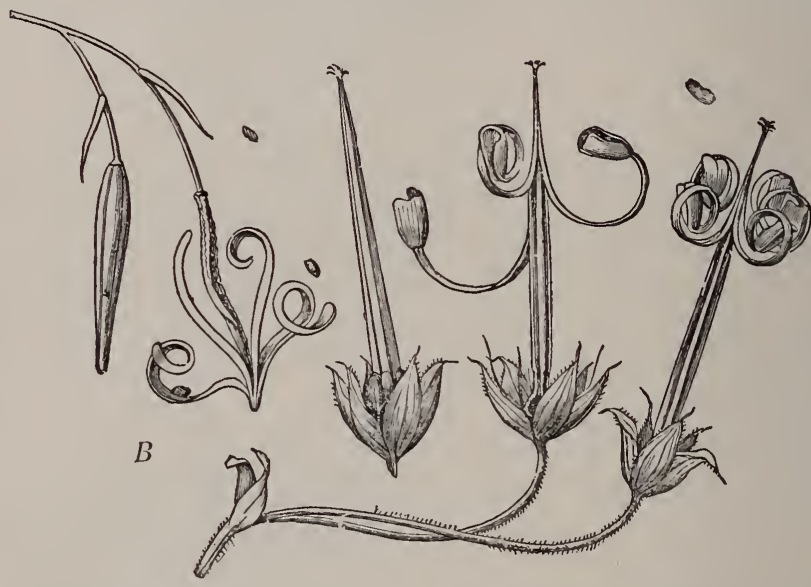

$A$

FIG. 240.-Elastic valves for slinging seeds. $A$, fruit of wild geranium (G. palustre) with persistent calyx. The five carpeis surround an elongated torus, from which they break first at bottom ; curling upward suddenly they sling the seed out of the basal part which has cracked along the inner side. $B$, fruit of touch-me-not (Impatiens noli-me tangere), one sound, the other bursted. 'The carpels have curled up elastically from the base and slung out the seeds. Natural size.-After Kerner.

it dries, and after it opens they are pinched out from the narrowing valves, as a wet apple or melon seed may be shot from between the thumb and finger. In others (e.g., touch-menot and cranesbill) the parts of the seed pod shorten on one side until the strain breaks them loose, when they suddenly become elastically curled and sling the seeds contained to a considerable distance (fig. 240). Somewhat similar causes, i.e., curvatures due to unequal shrinkage or swelling of the parts, enable some fruits with long awns or bristles to creep 
over the ground or to bury themselves in it when alternately moistened and dried (fig. 24r). The seed vessel of the squirting cucumber is so distended by the almost liquid pulp surrounding the seeds that it ejects the mass through the opening formed by its separation from the stem.

397. 2. Distribution by water.-In some plants this is secured by the fact that the fruits open only when moistened. In such cases the seeds may be either washed out from the opening pods by rain, or may be loosened in many other ways. The seeds are thus set free at the time best suited to their prompt germination. Some plants, adapted to distribution by water, are provided with floats. These floats may consist either of the enlarged and bladdery seed pod (or some portion of it), or of the spongy, airfilled seed coat. The fruits or seeds are thus made more buoyant and float upon the surface instead of sinking as usual. Naturally, water-loving plants are chiefly adapted to distribution in this manner.

398. 3. Distribution by winds.-Some plants which secure their distribution by winds are only lightly attached

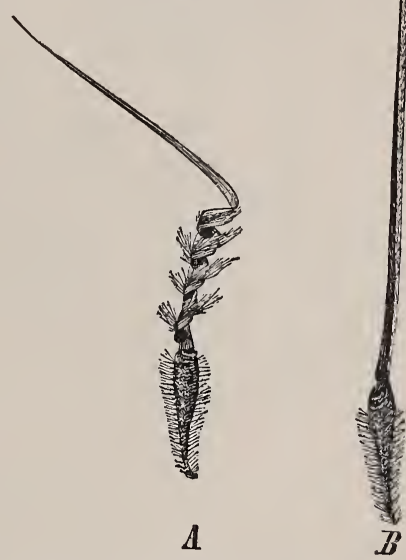

Fig. 241.--Pieces into which the fruit of storksbill breaks. There are five of these each corresponding to a carpel and arranged on the sides of a prolonged torus as in $A$, fig. 240. $A$, when dry the beak is spirally coiled; $B$. when moist. The base is hard and very sharp. Magnified about 2 diam.-After Noll.

to the soil at maturity, so that they are readily uprooted and carried bodily, when dry, for considerable distances by the wind. The transfer is facilitated by the incurving of the branches upon drying, so that the uprooted plant is more or less spherical in outline, or by the fact that the plant is nor- 
mally spherical by the proportion of the branches. Such plants are known as "tumble weeds." Singly or aggregated in large bundles they are rolled over plains and prairies for

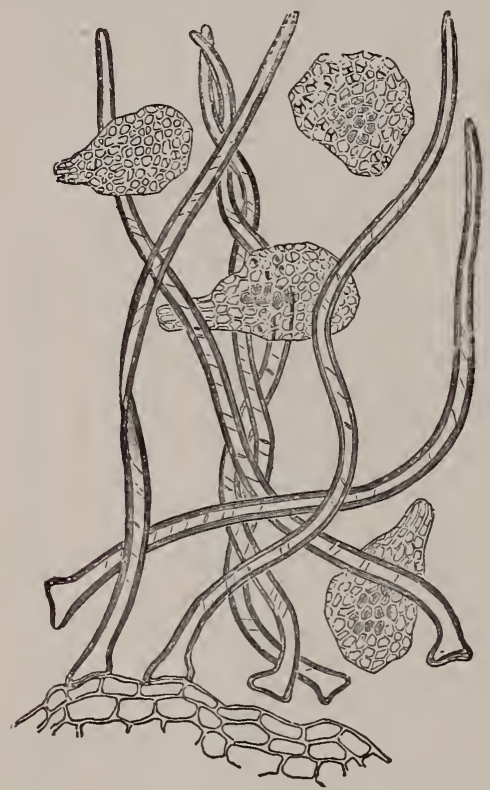

FIG. 242.-Seets of an orchid, Vanda teres), with cells of seed coat bladdery and filled with air. These seeds are ejected from the capsule by the contortions of the hairs on its inner faces which curve and twist as the moisture in the air varies. Magnified 100 diam.-After Kerner. long distances, shaking out their seeds as they go, or opening their fruits when moistened.

Another adaptation for distribution by the wind is the small size of some seeds. Those of some orchids are so diminutive that it takes 500,000 to weigh I gram. Such minute seeds are readily blown long distances by the wind. Relative lightness is also secured by the construction of some seeds, which are surrounded by a voluminous coat containing many large air spaces (fig. 242). Outgrowths from parts of the seed coat or pericarp also secure the same end. In such cases the fall of the fruit or seed through the air is so retarded that it may be carried laterally some distance by the wind. No seeds, however small, float long in quiet air, since buoyancy is derived only from air-containing tissues. A flattened form of the fruit or seed is very common, and this form is often exaggerated by the formation of wings, i.e., of thin outgrowths from the surface (fig. 243). The center of gravity in such cases is so placed that the plane of flattening will be 
nearly horizontal when the seed falls. 'These fruits or seeds sink from 2 to 30 times as slowly as the same bodies without the wing. Sometimes special floats are used for this purpose,

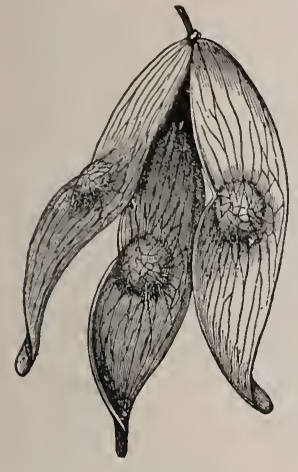

A

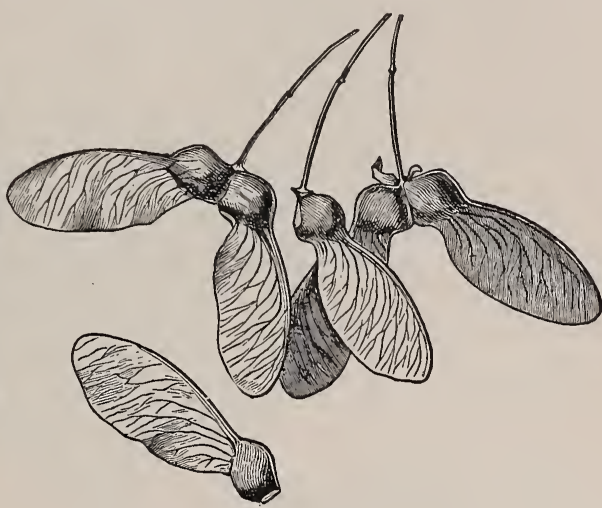

$B$

FIr. 243.- Fruits with wings. $A$, fruits of ailanthus tree $(. A$. glandulosus), each carpel with double wing. $B$, fruits of a maple tree, each carpel with a single wing. Natural size.-After Kerner.

as in dandelion and thistle (fig. 244). Hairs of the most various origin are produced in such numbers and position as to form either parachutes or tangled woolly envelopes to the fruit or seeds (figs. 245, 246).

399. 4. Distribution by animals.-To secure this there are two general methods observable. (a) The seed or fruit is either adapted for transport by adhering to the body of the animal ; or $(b)$ the seeds are surrounded by edible parts, and at the same time so protected against the digestive juices that they may pass uninjured through the alimentary canal. A few plants are distributed by animals which collect and hide their fruits or seeds (e.g., the squirrels). The adhesion of fruits or seeds to animals, especially to those which are provided with fur, is generally secured either by surfaces made adhesive by the sticky secretion from glandular hairs, or by the development of outgrowths in the form of hooks or barbed prickles 
(figs. 247, 248, 249, 250). A few water animals and wading birds distribute seeds which happen to fall into the mud by the adhesion of this mud to their bodies.

The fleshy fruits with edible parts are usually colored to attract the notice of the fruit-eating animals. Seeds which escape crushing by the teeth or grinding in the gizzard are apt to be in condition to germinate when voided. The seeds of the mistletoe are separated from the

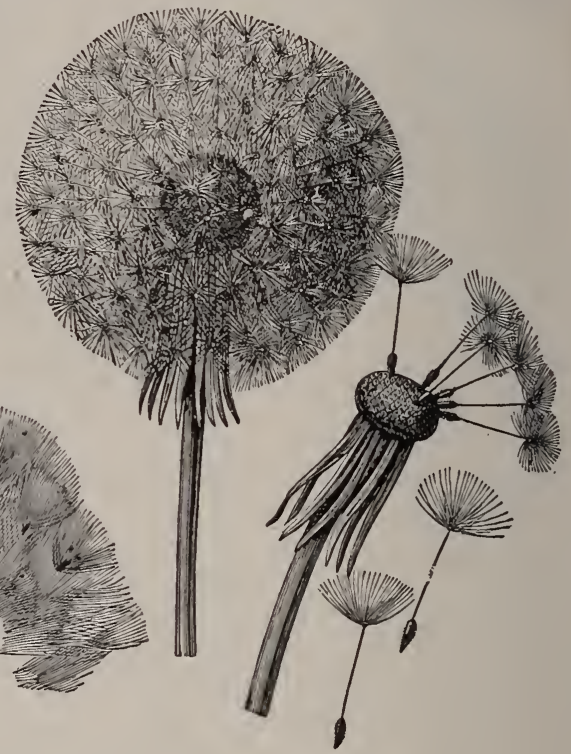

FIG. 244 .

FIG. 245 .

FIG. 244.-Heads of fruits of the dandelion: single fruits falling, exposing common torus and involucre. Natural size.-After Kerner.

FIG. 245.-Fruits of a willow, burst, and allowing the seeds, each with a tuft of silky hairs (coma), to escape. Natural size.-After Kerner.

pulp of the berry by the birds which eat them, and, sticking to the bill, are wiped off on the branches of trees, where they germinate.

The adaptation of plants to any one of these agents of distribution is likely to be more or less effective with other agents. For example, the tufts of hairs which increase the buoyancy of the seed in air would be equally effective should 


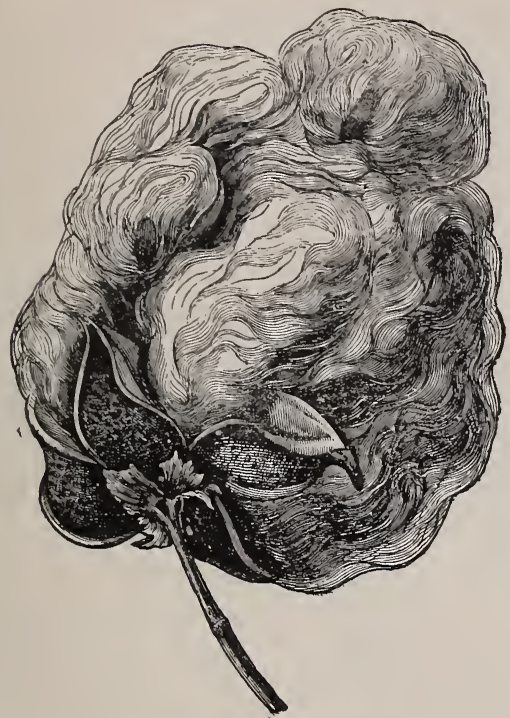

Fig. 246.-A fruit of Barbadoes cotton, open, exposing the voluminous hairs (commercial cotton) which clothe the seeds. Natural size.-After Kerner.

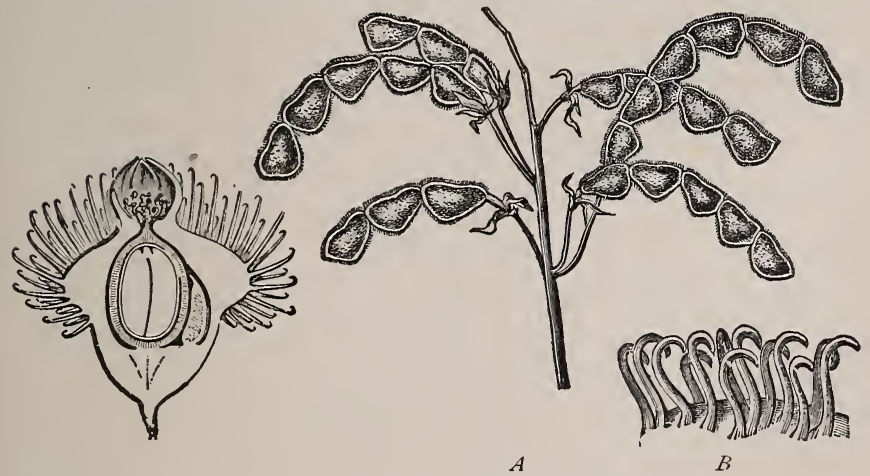

FIG. 247.

FIG. 248.

FIG. 247.-Fruit of Agrimonia, halved; showing torus, carrying calyx and withered stamens above, covered with hooks, and enclosing the hard pericarp, with a single seed. A pistil which did not mature lies to the right. Compare torus in fig. 175 . Magnified about 8 diam.-After Baillon.

FIG. 248.-Fruit of tick trefoil (Desmodium Canadense). A, pods which separate into sections, each containing one seed. They are covered with stiff hooked hairs, some of which are shown enlarged at $B$. $A$, natural size. $B$, magnified about 20 diam.After Kerner. 
the seed chance to alight upon water, or they may suffice to entangle the seed in the fur of animals.

400. Adaptations for germination. - Adaptations for distribution not infrequently also secure advantage in germina-

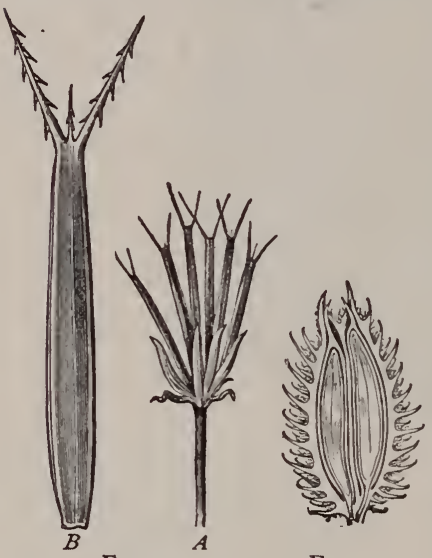

FIG. 249.
FIG. 250.

Fig. 249.- $A$, cluster of fruits of Spanish needles (Bidens bipinnata). $B$, a single fruit enlarged, showing barbed awns, representing the calyx lobes, by which it adheres to animals. $A$, natural size; $B$, magnified $2 \frac{1}{2}$ diam.---After Kerner.

FIG. 250.-Fruit of cockle-bur (Nanthium strum ariu $m$ ), halved, showing two seeds, the upper of which usually germinates a year later than the lower. Natural size -After Arthur.

by every change of moisture (fig. 24I).

401. Summary.-Plants have developed many ways for protecting and distributing their spores and seeds. Pollen is often protected against rain by closure of the flower-leaves or bending of the stalk. Fungus spores may be shot off or slung off. Many ferns sling out their spores from the cases. Water and air currents carry spores. Insects are also efficient distributors, especially for the seed-plants, which provide food, shelter, nest-building materials, etc., to secure their aid. This they advertise by color and odor. By irregular form 
they also provide suitable landing places, and exclude inefficrent visitors by obstructions both inside and outside the flower.

Seeds are distributed by being pinched or slung out by the drying seed pod, or shot out with the juice of the seed vessel when it breaks loose. Currents of water may float fruits or seeds long distances ; winds also carry them, especially if light or winged. Animals transport fruits or seeds which adhere to their bodies in mud or by hooks. Seeds in edible fruits may also escape destruction and be dropped far from the place where they were eaten.

Conclusion.-Study of plants in relation to their surroundings, therefore, yields the conclusion that these organisms are wonderfully plastic, responding either temporarily or permanently to every change in conditions. It is greatly to be desired that the too common thought of plants as only things to be classified may be replaced by the conception of them as beings at work, to be studied alive. 



\section{APPENDIX I.}

\section{DIRECTIONS FOR COLLECTING AND PRESERVING MATERIAL.}

Those who cannot collect the plants they require can order them from the Cambridge Botanical Supply Co., 1286 Massachusetts av., Cambridge, Mass.; or the Ithaca Botanical Supply Co., Ithaca. N. Y. Orders should be placed in advance of the collecting seasun to insure obtaining the material.

Pleurococcus.—For this and similar one-celled algæ, collect pieces of shaded fence boards near the ground, or flakes of bark from the north side of trees in groves and parks, which show a bright yellow-green color. These may be preserved dry.

0scillaria.-Search in drippings about watering troughs, city gutters where water stands, or any open drain which contains organic matter decaying in stagnant water. A glass jar or aquarium in which water plants have decayed will usually contain this plant. It may be recognized by its bluish or blackish green color, and often occurs in coherent films or thicker masses. It may be obtained fresh at any time of year, either out doors or in the laboratory.

Rivularia.-Collect in midsummer or later the larger water plants to whose leaves and stems adhere jelly-like lumps of a dirty green color, from the size of a pinhead to $I-2 \mathrm{~cm}$. in diameter. The margins of lakes, pools, and slow streams furnish the best localities.

Nostoc colonies form similar jelly masses, commonly larger and free floating or attached. Preserve both like the following.

Spirogyra or Zygnema.-Search in spring or early summer in slow streams fed by springs. It will be recognized when in vegetative condition by rich green color and slippery "feel." Under the microscope the form of the chloroplasts will show the genus. 
When conjugating it often loses the deep green and becomes yellowish, and the filaments seem to be double.

This condition can be recognized under the lens. Spirogyra may often be obtained all through the year in pools and springs. It should be preserved in the following solution: Camphor water $50 \mathrm{cc}$; water $50 \mathrm{cc}$; glacial acetic acid $0.5 \mathrm{cc}$; copper nitrate $2 \mathrm{gm}$.; copper chloride $2 \mathrm{gm}$.

Cladophora.-Species of this genus may be found attached to sticks and stones at the edge of lakes or pools, It often covers these completely with a thick mat of long, yellowish green, branched filaments. It may be found throughout the growing season. For winter use preserve in same solution as above.

Polysiphonia.-All species are marine, and any common species will serve, They are found in reddish brown, feathery tufts 2so $\mathrm{cm}$. high, on other larger sea-weeds, or on piles and stones, about low-water mark. They collapse completely when withdrawn from the water.

The plants should be fixed in one per cent. chromic acid (or in a saturated solution of picric acid in sea-water) for $12-24$ hours, washed in sea-water as described for Chara, and hardened in 40 , 60 and 80 per cent. alcohol successively, remaining in each 624 hours. They may be preserved in the latter. They may also be preserved in formalin.

Fucus.-All species are marine and any one will serve. The commonest is Fucus vesiculosus (fig. 42), which may be found on rocks between tide marks. It is of olive-brown color, with swollen tips to many of the branches, and bladders in pairs along the thallus. Plants may be obtained fresh at almost any season. Various species of brown sea-weed may be found fresh at the fish stores of all large cities, whither they are sent as packing.

Mucor or Rhizopus.-Saturate a piece of bread with water and keep it under a bell jar, in a warm place, for a few days. Several species of molds will appear, the most common of which is the black mold, Rhizopus nigricans. This may be recognized by its white fluffy mycelium, on which arise tufts of erect hyphæ developing at tips spherical sporangia, at first white, later black. These tufts occur at intervals along a stolon-like hypha. The same mold may be found on rotting vegetables and fruits, especially sweet potatoes and lemons, and may be raised more rapidly on bread by sowing spores. It will be followed by the green mold, Penicillium glaucum, and often later by other 
species. Since the plants may be grown promptly, the material used should be living.

Microsphæra or Uncinula or Erysiphe.-Any species of mildew will answer. Microsphara grows everywhere on the leaves of the cultivated lilac. Erysiphe is abundant on the leaves of blue or white vervain (Verbena hastata and $V$. urticafolia) and many Compositæ. Uncinula attacks leaves of many willows. About midsummer, when the fungus has a white powdery aspect, gather leaves and dry them under light pressure. Later, gather leaves of the same species showing yellow and black dots (the fruits) on the mycelium. Preserve in the same way.

Cystopus portulacæ. - This species is abundant throughout the summer on leaves and stems of purslane (Portulaca oleracea) which grows in every garden and cornfield. Another species grows in late spring on shepherd's-purse (Capsella bursa-pastoris) and another on the pigweeds (Amaranthus sp.). Any one will answer. The species on Capsella (Cystopus candidus) only occasionally forms resting spores in that host. They may be found in abundance in the flowers of radish which become much enlarged and distorted when this fungus is parasitic thereon. All species may be known by the white blisters formed by lifting the skin of the host. Preserve in formalin or alcohol leaves and stems of host bearing blisters. Some may also be dried.

Lichens.-Any common foliose species which forms apothecia abundantly will answer. A bright gray species with black apothecia (Physcia stellaris) is abundant on tree trunks, as is also a yellowish species with orange apothecia (Theloschistes polycarpa). These may be collected at any convenient time, and kept dry. Besides these, collect other foliose forms; also species of Cladonia growing on the ground, with body much lobed and the apothecia coral-red knobs on upright gray stalks; also species of Usnea, clothing the branches of trees with gray-green shrub-like or hairlike tufts.

Mushroom.-Any species with cap and gills will answer. They may be found in woods throughout the summer and especially in late summer or autumn during a rainy season following drought. Only the fructification need be collected. Select a small firm species with well defined stalk, cap and gills. Collect fructifications in all stages of development from young to mature. Preserve as soon as gathered in formalin or 70 per cent. alcohol. 
Other Hymenomycetes.-Collect fleshy cap fungi with hanging points instead of gills (Hydnum, fig. 217), or intersecting plates forming tubes (Boletus). Preserve these as mushroom. Collect also the woody bracket fungi (Polyporus, fig. 218), which grow on rotten trees and fallen limbs, showing innumerable fine tubes underneath. Preserve dry. Also the much branched firmfleshed Clavaria (fig. 215). Preserve as mushroom. All will be found in damp woods.

Marchantia.-Common on wet ground and rocks, or even in drier places among grass in the shade of walls or fences. It may be recognized by flattish green body about $\mathbf{I} \mathrm{cm}$. wide and 5-8 cm. long, attached by silky hairs. At some times it bears on the upper surface sessile cups containing green grains, and sends up erect slender sexual branches which spread out into flat heads 6-8 $\mathrm{mm}$. across, some scalloped at edge and some with finger-like rays. When cups or sexual branches are present no other liverwort can be mistaken for it. A very similar one, except in these parts (Conocephalus conicus) may be distinguished by its larger size and larger stomata, looking like needle pricks over the surface, while those of Marchantia are just visible. It may be used for the vegetative parts. Collect in July. Free from dirt as much as possible, and preserve in formalin or $70 \%$ alcohol.

Porella.-Abundant everywhere on the bases of trees especially in low grounds or wet bottom lands. It may be recognized by its dirty-green pinnately branched shoots, $1-2 \mathrm{~mm}$. wide, with crowded overlapping rounded leaves. The plants are always intricately interwoven. Flakes of the bark may be peeled off with a broad knife or chisel, taking care not to tear up the plants into too small patches. Collect in summer. Preserve dry, after drying under light pressure. Some should be kept in formalin or alcohol for demonstration of finer structure of sex organs.

Mnium.-Any species of the genus will do. The commonest species eastward is $M$. cuspidatum. It is abundant everywhere in patches on shady banks and in open woods about the bases of trees. It may be recognized by the yellow or orange oval capsule, thin and irregularly wrinkled when dry, horizontal or pendent on a stalk $2-3 \mathrm{~cm}$. long. The leaves are broadly oval, with fine sharp teeth under lens, and a distinct midrib. When moist the leaves are rather pale green, and not crowded or overlapping. When dry the clump is a dull, dirty green, and the leaves are much curled and twisted, expanding quickly when wetted. The 
male and female organs are in the same cluster, at the apex of the axis. Under the microscope the species may be recognized by the orange inner peristome with double rows of perforations in the membrane below the segments. Preserve as directed for Porella. Almost any similar moss will serve equally well, especially the common species of Bryum.

Adiantum.-Gametophytes of any fern will answer. They are flat green heart-shaped bodies $2-5 \mathrm{~mm}$. in diameter, attached to soil by rhizoids. They may be collected on fern pots or grown in greenhouses, or may be obtained from supply company named. Especial care should be taken to have some young sporophytes still attached to gametophytes. The sporophytes of the maidenhair fern are easily recognized by the peculiarly branched leaf. The stem is wholly underground. Each leaf has a slender polished stalk which forks into two equal branches; these fork, one branch of each pair growing straight and bearing leaflets while the other again forks in the same way; and so on until 4-8 branches have been formed on each half. Collect underground stems and roots, loosening them gently and washing off dirt carefully to avoid destroying all root tips and hairs. Preserve these in alcohol or formalin. Gather leaves when the crescent-shaped fruit dots at edges of leaflets are yellowish brown (August). Preserve by drying, spreading out each leaf to show its mode of branching clearly.

Caltha.-This plant is common in wet meadows and swamps northward. It is $15-30 \mathrm{~cm}$. high, smooth, with rather coarse hollow ribbed stems, orbicular or kidney-shaped alternate leaves, with broad clasping base to the petiole, and numerous bright yellow flowers 20-25 mm. in diameter, produced for two weeks or more in April or May. Gather entire plant; wash the roots. Preserve a few plants and an extra supply of flowers and fruits in alcohol or formalin. Dry most of the entire plants.

Lathyrus.-The sweet pea is grown in almost every flower garden and is known everywhere. Flowers and leaves of as great variety as desired may be preserved at the proper season in summer in alcohol or formalin. Or, simple flowers may be secured at greenhouses.

Stems. - The various sorts recommended may be collected at any convenient time and preserved in fluid.

Seeds. - The most useful seeds for laboratory work are Indian corn. wheat, buck wheat, castor bean (Ricinus), white lupine, (Lupinusal- 
bus), scarlet runner (Phaseolus), broad bean (Vicia faba), hemp, white mustard. These should be obtained fresh each year, as they deteriorate more or less with age. Those which cannot be had everywhere (such, perhaps, as lupine, castor bean, scarlet runner, and broad bean) may be purchased of seedsmen in large cities. See advertisements in magazines.

Potted plants.-Such as are grown in window gardens or all greenhouses will suffice. A commercial greenhouse, if accessible, will raise tomato, castor-bean, bean, and sunflower plants as ordered, and will furnish active young plants at any season required, in case pupils cannot grow them either at school or home.

Malt.-Can be obtained ground or unground at any brewery, or may be made by sprouting barley until the seedlings appear and then drying at about $100^{\circ} \mathrm{C}$. 


\section{APPENDIX II.}

\section{APPARATUS AND REAGENTS.}

THE chemicals required are so few that in most cases they may be most conveniently obtained through local dealers. It is desirable, however, to order apparatus from dealers who make a specialty of manufacturing or supplying optical, chemical, and physical apparatus. Schools are entitled to import such apparatus free of duty, and by doing so through importing firms a large part of the cost may be saved. The list is given here for its convenience as a summary. The amounts necessary are not specified as they vary with the size of classes, and the teacher who is prepared to conduct the experiments can readily determine how much is needed.

\section{CHEMICALS.}

Acetic acid.-Used for fixing protoplasm.

Alcohol.-Large schools should buy in barrel lots free of revenue tax. For regulations apply to the revenue collector of the district in which the school is situated, or to the Secretary of the Treasury.

Ammonium hydrate (ammonia).

Barium hydrate.-For making baryta water; or this can be obtained fresh as needed from druggist.

Chromic acid.-Used in fixing and decalcifying.

Corn starch.-As prepared for table or laundry.

Formalin.-This is a 40 per. cent solution of formaldehyde in water. Dilute solutions can be prepared as needed. Most plants require a Io per cent solution, i.e., formalin I part, water 9 parts.

Grafting wax.-Made as follows: Melt together resin (by 
weight) 4 parts, beeswax 2 parts, tallow I part; mix well; pour into a pail of cold water; grease the hands and "pull" till nearly white. In using it should be handled with greased fingers to prevent its sticking to them.

Iodine.-Either solid, from which the tincture can be prepared by dissolving a few flakes in alcohol, or the tincture may be purchased.

Mercury.-For directions for keeping it clean and dry, see Botanical Gazette 22: 471. Dec. 1896.

Paraffin.-A common quality, melting at about $65^{\circ} \mathrm{C}$.

Phenolphtalein.-A few grams will last a long time.

Potassic hydrate.-May be bought in sticks and the solution made, but it is more convenient to buy the liquor potassa of druggists.

Sodium chloride.-Table salt is pure enough.

Vaseline.

\section{APPARATUS FOR MORPHOLOGY.}

Dissecting microscopes. - Each pupil should be provided with one. A most effective low-priced dissecting microscope was designed by the author and is manufactured by several firms. In no case has the author any financial interest in the instruments. The stand T I, manufactured by the Bausch \& Lomb Optical Co., Rochester, N. Y., with I-inch lens, and a similar one by Queen \& Co., Philadelphia, have been approved by the designer. Many forms offered to schools by jobbers are not worth buying.

Compound microscopes. - The school should be supplied with at least one good compound microscope for demonstrations, and as many more as can be profitably used. If the teacher is capable of using such instruments properly he will be able to select it wisely with such advice as he may obtain from personal acquaintances on whose judgment he can rely. S hools are advised to deal directly with manufacturers of established reputation.

Scalpels. - Each pupil should be provided with a sharp knife with slender blade for dissection. It is desirable for the school to furnish scalpels of suitable form. The slender blades, 3-3.5 $\mathrm{cm}$. long on cutting edge, are recommended.

Forceps. - Straight form, with smooth points, will be found useful, though not indispensable.

Needles.-Each pupil should have a pair of needles (No: 6, 
sharps) with the eye end set into a soft pine penholder or similar handle. They must be kept sharp on a fine oil-stone.

Drazving materials. - A medium pencil (No. 3 or M) and a very hard one (No. 6 or $6 \mathrm{H}$ ) should be used and kept sharp. Slips of heaviest linen ledger paper (120 lb.) cut $14 \times 8 \mathrm{~cm}$. are recommended. Only one drawing should be put on a slip.

\section{APPARATUS FOR PHYSIOLOGY.}

Since much of the apparatus needs to be put together by the student, the requisites are mainly tools and a good supply of tubing, both glass and rubber, bottles, and bell jars. The following will enable the foregoing experiments to be carried out.

Tools.-Hammer, fine saw, three or four chisels, assorted files, brace and assorted bits, screw-driver, smoothing plane, with a supply of nails (especially finishing nails) and screws will be found most useful.

Glass tubing.-A little capillary tubing ( $0.5 \mathrm{~mm}$. bore) will be needed. Most used sizes are $5 \mathrm{~mm}$. ( $3 \mathrm{~mm}$. bore), $7 \mathrm{~mm}$. ( $5 \mathrm{~mm}$. bore.) Some larger sizes ( 13 and $19 \mathrm{~mm}$.) will also be useful.

Rubber tubing. -3 and $5 \mathrm{~mm}$. bore mostly; some of 10 and 15 $\mathrm{mm}$. bore.

Bottles.-Wide-mouthed, various sizes, up to I liter.

Tumblers.-Jelly glasses answer well. Odd lids and glass dishes from homes and stores can be made useful.

Corks.-Assorted sizes. Several rubber stoppers, sizes 8, I0, I2, 3-hole, are desirable.

Bell jars.-Several sizes are necessary ; $15 \times 20$ and $20 \times 30 \mathrm{~cm}$. will be found useful; also at least one $30 \times 50 \mathrm{~cm}$. All should have ground rim and tubulure at top.

Funnels.-Glass, assorted sizes. 6,8 , and $12 \mathrm{~cm}$. diam. are most used ; there should also be two or three larger ones.

Filter paper. - Buy cut filters 15 and $18 \mathrm{~cm}$. in diameter.

Thermometers. - Should be graduated in degrees, $-10^{\circ}$ to $+100^{\circ}$ C., with milk-glass scale.

Test tubes. $-2 \times 15 \mathrm{~cm}$. is a convenient size.

T-tubes. - Two sizes, 5 and $10 \mathrm{~mm}$. bore.

Bunsen burners.-If gas is not available, gasolene burners should be substituted. 
Marble.-A plate $25 \times 25 \times 2.5 \mathrm{~cm}$., polished on both sides. It can be re-polished after etching and used as of ten as desired.

Filter pump. - Can be used if water service is available, or if a head of $5 \mathrm{~m}$. can be secured by tank. Körting's is excellent.

Rulers. $-30 \mathrm{~cm}$. long, graduated in millimeters.

Brushes. - Camelhair brush of large size, and sablehair, smallest, are useful.

Pins.-Ordinary toilet pins.

7 in tube. $-3 \times 15 \mathrm{~cm}$. See experiment 20 .

Absorbent cotton.-Also a roll of cotton batting.

Sheet lead.-Light weight, used by plumbers.

Plate glass.-Cut into pieces 20, 25, and $35 \mathrm{~cm}$. square.

Pine sazudust and clean sand.-For germinating seeds. 


\section{APPENDIX III. \\ REFERENCE BOOKS.}

The following books will be found useful to teacher or pupil or both, and are recommended as suitable reference books for the school library. The list is not intended to be exhaustive, nor does it include books for popular reading.

\section{FOR GENERAL REFERENCE.}

Kerner: Natural history of plants. New York: Henry Holt \& Co. \$15.00. (Translated by Oliver.)

Strasburger, Noll, Schenck and Schimper: Text-book of botany. New York: The Macmillan Co. \$4.50. (Translated by Porter.)

BenNetT and MurRay : Handbook of cryptogamic botany. New York: Longmans, Green \& Co. $\$ 5.00$.

Vines : A student's text-book of botany. New York: The Macmillan Co. $\$ 3.75$.

SACHS : Lectures on the physiology of plants. New York: The Macmillan Co. \$7.0o. (Translated by Ward.)

GoEbeL : Outlines of classification and special morphology. New York: The Macmillan Co. \$5.50. (Translated by Garnsey and Balfour.)

WARMing: Handbook of systematic botany. New York: The Macmillan Co. \$3.75. (Translated by Potter.)

Gray: Systematic botany. New York: The American Book Co. $\$ 2.00$.

Bessey : Botany, Advanced Course. New York: Henry Holt \& Co. $\$ 2.20$.

GedDES: Chapters in modern botany. New York: Charles Scribner's Sons. \$1.25. 
CAmpbell: Evolution of plants. New York: The Macmillan Co. $\$ 1.25$.

Coulter: Plant relations. New York: D. Appleton \& Co. \$1. Io.

- : Plant structures. New York: D. Appleton \& Co. \$1.20. WARMING : Lehrbuch der ökologischen Pflanzengeographie. Berlin: Gebr. Bornträger. (A German translation by Knoblauch. An English translation is now in preparation.)

Pfeffer: Pflanzenphysiologie. Ed. II., vol. I. Leipzig: Wilhelm Engelmann. M. 20. (An English translation is now in preparation by Dr. A. J. Ewart.)

Vines: Lectures on the physiology of plants. New York: The Macmillan Co. $\$ 5.00$.

Goodale: Physiological botany. New York: The American Book Co. \$2.00.

\section{FOR LABORATORY DIRECTIONS.}

BERGEN : Elements of botany. Boston: Ginn \& Co. \$r.ro.

Spalding: Introduction to botany. Boston: D. C. Heath \& Co. $80 \mathrm{cts}$.

MACBRIDE: Lessons in elementary botany. Boston: Allyn \& Bacon. 6o cts.

MACDougal : Experimental plant physiology. New York : Henry Holt \& Co. \$1.00.

ARTHUR : Laboratory exercises in vegetable physiology. Lafayette, Ind.: Kimmel \& Herbert. (Pamphlet.) $35 \mathrm{cts}$.

Darwin and Acton: Practical physiology. New York: The Macmillan Co. \$r.6o.

Arthur, Barnes and Coulter: Plant dissection. New York: Henry Holt $\&$ Co. \$1.20.

Ganong: The teaching botanist. New York: The Macmillan Co. \$r.10. 
Subkingdom II. BRYOPHYTA. Bryophytes. Mossworts.

Class I. Hepaticx. Liverworts.

Order I. Ricciales.

Riccia.

Order 2. Marchantiales. Liverworts.

Marchantia. Lunularia.

Order 3. Anthocerotales. Horned liverworts.

Order 4. Jungermanniales. Leafy liverworts. Scale mosses.

Porella.

Class II. Musci. Mosses.

Order I. Sphagnales. Peat mosses.

Sphagnum.

Order 2. Andreaales.

Order 3. Archidiales.

Order 4. Bryales. True mosses.

Bryum. Mnium. Hypnum.

Subkingdom III. PTERIDOPHYTA. Pteridophytes. Fernworts.

Class I. Filicineæ.

Order I. Filicales. True ferns.

Adiantum. Pteris. Aspidium. Asplenium.

Order 2. Hydropteridales. Water ferns.

Class II. Equisetineæ. Horsetails. Scouring rushes. Equisetum.

Class III. Lycopodineæ.

Order I. Lycopodiales. Ground pines.

Lycopodium.

Order 2. Selaginellales. Club mosses.

Selaginella.

Subkingdom IV. SPERMATOPHYTA. Seed plants.

Class I. Gymnospermæ. Gymnosperms.

Order r. Cycadales. Cycads.

Cycas. 
Order 2. Coniferales.

Pines, spruces, larches, firs, etc。

Order 3. Gnetales.

Welwitschia.

Class II. Angiospermæ. Angiosperms.

Sub-class I. Monocotyledones. Monocotyledons.

Orders several. Lilies, irises, grasses, sedges, rushes palms.

Sub-class II. Dicotyledones. Dicotyledons.

Orders numerous. Most herbs with net-veined leaves deciduous shrubs and trees. 


\section{INDEX.}

All references are to pages. Italic figures indicate illustrations.

Absorption, limit of 128; of gases I39; of water $\mathbf{2 4 2}$

Acacia, shoot of 103

Accessory fruits 222

Adaptation I I7, 227

Aeration I46

Agrimonia, fruit of 283

Ailanthus, fruit of 281

Air, composition 23I, plants 125

Aldrovandia vesiculosa 265

Algæ 254, 255; filamentous I7; fission 6; larger 23; yellowgreen II

Allium, stem 89

Aloe socotrina 241

Alternation of generations 4 I

Amanita phalloides 192

Amorphophallus 104

Anagallis, capsule of 222

Angiosperms 198

Anther 202, 203, 204

Anthyllis 112

Ants 267

Apodanthes 259

Apple 224, twig of 78

Arbor-vitæ, shoot of 84

Armor, 266

Artemisia, hairs of 240

Ash, calyx and pistil of 200

Asparagus, twig of 79

Aspidium 195

Asplenium bulbiferum 212, spore cases 273 , gametophyte of 53

Assimilation $\mathbf{I} 37$

Bacteria 9, 10

Bacterium aceti 10

Barberry 267

Bark 92, 93, 94
Bast, secondary 9I, 92

Bazzania Novæ-Hollandiæ 45

Bean, roots of 176

Beech, rootlet of 254

Beet, stoma of 110

Begonia 88

Bellflower 171, capsules of 221

Bidens, fruits of 284

Bladderwort 263

Bracts 107

Branches, dwarf 77, leaf-like 77

Branching I9, 31, 43; monopodial 74; of leaves $\mathrm{IO}_{3}, 104$; of mosses 48 ; of roots 83 ; of shoot 73

Bryony 80

Bryum 194, capsules of 50

Budding 31, I87

Buds 73, 212; adventitious 70, 76; axillary 74; brood 2 II ; dormant 76 ; fleshy 212; lateral 74; on roots 69

Bulb 76, 244

Bulblets 79

Butomus, anther of 203

Calamus, root of 64

California poppy, ovules of 201

Calyptospora 37

Calyx 206

Campanula pusilla 171; rapunculoides 221

Capsule 200, 221, 222

Carbon dioxid 139

Carex stricta 267

Carnivorous plants 26I

Carpels 197

Carrot, chromoplasts of 4

Caulerpa 20, 21

Cecropia 268 
All references are to pages. Italic figures indicate illustrations.

Cells I, 2, 155, 167; division 16; growth I54; guard IIO; naked I I9, I64; union of 218 ; wall 2,4 Cellulose 4

Centrifuge 174

Cilia ro

Cinchona, bark of 93 ; stem of 91

Cinnamon flower 204

Cirsium, pollen grains 205

Cheiranthus, hairs of 86

Chelidonium 167

Cherry, fruit of 223; stem of 92

Chlorophyll 3, 140

Chloroplasts 3

Chondromyces serpens 253

Cladonia furcata $25 \%$

Cladophora 19

Clambering plants 250

Clavaria aurea 192

Climbing plants 249

Clover 256

Cobæa scandens $27 y$

Cockle bur, fruit of 284

Colonies, of Chondromyces 253; gelatinous 6,7

Color 24

Contractility II 7

Convolvulus, hairs of 240

Coprinus 191

Cork 9I ; cambium 66, 9I

Corm 77

Corn, cockle 199; bundles of Indian 90

Corolla 206

Cortex 27, 61, 64, 85, 86, I го

Cotton, fruit of 283 .

Cowberry 37

Cratægus, shoot of 100

Crowfoot 162

Crystals 151, 269

Cuttings 2 I4

Dandelion, fruit 282; pollen grains 205

Datura stramonium, anther of 203

Dehiscence 202; of seed pods 278

Desmids 14

Desmodium, fruit 283; gyrans 181

Development, rate of $\mathbf{2 3 4}$

Diatoms 12, 13
Digestion 137, I43

Dionæa muscipula 183, 264

Distribution of seeds and spores 270

Dodder, European 258

Dormant period 234

Drosera rotundifolia 264

Duration, of growth 163 ; of shoot $8 \mathbf{I}$

Ecology II 5, 226

Ectocarpus, filament of 254

Edelweiss, hairs of 240

Eel grass 274

Elæagnus angustifolia 241

Elatine, stem of 87

Elm, buds 75

Embryo 219 , sac 201

Empusa Muscæ 272

Energy, release of 147

Entoderma Wittrockii 254

Environment 228

Epidermis 6I, 85

Epiphytes 250

Eschscholtzia 271, ovules of 201

Excretion 147

Exobasidium, hyphæ of 35

Fagus sylvatica 254

Fern 109, 194, 212; leaflet 195

Fernworts 53

Fig, inflorescence of 209

Filament 202

Fission 16, I86; algæ 6

Flax, flower of $20 \%$; stem of 88

Flowers 77, 197; leaves 107; of flax 20\%; of mousetail 208; of mulberry 224; of raspberry 224; of sweet pea $20 \%$

Fly fungus 272

Foods 135, 275; of spores 189; storage of 142 ; transfer of 142

Fragmentation 187

Fraxinus, calyx and pistil of 200

Fructifications I9I

Fruit 219，220, 282, 283, 284; fleshy 22I; of apple 224; of cherry 223; of wintergreen 223; winged 281

Fucus $25,26,27$ 
All references are to pages. Italic figures indicate illustrations.

Funaria Americana $4 S$

Function I 15

Fungi 255, 257; fission 9

Fusion 38

\section{Gametes 4I}

Gametophyte 4I; of Bazzania 45; of fernworts 53; of Polytrichum 47 ; reduction of 54

Gaultheria procumbens 223

Gelatin 9

Geotropism I72; transverse I75

Geranium pods 2\%8

Gerardia, parasitic 258

Glœocapsa 6

Grasses I 75 ; leaf of 99, 238

Growth 24, 124, 154; conditions of 159; localization of 19; of cell-wall 5 ; of spores I9o; period of 156

Gymnosperms 198

Hairs 86, 199, 240; of nettle 267

Halophytes 237, 244

Haustoria 36 ; of Peronospora 38

Heat $\mathbf{1} 49$

Heliotropism I7o

Hellebore, pistil of 200

Helotism 255

Hibiscus, pollen grains of 205

Honeysuckle, buds 75 ; leaf 102

Hop, stem of $17 y$

Hosts 34

Houseleek 243

Hydrophytes 246

Hydrotropism I77; apparatus for I 78

Hyphæ 30; of Exobasidium 35; of lichen 257; of Trametes 36

Iberis, stem of 85

Impatiens pods 278

Impulse, transmission of 164

Infection 35

Inflorescence 74

Internodes 83

Irregularity 206

Irritability II7, I64; localization of 164
Land plants 125

Larch, shoot of 239

Lasiagrostis 238

Leaves 96 ; arrangement 98 ; base 99; blade IO2; compound IO4; fall of II 3 ; foliage 98 ; form 98 ; margin 24I; mosaics I70; of mosses 47; sections 109, 111, 112, 183, 238; simple I04; spore I95; stalk IOI; storage I08

Lichens 39, 257; mycelium of 38

Light I4I, I60, 232, 247

Lilium bulbiferum 212

Lily 212; anther of 203; cell of 3; pollen grains of water 205

Linden, shoot of 74

Liverworts 42, I94, thallose 44

Locust, stem of 108

Lodgers 253

Lonicera buds $\% 5$

Lotus corniculatus 222

Lunularia cruciata 43

Lychnis githago 199

Mallow, pollen grains of 205

Maple, bud of red 75 ; fruit of 281 ; Norway 171

Marchantia 211

Marsilia, root of 61

Megaspore of lily 3

Melampsora salicina 189

Mesophytes 23I

Metabolism I I 6

Micrococcus 10

Mildew 37

Mimicry 267

Moisture I62, 234

Mold, black 34

Monopodial branching 48

Mosses 46, 194; brood buds of 211; capsules 194; gametophyte 193

Motor organs 180

Mougeotia 17

Mountain ash, chromoplast 4

Mousetail 208

Movements I64; air 232; combined 172 ; contact 178,182 ; growth I68; light I8I; multicellular members I68; paratonic 
All references are to pages. Italic figures indicate illustrations.

168, 169; photeolic 182; protoplasm 164; spontaneous 168 , I8I; to reduce illumination 238 ; turgor I79; water 247

Mucor 193, Mucedo 32

Mulberry flower 224

Multiple fruits 223

Mustard 173

Mutualism 252

Mycelium 32; of lichen 38

Mycorhiza 254; of orchids 255

Myosurus minimus 208

Nasturtium 106, 170

Nepenthes villosa 262

Nettle 267

Nitrogen supply 26I

Nodes 83,241

Nostoc 7

Nucleus 3

Nutation 168

Nutrition 49, 124; of green plants 138

Nymphæa, pollen grains of 205

Oat, cell of 4; grain 220

Offsets 77,213

Oil receptacle 151

Oleaster, scales of 241

Oligotrichum aligerum 48

Onion stem 89

Opuntia vulgaris 240

Orchid, chromoplast of 4; mycorhiza of 255; pollen mass of 205; seeds of 280

Organ II 5

Orthotrichum 49

Oscillaria 8

Ovulary 200

Ovules 197, 198, 200, 201

Oxygen 162

Palm stem 85

Pansy seed 219

Parasites 34,138

Parasitism 257

Parmelia conspersa 257

Pea, root of $15 \%$; seedling 68 ; shoot of 108
Pear, prickly 240

Penicillium glaucum 191

Peperomia trichocarpa 244

Perianth 205

Pericarp 219

Periderm 66, 9I

Peronospora 38

Petiole, scarlet runner 180

Phascum cuspidatum 50

Photosynthesis 140, 146; product of $14 \mathrm{I}$

Physiology II5

Phytolacca decandra 219

Pilobolus crystallinus 271

Pimpernell, capsule of 222

Pine, Scotch 78

Pistils 200; closed 198; simple and compound 199

Pitcher plant 107

Pith 27,89 ; rays 93

Placenta 202

Plasmodia 120

Plastids 3

Plectranthus, hairs of 86

Pleurococcus 11, 12

Pokeberry seed 219

Pollen 203, 204, 205

Pollination 207, 275; of eel grass 274

Polygonatum, leaf of 105

Polygonum, stipules of 102; viviparum 80

Polypodium vulgare 54

Polyporus 33

Polysiphonia 24

Polytrichum commune 47

Pond weed 213

Poplar, white 254

Poppy, California 271

Porella platyphylla 46

Potamogeton crispus 213

Potassium, salts I4I

Potato 216; cell of 4; pistil of white 200

Precipitation 234

Protection 233, 266; of spores and seeds 270

Proteids 142

Protococcus 257

Protonema 49 
All references are to pages. Italic figures indicate illustrations.

Protoplasm I, 2, II9; movements of 164 ; powers of 116

Pteris 69, 109

Pyrola chlorantha 221

Ranunculus aquatilis 162; leaf of 99

Reaction 165

Repair 124

Reproduction 3, II 7, I85; sexual I86, 218 ; vegetative 186

Respiration I45; intramolecular I 47

Rhizoid I9, 21, 46, 76

Rhododendron, anther and pollen of 204

Riccia sorocarpa 42

Rigidity, mechanical 122

Rings, annual 94

Robinia, stem of 108

Roots, 59, 62, 70; absorption 128; cage 176 ; cap 60,63 ; climbers 250 ; fleshy 67 ; float 67 ; hairs 6r, 63; hairs and soil 127; of fern 69 ; pressure 130 ; tubercles 255 ; woody 66

Rose, flower of 209; shoot of 101

Rotation 167

Rubus idæus 224

Runners 77

Rye, stem of 161

Saccharomyces cerevisiæ 31

Salts, absorbed 138; dissolved 127

Salvinia natans 196

Saprolegnia lactea 188

Saprophytes 137

Sarcina 10

Sarracenia purpurea 10\%; variolaris 262

Saxifrage 277

Scales 106, 241

Scarlet runner 180

Scions 214

Scotch pine 198

Sedge 267

Sedum, acre 79; dasphyllum 214; ternatum 208
Seed 218; coats 219; of orchid 280 ; plants 57 ; pods, dehiscence of 278

Seedlings 97

Sempervivum tectorum 243

Sensitive plant, leaf of 183

Sepals 206

Shepherd's purse 200

Shoot 45, 72, 82, 21I; of larch 239; of linden 74 ; winter $2 \mathrm{I} 3$

Snowberry, fruit of 155

Societies 249

Soil I26, 235; water 127

Spanish needle, fruits of 284

Spirogyra 17, I8

Splachnum ampullaceum 50; luteum 50

Spores 4I, I85, I88; cases 192, 196, 273; chain 191; free 190; leaves I96; non-motile I 89

Sporophyte 4I, I93; of fernworts 55; of mosses 49; of Phascum 50; of Polypodium 54

Stamens 202; union of 203

Starch, reserve 143

Stele 6r, 63, 85, 86, 87, I I r r

Stem 46, 83, 95; habit 84; sections of $85,87,88,89,91,92$, 94, 122, 161

Stigma 199

Stimulation 164

Stipules 99

Stolons 77

Stoma I IO

Stonecrop 208, 214

Storksbill pods 279

Strains 162

Strawberry, flower 208; runner 215

Streaming 167

Style 199

Sugar cane, node of 241

Sundew leaves 264

Sweetbrier rose 209

Sweet pea, flower of 207

Sweet violet, anther of 204

Symbiosis 252

Symphoricarpus 155

Sympodial, branching 48 
All references are to pages. Italic figures indicate illustrations.

Taraxacum, pollen grains 205

Temperature $160,233,247$

Tendrils 67,80 , 106

Tension, due to growth 157 ; of tissues I2 I

Thallus $19,21,23,27$; of liverworts 42, 4?, 43; of Marchantia 211

Thistle, pollen grains of 205

Thlaspi, leaf of 102

Thorns 67, 80, 100, 106; apple, anther of 203; of Vella 81

Tick trefoil, fruit of 283

Tococa lancifolia 269

Torus 209, 208

Touch-me-not, pods of 278

Trametes Pini, hyphæ of 36

Transfer of food I $^{2} 2$

Transpiration 133 , reducing 237

Tropæolum 170

Tubers 79, 244

Turgor I20; movements 179

Twining plants 176,250

Ulothrix I9

Ulva lactuca 23

Urtica 267

Utricularia, Grafiana 263; vulgaris, bladder of 264

Uvularia, leaf of 102
Vallisneria spiralis 274

Vanda teres 280

Vascular bundles $\sigma_{3}$

Vaucheria 19, 20

Vella spinosa 81

Venation 104, 105

Venus' fly-trap 183, 264

Veratrum, pistil of 200

Viola, anther of 204

Violet, capsule 222

Water, composition of 248; loss of I33, 237; movements of 247; movement of in plant 129; plants 125: solutions in 125

Weight, loss of 148

Wheat, seedling 97 ; stalk 175

Willow, fruit 2S2; leaf of 105,189

Wintergreen, capsule 221; fruit 293

Wood, secondary 91, 92

Xanthium fruits 284

Xerophytes 237

Zoospores 119, 188

Zygnema 17 


\section{SCIENCE}

\section{REFERENCE AND TEXT-BOOKS}

\section{PUBLISHED BY \\ HENRY HOLT \& COMPANY, ${ }^{29} \mathrm{WEST}_{\mathrm{New}} 23 \mathrm{SOR}$ ST.}

Books marked * are chiefly for reference and supplementary use, and are to be found in Henry Holt \& Co.'s List of Works in General Literature. For further particulars about books not so marked see Henry Holt Eo Co.'s Descriptive Educational Catalogue. Excepting JAMEs' Psychologies, WALKeR's Political ECONOMIES, and AdAMS' Finance, all in the American Science Series, this list contains no works in Philosophy or Economics. Postage on net books 8 per cent. additional.

\section{ZAmerícan ฐcience ฐeries}

I. Astronomy. By Simon Newcomb, Professor in the Johns Hopkins University, and EDWARD S. HOLDEN, Director of the Lick Observatory, California. Advanced Course. 512 pp. 8vo. \$2.00 net.

The same. Briefer Course. 352 pp. I2mo. \$r.12, net.

The same. Elementary Course. By EDward S. Holden.

2. Zoology. By A.S. PACKARD, Jr., Professor in Brown University. Advanced Course. 722 pp. $8 \mathrm{vo}$. \$2.40 net.

The same. Briefer Course. (Revised and enlarged, 1897.) 338 pp. \$1.12 net. The same. Elementary Course. $290 \mathrm{pp}$. r2mo. 8o cents net.

3. Botany. By C. E. Bessey, Professor in the University of Nebraska. Advanced Course. 6ri pp. 8vo. \$2.20 net.

The same. Briefer Course. (Entirely new edition, 1896.) 356 pp. \$1.r2 net.

4. The Human Body. By H. Newell Martin, sometime Professor in the Johns Hopkins University.

Advanced Course. (Entirely new edition, 1896.) 685 pp. 8vo. \$2.50 net. Copies without chapter on Reproduction sent when specially ordered.

The same. Briefer Course. (Entirely new edition revised by Prof. G. Wells Fitz, 1898.) $408 \mathrm{pp}$. 12mo. \$r.20 net.

The same. Elementary Course. 26r pp. 12mo. 75 cents net.

The Human Body and the Effect of Narcotics. 26r pp. ramo. \$r.20 net.

5. Chemistry. By Ira Remsen, Professor in Johns Hopkins University. Advanced Course. (Inorganic entirely new edition, 1898.) 850 pp. $8 \mathrm{vo.}$ $\$ 2.80$ net.

The same. Briefer Course. (Entirely new edition, 1893.) 435 pp. \$r.12 net.

The same. Elementary Course. 272 pp. rmo. 8o cents net.

Laboratory Manual (to Elementary Course). $196 \mathrm{pp}$. 12mo. 40 cents net.

Chemical Experiments. By Prof. Remsen and Dr. W. W. Randall. (For Briefer Course.) No blank pages for notes. $158 \mathrm{pp}$. I2mo. 50 cents net.

6. Political Economy. By Francis A. WALKer, President Massachusetts Institute of Technology. Advanced Course. 537 pp. 8vo. \$2.00 net.

The same. Briefer Course. 415 pp. 12mo. \$1.20 net.

The same. Elementary Course. 423 pp. ramo. \$1.00 net.

7. General Biology. By Prof. W. T. SEDGwiCk, of Massachusetts Institute of Technology, and Prof. E. B. Wilson, of Columbia College. (Rerised and enlarged, 1896.) 231 pp. 8vo. \$r.75 net.

8. Psychology. By William James, Professor in Harvard College. Advanced Course. $689+704$ pp. 8 vo. 2 vols. \$4.80 net.

The same. Briefer Course. $478 \mathrm{pp}$. r2mo. \$r.6o net.

9. Physics. By George F. Barker, Professor in the University of Pennsylvania. Advanced Course. 902 pp. 8vo. \$3.50 net.

10. Geology. By Thomas C. Chamberlin and Rollin D. Salisbury, Professors in the University of Chicago. (In Preparation.)

I1. Finance. By Henry Carter Adams, Professor in the University of Michigan. Advanced Course. xiii +573 pp. 8vo. \$3.50 net.

v'99 
Allen's Laboratory Exercises in Elementary Physics. By ChARLES R. Allen, Instructor in the New Bedford, Mass., High School. Pupil's Edition: $\mathrm{x}+209$ pp. I2mo. 80c., net. Teachers' Edi. tion; $\$ \mathrm{I} .00$, net.

Arthur, Barnes, and Coulter's Handbook of Plant Dissection. By J. C. Arthur, Professor in Purdue Univ., C. R. BARnes, Professor in Uinv. of Wisconsin, and JohN M. Coulter, President of Lake Forest University. xi 256 pp. I 2 mo. \$r.20, net.

Atkinson's Elementary Botany. By Geo. F. Atrinson, Professor in Cornell. For beginners. Fully illustrated. xxiii + 44I pp. r2mo. \$I.25, net.

Barker's Physics. See American Science Series.

Barnes' Plant Life. By C. R. BARnes, Professor in Uuiversity of Chicago. Illustrated. $\mathrm{x}+428 \mathrm{pp}$. I2mo. \$r.x2, net.

Beal's Grasses of North America. For Farmers and Students. By Prof. W. J. BEAL, of Mich. Agricultural College. Copiously Ill'd. 8vo. Vol. I., 457 pp. \$2.50, net. Vol. II., 707 pp. \$5, net.

Bessey's Botanies. See American Science Series.

Black and Carter's Natural History Lessons. By GEO. A. BLACK, and Kathleen Carter. (For the very young.) 98 pp. 50c., net.

Britton's Manual of the Flora of the Northern States and Canada. By Prof. N. L. BritTon, Director of N. Y. Botanical Garden.

Bumpus's Laboratory Course in Invertebrate Zoology. By H. C. Bumpus, Professor in Brown University. Revised. I57 pp. \$r, net.

Cairns's 'Quantitative Chemical Analysis. By Fren' K A. CAIRns. Re. vised and edited by Dr. E. WALler. $4 I 7$ pp. 8vo. \$2, net.

Champlin's Young Folks' Astronomy. By John D. Champlin, Jr., Editor of Champlin's Young Folks' Cyclopadias. Illustrated. vi +236 pp. r6mo. $48 \mathrm{c}$., net.

Congdon's Qualitative Analysis. By ERnest A. Congdon, Professor in Drexel Institute. $64 \mathrm{pp}$. Interleaved. 8 vo. 6oc., net.

Crozier's Dictionary of Botanical Terms. 202 pp. 8vo. \$2.40, net.

Hackel's The True Grasses. Translated from "Die natïrlichen Pflanzenfamilien" by F. LAMSON-SCRIBNer and EFFie A. SOUTHWORTH. $\mathrm{v}+228$ pp. 8vo. \$I.5O.

Hall's First Lessons in Experimental Physics. For young beginners, with quantitative work for pupils and lecture-table experiments for teachers. By EDwin H. HALL, Assistant Professor in Har. vard College. viii + I20 pp. I2mo. 65c., net.

Hall and Bergen's Text-book of Physics. By Edwin H. HALL, Assistant Professor of Physics in Harvard College, and JosePH Y. Bergen, Jr., Junior Master in the English High School, Boston. Greatly enlarged edition. 596 pp. 12mo. \$I.25, net.

Postage 8\% additional on net books. Descriptive list free. 
Hertwig's General Prineiples of Zoology. From the Third Edition or Dr. Richard Hertwig's Lehrbuch der Zoologie. Translated and edited by George Wilton Field, Professor in Brown Univeřsity. 226 pp. 8 vo. \$r.6o net.

Howell's Dissection of the Dog. As a Basis for the Study of Physiology. By W. H. Howell, Professor in the Johns Hopkins University. IOO pp. 8vo. \$r.00 net.

Jackman's Nature Study for the Common Schools. (Arranged by the Months.) By Wilbur Jackman, of the Cook County Normal School, Chicago Ill. 448 pp. I2mo. \$r.20 net.

Kerner \& Oliver's Natural History of Plants. Translated by Prof. F. W. Oliver, of University College, London. fto. 4 parts. With over rooo illustrations and I6 colored plates. \$I5.00 net.

Kingsley's Elements of Comparative Zoölogy. By J. S. Kingsley, Prof. in Tufts College. With abundant laboratory drill. $357 \mathrm{pp}$. I2mo. \$1.20 net.

Macalister's Zoology of the Invertebrate and Vertebrate Animals. By Alex. Macalister. Revised by A. S. PaCKard. 277 pp. r6mo. 80 cents net.

MacDougal's Experimental Plant Physiology. On the Basis of Oels' Pfanzenphysiologische Versuche. By D. T. MacDougal, Uni. versity of Minnesotav vi +88 pp. 8vo. \$r.oo net.

Macloskie's Elementary Botany. With Students' Guide to the Examination and Description of Plants. By George MAClOskie, D.Sc., LL.D. 373 pp. I2mo. \$1.30 net.

McMurrich's Text-book of Invertebrate Morphology. By J. Playfarr McMurrich, M.A., Ph.D., Professor in the University of Cincinnati. vii $+66 \mathrm{r}$ pp. 8vo. New Edition. \$3.00 net.

McNab's Botany. Outlines of Morphology, Physiology, and Classification of Plants. By William Ramsay MCNab. Revised by Prof. C. E. Bessey. 400 pp. I6mo. 8oc. net.

Martin's The Human Body. See American Science Series.

* Merriam's Mammals of the Adirondack Region, Northeastern New York. With an Introductory Chapter treating of the Location and Boundaries of the Region, its Geological History, Topography, Climate, General Features, Botany, and Faunal Position. By Dr. C. HART MERriam. 3I6 pp. 8vo. \$3.50 net.

Newcomb \& Holden's Astronomies. See American Science Series.

* Noel's Buz; or, The Life and Adventures of a Honey Bee. By Maurice Noel. I34 pp. I2mo. \$I.00.

Noyes's Elements of Qualitative Analysis. By Wm. A. Noyes, Pro. fessor in the Rose Polytechnic Institute. 9I pp. 8vo. 8oc. net.

Packard's Entomology for Beginners. For the use of Young Folks, Fruit-growers, Farmers, and Gardeners. By A. S. PACKARD. xvi + 367 pp. I2mo. Third Edition, Revised. \$1.40 net.

Postage 8 per cent additional on net books. Descriptive list free. 
Packard's Guide to the Study of Insects, and a Treatise on those Injurious and Beneficial to Crops. For Colleges, Farm-schools, and Agriculturists. By A. S. PACKARD. With 5 plates and 670 wood-cuts. Ninth Edition. 7 I5 pp. 8 vo. \$4.50 net.

Outlines of Comparative Embryology. Illustrated. 243 pp. 8vo. $\$ 2.00$ net.

Zoologies. See American Science Series.

Peabody's Laboratory Exercises in Anatomy and Physiology. By JAs. EDward PEABody, of the High School for Boys and Girls, New York. $\mathrm{x}+79 \mathrm{pp}$. Interleaved. I2mo. 6oc. net.

Perkins's Outlines of Electricity and Magnetism. By Prof. Chas. A PERkins, of the University of Tennessee. $277 \mathrm{pp}$. I2mo. \$I. IO net.

Pierce's Problems in Elementary Physics. Chiefly numerical. By E. DANA Pierce, of the Hotchkiss School. I94 pp. 6oc. net.

* Price's The Fern Collector's Handbook and Herbarium. By Miss SAdiE F. PrICE. 72 plates, mostly life-size, with guide. 4to. \$2.25. Randolph's Laboratory Directions in General Biology. I63 pp. 8oc. net. Remsen's Chemistries. See American Science Series.

Scudder's Butterflies. By S. H. Scudder. 322 pp. I2mo. \$1.20 net. - Briof Guide to the Commoner Butterflies. xi+2o6 pp. I2mo. \$. OO net.

The Life of a Butterfly. A Chapter in Natural History for the General Reader. By S. H. SCUDDER. I 86 pp. I6mo. 80c. net. Sedgwick and Wilson's Biology. See American Science Series.

* Step's Plant Life. Popular Papers. Ill'd. 218 pp. I2mo. \$1.00 net.

Torrey's Elementary Studies in Chemistry. By JOSEPH TORREY, Jr. Instructor in Harvard. 400 pp. I2mo.

Underwood's Our Native Ferns and their Allies. By LuCien M. Underwood, Professor in DePauw University. I56 pp. I $2 \mathrm{mo}$. \$I.0o net.

Williams's Elements of Crystallography. By George Huntington Williams, late Professor in the Johns Hopkins University. $\mathrm{x}+270 \mathrm{pp}$. 12mo. Revised and Enlarged. \$1.25 net.

Williams's Geological Biology. An Introduction to the Geological History of Organisms. By Henry S. Willians, Professor of Geology in Yale College. 8vo. 395 pp. \$2.80 net.

Woodhull's First Course in Science. By John F. Woodhull, Professor in the Teachers' College, New York City.

I. Book of Experiments. xiv +79 pp. 8vo. Paper. 5oc. net. II. Text-Book. $\mathrm{xv}+\mathrm{I} 33 \mathrm{pp}$. I2mo. Cloth. 65c. net. III. Box of Apparatus. \$2.00 net (actual cost to the publishers).

Woodhull and Van Arsdale's Chemical Experiments. An elementary manual, largely devoted to the Chemistry of every-day life. Interleaved. I $36 \mathrm{pp}$. I $2 \mathrm{mo}$. 6oc. net.

Zimmermann's Botanical Microtechnique. Translated by JAMES ELLIS HUMPHREY, S.C. xii + 296 pp. 8vo. \$2.50 net.

HENRY HOLT \& CO., 29 WEST 23D Sr., NEW YORK. 
. 


LIBRARY OF CONGRESS

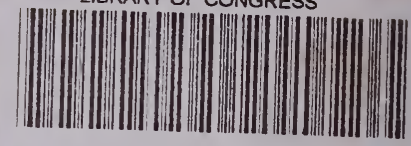

00053372673 